\title{
Hybrid thoracoscopic epicardial and transvenous endocardial catheter ablation of atrial fibrillation
}

Citation for published version (APA):

La Meir, M. (2012). Hybrid thoracoscopic epicardial and transvenous endocardial catheter ablation of atrial fibrillation. [Doctoral Thesis, Maastricht University]. Maastricht University. https://doi.org/10.26481/dis.20121130mm

Document status and date:

Published: 01/01/2012

DOI:

10.26481/dis.20121130mm

Document Version:

Publisher's PDF, also known as Version of record

\section{Please check the document version of this publication:}

- A submitted manuscript is the version of the article upon submission and before peer-review. There can be important differences between the submitted version and the official published version of record.

People interested in the research are advised to contact the author for the final version of the publication, or visit the DOI to the publisher's website.

- The final author version and the galley proof are versions of the publication after peer review.

- The final published version features the final layout of the paper including the volume, issue and page numbers.

Link to publication

\footnotetext{
General rights rights.

- You may freely distribute the URL identifying the publication in the public portal. please follow below link for the End User Agreement:

www.umlib.nl/taverne-license

Take down policy

If you believe that this document breaches copyright please contact us at:

repository@maastrichtuniversity.nl

providing details and we will investigate your claim.
}

Copyright and moral rights for the publications made accessible in the public portal are retained by the authors and/or other copyright owners and it is a condition of accessing publications that users recognise and abide by the legal requirements associated with these

- Users may download and print one copy of any publication from the public portal for the purpose of private study or research.

- You may not further distribute the material or use it for any profit-making activity or commercial gain

If the publication is distributed under the terms of Article $25 \mathrm{fa}$ of the Dutch Copyright Act, indicated by the "Taverne" license above, 


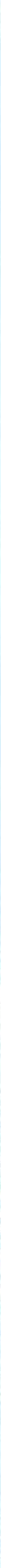

Hybrid thoracoscopic epicardial and transvenous endocardial catheter ablation of atrial fibrillation

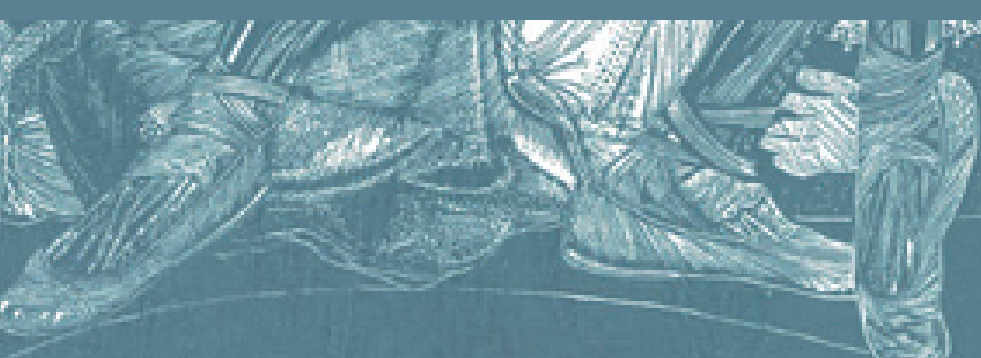




\section{Hybrid thoracoscopic epicardial and transvenous endocardial catheter ablation of atrial fibrillation}


ISBN: 978-90-817958-1-4

Support with graphic design: Grafische Dienstverlening Facilitair Bedrijf AzM

Printed by:

Schrijen-Lippertz

Printing of this thesis was financially supported by:

Stichting Hartsvrienden RESCAR Maastricht.

Cover illustration: Dhr. La Meir 


\title{
Hybrid thoracoscopic epicardial and transvenous endocardial catheter ablation of atrial fibrillation
}

\author{
Proefschrift
}

Ter verkrijging van de graad van doctor aan de Universiteit Maastricht, op gezag van de Rector Magnificus, Prof. Dr. L.L.G. Soete volgens het besluit van het College van Decanen, in het openbaar te verdedigen op vrijdag 30 november 2012 om 14:00 uur

Door

Mark La Meir 
Promotor

Prof. dr. J.G. Maessen

Co-promotores

Prof. dr. F. Wellens (UZ Brussel)

Dr. S. Gelsomino

Beoordelingscomissie

Prof. dr. H.J.G.M. Crijns (voorzitter)

Prof. dr. P. Brugada (UZ Brussel)

Prof.dr. ir. H.A. van Swieten (UMC Nijmegen)

Prof.dr. H. ten Cate

Prof. dr. U.Schotten 


\section{Contents}

Chapter 1 Introduction

Treatment of Lone Atrial Fibrillation: A Look at the Past,

a View of the Present and a Glance at the Future.

Chapter 2 Minimal Invasive Surgery for Atrial Fibrillation: An updated Review

Chapter 3 Time-Related Prevalence of Postoperative Atrial Fibrillation

After Stand-Alone Minimally Invasive Radiofrequency Ablation.

Chapter 4 The Hybrid Approach for The Surgical Treatment of Lone Atrial

Fibrillation: One-year Results Employing a Monopolar

Radiofrequency Source.

Chapter 5 Hybrid Thoracoscopic Surgical and Transvenous Catheter Ablation of Atrial Fibrillation.

Chapter 6 Minimally Invasive Hybrid Treatment of Lone Atrial Fibrillation:

Early Results of Monolateral Versus Bilateral Thoracoscopic Approach Employing Radiofrequency Sources.

Chapter 7 Minimally Invasive Surgical Treatment of Lone Atrial Fibrillation:

Early Results of Hybrid Versus Standard Minimally Invasive Approach Employing Radiofrequency Sources.

Chapter 8 Improvement of Left Atrial Function And Left Atrial Reverse

Remodeling After Minimally Invasive Radiofrequency Ablation

Evaluated By Two-Dimensional Speckle Tracking Echocardiography.

Chapter 9 General discussion and conclusion

Nederlandse samenvatting

Dankwoord

Curriculum vitae 


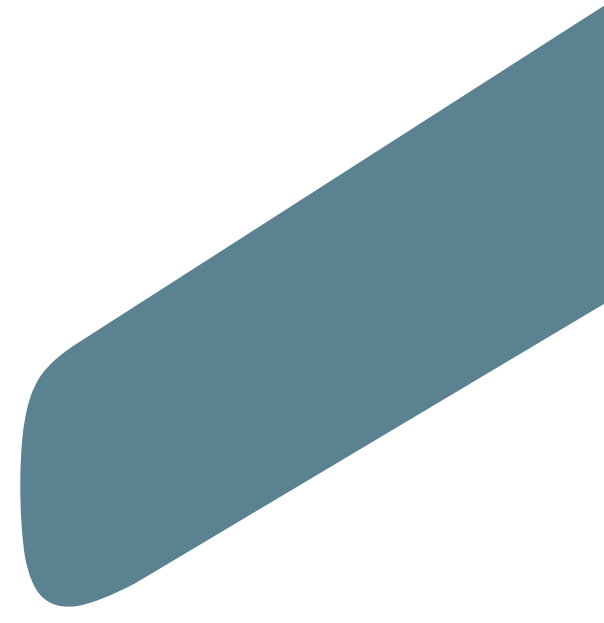

Treatment of Lone Atrial Fibrillation: A Look at the Past, a View of the Present and a Glance at the Future.

Sandro Gelsomino, Mark La Meir, Fabiana Lucà, Laurent Pison, MD, Roberto Lorusso, Rocco Carella, Carlo Rostagno, Giuseppe Billè, Elena Crudeli, Luigi Padeletti, Gian Franco Gensini and Jos Maessen. Eur J Cardiothorac Surg. 2012 Jan 10.

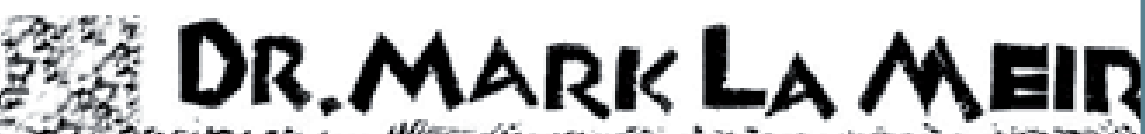
t.

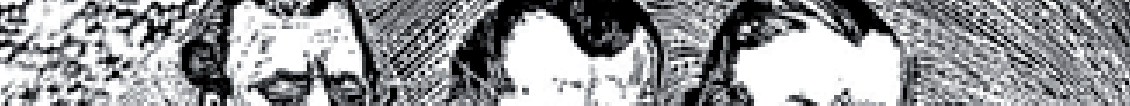

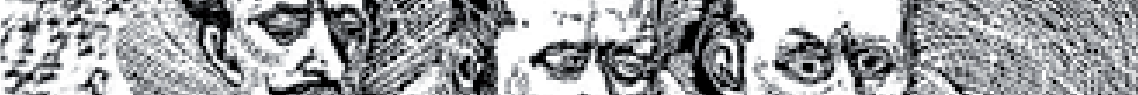
50
$3 * 2$
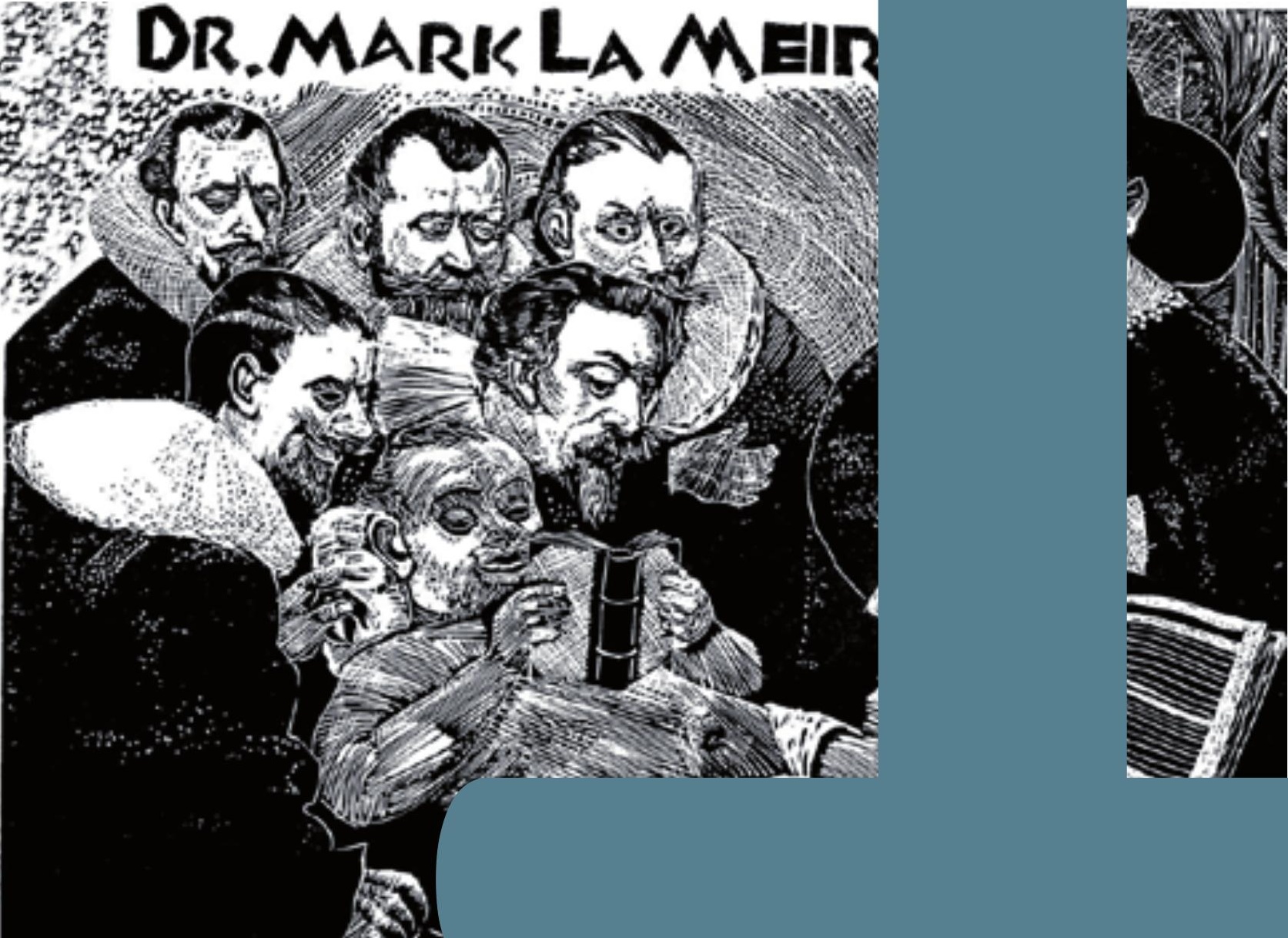


\section{Chapter 1}

Treatment of Lone Atrial Fibrillation: A Look at the Past, a View of the Present and a Glance at the Future.

Sandro Gelsomino, Mark La Meir, Fabiana Lucà, Laurent Pison, MD, Roberto Lorusso, Rocco Carella, Carlo Rostagno, Giuseppe Billè, Elena Crudeli, Luigi Padeletti, Gian Franco Gensini and Jos Maessen.

Eur J Cardiothorac Surg. 2012 Jan 10.

\section{$\underline{\text { Abstract }}$}

Background. Despite its proven efficacy, the Cox-Maze III procedure did not gain widespread acceptance for the treatment of lone atrial fibrillation (LAF) because of its complexity and technical difficulty. Surgical ablation for LAF can now be successfully performed utilizing minimally invasive techniques. This article provides an overview of the current state of the art in the surgical treatment of LAF.

Methods. Papers selected for this review were identified on PUBMED using the search terms "lone atrial fibrillation" and "lone atrial fibrillation surgery". All articles were reviewed and references were selected on the basis of historical contribution, number of patients and new contributions to the field.

Results. The most widely employed minimally invasive approach to LAF has been the video-assisted bilateral mini-thoracotomy or thoracoscopic 
pulmonary vein island creation and left atrial appendage removal or exclusion, usually with ganglionic plexi evaluation and destruction.

Recently, a hybrid approach has been introduced, which combines a mono or bilateral epicardial approach with a percutaneous endocardial ablation in a single-step procedure to limit the shortcomings of both techniques.

Conclusions. The ideal approach should be patient-tailored, employing a procedure which is adapted to the origin of the patient's AF and takes into consideration triggers and substrate. This can only be achieved through a close collaboration between the surgeon and the electrophysiologist.

\section{Introduction}

Atrial fibrillation (AF) is the commonest sustained cardiac arrhythmias ${ }^{1}$ and it is associated with increased morbidity and mortality ${ }^{2}$. AF is the cause of one-third of all hospitalizations associated with cardiac rhythm disturbances and it has been estimated that it affects more than 2.2 million people in the US, and that 4.5 million people in the European Union have paroxysmal or persistent $\mathrm{AF}^{3,4}$. AF is commonly associated with a number of cardiac and non-cardiac risk factors including ischemic heart disease, cardiac failure, valvular heart disease, hypertension, diabetes, alcohol abuse, thyroid disorders, and pulmonary disease $\mathrm{e}^{5}$. It has been estimated that up to $80 \%$ of people presenting with AF have structural or organic heart disease $^{6}$ and such cases have been referred to as "pathological AF" Nonetheless, in a not negligible percentage of people presenting with AF, there is no identifiable etiology and this subset of patients is often referred to as "lone $\mathrm{AF}$ " (LAF) ${ }^{8}$.

This review focuses on the state-of-the art of the surgical treatment of LAF. 


\section{Review criteria}

Papers selected for this review were identified on PUBMED using the search terms "lone atrial fibrillation" and "lone atrial fibrillation surgery". Up to March 2010, 516 published articles contained both "lone atrial fibrillation" and "surgery";

All articles were reviewed and references were selected on the basis of historical contribution, number of patients and new contributions to the field.

\section{A Brief History}

Atrial fibrillation was not known until 1874, when Edmé Félix Alfred Vulpian observed the irregular atrial electrical behavior that he termed "fremissement fibrillaire" in dog hearts ${ }^{9}$. In the mid-eighteenth century, Jean-Baptiste de Sénac took note of dilated, irritated atria in people with mitral stenosis ${ }^{10}$. The irregular pulse associated with AF was first recorded in 1876 by Carl Wilhelm Hermann Nothnagel and termed "delirium cordis", stating that in this form of arrhythmia "the heartbeats follow each other in complete irregularity... the height and tension of the individual pulse waves are continuously changing" ${ }^{11}$. Correlation of delirium cordis with the loss of atrial contraction as reflected in the loss of a wave in the jugular venous pulse was made by Sir James MacKenzie in1904 ${ }^{12}$. In 1906, Arthur Cushny and Charles Edmunds, pharmacologists at the University of Michigan, published an article on "paroxysmal irregularity of the heart and auricular fibrillation"13. They concluded that atrial fibrillation, known to develop acutely in dogs under certain (open-chest) experimental conditions, could occur in humans. 
Willem Einthoven had first reported his invention of the electrocardiograph in 1902 but it was not until 1906 with the article "Le Télécardiogramme" that he demonstrated the clinical value of the technique ${ }^{14}$.This article included a tracing depicting what we now recognize as atrial fibrillation, which he termed "pulsus inaequalis et irregularis"15,16.

The connection between the anatomical and electrical manifestations of AF and the irregular pulse of "delirium cordis" was made in 1909 by Carl Julius Rothberger, Heinrich Winterberg, and Sir Thomas Lewis ${ }^{17-19}$.

The term "lone auricular fibrillation" was introduced by Evans and Swann in $1953^{20}$. More recently, Kopecky ${ }^{21}$ reported ninety-seven patients aged 60 years or younger at diagnosis, with lone atrial fibrillation defined as "atrial fibrillation in the absence of overt cardiovascular disease or precipitating illness" and concluded that it was associated with a very low risk of stroke.

\section{Definition of Lone Atrial Fibrillation}

Lone atrial fibrillation was initially defined in the era before modern echocardiography to identify a cohort of young patients with AF who had no clinical evidence of cardiovascular disease and were at low risk for thromboembolism ${ }^{20-22,23}$. Patients could have paroxysmal, persistent, or chronic $\mathrm{AF}^{21}$. With the availability of echocardiography, the definition now also includes no echocardiographic evidence of cardiac or pulmonary disease $^{1,21}$. It is still unclear whether LAF and pathological AF are two distinct disorders requiring different approaches and management strategies. In recent years, it has even been hypothesized that LAF and pathological AF are different disease processes with contrasting risk predictors ${ }^{6}$. However, certain questions remain unanswered, including 
patient age, other comorbid conditions, and the importance of mild echocardiographic abnormalities.

Indeed, LAF has generally been applied to patients under 60 years of age $^{1,21}$. However, some studies have included those up to age 65 or even older who appear to be at increased thromboembolic risk compared to younger patients ${ }^{24,25}$. Furthermore, in some risk models of patients with AF, the presence of diabetes is considered a risk factor for thromboembolism ${ }^{1,26-29}$. By conventional definitions, such patients could still have LAF.

Finally, there are no data concerning whether or how the presence of mild echocardiographic abnormalities (e.g., mild mitral regurgitation, left atrial enlargement, or increased left ventricular mass) alters the natural history of lone $\mathrm{AF}$.

Based upon these unresolved issues, the $2006 \mathrm{ACC} / \mathrm{AHA} / \mathrm{ESC}$ guidelines concluded that there was no standard definition for lone $\mathrm{AF}^{1}$. The guidelines applied the term to

"Young individuals younger than 60 years without clinical or echocardiographic evidence of cardiopulmonary disease, including hypertension", ${ }^{, 21}$.

However, although these patients have a favorable prognosis with respect to thromboembolism and mortality, over time they move out of the LAF category owing to aging or to the development of cardiac abnormalities, and their risks of thromboembolism and mortality rise $\mathrm{e}^{1,2,30}$.

By convention, the term "non-valvular AF" is restricted to cases in which the rhythm disturbance occurs in the absence of rheumatic mitral valve disease, a prosthetic heart valve, or mitral valve repair $^{1}$. A recent 
international consensus on nomenclature and classification of AF mentions that only AF in the absence of heart disease is termed 'lone' while in the absence of any disease is termed "idiopathic" 31 .

Indeed, lone AF does not necessarily mean "idiopathic". In addition, in recent years an increasing body of evidence has indicated several novel epidemiological and pathophysiological associations of $\mathrm{AF}^{32-34}$. It could therefore be hypothesized that many of the recorded lone or idiopathic AF cases are linked to other not well-known factors ${ }^{35}$.

However, the diagnosis of lone AF is essentially a diagnosis of exclusion, and should be preceded by careful evaluation, including thorough collection of the patient's medical history, physical examination, blood pressure measurement, laboratory tests, ECG, echocardiography and, according to some experts, chest $\mathrm{x}$-ray and exercise testing ${ }^{1}$.

\section{Incidence, Prevalence and Natural History}

The overall prevalence of $\mathrm{AF}$ is $0.4 \%$ to $1 \%$ in the general population ${ }^{36-38}$. Among that Group, LAF occurs in 1.6 to $11.4 \%$ of all cases of $\mathrm{AF}^{21,24,38}$. However, the ALFA study (Etude en Activité Libérale de la Fibrillation Auriculaire) report the proportion of lone AF among all cases of AF to be over $30 \%{ }^{39}$. In other epidemiological studies lone AF was reported to occur in a percentage ranging between $1.9 \%$ and $32 \%{ }^{40-42}$.

Epidemiological data show a male predominance in patients with lone AF, since men constitute $78 \%$ of this patient population ${ }^{43}$. In a recent study, this sex difference was further investigated, showing that the proportion of males was greater among sporadic lone AF. Sporadic lone AF is also more common in men than in women ${ }^{44}$.The natural history of lone AF has not 
been well-studied. However, accumulated data suggest that it is associated with a low risk of progression to permanent AF, mortality, congestive heart failure, and stroke/transient ischemic attack ${ }^{43,45}$.

The clinical course of lone AF also suggests that many of these patients have a paroxysmal form of the arrhythmia, with an estimated risk of progression to permanent AF of $29 \%$ over 30 years ${ }^{43}$. Patton and coworkers ${ }^{46}$ confirmed the prevalence of a paroxysmal form of lone AF (94\% of patients) with a lower progression rate $(7.8 \%)$, but this was evaluated on the basis of a shorter follow-up period.

The course of LAF may be influenced by several factors such as the left atrial volume. Indeed, Osranek and coworkers ${ }^{47}$ demonstrated that patients with LAF and increased left atrial volume at diagnosis or later during the follow-up experienced more adverse events, such as cerebral infarction, myocardial infarction and congestive heart failure. Furthermore, increasing age and the development of hypertension may increase the risk of cerebrovascular events ${ }^{43}$. Finally, approximately $44 \%$ of patients with an initial diagnosis of lone AF may represent occult cases of arterial hypertension. In these patients, hypertension may affect AF recurrence and treatment outcomes ${ }^{48}$.

\section{Pathophysiology}

The onset and the maintenance of LAF require an event (trigger) that initiates the arrhythmia and the presence of a predisposing substrate and genetic factors that perpetuate it. Additional factors may also cooperate as modulators in facilitating initiation or continuation of AF (Figure 1). 


\section{Substrate}

Several recent studies have focused on the underlying substrate in patients with $\mathrm{LAF}^{49}$. For instance, patients with lone AF have an abnormal atrial substrate and these abnormalities are essential contributors to the "second factor" that promotes progression of AF. Studies employing electrophysiological and electro-anatomic mapping gave new insights into the nature of abnormalities within the atria of patients with LAF: a) structural abnormalities characterized by atrial dilation and lower mean atrial voltage, suggesting the loss of atrial myocardium b) conduction abnormalities, characterized by prolongation of conduction times, longer Pwave duration and slower conduction. c) Impaired sinus node function. d) Increase in effective refractory period consistent with prior studies evaluating clinical substrates for AF but in contrast to the remodeling attributed to AF itself.

Furthermore, it has been demonstrated that left ventricular diastolic dysfunction relates to left atrial dilatation and stretch as well as to the development of $\mathrm{AF}^{50}$. In addition, a recent echocardiographic case-control study demonstrated that in patients with lone paroxysmal AF, LA area and volume were larger than in healthy volunteers, despite there being similar LV dimensions, ejection fraction, and diastolic function and regardless of the recurrence of the arrhythmia ${ }^{51}$. Thus, 2-dimensional echocardiography in the antero-posterior dimension underestimates the true LA size in patients with lone paroxysmal $\mathrm{AF}^{52}$. Even in the presence of normal LV systolic and diastolic functions, LA diameter, and LA systolic activity, the LA diastolic performance may be compromised in patients with lone AF, as evidenced by abnormalities of the systolic phase of pulmonary vein (PV) flow ${ }^{53}$. Collectively, it appears that LV diastolic and LA abnormalities are 
prevalent in apparently lone AF but it is still unclear whether they represent a cause and/or consequence of the arrhythmia.

\section{Genetic Factors}

Evidence of a genetic contribution in the development of AF was first provided in 1943 by Wolff ${ }^{54}$ who documented transmission of lone AF in a family with an autosomal dominant pattern of inheritance. Since that time, large epidemiological studies have documented evidence of heritability in $\mathrm{AF}$, in particular in the context of lone $\mathrm{AF}^{55-57}$.

It is now evident that LAF may be caused by mutations of different genes controlling cardiac excitability such as the potassium channel genes KCNQ1, KCNE2, KCNJ2 KCNE5, KCNA5 and KCNH2 or the SCN5A sodium channel gene ${ }^{58-63}$. The final effect of ion channel mutations is reduced action potential duration. Consequently, carriers of genetic channelopathies have a short atrial refractory period that creates a vulnerable substrate for the development of AF. The mechanism translating cellular hyper excitability secondary to SCN5A gain-of-function mutations into the phenotype of AF potentially relates to enhanced automaticity of atrial cardiomyocytes. The resultant triggers, in the setting of an ideal substrate such as the pulmonary veins, may be sufficient to both induce and maintain AF. Subsequent screening of lone AF cohorts suggested that these channels were a rare cause of the arrhythmia ${ }^{64,65}$. However, the association between Brugada's syndrome and AF supports the pathogenic rule of $\operatorname{SCN} 5 \mathrm{~A}^{66}$

These findings implied that there were likely other classes of genes that played an important role in the development of the more common sporadic form of AF. Attractive candidate genes included connexins, transmembrane-spanning proteins that form gap junctions, which serve as 
intercellular pores, providing low-resistance pathways for the passage of current between adjacent cells ${ }^{67}$. Of the 5 connexin isoforms expressed in the heart, connexin $40(\mathrm{Cx} 40)$ seemed the most intriguing in the context of AF given its high level of expression within the atria and absence from ventricular myocardium ${ }^{68}$. Defects in connexin 40 are expected to lead to increased propensity to AF through an impaired electrical coupling between cells and decreased atrial conduction velocity. Another study ${ }^{69}$ has highlighted the role of age-related accumulation of mitochondrial DNA mutations.

The most recent culprit gene identified (NPPA) encodes a circulating hormone, the atrial natriuretic peptide $(\mathrm{ANP})^{70}$. Before this work, ANP had generally been viewed as a cardio protective hormone with an important role in sodium balance and blood pressure regulation ${ }^{71}$. There was evidence, however, that ANP was capable of modulating the activity of various ion channels within the heart ${ }^{72,73}$. Although the potential role of ANP in directly modulating atrial electrophysiology and promoting an AF substrate is intriguing, other pro-arrhythmic actions of ANP are also conceivable, an example being inflammation that could stem from the important role of ANP in the regulation of the innate immune system ${ }^{74,75}$. Given that ANP is a known mediator of inflammation, long-term exposure to altered levels of ANP might induce structural changes related to inflammation that ultimately result in atrial fibrosis and subsequent development of an AF substrate.

Other peptides that have been investigated are the serum B-natriuretic peptide (BNP), whose concentration in LAF is significantly higher than in age- and sex- matched healthy subjects ${ }^{76}$ and the Apelin, an endogenous peptide hormone that appears to have a physiological role in counter- 
regulation of the angiotensin and vasopressin systems, whose levels where significantly lower in patients with LAF compared with control subjects with sinus rhythm ${ }^{77}$.It has been demonstrated that activation of the reninangiotensin system (RAS) with increase in Angiotensin II levels promotes formation of collagen. Therefore, pharmacological inhibition of this system could represent a novel approach to counteract the development of fibrosis and recurrence of $\mathrm{AF}^{78}$. Finally, it has been suggested that a specific polymorphism of matrix metalloproteinase- 2 gene is a risk factor for chronic LAF, while $\mathrm{C}$ allele of the interleukin-10 (IL-10) polymorphism represents a protective factor ${ }^{79}$

\section{Triggers}

There is general agreement that $\mathrm{AF}$ requires a trigger usually located in the pulmonary veins and left atrium ${ }^{80-84}$. Haissaguerre and colleagues ${ }^{85}$ demonstrated that paroxysmal AF originates from ectopic beats in the pulmonary veins in $94 \%$ of cases. This likely relates to the anatomical transition from pulmonary vein endothelium to left atrial endocardium; at this juncture, two types of tissue with different electric properties are juxtaposed, and this may potentiate development of $\mathrm{AF}^{85,86}$. Catheter ablation of the posterior left atrium, including the antra surrounding the pulmonary veins, has proven effective at ablating both paroxysmal and permanent $\mathrm{AF}^{85,87,88}$.

Other anatomical structures that may also provide ectopic beats causing LAF are the superior vena cava, the vein of Marshall, the musculature of coronary sinus and the posterior wall of the left atrium (LA). However, for LAF to become sustained the presence of an atrial substrate of sufficient mass capable of maintaining re-entrant circuits is necessary. The LA-PV 
junction and the posterior wall of the LA are critical structures in this $\operatorname{regard}^{89}$.

Finally, increasing evidence suggests that sustained AF is the result of a combination of PV vein focal discharge and PV-LA re-entrant activity ${ }^{90}$.

\section{Modulating Factors}

Currently, there is an intense research interest in the role of inflammation in the pathophysiology of $\mathrm{AF}^{91,92}$. Inflammatory indexes, mainly $\mathrm{C}$-reactive protein (CRP) have been related to future AF development, AF recurrences after cardioversion, and to the persistence of the arrhythmia ${ }^{93}$. The role of inflammation in the pathogenesis of lone AF remains equivocal and limited. Indeed, only the study by Frustaci et $\mathrm{al}^{94}$. demonstrated abnormal atrial histology in most of the patients with paroxysmal lone AF refractory to conventional anti-arrhythmic therapy (inflammatory infiltrates in $66 \%$ of patients).

Conversely, other investigators failed to show inflammatory changes in LA histological specimens from lone AF patients ${ }^{95}$. Furthermore, Ellinor et al. ${ }^{96}$ failed to demonstrate increased CRP levels in patients with lone AF compared to controls while the opposite was observed in patients with $\mathrm{AF}$ and hypertension. It has therefore been postulated that markers of inflammation are associated with the presence of other concomitant diseases $^{94}$. Another case-control study showed elevated CRP levels in lone AF patients; however, subjects with hypertension had not been excluded ${ }^{97}$. An imbalance of autonomic nerve activity has been implicated in the initiation of $\mathrm{AF}^{98}$.

Parasympathetic nerves (which slow heart rate) and sympathetic nerves (which increase heart rate) can both initiate AF, due to shortening of the 
atrial effective refractory period and to changes in intracellular calcium cycling ${ }^{99,100}$. The pulmonary veins are a primary location for entry of vagal nerves into the left atrium ${ }^{101,102}$. Depending on the branches stimulated, vagal activity can cause slowing of heart rate, slowing of atrio-ventricular nodal conduction, or heterogeneous shortening of atrial action potentials; these effects result from activation of the potassium channels coupled to muscarinic (M2) receptors that are present at high density in atrial and nodal myocytes ${ }^{103}$.

Results from experimental studies on isolated canine pulmonary vein preparations suggest that simultaneous sympathetic and parasympathetic (adrenergic and cholinergic) stimulation is most effective at promoting PV ectopy, by simultaneously stimulating calcium overload while abbreviating the effective refractory period. ${ }^{104}$. In addition, Armour and colleagues ${ }^{105}$ were the first to document the presence of an intrinsic cardiac nervous system, consisting of bundles of neurons (ganglionic plexuses, GP) located in multiple atrial and ventricular locations ${ }^{104}$. They noted that activity of these GP neurons could modify cardiac activity. Ganglionic plexuses are embedded in fat pads on the epicardium of the heart. Stimulation of GP located at the PV-atrial junction has been reported to convert PV focal activity into $\mathrm{AF}^{106}$.

On this basis, it has been suggested that selective elimination of ganglionic plexuses might attenuate the occurrence of AF. Other modulating factors ${ }^{107-}$ ${ }^{116}$ are shown in Figure 1. 


\section{Types of AF}

Following the recently updated guidelines five types of AF are distinguished ${ }^{117}$ :

1) First diagnosed $A F$, irrespective of the duration of the arrhythmia or the presence and severity of AF-related symptoms.2) Paroxysmal AF is selfterminating, usually within $48 \mathrm{~h}$.

3) Persistent $\mathrm{AF}$ is present when an $\mathrm{AF}$ episode either lasts longer than 7 days or requires termination by cardioversion, either with drugs or by direct current cardioversion (DCC).

4) Long-standing persistent $A F$ has lasted for $\geq 1$ year when it is decided to adopt a rhythm control strategy. 5) Permanent AF is said to exist when the presence of the arrhythmia is accepted by the patient (and physician).

\section{Medical Treatment: An Overview and the Latest Updates}

Medical therapy for AF in restoring sinus rhythm showed poor results. Indeed, antiarrhythmic drugs have low therapeutic indices and limited long-term efficacy ${ }^{118}$ and attainment and maintenance of sinus rhythm have been suboptimal in comparative studies such as AFFIRM ${ }^{119}$, HOT $\mathrm{CAFE}^{120}, \mathrm{PIAF}^{121}{ }^{1} \mathrm{RACE}^{122,} \mathrm{STAF}^{123}$ and AF-CHF ${ }^{124}$.

According to current guidelines amiodarone, dronedarone, flecainide, propafenone and I-sotalol are recommended for rhythm control ${ }^{117}$.

Vernakalant is a is a relatively atrial-selective antiarrhythmic agent ${ }^{125}$ recently recommended for approval by the European Medicines Agency for rapid cardioversion of recent-onset $\mathrm{AF}$ to sinus rhythm in adults ( $\leq 7$ days for non-surgical patients; $\leq 3$ days for surgical patients) ${ }^{126,127}$. Atrial- 
selectivity of Vernakalant is achieved by targeting atrial specific channels: the Kv1.5 channel which carries K+ current (IKur) and the Kir3.1/3.4 channel which carries muscarinic $\mathrm{K}+$ current ( IKAch). Vernakalant can also work to block Ito, late Ina, with minor blockade of IKr currents A direct comparison with amiodarone in the AVRO trial ${ }^{128}$ showed that Vernakalant was more effective than amiodarone for the rapid conversion of AF to sinus rhythm

In selected highly symptomatic patients with occasional recurrences of AF (i.e. between once per month and once per year), the 'pill-in-the-pocket' approach consisting in oral propafenone (450-600 mg) or flecainide (200$300 \mathrm{mg}$ ) may be used. ${ }^{129}$.

Rate reduction, allowing adequate time for ventricular filling and avoiding rate-related ischemia, may result in improved hemodynamics. However, the RACE II study shows that lenient-rate control $<110 \mathrm{bpm}$ is not inferior to strict-rate control $<80 \mathrm{bpm}^{130}$. As lenient-rate control is generally more convenient, requiring fewer outpatient visits and examinations, it may be adopted as a reasonable strategy in patients with permanent AF.

Drugs commonly used for rate control are b-blockers, non-dihydropyridine calcium channel antagonists, and digitalis. Amiodarone may be suitable for some patients with otherwise refractory rate control ${ }^{117}$. Dronedarone is similar to amiodarone but lacks an iodine moiety. Possessing both rate- and rhythm-control properties, Dronedarone has proved safe and effective in preventing recurrence of $\mathrm{AF}$ in patients with persistent $\mathrm{AF}$ in the DAFNE (Dronedarone Atrial Fibrillation Study After Electrical Cardioversion) trial, the first prospective randomized trial to evaluate its efficacy and safety ${ }^{131}$. Nonetheless, the DIONYSOS study ${ }^{132}$ (Efficacy \& Safety of Dronedarone Versus Amiodarone for the Maintenance of Sinus Rhythm in Patients With 
Persistent Atrial Fibrillation) suggests higher tolerability but less efficacy for Dronedarone than for amiodarone. In the ATHENA trial ${ }^{133}$

Dronedarone improved the composite endpoint of cardiovascular hospitalizations and all-cause mortality in a carefully selected, high-risk, nonpermanent AF population. The new ESC 2010 AF guidelines incorporate Dronedarone into the algorithm previously recommended for therapy to maintain sinus rhythm in patients with recurrent paroxysmal or persistent $\mathrm{AF}^{117}$.

Recommendations for antithrombotic therapy should be based on the presence (or absence) of risk factors for stroke and thrombo-embolism. Unless contraindicated, chronic oral anticoagulation therapy (OAC) is recommended in patients with a CHADS2 [cardiac failure, hypertension, age, diabetes, stroke (doubled)] score $\geq 2$ to achieve an International Normalized Ratio (INR) value of 2.0-3.0. In patients with $\mathrm{CHADS}_{2} 0-1$ the $\mathrm{CHA}_{2} \mathrm{DS}_{2}-\mathrm{VAS}_{\mathrm{c}}$ [congestive heart failure, hypertension, age $\geq 75$ (doubled), diabetes, stroke (doubled), vascular disease, age 65-74, and sex category (female)]score is recommended and OAC therapy is suggested if the CHA2DS2-VASc score $>2{ }^{117}$.

Moreover, the new AF guidelines emphasize the importance of bleeding risk assessment before starting anticoagulation. In this case the HAS-BLE [Hypertension, Abnormal renal and liver function, stroke, bleeding, labile INRs, elderly] bleeding risk score is recommended. A score of $\geq 3$ is considered indicative of 'high-risk' patients who require caution and regular review after starting antithrombotic therapy ${ }^{117}$. 


\section{Catheter Ablation, Present and Future: Ready for first-line}

\section{therapy?}

Multiple approaches have been developed for catheter ablation, all aimed at eliminating mechanisms in the initiation and maintenance of AF. A complete isolation of the PVs and application of the lesion set proximal to the junction of the left atrium and tube-like portion of the PV are considered necessary by most techniques.

The different approaches proposed for catheter ablation include :

a) Segmental/ostial PV isolation; b) Circumferential PV ablation; c) Circumferential/antral PV isolation; d) Electrogram-based ablation or complex fractionated atrial electrograms (CFAEs) ablation; e) Linear lesions; f) Autonomic ganglionated plexi ablation; g) ablation of AF Nest; h) Sequential ablation strategy.

Segmental PV isolation requires ablation inside the vein or very close to the output into the atrium ${ }^{85,134}$. It is accepted that ablation in the PVs needs to be avoided thus an extensive atrial ablation, often circumferential is carried out with a trans-septal circular mapping catheter placed at the ostia of the four PVs ${ }^{134}$ which creates a series of segmental lesions until isolation of the vein can be demonstrated. Circumferential PV ablation has been widely employed ${ }^{135,136}$.Over time the lesion set has been modified with wider circumferential lesions (1-2 cm outside PV ostia) by adding posterior lines connecting PVs and the mitral isthmus line and, finally, by abolishing the evoked vagal reflexes, in order to prevent recurrences of atrial tachycardia ${ }^{137,138}$.

Circumferential PV isolation can be monitored by various tools, according to operator preference. Selective pulmonary venography is widely 
employed to define the relevant anatomy. Intracardiac Echocardiography (ICE), computerized mapping and navigation techniques (Carto, NaviX, etc) help to define anatomy and catheter guidance. Registration with other techniques such as Magnetic Resonance (MR) or Computed Tomography (CT) facilitates a more accurate anatomical definition. However the critical goal of all these techniques is to ensure that the lesion is made outside the $\mathrm{PVs}^{139}$. Some investigators have extended the PV isolation concept to include ablation of the PV antrum ${ }^{140}$ which, combined with spectral mapping, has been demonstrated to improve AF success in patients with long-lasting persistent $\mathrm{AF}^{141}$. CFAE ablation, instead of ablating sites in the pulmonary veins, targets sites in specific areas of the atria where the electrograms break up (become fractionated) ${ }^{142}$. These ablation sites are determined on an individual patient basis, offering a customized and often reduced area of treatment. Linear lesions are generally deployed at the LA roof and /or at the mitral isthmus ${ }^{143,144}$. Their goal is to create a bidirectional block and they have been demonstrated to be associated with conversion of $\mathrm{AF}$, further demonstrating that such lesions may at least in some patients deeply modify the substrate of $\mathrm{AF}^{145,146}$. Based on previous experience by Pappone et al ${ }^{138}$ four major left atrial ganglionated plexi have recently been identified in patients with AF. Plexi may be localized at the time of ablation using high-frequency stimulation delivered by a mapping catheter in the LA. For ablation, RF current (20-35W) can be applied at each site of positive vagal response to high-frequency stimulation. Pachon et $\mathrm{al}^{147}$ have developed a system for real-time spectral mapping that identifies sites in which the unfiltered, bipolar electrograms contain unusually high frequencies, namely fibrillar myocardium or the socalled AF Nest. The investigators have successfully targeted biatrial AF Nests, without intentional PV isolation, as a novel approach for AF. The 
adjunct of AF Nest ablation has shown a favourable impact on long-term outcome following a single antral PV isolation ${ }^{141}$. Finally, a stepwise approach has been recently developed in patients with long-lasting persistent AF with different sequences that target multiple atrial areas ${ }^{148}$.

New ablation technologies are currently under intense investigation. Balloon-based ablation systems have been developed to create circular lesions around PVs at atrial level. Furthermore, new software algorithms have been developed to support the various methods of image integration (from MR or CT) and to further improve the image registration process. Finally, real-time catheter-based imaging systems for on-line 3-D cardiac chamber reconstruction based on ICE technology are under investigation. The absence of new anti-arrhythmics with an improved benefit/risk profile as well as the results of several recently published clinical trials demonstrating superior outcomes with catheter ablation for AF relative to anti-arrhythmic drug therapy ${ }^{149-151}$ suggest that $\mathrm{AF}$ ablation may warrant consideration as first-line therapy in selected patients ${ }^{152}$.

Indeed some authors ${ }^{153}$ believe that first-line should at least be considered for those patients with symptomatic AF, mild to moderate structural heart disease, and paroxysmal or persistent AF. Ablation might particularly benefit younger patients with lone AF who are frequently symptomatic and for whom very-long-term anti-arrhythmic and anticoagulation poses higher risks and lifestyle costs. Asymptomatic or minimally symptomatic AF patients may also benefit from ablation and sinus rhythm in the long term, but until further clinical data are available, it is difficult to justify an invasive procedure to a patient who may not be aware that they have a problem. 
Nonetheless there is no full consensus ${ }^{154,155}$ about AF ablation as first-line therapy. Areas of concern are the variable short-term efficacy of catheter ablation, its unknown long-term efficacy, significant procedure-related complications and the significant variance of success among laboratories using similar technique of ablation ${ }^{156}$.

\section{Surgical Treatment}

\section{Indications For Surgery}

Based on the Heart Rhythm Society/ European Heart Rhythm Association/ European Cardiac Arrhythmia Society (HRS/EHRA/ECA) expert consensus statement on catheter and surgical ablation of $\mathrm{AF}^{156}$ "Standalone" AF surgery should be considered for symptomatic AF patients who prefer a surgical approach have failed one or more attempts at catheter ablation are not candidates for catheter ablation.

The term "lone AF" is commonly employed in the surgical literature to refer to "stand-alone surgery" for AF, as compared with AF surgery performed in conjunction with another type of cardiac surgical procedure such as mitral valve replacement.

This differs distinctly from the use of the term "lone AF" in the electrophysiological literature which includes AF developing in a subset of young patients (e.g. aged $<60$ years), with no evidence of associated cardiopulmonary or other co-morbid disease (including hypertension) and which has a favorable prognosis . From this approach 'lone' AF is still a diagnosis of exclusion but it should be made only after careful assessment including detailed medical history, physical examination, laboratory testing with thyroid status, electrocardiogram, echocardiography and, possibly, 
chest X-ray and exercise testing ${ }^{157}$ Surgery ought to be preferred also in the following cases $^{156}$.

Patients who have developed a contraindication to warfarin and who will benefit from the elimination of the left atrial appendage at surgery which reduces the incidence of postoperative stroke ${ }^{158}$.

Patients with a left atrial thrombus which represents a contraindication to catheter-based ablation.

Patients with a large left atria $>5 \mathrm{~cm}$ (Relative indication).

The referral of patients for surgery with symptomatic, medically refractory $\mathrm{AF}$ in lieu of catheter ablation remains controversial. There have been no head-to-head comparisons of the outcomes of catheter and surgical ablation of AF. The decision-making in these instances needs to be based on each institution's experience with catheter ablation and surgical ablation of AF, the relative outcomes and risks of each in the individual patient, and patient preference $^{156}$.

However, the development of simpler, more effective and less invasive procedures will undoubtedly expand the indication for surgery, and as stated by Damiano and Bayley: “...it is misguided to view surgery as competitive with catheter-based procedures. Surgeons need to work together with electrophysiologists to define the indication for surgery, refine our procedures, improve intraoperative electrophysiological testing, and develop consensus for reporting our results. In the long run, the success of catheter ablation will likely increase surgical referrals. When electrophysiologists convince the medical community that catheter ablation is appropriate therapy for medically refractory atrial fibrillation, it will also provide justification for a surgical approach". 


\section{Surgical Procedures}

The Cox-Maze III Technique

In 1987, Dr. James Cox pioneered an open-heart surgical procedure to cure atrial fibrillation ${ }^{159-161}$. He developed, in collaboration with cardiologist John Boineau and physiologist Richard Schuessler, the concept of using scar tissue to direct the electrical impulse from the sinus node to the AV node. To improve the results and simplify the operation, they modified the procedure twice, culminating in the Cox-Maze III technique ${ }^{162}$.

In the Cox Maze III, sometimes referred to as the "Traditional Maze", the "cut and sew Maze", or simply the "Maze", right and left atrial incisions are made to interrupt the multiple, disorganized re-entrant circuits that characterize AF. In addition, these lesions direct the sinus impulse from the sinoatrial node to the atrio-ventricular node along a specified route. Multiple "blind alleys" off this main conduction pathway (the Maze analogy) allow coordinated electric activation of the atrial myocardium. Key components of the Maze procedure include isolation of the pulmonary veins and excision of the left atrial appendage. These features are maintained in most of the newer operations designed to ablate AF.

Table 1 summarizes results of "cut and sew Maze" in published studies including variable percentages of patients with lone atrial fibrillation ${ }^{163-172}$. The Maze procedure requires cardiopulmonary bypass and cardiac arrest and, also in experienced hands, it requires 45 to 60 minutes of cardiopulmonary bypass and cardiac arrest ${ }^{163,173,174}$. Thus, even with these modifications, the Maze III remained complex and this may explain why many surgeons worldwide are reluctant to perform this procedure. 


\section{Surgical Ablation Techniques}

On the basis of advances in understanding of the pathophysiology of AF, a variety of new ablation tools have been developed to facilitate surgical ablation of AF. These probes and catheters rely on alternate energy sources to create long, continuous, linear lesions that block conduction. An optimal ablation device for AF surgery would (1) reliably create conduction block (i.e., transmural lesions) on the beating heart from either the endocardial or epicardial surface; (2) exhibit a precise dose-response curve; (3) create lesions rapidly and safely; (4) have adequate flexibility and maneuverability; and (5) be adaptable to a minimally invasive approach ${ }^{175}$. These new technologies have supported efforts to develop more limited lesion sets that can be performed less invasively, often through small incisions or ports. The ultimate goal has been to perform a curative lesion set epicardially on the beating heart, without the need for cardiopulmonary bypass especially in patients with LAF.

\section{Energy Sources}

The goal of any energy source is to create a scar by exposing tissue to extremes of temperature, inducing thermal injury, coagulation necrosis, and healing. To produce such an irreversible injury, the tissue must be heated to $50^{\circ} \mathrm{C}$ or frozen to $-60^{\circ} \mathrm{C}^{176}$.

The various energy sources differ mainly in the method by which they transfer energy to the tissue and how deeply that energy is conducted into the tissue. Heat based energy sources include radiofrequency, laser, microwave, and high-intensity focused ultrasound. Cold-based sources include argon and nitrous oxide gases ${ }^{177}$. Table 2 shows the energy sources available for the clinical use with their advantages and disadvantages. 
The various technologies can be organized in two major Groups: those that use a unipolar energy source and those that use a bipolar clamp. The unipolar energy sources (cryosurgery, unipolar radiofrequency energy, microwave, laser, ultrasound) all share a common weakness. These energy sources radiate either heat or cold from a single source. With the exception of high-frequency ultrasound, the energy is unfocused. Furthermore none of the devices give the surgeon an indication of when the ablation results in a transmural lesion. Because most were released clinically without accurate dose-response curves, this led to occasional collateral cardiac and extra cardiac damage with these devices ${ }^{178-184}$. Moreover, unipolar energy sources have had difficulty creating transmural lesions when used from the epicardial surface on the beating heart ${ }^{185}$.

This is due to the heat-sink effect of the circulating intracardiac blood. Melby and coworkers ${ }^{186}$ have shown that lesion depth on the beating heart is dependent on cardiac output, with reliable transmural lesions occurring only at very low cardiac outputs $(<1 \mathrm{~L} / \mathrm{min})$. High Frequency Ultrasound (HIFU) is the one unipolar source that results in a focused delivery of energy. Thus, it potentially has the ability to create transmural lesions on the beating heart. Indeed, HIFU directly heats the tissue in the acoustic focal volume, making it much less susceptible to the heat-sink of circulating intracardiac blood. Although HIFU is effective, it has a fixed depth of penetration, which may be problematic because of the anatomical variability in atrial wall thickness. Also, a recent study has reported that gradual heating of surrounding tissue due to conductive heating can cause phrenic nerve injury when located within 4 to $7 \mathrm{~mm}$ of the focused ablation ${ }^{187}$. Bipolar radiofrequency ablation has been able to overcome some of these shortcomings ${ }^{188-190}$ because energy is delivered between two 
closely positioned electrodes and is confined within the jaws of the clamp, eliminating the possibility of collateral cardiac or extra cardiac damage. By measuring the tissue conductance between the two electrodes, algorithms have been developed that have accurately predicted lesion transmurality. This allows these devices to adapt the energy delivery to the physiological characteristics of the tissue being ablated. Finally, bipolar ablation has the advantage of shorter ablation times when compared with unipolar devices. The weakness of these devices is that they can only ablate tissue that can be clamped within the jaws of the device. This has limited the potential lesion sets, particularly on the beating heart. These devices have also been incapable of fully ablating the right and left atrial isthmuses and have required adjunctive unipolar ablation to perform a complete Cox maze lesion set.

\section{The Cox Maze IV Technique}

In 2002, a new iteration of the Cox maze procedure was introduced, termed the Cox maze IV procedure, which replaced most of the incisions with linear lines of bipolar radiofrequency ablation ${ }^{191}$. Initially, the procedure had only a single inferior connecting ablation line between the pulmonary veins in an attempt to better preserve left atrial function. However, a second connecting superior lesion was added several years later to anatomically isolate the entire posterior left atrium (termed the box lesion set) in an attempt to improve early and late results.

The Group of Dr Damiano ${ }^{192}$ has recently published updated results on 282 patients undergoing Cox-Maze IV procedure, adopting a more rigorous follow-up of the patients, with all patients having either electrocardiographic or 24-h Holter monitoring at 3,6 and 12 months. Freedom from AF recurrence was $89 \%$ at 12 months and 1-year freedom 
from AF and anti-arrhythmic drugs was 67\%. This Group had previously carried out a propensity analysis of matched patients undergoing the CoxMaze III versus Cox-Maze-IV ${ }^{171}$ which showed that there was no significant difference between these two procedures in terms of the rates of freedom from $\mathrm{AF}$ at 3, 6, and 12 months with the advantage of shortening operative times while maintaining the efficacy of the traditional cut-andsew Cox-Maze III.

Table 1 shows the published study employing the Cox-Maze IV procedure and including patients with $\mathrm{LAF}^{171,191-199}$.

Nonetheless, the growth of surgery for lone LAF has not paralleled that for AF associated with other types of heart disease. The traditional sternotomy approach has not achieved widespread application, despite its efficacy. Instead catheter-based procedures are used more often for LAF. In fact, in 2007, only 700 procedures for LAF were reported for that year in the Society for Thoracic Surgeons database ${ }^{200}$.

Indeed, sternotomy and cardiopulmonary bypass are invasive procedures with substantial associated morbidity which most patients are willing to avoid for treatment of AF.

\section{Minimally Invasive Surgery}

Recently, $\operatorname{Cox}^{201}$ defined the characteristics of the ideal technique required for the development and wide adoption of a surgical procedure for the treatment of AF. He reported that this procedure should be minimally invasive (preferably thoracoscopic), epicardial and without cardiopulmonary bypass. 
Indeed, video-assisted beating heart surgery has the advantage of direct visualization and access to the epicardial surface of the heart through limited 1-cm skin incisions.

Furthermore, it is performed on the beating heart thus avoiding extracorporeal circulation. In addition, this approach enables the surgeon to position the ablation device accurately around or on the structure he wishes to isolate in a very quick and precise way. Finally the large epicardial space makes the use of longer and bigger ablation catheters possible and, as a consequence, the lesions are easily made into lines thus reducing the risk of discontinuity compared to the point-like ablation achieved through an endocardial approach.

Over the last decades a plethora of new ablation technologies and thoracoscopic and video-assisted thoracic surgical approaches have been introduced.

The advent of reliable single lung ventilation under general anesthesia has afforded the surgeon easy access to either hemi-thorax for a variety of procedures. Furthermore, bilateral approaches during a single session are relatively easy to perform, enabling precise device placement, direct and immediate visual feedback for lesion creation, and straightforward management of the left atrial appendage.

Nonetheless, thoracoscopic instruments are still somewhat primitive and generally may be characterized as having somewhat limited maneuverability. They also require specific skills and expertise. Finally, the vision provided on the operating room monitors is flat and twodimensional, lacking depth perception and visibility behind the heart, and in the transverse and oblique sinuses, is severely limited. 
Recent developments in robotic technology have largely overcome these limitations. The robot allows the operator to see the field in three dimensions and the "wrist" of the operating instrument permits many more degrees of freedom. Unfortunately, there is considerable expense incurred with the use of the robot and considerable time spent in the setup of the operative field. Therefore almost all purely robotic procedures have been performed from the right side of the chest only, leaving considerable risk for incorrect positioning of ablative instruments and limiting the options for management of the left atrial appendage.

Designed to overcome the limitations of the purely thoracoscopic and robotic approaches, video-assisted ("VATS") methods have been gaining in popularity. VATS aims to reduce the size of the intercostal incision(s) yet maintain visibility through the use of a port-accessed camera. Although the visibility is excellent with this approach, it does require essentially "two operations" as each hemithorax is accessed separately.

However, the choice between a thoracoscopic, VATS or a thoracotomic approach depends on the surgeon's skills and preferences.

The decision to opt for a single-side or a bilateral approach depends on the ablation device available. A single-sided approach is less traumatic but only monopolar devices will be used and, due to the properties of these devices on the beating heart, only a significant delay can be obtained and not a bi-directional conduction block. In contrast, bipolar radiofrequency clamps can guarantee transmural and continuous lesions but require a bilateral approach which makes the procedures more invasive and increases the possible complication rates (bleeding, phrenic nerve lesion, pulmonary complications). 
The available incomplete literature makes it very difficult to decide whether one approach should be preferred considering the potential of a lower complication rate for the monolateral approach but probably a higher success rate in the long-term due to the completeness of the lines with a bilateral approach using bipolar clamps.

\section{Bilateral Thoracoscopic Approach}

The most widely employed minimally invasive approach to LAF has been the video-assisted bilateral mini-thoracotomy or thoracoscopic pulmonary vein island creation and left atrial appendage removal or exclusion, usually with ganglionic plexus evaluation and destruction. Most surgeons prefer this approach to avoid the difficult passage of the ablation device around the PVs (through the transverse and the oblique sinus) when performing a monolateral thoracoscopic approach.

The percentage of success with this technique ranged from $42 \%$ to $91 \%$ in published papers (excluding case reports) at follow-up ranging from 6 and 40 months (Table 3$)^{202-220}$.

\section{Right-sided Thoracoscopic Approach}

A right sided port approach with two or three ports has been described by several authors ${ }^{21-226}$. Initially, microwave technology was employed followed by laser and unipolar suction-assisted radiofrequency. Unfortunately, significant published assessments are lacking and the only substantial reports available are for microwave technology.

Recently Klinkenberg and coworkers ${ }^{226}$ published their experience with 15 patients who underwent minimally invasive epicardial off pump monolateral right-sided video assisted thoracic surgery employing HIFU 
energy. These authors reported very poor results with $27 \%$ of patients in sinus rhythm after $1.3 \pm 0.6$ years and $73 \%$ requiring a re-ablation.

In contrast, in other reports ${ }^{221-225}$, the percentage of success ranged from $60 \%$ to $100 \%$.

This approach is promising, although a limitation potentially includes the inability to remove the left atrial appendage. For this reason, Balkhy and coworkers $^{223}$ combined the right thoracoscopic MW ablation with the incorporation of a new device for left atrial appendage exclusion (SurgASSIST computer-mediated thoracoscopic stapling system [Power Medical Intervention, New Hope, PA, USA]).

\section{Right-sided Thoracotomic Approach}

A full maze lesion set using a right thoracotomy and a beating heart on cardiopulmonary bypass has been performed clinically with cryothermia $^{227,228}$. More recently Lee and coworkers ${ }^{229}$ published their results in 22 consecutive LAF patients undergoing RF ablation through a right side thoracotomic approach. If these results are confirmed this approach has an important role to play in the treatment of LAF.

\section{Left-sided Thoracoscopic Approach}

Grandmougin and Tiffet ${ }^{230}$ presented a case of a 68-year old female with permanent LAF who, due to consequences resulting from chemotherapy and oral anticoagulation (anemia and hemithorax) and the poor health status of the patient underwent video-assisted thoracoscopic drainage associated with successful epicardial radiofrequency isolation of the pulmonary veins (stable SR at 3-month follow-up). On the basis of this experience, the authors raised the question of whether to perform ablation of both right and left PVs in the same operation rather than delaying an 
additional ablation of the controlateral side according to rhythmologic results

\section{Exclusion/Excision of the Left Atrial Appendage}

It is widely believed that formation and embolism of left atrial appendage thrombi are responsible for the increased risk of stroke in AF patients ${ }^{231}$. Excision or exclusion of the left atrial appendage is currently performed during surgical ablation of AF and is recommended in ACC/AHA Guidelines for patients undergoing mitral valve surgery ${ }^{1}$.

Patients undergoing Cox-Maze procedure had an extraordinarily low incidence of late stroke. In a series of almost 200 consecutive patients with a mean follow-up of more than 5 years, there was only one incident of stroke during follow-up. Most patients were off all anticoagulation ${ }^{168}$. This high success rate has been attributed to not only eliminating atrial fibrillation but also to the fact that the left atrial appendage is excised during this procedure.

Recently, there has been great interest in development and assessment of endocardial and epicardial procedures for exclusion of the left atrial appendage ${ }^{232}$. Many of these approaches now use a stapler to exclude the appendage or, in some instances, endocardial suture exclusion. Nonetheless, Kanderian et al, demonstrated, at transesophageal echocardiography (TEE) that only 55 of 137 (40\%) of closures were successful and that LAA closure occurred more often with excision (73\%) than suture exclusion $(23 \%)$ and stapler exclusion $(0 \%)(\mathrm{p}>0.001)^{233}$.

In the available literature the ligation/exclusion of LAA was performed in $618(83.6 \%)$ patients undergoing minimally invasive surgical ablation for lone atrial fibrillation.. The occurrence of perioperative cerebrovascular 
accident was low $(0.32 \%)^{213,216}$ and comparable with the Cox Maze procedure $(0.5 \%)^{168}$. Alike, the occurrence of cerebrovascular accident during the follow up was low (0.64\%) and this figure compares favorably with occurrence rates reported after the Cox-Maze operation ${ }^{163,165168}$. However, notably, the percentage of patients with anticoagulant therapy was much lower in Cox Maze (16.3\% ) compared to minimally invasive LAF patients $(n=214,31.4 \%)$.

Excision of the left atrial appendage may be difficult during minimally invasive surgery and there has been growing concern regarding the safety of this maneuver. This has led to the development of new surgical tools making this potentially dangerous maneuver easier ${ }^{234-236}$. However, from our review the procedure resulted to be safe. Indeed, among LAF patients undergoing minimally invasive surgical ablation and LAA ligation/excision, we found only a case $(0.16 \%)$ of serious complication related to tearing of the base of the $\mathrm{LAA}^{211}$.

However, all these figures were not the result of a meta-analysis of quantitative studies . Furthermore, the small number of patients undergoing minimally invasive surgery without a concomitant LAA procedure, do not allow us to draw any conclusion. Consequently, data must be evaluated in the light of these limitations and further large prospective studies are necessary to determine whether patients who undergo LAA closure really demonstrate a reduction in thrombo-embolic events and whether anticoagulation in these patients has to be discontinued ${ }^{232}$.

\section{The Hybrid Approach}

The rationale of the Hybrid approach, which combines a mono or bilateral epicardial approach with a percutaneous endocardial ablation in a single- 
step procedure, is to limit the shortcomings of both techniques and, at the same time, to combine their advantages.

A worldwide survey on the methods, efficacy and safety of catheter ablation in AF was published in $2005^{237}$ and updated in $2010^{238}$. It showed that the success rate without anti-arrhythmic drugs was $75 \%$ for paroxysmal AF, $65 \%$ for persistent and $63 \%$ for permanent AF. However, along with the disadvantage of a low success rate in patients with persistent and permanent $\mathrm{AF}$, with this procedure there is the advantage of evaluating the end points of the ablation. It also allows surgeons to perform ablations in regions which can only be reached endocardially. On the other hand, the epicardial approach alone failed to guarantee satisfactory long-term results (Table 3).

For this reason the hybrid approach has been introduced, with the surgeon performing a monolateral or bilateral thoracoscopy (depending on the ablation devices chosen and the lesion set he/she wants to create). Considering the different possible etiologies in paroxysmal, persistent and long-lasting persistent AF, the procedure can be tailored to the patient's needs combining efficient epicardial lines with measured electrophysiological endpoints. The surgeon will for every patient at least isolate the pulmonary veins. If this is insufficient to treat the AF he/she has the possibility to make a roof line (connecting left and right superior pulmonary veins) and inferior line (connecting inferior left and right pulmonary veins). In addition he/she can create a left isthmus line which extends from left inferior pulmonary vein to the mitral annulus. On the right atrium he/she can isolate the superior vena cava and create a bicaval line. If necessary the risk for thrombo-embolic events can be reduced by excluding the left atrial appendage; this will also have an impact on the 
substrate. After checking for possible incomplete transmurality of the epicardial lines endocardially, the electrophysiologist can complete any line by focused endocardial applications. Thus in case of an incomplete isolation of one of the pulmonary veins, or any other line, an endocardial ablation is added. Furthermore, lines that cannot be made epicardially are carried out endocardially such as right and left isthmus line.

We previously published the experience of our Group (Department of Cardiac Surgery, Academic Hospital, Maastricht, The Netherlands and UCL Mont-Godinne, Belgium) with a hybrid procedure performing a right-sided thoracoscopic box-lesion obtained with a monopolar radiofrequency catheter (Cobra Adhere XL, Estech, San Ramon, CA) and an associated endocardial radiofrequency ${ }^{239}$. We have recently reviewed data which were collected following Guidelines for reporting data and outcomes for the surgical treatment of atrial fibrillation ${ }^{240}$.

Nineteen patients with paroxysmal $(n=2)$, persistent $(n=7)$ or long-standing persistent $(\mathrm{n}=10)$ LAF underwent hybrid right-sided thoracoscopic procedure. Preoperative AF prevalence was 38.7\% (paroxysmal 20\%, persistent $34.7 \%$, long standing persistent $63.6 \%$ ). Postoperative electrocardiograms (ECG) were used to assess AF. Recommended ECG follow-up intervals were 1, 3, 6 months, 1 year and annually thereafter. We performed the analysis of the intermittent data available in terms of timerelated prevalence (burden) of AF, use of anti-arrhythmic drugs and use of Warfarin with ordinary or non-longitudinal (mixed) models that account for all repeated measurements. Fifty-six-week postoperative prevalence of AF was $13.3 \%$ (68\% Confidence Limits [CL] 11.0-17.4). It was $21.1 \%$ (17.624.9 ) in long standing persistent $(\mathrm{p}<0.001$ vs. preoperative value) and $0 \%$ in persistent and paroxysmal $(\mathrm{p}<0.001)$.At 56 months prevalence of anti- 
arrhythmic drugs and Warfarin use were 26\% ( CL 17.4-33.1) and 48\% [68\% CI 37.2-53.2\%], respectively (Unpublished results).

The comparison of these results with those of patients who had first epicardial procedure with a subsequent endocardial procedure ${ }^{241}$ (using both microwave ablation [Flex 10, Boston Guidant, Santa Clara, CA] and radiofrequency ablation [Cobra Adhere XL, Estech, San Ramon, CA]) with results of the hybrid procedure employing the bipolar radiofrequency clamp $^{242}$ (Atricure INC, West Chester, $\mathrm{OH}$ ) in combination with a radiofrequency linear pen (Atricure INC) and the Coolrail system (Atricure INC) to create additional lesion lines, will be the subject of ongoing studies.

In our policy, patients are referred for hybrid procedure in case of persistent or long-standing persistent AF with LA dilatation ( $>45 \mathrm{~mm}$ ) or after one or more failed catheter ablations. We don't perform a MRI to make the decision. The indication is based on the history of AF and the LA size. A transthoracic echocardiography and a CT scan are carried out preoperatively (pulmonary vein anatomy, coronary artery) and potential candidates to a hybrid procedure undergo lung function test. The preferred approach is bilateral whereas the monolateral approach is chosen for patients with significant chronic obstructive pulmonary disease.

To evaluate bidirectional block, we pace endocardially from both sides of the line and we assess the presence of double potentials on the line. We perform "endocardial touch" whenever linear lesions are not complete or when they cannot be completed from the epicardial side. We follow a stepwise approach (Figure 2) ${ }^{243}$.

If the patient had a previous catheter ablation we first do the surgical dissection thoracoscopically without ablating, in order to avoid surgical 
trauma while the patient is heparinised. After the surgical dissection, the EP carries out a trans-septal puncture, the patient is heparinised, the isolation of the PVs is checked as well as any additional previous ablation line. The hybrid approach is then tailored to the EP findings.

Figure 3 A-D depicts some endpoints reached at the end of the hybrid procedure.

Previous cardiac surgery, in our opinion, is not an absolute contraindication for the hybrid procedure. The advantage of the hybrid approach is that a possible incomplete epicardial line in these patients because of difficult access due to adhesions can be mapped and completed endocardially. CFAEs mapping and ablation are greatly facilitated by endocardial mapping, nonetheless, until recently, the CFAEs had not been specifically targeted. Preliminary data of our ongoing study mapping the CFAEs before and after the epicardial ablation, show that only the CFAEs at the septum and at the base of the LAA remain and have to be ablated endocardially. In conclusion, combined epicardial surgical and percutaneous endocardial approaches aim to solve some of the problems related to each of the procedures independently.

It presents some advantages: 1) There is no risk of tamponade during the trans-septal puncture since the pericardium is open. 2) The surgeon can protect the phrenic nerves and the esophagus and the effective surgical ablation reduces the fluoroscopy time. 3) Since the surgical ablation device is located on the antrum of the left atrium and left as a radiopaque marker, it is almost impossible to create stenosis of the pulmonary veins. 4) Most of the ablation lines are made epicardially, therefore the number of endocardial application ablation lines employed is small with consequent 
reduction in the occurrence of embolic events which may complicate the endocardial ablation.

Potential disadvantages are: 1) The procedure is time consuming and significantly longer than surgery-alone techniques: 2) The heparinization of the patient after the septal puncture might cause bleeding of surgically dissected areas.

\section{A Glance at the Future}

The treatment of LAF continues to progress and the future of surgery will focus on two areas: better understanding of the mechanism of LAF and developing techniques that are progressively less invasive.

In understanding the mechanism of AF, more studies are now more focused on the autonomic ganglia which are located around the pulmonary veins, so they might be the true triggers and have a major role in the maintenance of $\mathrm{AF}^{244}$, and it is still disputed whether autonomic ganglia could reconnect or regrow ${ }^{245}$. However, the role of ganglia and their destruction during minimally invasive surgery remains an area of active research $^{216,246-248}$.

Ideally, the mechanism of AF should be defined before planning surgery but, unfortunately, the mapping systems available for non-invasive endocardial mapping have poor resolution and, although EPs have been able to map high-frequency activation in PVs as well as CFEAs, some patients require more sophisticated waveform. Epicardial activation sequence mapping has been the gold standard for this ${ }^{159}$ but, unfortunately it is invasive and time-consuming. For this reason some Groups have developed frequency mapping ${ }^{249,250}$ which identifies the fastest activating 
regions during FA. It requires very little subjective analysis and can be done in real time.

Furthermore, in, the area of noninvasive method to accurately diagnose AF patients electrocardiogram imaging (ECGI) is promising ${ }^{251-253}$. An inverse solution can be calculated by using anatomical information obtained by CT scan made at the time of the recording. Electrograms can be reconstructed on the atrial epicardial surface.

The search for the ideal ablation technology able to create trans-mural linear lesions on the beating heart through a mini-invasive approach to minimize operative trauma is still ongoing.

Although no publication has described them yet, other less invasive techniques are under evaluation, such as the subxiphoid approach.

\section{Conclusions}

Future success in the treatment of LAF will probably rely on a combination of available therapies (medical, catheter and surgical) because some of the maze lesions, e.g. the lesion of the mitral annulus, are very difficult to create on a closed beating heart. However, the ideal approach should be patient-tailored, employing a procedure which is adapted to the origin of the patient's AF and takes into consideration triggers and substrate. This can only be achieved through a close collaboration between the surgeon and the electrophysiologist, knowing that the surgeon probably has the best tools to ablate, whereas the electrophysiologist has a better knowledge of this pathology and possesses the tools to measure the effectiveness of the performed ablation. 


\section{Acknowledgments}

Heartfelt thanks to Mrs Monique De Jong and Mr. Pol Chambille for their invaluable help in Pubmed Search and Manuscript preparation. 


\section{Aim and outline of this thesis}

In this thesis a new and innovative minimal invasive treatment of lone atrial fibrillation (LAF) has been studied. The desire to improve the outcome (increase of success rate and reduction of complication rate) of percutaneous endocardial ablation procedures and the necessity to minimize the invasiveness of existing surgical approaches has directed us towards the design of a single-step combined percutaneous endocardial procedure with a thoracoscopic epicardial procedure on the beating heart. A team of electrophysiologists and cardiothoracic surgeons working simultaneously in a dedicated environment developed the so-called hybrid AF procedure. This dual endocardial / epicardial procedure was studied in different types of AF with a monolateral or bilateral thoracoscopic procedure. The results of this hybrid approach can guide us to determine if there is an add-on value of an epicardial access in the treatment of LAF and if so, which minimal invasive surgical technique is able to give us a three-dimensional knowledge and a three-dimensional treatment of AF. As a result we expect to obtain a higher single procedure long-term success rate with an acceptable low complication rate.

In chapter one, a general introduction, we summarize the history of $\mathrm{AF}$, the types and pathophysiology of AF, and past, current and possible future treatment options in patients with LAF. Building upon this knowledge, chapter two is an 
updated review of current state-of-the-art minimally invasive surgery for the treatment of LAF.

In chapter 3 we present our results of a minimally invasive surgical treatment of lone atrial fibrillation employing a radiofrequency source through a bilateral thoracoscopy. This clinical experience was the basis of our quest towards better understanding of the three-dimensional structure of AF and to try to improve the treatment modalities for LAF.

In chapter 4 we describe a simplified hybrid technique to treat patients in lone atrial fibrillation with a combined percutaneous endocardial approach with a monolateral right thoracoscopic approach. An electrical isolation of the four pulmonary veins (box lesion) was aimed for with a monopolar radiofrequency catheter. This approach yielded unsatisfactory results after 1 year in patients with persistent and long-standing persistent AF, but with a high degree of safety. This experience prepared the field for a hybrid procedure using bipolar epicardial ablation devices with a bilateral thoracoscopy which is described in chapter 5. The results of this hybrid bilateral thoracoscopic approach are compared to the results of a hybrid right thoracoscopic approach in chapter 6 . The hybrid bilateral approach using bipolar devices showed a good 1-year success rate independently of the AF type and seems to be the better choice for long-standing persistent and persistent LAF. 
In an effort to further increase our understanding of the potential of the hybrid approach we compare the standard non-hybrid bilateral thoracoscopic approach with this new bilateral hybrid procedure in chapter 7 .

In chapter 8 we demonstrate the beneficial effect of minimally invasive radiofrequency surgical ablation on left atrial reverse remodeling and improvement of LA compliance and function employing two-dimensional speckle-tracking echocardiography 2D-STE.

Finally, in chapter 9 the findings of this thesis are brought into perspective comparing the hybrid AF procedure to current general practice. The possible future implications are considered and discussed. 


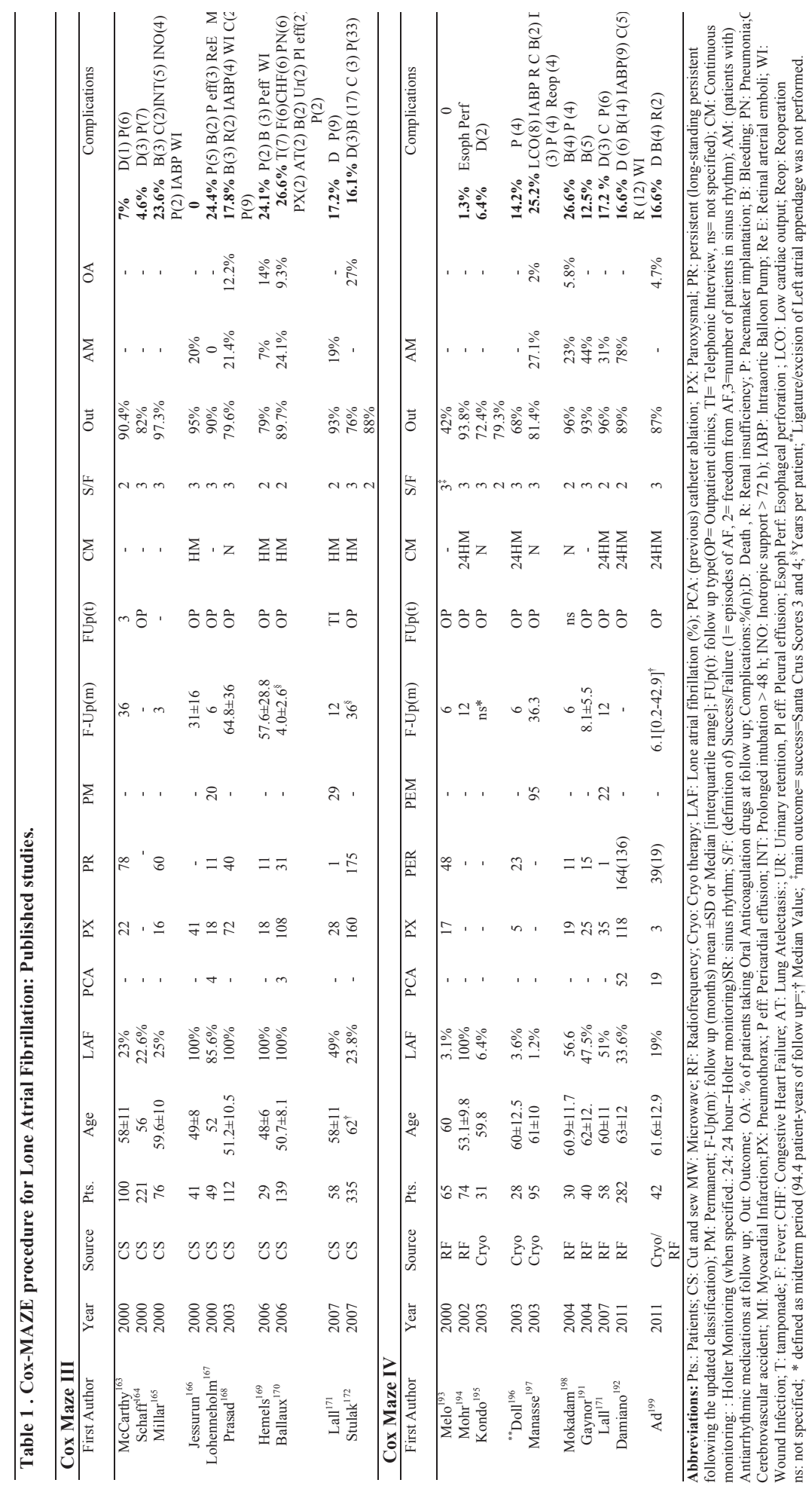




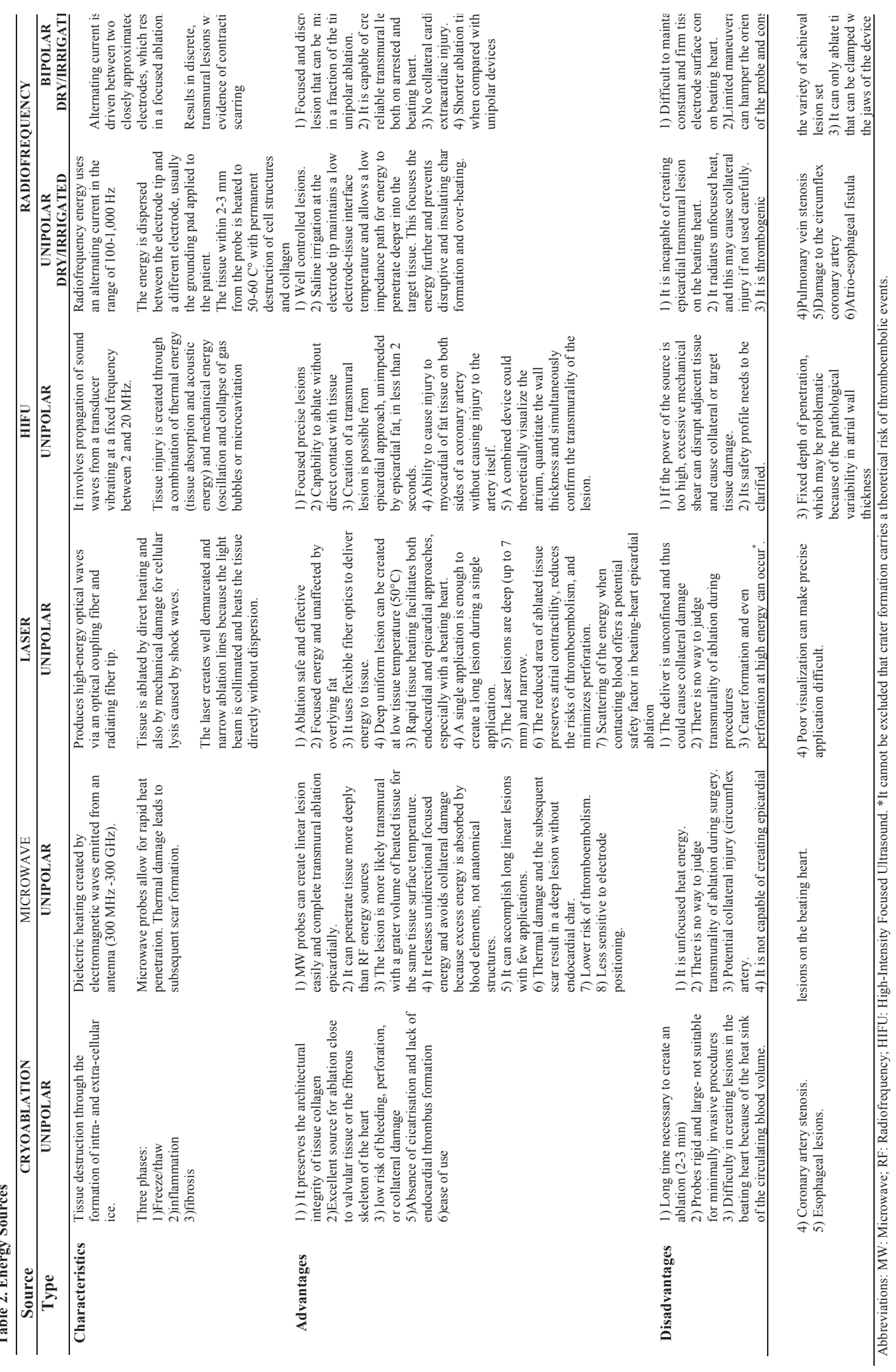




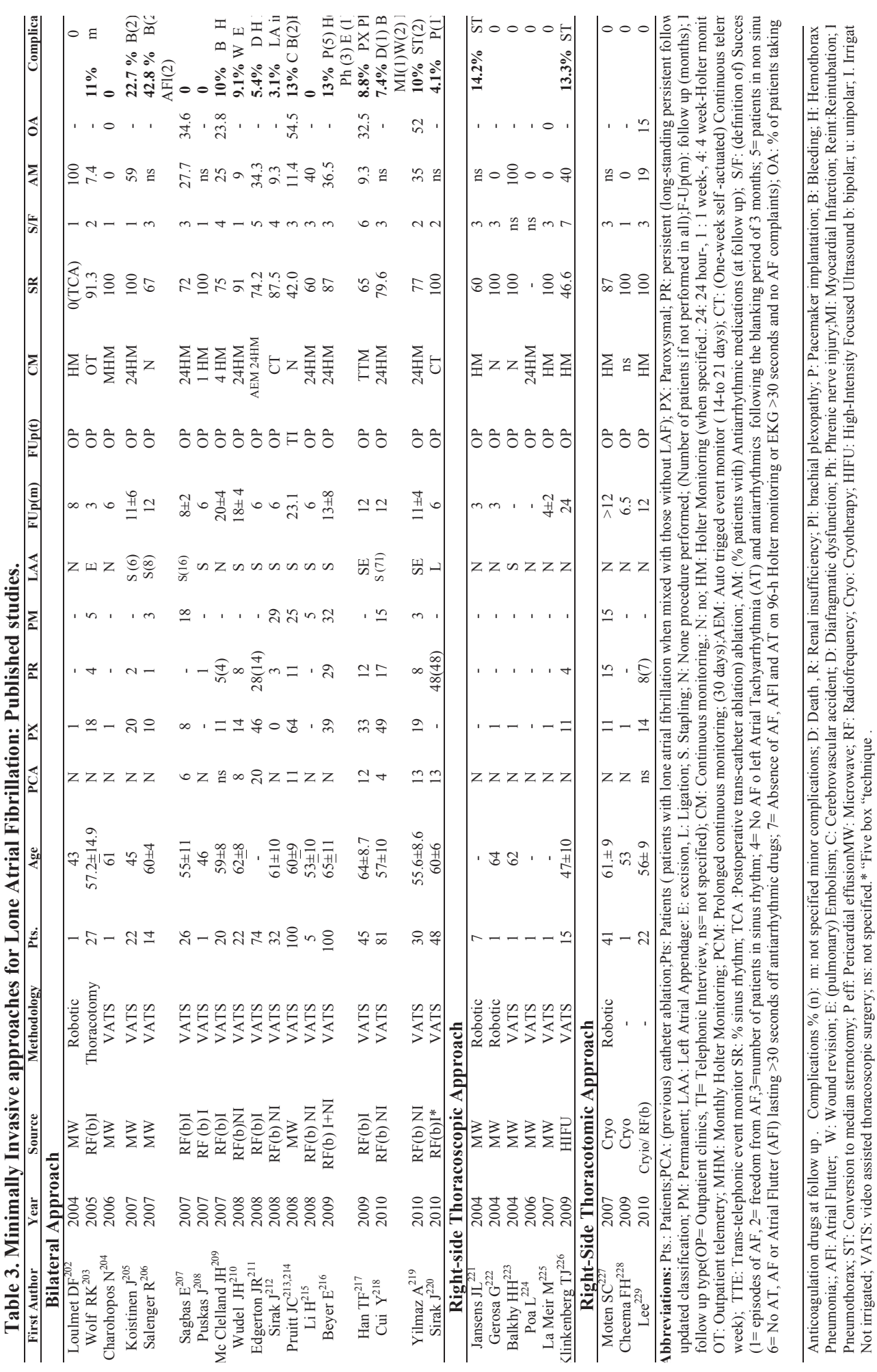




\section{Figure Legends}

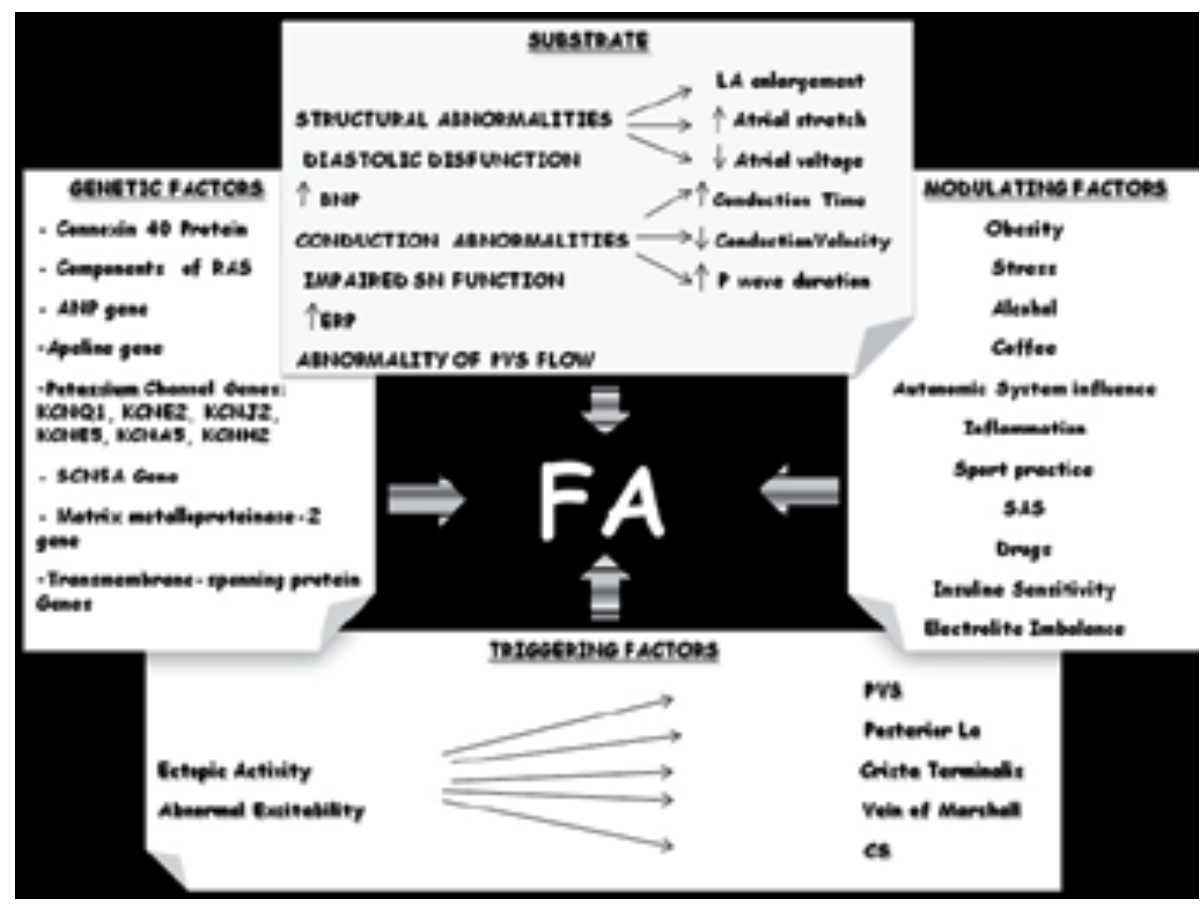

Figure 1. Pathophysiology of Lone Atrial Fibrillation (see text). Abbreviations: RAS: Reninangiotensin system; ANP: Atrial natriuretic peptide;LA: Left Atrial; BNP: Brain natriuretic peptide; ERP: Effective refractory period; PVS: Pulmonary Veins; SAS: Sleep Apnea Syndrome; PVS: Pulmonary Veins; CS: Coronary Sinus. 


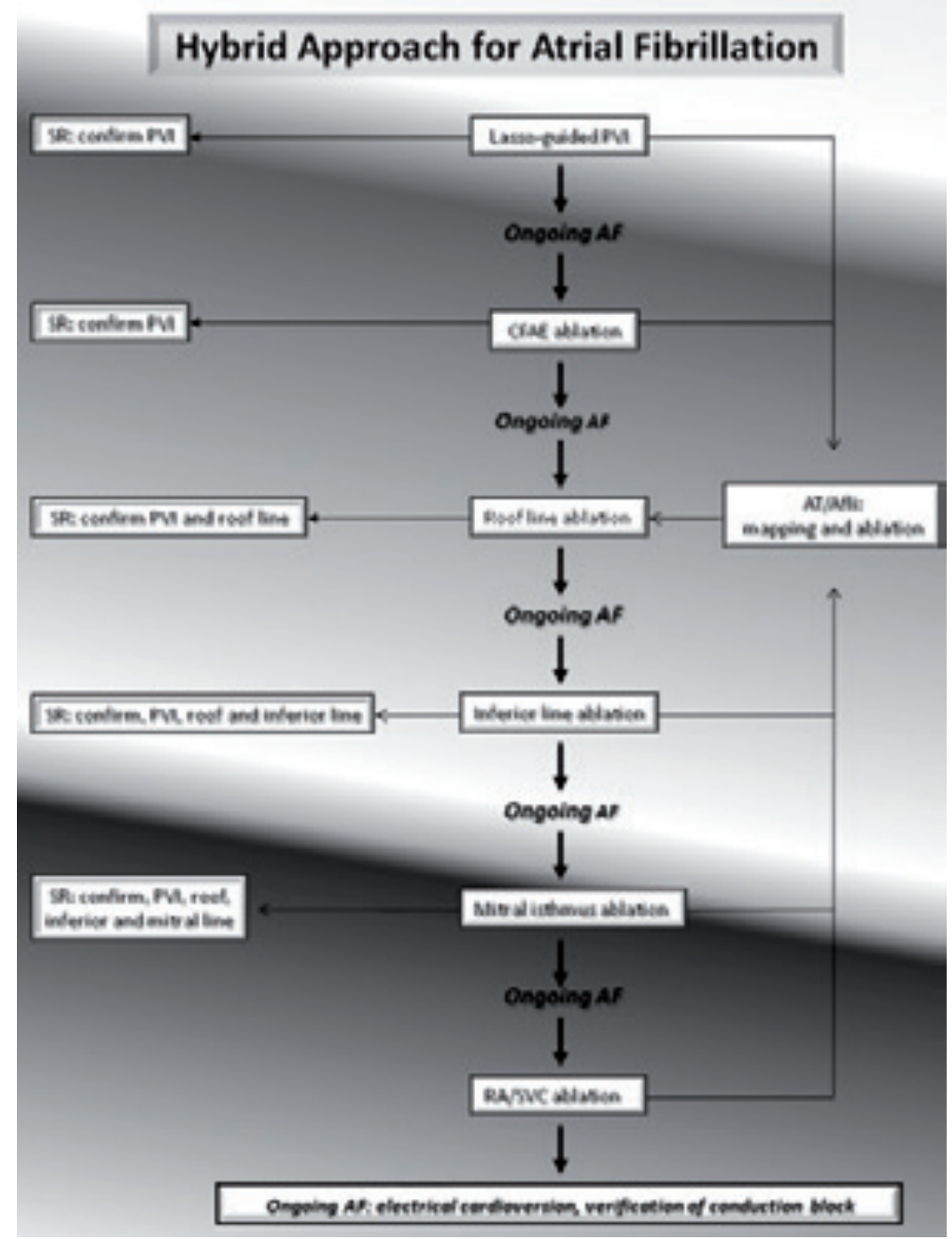

Figure 2 The steps of the hybrid approach. Abbreviations: AF: Atrial Fibrillation; SR:

Sinus Rhythm; PVI: Pulmonary Vein Isolation; CAFE: Complex Atrial Fractionated

Electrograms; AT: Atrial tachycardia; Afl: Atrial Flutter; RA: Right Atrium; SVC:

Superior Vena Cava. 

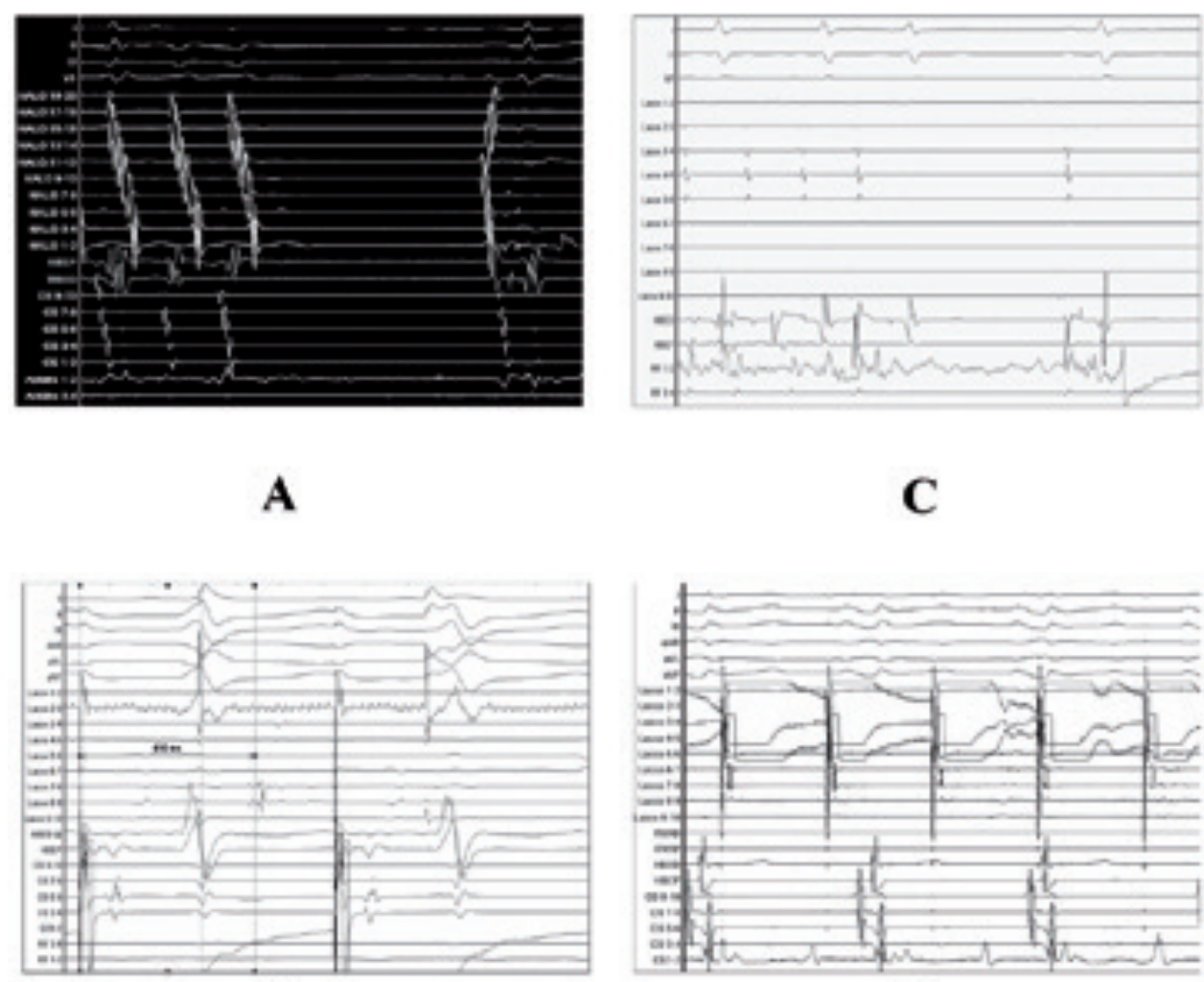

B

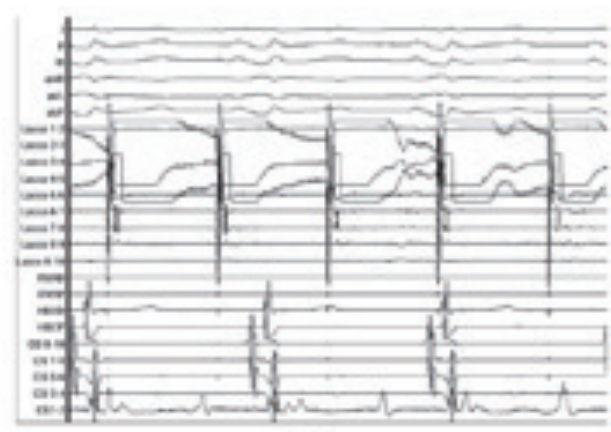

D

Figure 3. A. Conversion of atrial flutter to sinus rhythm: it is a typical counterclockwise flutter during hybrid AF ablation. During endocardial ablation of the posterior isthmus there is conversion to sinus rhythm. This was also the endpoint of the procedure. B. Closure of the box lesion: after the isolation of the PVs and making the roof and inferior line there was still a gap were the roofline meets the line around the left PVs. Indeed the clamp was too short to isolate the left PVs. The figure shows very late pulmonary vein potentials on Lasso 7-8 and 8-9 (410 milliseconds after pacing artifact in the coronary sinus). In the following beat those signals are disappeared due to complete isolation of the box and left pulmonary veins. C. Conversion of atrial tachycardia to sinus rhythm: 
during hybrid procedure, AF organized to atrial tachycardia. By endocardial ablation at the base of the right atrial appendage, we had conversion to sinus rhythm. This was the endpoint of the procedure. D. Endocardial exit block from the box: the figure shows pacing and local capture in the box (signals on Lasso 6-7 and 7-8, the Lasso catheter is within the box in this case!) and lack of conduction to the LA during sinus rhythm. 


\section{$\underline{\text { References }}$}

1. Fuster V, Rydén LE, Cannom DS, Crijns HJ, Curtis AB, Ellenbogen KA, Halperin JL et al. ACC/AHA/ESC 2006 guidelines for the management of patients with atrial fibrillation: a report of the American College of Cardiology/American Heart Association Task Force on Practice Guidelines and the European Society of Cardiology Committee for Practice Guidelines (Writing Committee to Revise the 2001 Guidelines for the Management of Patients With Atrial Fibrillation). J Am Coll Cardiol. 2006;48(4):854-906.

2. Benjamin EJ Impact of atrial fibrillation on the risk of death. The Framinghan Heart Study. Circulation 1998;98:946-52

3. Thom T, Haase N, Rosamond W, Howard VJ, Rumsfeld J, Manolio T, Zheng ZJ, et al. American Heart Association Statistics C, Stroke Statistics S: Heart disease and stroke statistics 2006 update: A report from the American Heart Association Statistics Committee and Stroke Statistics Subcommittee. Circulation 2006; 113:e85-e151.

4. Feinberg WM, Cornell ES, Nightingale SD, Pearce LA, Tracy RP, Hart RG, Bovill EG. Relationship between prothrombin activation fragment F1.2 and international normalized ratio in patients with atrial fibrillation. Stroke Prevention in Atrial Fibrillation Investigators. Stroke 1997; 28: 1101-6.

5. Benjamin EJ, Levy D, Vaziri SM, D’Agostino RB, Belanger AJ, Wolf PA. Independent risk factors for atrial fibrillation in a population-based cohort. The Framingham Heart Study. JAMA 1994;271:840-4.

6. Chambers PW. Lone atrial fibrillation: Pathologic or not? Med Hypotheses 2007; 68:281-7. 
7. Taggar JS, Lip GY. Risk predictors for lone atrial fibrillation. Europace. 2008: 10 (1): 6-8.

8. Levy S. Epidemiology and classification of atrial fibrillation. J

Cardiovasc Electrophysiol 1998; 8:S78-82.

9. Vulpian A. Note sur les effets de la faradisation directe des ventricules du coeur chez le chien. Archives de Physiologie Normale et Pathologique $1874 ; 6: 975$.

10. McMichael J. History of atrial fibrillation 1628-1819 Harvey-de SenacLaennec. Br Heart J 1982; 48: 193-7.

11. Nothnagel H. Ueber arythmische Herzthatigkeit. Deutsches Archiv fur Klinische Medizin 1876; 17: 190-220.

12. MacKenzie J.The inception of the rhythm of the heart by the ventricle. Br Med J 1904; 1: 529-36.

13. Cushny AR, Edmunds CW. Paroxysmal irregularity of the heart and auricular fibrillation. In: Bulloch W, ed. Studies in pathology. Aberdeen, Scotland: University of Aberdeen, 1906:95-110.

14. Einthoven W. Le télécardiogramme. Arch Int Physiol 1906;4:132-164.

15. Fye WB. Disorders of the heartbeat: a historical overview from antiquity to the mid-20th century. Am J Cardiol 1993;72:1055-1070.

16. Fye WB. Tracing Atrial Fibrillation-100 Years. 2006; 355:1412-141.

17. Rothberger CJ, Winterberg H. (1909). Vorhofflimmern und Arhythmia perpetua. Wiener Klinische Wochenschrift 1909; 22: 839-44.

18. Lewis T. Auricular fibrillation: a common clinical condition. Br Med J 1909; 2: 1528 . 
19. Flegel KM. "From delirium cordis to atrial fibrillation: historical development of a disease concept". Ann. Intern. Med. 1995; 122 (11): 867 73.

20. Evans W, Swann P. Lone auricular fibrillation. Br Heart J. 1954; 16: 189-194.

21. Kopecky SL, Gersh BJ, McGoon MD, Whisnant JP, Holmes DR Jr, Ilstrup DM, Frye RL. The natural history of lone atrial fibrillation. A population-based study over three decades. N Engl J Med 1987; 317:66974.

22. Lamb LE, Pollard LW. Atrial fibrillation in flying personnel. Circulation 1964; 29:694-701.

23. Peter, RH, Gracey, JG, Beach, TB. A clinical profile of idiopathic atrial fibrillation. A functional disorder of atrial rhythm. Ann Intern Med 1968; 68:1288-95.

24. Brand, FN, Abbott, RD, Kannel, WB, Wolf, PA. Characteristics and prognosis of lone atrial fibrillation: 30 year followup in the Framingham study. JAMA 1985; 254:3449-53.

25. Kopecky SL, Gersh BJ, McGoon MD, Chu CP, Ilstrup DM, Chesebro JH, Whisnant JP. Lone atrial fibrillation in elderly persons: a marker for cardiovascular risk. Arch Intern Med 1999; 159:1118-22.

26. Gage BF, Waterman AD, Shannon W, Boechler M, Rich MW, Radford MJ. Validation of clinical classification schemes for predicting stroke: results from the National Registry of Atrial Fibrillation. JAMA 2001; 285:2864-70.

27. Go AS, Hylek EM, Chang Y, Phillips KA, Henault LE, Capra AM, Jensvold NG, et al. Anticoagulation therapy for stroke prevention in atrial 
fibrillation: how well do randomized trials translate into clinical practice?. JAMA 2003; 290:2685-92.

28. Singer DE, Albers GW, Dalen JE, Fang MC, Go AS, Halperin JL, Lip GY, et al. Antithrombotic therapy in atrial fibrillation: American College of Chest Physicians Evidence-Based Clinical Practice Guidelines (8th Edition). Chest 2008; 133:546S-592S.

29. Straus, SE, Majumdar, SR, McAlister, FA. New evidence for stroke prevention: scientific review. JAMA 2002; 288:1388-95.

30. Cooper HA, Bloomfield DA, Bush DE, Katcher MS, Rawlins M, Sacco JD, Chandler M; AFFIRM Investigators. Relation between achieved heart rate and outcomes in patients with atrial fibrillation (from the Atrial Fibrillation Follow-up Investigation of Rhythm Management [AFFIRM] study). Am J Cardiol 2004; 93:1247-53.

31. Lévy S, Camm AJ, Saksena S, Aliot E, Breithardt G, Crijns H, Davies $\mathrm{W}$, et al. International consensus on nomenclature and classification of atrial fibrillation; a collaborative project of the Working Group on Arrhythmias and the Working Group on Cardiac Pacing of the European Society of Cardiology and the North American Society of Pacing and Electrophysiology. Europace 2003; 5:119-22.

32. Chen LY, Shen WK. Epidemiology of atrial fibrillation: a current perspective. Heart Rhythm 2007; 4:S1-6.

33. Van Wagoner DR. Recent insights into the pathophysiology of atrial fibrillation. Semin Thorac Cardiovasc Surg 2007; 19:9-15.

34. Frost L. Lone atrial fibrillation: good, bad, or ugly? Circulation.2007; 115:3040-1. 
35. Potpara TS, Lip GY. Lone atrial fibrillation: what is known and what is to come. Int J Clin Pract. 2011. Apr;65(4):446-57.

36. Go AS, Hylek EM, Phillips KA, Chang Y, Henault LE, Selby JV, Singer DE. Prevalence of diagnosed atrial fibrillation in adults: national implications for rhythm management and stroke prevention: the Anticoagulationand Risk Factors in Atrial Fibrillation (ATRIA) Study. JAMA 2001; 285: 2370-5.

37. Feinberg WM, Blackshear JL, Laupacis A, Kronmal R, Hart RG. Prevalence, age distribution, and gender of patients with atrial fibrillation. Analysis and implications. Arch Intern Med 1995; 155: 469-73.

38. Furberg CD, Psaty BM, Manolio TA, Gardin JM, Smith VE, Rautaharju PM. Prevalence of atrial fibrillation in elderly subjects (the Cardiovascular Health Study). Am J Cardiol.1994; 74: 236-41.

39. Lévy S, Maarek M, Coumel P, Guize L, Lekieffre J, Medvedowsky JL, Sebaoun A.Characterization of different subsets of atrial fibrillation in general practice in France: the ALFA study. The College of French Cardiologists. Circulation 1999; 99:3028-35.

40. Scardi S, Mazzone C, Pandullo C, Goldstein D, Poletti A, Humar F. Lone atrial fibrillation: prognostic differences between paroxysmal and chronic forms after 10 years of follow-up. Am Heart J 1999; 137(4 Pt 1): 686-91.

41. Onundarson PT, Thorgeirsson G, Jonmundsson E, Sigfusson N, Hardarson T. Chronic atrial fibrillation-epidemiologic features and 14 year follow-up: a case control study. Eur Heart J 1987; 8: 521-7.

42. Davidson E, Rotenberg Z, Weinberger I, Fuchs J, Agmon J. Diagnosis and characteristics of lone atrial fibrillation. Chest 1989; 95:1048-50. 
43. Jahangir A, Lee V, Friedman PA, Trusty JM, Hodge DO, Kopecky SL, Packer DL. et al. Long-term progression and outcomes with aging in patients with lone atrial fibrillation. A 30-year follow-up study. Circulation 2007;115:3050-6.

44. Chen LY, Herron KJ, Tai BC, Olson TM. Lone atrial fibrillation: influence of familial disease on gender predilection. J Cardiovasc Electrophysiol 2008; 19: 802-6.

45. Gersh BJ, Solomon A. Lone atrial fibrillation: epidemiology and natural history. Am Heart J 1999;137:592-5.

46. Patton KK, Zacks ES, Chang JY, Shea MA, Ruskin JN, Macrae CA, Ellinor PT.. Clinical subtypes of lone atrial fibrillation. Pacing Clin Electrophysiol 2005; 28: 630-8.

47. Osranek M, Bursi F, Bailey KR, Grossardt BR, Brown RD Jr, Kopecky SL, Tsang TS, et al. Left atrial volume predicts cardiovascular events in patients originally diagnosed with lone atrial fibrillation: three-decade follow-up. Eur Heart J. 2005 ;26(23):2556-61.

48. Katritsis DG, Toumpoulis IK, Giazitzoglou E, Korovesis S, Karabinos I, Paxinos G, Zambartas C, et al. Latent arterial hypertension in apparently lone atrial fibrillation. J Interv Card Electrophysiol 2005; 13: 203-7.

49. Stiles MK, John B, Wong CX, Kuklik P, Brooks AG, Lau DH, Dimitri $\mathrm{H}$,et al. Paroxysmal lone atrial fibrillation is associated with an abnormal atrial substrate. J Am. Coll Cardiol 2009; 53: 1182-91.

50. Tsang TS, Gersh BJ, Appleton CP, Tajik AJ, Barnes ME, Bailey KR, Oh JK, et al. Left ventricular diastolic dysfunction as a predictor of the first diagnosed nonvalvular atrial fibrillation in 840 elderly men and women. $\mathrm{J}$ Am Coll Cardiol 2002 Nov 6;40:1636-44. 
51. Sitges M, Teijeira VA, Scalise A, Vidal B, Tamborero D, Collvinent B, Rivera S. et al. Is there an anatomical substrate for idiopathic paroxysmal atrial fibrillation? A case-control echocardiographic study. Europace 2007; 9:294-8.

52. Phang RS, Isserman SM, Karia D, Pandian NG, Homoud MK, Link MS, Estes NA 3rd, et al. Echocardiographic evidence of left atrial abnormality in young patients with lone paroxysmal atrial fibrillation. Am J Cardiol 2004; 94:511-3.

53. Kosmala W, Przewlocka-Kosmala M, Mazurek W. Abnormalities of pulmonary venous flow in patients with lone atrial fibrillation. Europace 2006; 8:102-6.

54. Wolff L. Familial auricular fibrillation. N Engl J Med 1943; 229: 3967.

55. Fox CS, Parise H, D'Agostino RB Sr, Lloyd-Jones DM, Vasan RS, Wang TJ, Levy D, et al. Parental atrial fibrillation as a risk factor for atrial fibrillation in offspring. JAMA 2004; 291: 2851-5.

56. Ellinor PT, Yoerger DM, Ruskin JM, MacRae CA. Familial aggregation in lone atrial fibrillation. Hum Genet 2005; 118:179-84.

57. Christophersen IE, Ravn LS, Budtz-Joergensen E, Skytthe A, Haunsoe S, Svendsen JH, Christensen K. Familial aggregation of atrial fibrillation: a study in Danish twins. Circ. Arrhythm Electrophysiol 2009; 2:378-83.

58. Chen YH, Xu SJ, Bendahhou S, Wang XL, Wang Y, Xu WY, Jin HW. et al. KCNQ1 gain-of-function mutation in familial atrial fibrillation. Science 2003; 299:251-4. 
59. Yang Y, Xia M, Jin Q, Bendahhou S, Shi J, Chen Y, Liang B et al. Identification of a KCNE2 gain-offunction mutation in patients with familial atrial fibrillation. Am J Hum Genet 2004; 75:899-905.

60. Xia M, Jin Q, Bendahhou S, He Y, Larroque MM, Chen Y, Zhou Q. et al. A Kir2.1 gain-of-function mutation underlies familial atrial fibrillation. Biochem Biophys Res Commun 2005; 332:1012-9.

61. Ravn LS, Aizawa Y, Pollevick GD, Hofman-Bang J, Cordeiro JM, Dixen U, Jensen G. et al. Gain-of-function in Iks secondary to a mutation in KCNE5 associated with atrial fibrillation. Heart Rhythm 2008;5:427-35.

62. Olson TM, Alekseev AE, Liu XK, et al. Kv1.5 channelopathy due to KCNA5 loss-of-function mutation causes human atrial fibrillation. Hum Mol Genet. 2006; 15(14):2185-91.

63. Olson TM, Alekseev AE, Liu XK, Park S, Zingman LV, Bienengraeber M, Sattiraju S et al. Sodium channel mutations and susceptibility to heart failure and atrial fibrillation. JAMA. 2005; 293(4):491-3.

64. Ellinor PT, Moore RK, Patton KK, Ruskin JN, Pollak MR, MacRae CA. Mutations in the long QT gene, KCNQ1, are an uncommon cause of atrial fibrillation. Heart 2004; 90:1487-8.

65. Ellinor PT, Petrov-Kondratov VI, Zakharova E, Nam EG, MacRae. Potassium channel gene mutations rarely cause atrial fibrillation. BMC Med Genet 2006; 7:70.

66. Morita H, Kusano-Fukushima K, Nagase S, Fujimoto Y, Hisamatsu K, Fujio $\mathrm{H}$, Haraoka $\mathrm{K}$ et al. Atrial fibrillation and atrial vulnerability in patients with Brugada syndrome. J Am Coll Cardiol 2002; 40:1437-44. 
67. Herve JC, Bourmeyster N, Sarrouilhe D, Duffy HS. Gap junctional complexes: from partners to functions. Prog Biophys Mol Biol 2007; 94:29-65.

68. Vozzi C, Dupont E, Coppen SR, Yeh HI, Severs NJ. Chamberrelated differences in connexin expression in the human heart. J Mol Cell Cardiol 1999; 31:991-1003.

69. Juang JM, Chern YR, Tsai CT, Chiang FT, Lin JL, Hwang JJ, Hsu KL et al The association of human connexin 40 genetic polymorphisms with atrial fibrillation. Int J Cardiol. 2007; 116(1):107-12.

70. Hodgson-Zingman DM, Karst ML, Zingman LV, Heublein DM, Darbar $\mathrm{D}$, Herron KJ, Ballew JD et al. Atrial natriuretic peptide frameshift mutation in familial atrial fibrillation. N Engl J Med 2008; 359:158-65.

71. Rubattu S, Sciarretta S, Valenti V, Stanzione R, Volpe M. Natriuretic peptides: an update on bioactivity, potential therapeutic use, and implication in cardiovascular diseases. Am J Hypertens 2008; 21:733-41. 72. Sorbera LA, Morad M. Atrionatriuretic peptide transforms cardiac sodium channels into calcium-conducting channels. Science 1990; 247: 969-73.

73. Le Grand B, Deroubaix E, Couetil JP, Coraboeuf E. Effects of atrionatriuretic factor on $\mathrm{Ca} 2+$ current and Cai-independent transient outward K+ current in human atrial cells. Pflugers Arch 1992; 421:486-91. 74. Vollmar AM. The role of atrial natriuretic peptide in the immune system. Peptides 2005; 26:1086-94.

75. Chung MK, Martin DO, Sprecher D, Wazni O, Kanderian A, Carnes CA, Bauer JA,et al. C-reactive protein elevation in patients with atrial 
arrhythmias: inflammatory mechanisms and persistence of atrial fibrillation. Circulation 2001; 104:2886-91.

76. Li J, Wang L. B-type natriuretic peptide levels in patients with paroxysmal lone atrial fibrillation. Heart Vessels 2006; 21: 137-40.

77. Ellinor PT, Low AF, Macrae CA. Reduced apelin levels in lone atrial fibrillation. Eur Heart J 2006; 27: 222-6.

78. Sakabe M, Fujiki A, Nishida K, Sugao M, Nagasawa H, Tsuneda T, Mizumaki K, et al. Enalapril preserves sinus node function in a canine atrial fibrillation model induced by rapid atrial pacing. J Cardiovasc Electrophysiol. 2005 Nov; 16(11):1209-14.

79. Kato K, Oguri M, Hibino T, Yajima K, Matsuo H, Segawa T, Watanabe S, et al. Genetic factors for lone atrial fibrillation. Int J Mol Med 2007; 19:933-9.

80. Falk RH. Atrial fibrillation. N Engl J Med. 2001; 344:1067-78.

81. Nattel S. New ideas about atrial fibrillation 50 years on. Nature. 2002; 415:219-226.

82. Ho SY, Anderson RH, Sanchez-Quintana D. Atrial structures and fibres: morphological basis of atrial conduction. Cardiovascular Res 2002; 54: 325-36.

83. Cheung DW. Electrical activity of the pulmonary vein and its interaction with the right atrium in the guinea-pig. J Physiol 1981; 314: 445-56.

84. Chen YJ, Chen SA. Electrophysiology of pulmonary veins. J Cardiovasc Electrophysiol. 2006; 17: 220-24. 
85. Haïssaguerre M, Jaïs P, Shah DC, Takahashi A, Hocini M, Quiniou G, Garrigue S, et al. Spontaneous initiation of atrial fibrillation by ectopic beats originating in the pulmonary veins. N Engl J Med. 1998:339:659-666. 86. Nathan H, Eliakim M. The junction between the left atrium and the pulmonary veins: an anatomic study of the human hearts. Circulation. $1966 ; 34: 412-422$.

87. Pappone C, Santinelli V, Manguso F, Vicedomini G, Gugliotta F, Augello G, Mazzone P et al. Pulmonary vein denervation enhances longterm benefit after circumferential ablation for paroxysmal atrial fibrillation. Circulation. 2004; 109:327-334.

88. Oral H, Pappone C, Chugh A, Good E, Bogun F, Pelosi F Jr, Bates ER, et al. Circumferential pulmonary-vein ablation for chronic atrial fibrillation. N Engl J Med. 2006; 354:934 -941.

89. Chen SA, Napolitano C, Allessie M. Phatophysiology of atrial Fibrillation. In Atrial Fibrillation Ablation. Eds. Natale A, Raviele A. Blackwell Publishing. Malden 2007;11-16.

90. Chou CC, Chen PS. New concepts in atrial fibrillation: mechanism and remodeling. Med Clin North Am 2008; 92:53-63.

91. Ozaydin M. Atrial fibrillation and inflammation.World J Cardiol. 2010;2(8):243-50.

92. Boos CJ, Anderson RA, Lip GY. Is atrial fibrillation an inflammatory disorder? Eur Heart J 2006; 27:136-49.

93. Liu T, Li G, Li L, Korantzopoulos P. Association between C-reactive protein and recurrence of atrial fibrillation after successful electrical cardioversion: a meta-analysis. J Am Coll Cardiol 2007; 49:1642-8. 
94. Frustaci A, Chimenti C, Bellocci F, Morgante E, RussoMA, Maseri A. Histological substrate of atrial biopsies in patients with lone atrial fibrillation. Circulation 1997;96:1180-4.

95. Todd DM, Skanes AC, Guiraudon G, Guiraudon C, Krahn AD, Yee R, Klein GJ. Role of the posterior left atrium and pulmonary veins in human lone atrial fibrillation: electrophysiological and pathological data from patients undergoing atrial fibrillation surgery. Circulation 2003; 108:310814.

96. Ellinor PT, Low A, Patton KK, Shea MA, MacRae CA. C-reactive protein in lone atrial fibrillation. Am J Cardiol 2006; 97:1346-50.

97. Hatzinikolaou-Kotsakou E, Tziakas D, Hotidis A, Stakos D, Floros D, Papanas N, Chalikias G, et al. Relation of C-reactive protein to the first onset and the recurrence rate in lone atrial fibrillation. Am J Cardiol 2006; 98:659-61.

98. Chen PS, Tan AY. Autonomic nerve activity and atrial fibrillation. Heart Rhythm. 2007;4(3 Suppl):S61-4.

99. Coumel P. Autonomic influences in atrial tachyarrhythmias. J Cardiovasc Electrophysiol 1996; 7:999-1007.

100. Nattel S: New ideas about atrial fibrillation 50 years on. Nature 2002; 415:219-226.

101. Armour JA, Randall WC, Sinha S:. Localized myocardial responses to stimulation of small cardiac branches of the vagus. Am J Physiol 1975; 228: $141-148$.

102. Wallick DW, Martin PJ: Separate parasympathetic control of heart rate and atrioventricular conduction of dogs. Am J Physiol 1990; 259:H536-H542. 
103. Koumi S, Arentzen CE, Backer CL, Wasserstrom JA. Alterations in muscarinic $\mathrm{K}+$ channel response to acetylcholine and to $\mathrm{G}$ protein-mediated activation in atrial myocytes isolated from failing human hearts.

Circulation 1994; 90:2213-24.

104. Patterson E, Lazzara R, Szabo B, Liu H, Tang D, Li YH, Scherlag BJ, et al. Sodium-calcium exchange initiated by the $\mathrm{Ca} 2+$ transient: an arrhythmia trigger within pulmonary veins. J Am Coll Cardiol 2006; 47:1196-1206.

105. Armour JA, Murphy DA, Yuan BX, Macdonald S, Hopkins DA. Gross and microscopic anatomy of the human intrinsic cardiac nervous system. Anat Rec 1997; 247: 289-298.

106. Scherlag BJ, Yamanashi W, Patel U, Lazzara R, Jackman WM. Autonomically induced conversion of pulmonary vein focal firing into atrial fibrillation. J Am Coll Cardiol 2005; 45:1878-86.

107. Chen LY, Shen WK. Epidemiology of atrial fibrillation: a current perspective. Heart Rhythm 2007;4:S1-6.

Dublin S, French B, Glazer NL, Wiggins KL, Lumley T, Psaty BM, Smith 108. NL, et al Risk of new-onset atrial fibrillation in relation to body mass index. Arch Intern Med 2006; 166: 2322-8.

109. Frost L, Hune LJ, Vestergaard P. Overweight and obesity as risk factors for atrial fibrillation or flutter: the Danish Diet, Cancer, and Health Study. Am J Med 2005; 118: 489-95.

110. Mattioli AV, Bonatti S, Zennaro M, Mattioli G. The relationship between personality, socio-economic factors, acute life stress and the development, spontaneous conversion and recurrences of acute lone atrial fibrillation. Europace 2005; 7: 211-20. 
111. Mattioli AV, Bonatti S, Zennaro M, Melotti R, Mattioli G. Effect of coffee consumption, lifestyle and acute life stress in the development of acute lone atrial fibrillation. J Cardiovasc Med (Hagerstown) 2008; 9: 7948.

112. Ettinger PO, Wu CF, De La Cruz C Jr, Weisse AB, Ahmed SS, Regan TJ. Arrhythmias and the "Holiday Heart": alcohol-associated cardiac rhythm disorders. Am Heart J 1978; 95: 555-62.

113. Djoussé L, Levy D, Benjamin EJ, Blease SJ, Russ A, Larson MG, Massaro JM, et al. Long-term alcohol consumption and the risk of atrial fibrillation in the Framingham Study. Am J Cardiol 2004; 93:710-3.

114. Mukamal KJ, Tolstrup JS, Friberg J, Jensen G, Grønbaek M. Alcohol consumption and risk of atrial fibrillation in men and women: the Copenhagen City Heart Study.Circulation 2005; 112: 1736-42.

115. Molina L, Mont L, Marrugat J, Berruezo A, Brugada J, Bruguera J, Rebato C. Long-term endurance sport practice increases the incidence of lone atrial fibrillation in men: a follow-up study. Europace 2008; 10: 61823.

116. Roche F, Xuong AN, Court-Fortune I, Costes F, Pichot V, Duverney D, Vergnon JM, et al. Relationship among the severity of sleep apnea syndrome, cardiac arrhythmias, and autonomic imbalance. Pacing Clin Electrophysiol 2003; 26: 669-77.

117. Camm AJ, Kirchhof P, Lip GY, Schotten U, Savelieva I, Ernst S, Van Gelder IC, et al. Guidelines for the management of atrial fibrillation: the Task Force for the Management of Atrial Fibrillation of the European Society of Cardiology (ESC) Europace.2010;12(10):1360-420. 
118. Miller MR, McNamara RL, Segal JB, Kim N, Robinson KA, Goodman SN, Powe NR, Bass EB. Efficacy of agents for pharmacologic conversion of atrial fibrillation and subsequent maintenance of sinus rhythm: a meta-analysis of clinical trials. J Fam Pract. 2000; 49(11):103346.

119. Olshansky B, Rosenfeld LE, Warner AL, Solomon AJ, O'Neill G, Sharma A, Platia E, et al.The Atrial Fibrillation Follow-up Investigation of Rhythm Management (AFFIRM) study: approaches to control rate in atrial fibrillation. J Am Coll Cardiol. 2004; 43:1201-8.

120. Opolski G, Torbicki A, Kosior DA, Szulc M, Wozakowska-Kaplon B, Kolodziej P, Achremczyk P; Investigators of the Polish How to Treat Chronic Atrial Fibrillation. Chest. 2004 Aug; 126(2):476-86.

121. Hohnloser SH, Kuck KH, Lilienthal J. Rhythm or rate control in atrial fibrillation--Pharmacological Intervention in Atrial Fibrillation (PIAF): a randomised trial. Lancet. 2001;357(9262):1127-8.

122. Van Gelder IC, Hagens VE, Bosker HA, Kingma JH, Kamp O, Kingma T, Said SA,et al. A comparison of rate control and rhythm control in patients with recurrent persistent atrial fibrillation. N Engl J Med. 2002; 347(23):1834-40.

123. Carlsson J, Miketic S, Windeler J, Cuneo A, Haun S, Micus S, Walter $\mathrm{S}$, et al. STAF Investigators. Randomized trial of rate-control versus rhythm-control in persistent atrial fibrillation: the Strategies of Treatment of Atrial Fibrillation (STAF) study. J Am Coll Cardiol. 2003; 41(10):16906.

124. Roy D, Talajic M, Nattel S, Wyse DG, Dorian P, Lee KL, Bourassa MG, et al. Atrial Fibrillation and Congestive Heart Failure Investigators. 
Rhythm control versus rate control for atrial fibrillation and heart failure. $\mathrm{N}$ Engl J Med. 2008; 358(25):2667-77.

125. Stiell IG, Dickinson G, Butterfield NN, Clement CM, Perry JJ, Vaillancourt C, Calder LA. Vernakalant Hydrochloride: A NovelAtrialselective Agent for the Cardioversionof Recent-onset Atrial Fibrillation in the Emergency Department. Acad Emerg Med. 2010; 17(11):1175-82. 126. Kowey PR, Dorian P, Mitchell LB, Pratt CM, Roy D, Schwartz PJ, Sadowski J, et al. Vernakalant hydrochloride for the rapid conversion of atrial fibrillation after cardiac surgery: a randomized, double-blind, placebo-controlled trial. Circ Arrhythm Electrophysiol 2009;2:652-659 127. Roy D, Pratt CM, Torp-Pedersen C, Wyse DG, Toft E, Juul-Moller S, Nielsen T,Rasmussen SL, et al. Vernakalant hydrochloride for rapid conversion of atrial fibrillation: a phase 3, randomized, placebo-controlled trial. Circulation 2008; 117:1518-1525.

128. Camm AJ, Capucci A, Hohnloser SH, et al. A randomized activecontrolled study comparing the efficacy and safety of vernakalant to amiodarone in recent-onset atrial fibrillation. J Am Coll Cardiol 2011; $57: 313-321$.

129. Alboni P, Botto GL, Baldi N, Luzi M, Russo V, Gianfranchi L, Marchi P,et al. Outpatient treatment of recent-onset atrial fibrillation with the 'pill-in-the-pocket' approach. N Engl J Med 2004; 351:2384-2391. 130. Van Gelder IC, Groenveld HF, Crijns HJ, et al. Lenient versus strict rate control in patients with atrial fibrillation. N Engl J Med. 2010; 362:1363-73. 
131. Wegener FT, Ehrlich JR, Hohnloser SH. Dronedarone: an emerging agent with rhythm- and rate-controlling effects. J Cardiovasc

Electrophysiol. 2006 Sep;17 Suppl 2:S17-2.

132. Le Heuzey JY, De Ferrari GM, Radzik D, Santini M, Zhu J, Davy JM. A short-term, randomized, double-blind, parallel-group study to evaluate the efficacy and safety of dronedarone versus amiodarone in patients with persistent atrial fibrillation: the DIONYSOS study. J Cardiovasc Electrophysiol. 2010 Jun 1;21(6):597-605.

133. Hohnloser SH, Crijns HJ, van Eickels M, Gaudin C, Page RL, TorpPedersen C, Connolly SJ; ATHENA Investigators. Dronedarone in patients with congestive heart failure: insights from ATHENA. Eur Heart J. 2010; 31(14):1717-21.

134. Haïssaguerre M, Shah DC, Jaïs P, Hocini M, Yamane T, Deisenhofer I, Chauvin M, et al. Electrophysiological breakthroughs from the left atrium to the pulmonary veins. Circulation. 2000; 102(20):2463-5.

135. Pappone C, Santinelli V.How to perform encircling ablation of the left atrium. Heart Rhythm. 2006; 3(9):1105-9.

136. Kottkamp H, Tanner H, Kobza R, Schirdewahn P, Dorszewski A, Gerds-Li JH, Carbucicchio C, et al. Time courses and quantitative analysis of atrial fibrillation episode number and duration after circular plus linear left atrial lesions: trigger elimination or substrate modification: early or delayed cure? J Am Coll Cardiol. 2004; 44(4):869-77.

137. Pappone C, Manguso F, Vicedomini G, Gugliotta F, Santinelli O, Ferro A, Gulletta S, ,et al. Prevention of iatrogenic atrial tachycardia after ablation of atrial fibrillation: a prospective randomized study comparing 
circumferential pulmonary vein ablation with a modified approach. Circulation. 2004; 110(19):3036-42.

138. Pappone C, Santinelli V, Manguso F, Vicedomini G, Gugliotta F, Augello G, Mazzone P, et al. Pulmonary vein denervation enhances longterm benefit after circumferential ablation for paroxysmal atrial fibrillation. Circulation. 2004; 109(3):327-34.

139. Ouyang F, Bänsch D, Ernst S, Schaumann A, Hachiya H, Chen M, Chun J, et al.Complete isolation of left atrium surrounding the pulmonary veins: new insights from the double-Lasso technique in paroxysmal atrial fibrillation. Circulation. 2004; 110(15):2090-6.

140. Verma A, Marrouche NF, Natale A.Pulmonary vein antrum isolation: intracardiac echocardiography-guided technique. J Cardiovasc Electrophysiol. 2004; 15(11):1335-40.

141. Arruda M, Natale A. Ablation of permanent AF: adjunctive strategies to pulmonary veins isolation: targeting AF NEST in sinus rhythm and CFAE in AF. J Interv Card Electrophysiol. 2008; 23(1):51-7.

142. Kong MH,Piccini JP,Bahnson TD. Efficacy of adjunctive ablation of complex fractionated atrial electrograms and pulmonary vein isolation for the treatment of atrial fibrillation: a meta-analysis of randomized controlled trials. Europace. 2011; 13 (2): 193-204.

143. Jaïs P, Hsu LF, Rotter M, Sanders P, Takahashi Y, Rostock T, Sacher F, et al. Mitral isthmus ablation for atrial fibrillation. J Cardiovasc Electrophysiol. 2005, 16(11):1157-9.

144. Hocini M, Jaïs P, Sanders P, Takahashi Y, Rotter M, Rostock T, Hsu LF, et al. Techniques, evaluation, and consequences of linear block at the 
left atrial roof in paroxysmal atrial fibrillation: a prospective randomized study. Circulation. 2005; 112(24):3688-96.

145. Jaïs P, Shah DC, Haïssaguerre M, Takahashi A, Lavergne T, Hocini M, Garrigue S, et al. Efficacy and safety of septal and left-atrial linear ablation for atrial fibrillation. Am J Cardiol. 1999; 84(9A):139R-146R. 146. Kottkamp H, Hindricks G, Autschbach R, Krauss B, Strasser B, Schirdewahn P, Fabricius A, et al. Specific linear left atrial lesions in atrial fibrillation: intraoperative radiofrequency ablation using minimally invasive surgical techniques. J Am Coll Cardiol. 2002; 40(3):475-80. 147. Pachon M JC, Pachon M EI, Pachon M JC, Lobo TJ, Pachon MZ, Vargas RN, Pachon DQ, et al. A new treatment for atrial fibrillation based on spectral analysis to guide the catheter RF-ablation. Europace. 2004; 6(6):590-601.

148. Haïssaguerre M, Sanders P, Hocini M, Takahashi Y, Rotter M, Sacher F, Rostock T, et al. Catheter ablation of long-lasting persistent atrial fibrillation: critical structures for termination..J Cardiovasc Electrophysiol. $2005 ; 16(11): 1125-37$.

149. Pappone C, Augello G, Sala S, Gugliotta F, Vicedomini G, Guletta S, Paglino G, et al. A randomized trial of circumferential pulmonary vein ablation versus antiarrhythmic drug therapy in paroxysmal atrial fibrillation. The APAF study. J Am Coll Cardiol 2006; 48:2340-2347.

150. Oral H, Pappone C, Chugh A, Good E, Bogun F, Pelosi F Jr, Bates ER, et al. Circumferential pulmonary-vein ablation for chronic atrial fibrillation. N Engl J Med 2006; 354:934-941.

151. Wazni OM, Marrouche NF, Martin DO, Verma A, Bhargava M, Saliba W, Bash D, et al. Radiofrequency ablation versus antiarrhythmic 
drugs as first-line treatment of symptomatic atrial fibrillation. A randomized trial. JAMA 2005; 293:2634-2640.

152. Pappone C, Santinelli V. Atrial Fibrillation ablation: a realistic alternative to Pharmacologic Therapy. Nat Clin Pract Cardiovasc Med. 2005;2(12):608-9.

153. Verma A, Natale A Should atrial fibrillation ablation be considered first-line therapy for some patients? Why atrial fibrillation ablation should be considered first-line therapy for some patients. Circulation. 2005; 112(8):1214-22.

154. Padanilam BJ, Prystowsky EN. Should atrial fibrillation ablation be considered first-line therapy for some patients? Should ablation be first-line therapy and for whom? the antagonist position. Circulation. 2005 Aug 23; 112(8):1223-9.

155. Jais P, Packer DL. Ablation vs. drug use for atrial fibrillation. Eur Heart J 2007; 9 (Supplement G): G26-G34.

156. Calkins H, Brugada J, Packer DL, Cappato R, Chen SA, Crijns HJ, Damiano RJ Jr, et al. HRS/EHRA/ECAS expert consensus statement on catheter and surgical ablation of atrial fibrillation: recommendations for personnel, policy, procedures and follow-up. Heart Rhythm. 2007; 4:816861.

157. Shemin RJ, Cox JL, Gillinov AM, Blackstone EH, Bridges CR; Workforce on Evidence-Based Surgery of the Society of Thoracic Surgeons.Workforce on Evidence-Based Surgery of the Society of Thoracic Surgeons. Guidelines for reporting data and outcomes for the surgical treatment of atrial fibrillation. Ann Thorac Surg. 2007; 83:122530. 
158. Shen J, Bailey M, Damiano RJ. Surgery for lone atrial fibrillation: Present state-of-the-art. Innovations 2009: 4: 248-255.

159. Cox JL, Canavan TE, Schuessler RB, Cain ME, Lindsay BD, Stone C, Smith PK, et al. The surgical treatment of atrial fibrillation. II. Intraoperative electrophysiological mapping and description of the electrophysiological basis of atrial flutter and atrial fibrillation. J Thorac Cardiovasc Surg. 1991; 101:406-426.

160. Cox JL, Schuessler RB, D’Agostino HJ Jr, et al. The surgical treatment of atrial fibrillation. III. Development of a definitive surgical procedure. J Thorac Cardiovasc Surg. 1991; 101:569-583.

161. Cox JL. The surgical treatment of atrial fibrillation. IV. Surgical technique. J Thorac Cardiovasc Surg. 1991; 101:584-592.

162. Cox JL, Jaquiss RD, Schuessler RB, Boineau JP. Modification of the maze procedure for atrial flutter and atrial fibrillation. II. Surgical technique of the maze III procedure. J Thorac Cardiovasc Surg. 1995; 110(2):485-95.

163. McCarthy PM, Gillinov AM, Castle L, Chung M, Cosgrove D 3rd.The Cox-Maze procedure: the Cleveland Clinic experience. Semin Thorac Cardiovasc Surg;12(1):25-9

164. Schaff HV, Dearani JA, Daly RC, Orszulak TA, Danielson GK. CoxMaze procedure for atrial fibrillation: Mayo Clinic experience. Semin Thorac Cardiovasc Surg. 2000 Jan; 12(1):30-7. Review.

165. Millar RC, Arcidi JM Jr, Alison PJ. The maze III procedure for atrial fibrillation: should the indications be expanded? Ann Thorac Surg. 2000 Nov; 70(5):1580-6. 
166. Jessurun ER, van Hemel NM, Defauw JA, Stofmeel MA, Kelder JC, de la Rivière AB, Ernst JM. Results of maze surgery for lone paroxysmal atrial fibrillation.Circulation. 2000; 101(13):1559-67.

167. Lönnerholm S, Blomström P, Nilsson L, Oxelbark S, Jideus L, Blomström-Lundqvist C. Effects of the maze operation on health-related quality of life in patients with atrial fibrillation. Circulation. 2000; 101(22):2607-11.

168. Prasad SM, Maniar HS, Camillo CJ, Schuessler RB, Boineau JP, Sundt TM 3rd, Cox JL, Damiano RJ Jr. The Cox maze III procedure for atrial fibrillation: long-term efficacy in patients undergoing lone versus concomitant procedures. J Thorac Cardiovasc Surg. 2003; 126(6):1822-8. 169. Hemels ME, Gu YL, Tuinenburg AE, Boonstra PW, Wiesfeld AC, van den Berg MP, Van Veldhuisen DJ et al. Favorable long-term outcome of maze surgery in patients with lone atrial fibrillation. Ann Thorac Surg 2006; 81: 1773-9.

170. Ballaux PK, Geuzebroek GS, van Hemel NM, Kelder JC, Dossche KM, Ernst JM, Boersma LV et al. Freedom from atrial arrhythmias after classic maze III surgery: a 10-year experience. J Thorac Cardiovasc Surg. 2006; 132:1433-40.

171. Lall SC, Melby SJ, Voeller RK, Zierer A, Bailey MS, Guthrie TJ, Moon MR, et al. The effect of ablation technology on surgical outcomes after the Cox-maze procedure: a propensity analysis. J Thorac Cardiovasc Surg. 2007; 133(2):389-96.

172. Stulak JM, Sundt TM 3rd, Dearani JA, Daly RC, Orsulak TA, Schaff HV. Tenyear Experience With the Cox Maze Procedure for Atrial Fibrillation: How Do We Define Success? Ann Thorac Surg 2007; 83:1319-25. 
173. Henry L, Ad N. The Maze procedure: a surgical intervention for ablation of atrial fibrillation. Heart Lung. 2008 Nov-Dec;37(6):432-9. 174. Arcidi JM Jr, Doty DB, Millar RC. The maze procedure: the LDS hospital experience. Semin Thorac Cardiovasc Surg. 2000 ;12:38-43. 175. Cox JL. The minimally invasive Maze III procedure. Open Tech Thorac Cardiovasc Surg, 2000; 5: 79-92.

176. Nath S, Lynch C 3rd, Whayne JG, Haines DE. Cellular electrophysiological effects of hyperthermia on isolated guinea pig papillary muscle. Implications for catheter ablation. Circulation 1993; 88(4):1826-31.

177. Lustgarten DL, Keane D, Ruskin J. Cryothermal ablation: mechanism of tissue injury and current experience in the treatment of tachyarrhythmias. Prog Cardiovasc Dis 1999; 41(6):481-98.

178. Saltman AE, Gilnov AM. Surgical approaches for Atrial Fibrillation. Cardiol Clin.2009; 27: 179-88.

179. Gillinov AM, Pettersson G, Rice TW. Esophageal injury during radiofrequency ablation for atrial fibrillation. J Thorac Cardiovasc Surg 2001; 122(6):1239-1240.

180. Laczkovics A, Khargi K, Deneke T. Esophageal perforation during left atrial radiofrequency ablation. J Thorac Cardiovasc Surg.2003; 126(6):2119-2120.

181. Demaria RG, Pagé P, Leung TK, Dubuc M, Malo O, Carrier M, Perrault LP. Surgical radiofrequency ablation induces coronary endothelial dysfunction in porcine coronary arteries. Eur J Cardiothorac Surg. 2003; 23(3):277-282. 
182. Doll N, Kornherr P, Aupperle H, Fabricius AM, Kiaii B, Ullmann C, Schneider K. Epicardial treatment of atrial fibrillation using cryoablation in an acute off-pump sheep model. Thorac Cardiovasc Surg.2003; 51(5):267273.

183. Thomas SP, Guy DJ, Boyd AC, Eipper VE, Ross DL, Chard RB. Comparison of epicardial and endocardial linear ablation using handheld probes. Ann Thorac Surg.2003 75(2):543-548.

184. Santiago T, Melo J, Gouveia RH, Neves J, Abecasis M, Adragão P, Martins AP. Epicardial radiofrequency applications: in vitro and in vivo studies on human atrial myocardium. Eur J Cardiothorac Surg. 2003; 24(4):481-486.

185. van Brakel TJ, Bolotin G, Salleng KJ, Nifong LW, Allessie MA, Chitwood WR Jr, Maessen JG. Evaluation of epicardial microwave ablation lesions: histology versus electrophysiology. Ann Thorac Surg.2004 78(4):1397-1402.

186. Melby SJ, Zierer A, Kaiser SP, Schuessler RB, Damiano RJ Jr. Epicardial microwave ablation on the beating heart for atrial fibrillation: the dependency of lesion depth on cardiac output. J Thorac Cardiovasc Surg. 2006; 132:355-360.

187. Okumura Y, Kolasa MW, Johnson SB, Bunch TJ, Henz BD, O'Brien CJ, Miller DV. Mechanism of tissue heating during high intensity focused ultrasound pulmonary vein isolation: implications for atrial fibrillation ablation efficacy and phrenic nerve protection. J Cardiovasc Electrophysiol. 2008; 19:945-951. 
188. Prasad SM, Maniar HS, Schuessler RB, Damiano RJ Jr. Chronic transmural atrial ablation by using bipolar radiofrequency energy on the beating heart. J Thorac Cardiovasc.2002; Surg 124(4):708-713.

189.Prasad SM, Maniar HS, Diodato MD, Schuessler RB, Damiano RJ Jr. Physiological consequences of bipolar radiofrequency energy on the atria and pulmonary veins: a chronic animal study. Ann Thorac Surg. 2003; 76(3):836-841.

190. Gaynor SL, Ishii Y, Diodato MD, Prasad SM, Barnett KM, Damiano NR, Byrd GD. Successful performance of Cox maze procedure on beating heart using bipolar radiofrequency ablation: a feasibility study in animals. Ann Thorac Surg.2004 78(5):1671-1677.

191. Gaynor SL, Diodato MD, Prasad SM, Ishii J, Schuessler RB, Bailey MS, Damiano NR, et al. A prospective, single-center clinical trial of a modified Cox maze procedure with bipolar radiofrequency ablation. J Thorac Cardiovasc Surg. 2004; 128:535-42.

192. Damiano RJ Jr, Schwartz FH, Bailey MS, Maniar HS, Munfakh NA, Moon MR, Schuessler RB. The Cox maze IV procedure: predictors of late recurrence. J Thorac Cardiovasc Surg. 2011; 141(1):113-21.

193. Melo J, Adragão P, Neves J, Ferreira M, Timóteo A, Santiago T, Ribeiras R, Canada M. Endocardial and epicardial radiofrequency ablation in the treatment of atrial fibrillation with a new intra-operative device. Eur J Cardiothorac Surg. 2000; 18(2):182-6.

194. Mohr FW, Fabricius AM, Falk V, Autschbach R, Doll N, Von Oppell U, Diegeler A, et al. Curative treatment of atrial fibrillation with intraoperative radiofrequency ablation: short-term and midterm results. J Thorac Cardiovasc Surg. 2002; 123(5):919-27. 
195. Kondo N, Takahashi K, Minakawa M, Daitoku K. Left atrial maze procedure: a useful addition to other corrective operations.Ann Thorac Surg. 2003;75(5):1490-4.

196. Doll N, Kiaii BB, Fabricius AM, Bucerius J, Kornherr P, Krakor R, Gummert JF, et al. Intraoperative left atrial ablation (for atrial fibrillation) using a new argon cryocatheter: early clinical experience. Ann Thorac Surg. 2003 Nov; 76(5):1711-5.

197. Manasse E, Gaita F, Ghiselli S, Barbone A, Garberoglio L, Citterio E, Ornaghi D, et al. Cryoablation of the left posterior atrial wall: 95 patients and 3 years of mean follow-up. Eur J Cardiothorac Surg. 2003; 24(5):73140 .

198. Mokadam NA, McCarthy PM, Gillinov AM, Ryan WH, Moon MR, Mack MJ, Gaynor SL, Prasad SM, et al.A prospective multicenter trial of bipolar radiofrequency ablation for atrial fibrillation: early results.Ann Thorac Surg. 2004 ;78(5):1665-70.

199. Ad N, Henry L, Hunt S. The impact of surgical ablation in patients with low ejection fraction, heart failure, and atrial fibrillation .Eur $\mathrm{J}$ Cardiothorac Surg. 2011 Jul;40(1):70-6.

200. Society of Thoracic surgeons National Adult Cardiac surgery Database: spring 2007 report. The Society of Thoracic Surgeons. http://www.sts.org. (Last access 10h August 2010)

201. Cox JL. Atrial Fibrillation II: rationale for surgical treatment. J Thorac Cardiovasc Surg 2003; 126: 1693-9.

202. Loulmet DF, Patel NC, Patel NU, Frumkin WI, Santoni-Rugiu F, Langan MN, Subramanian VA. First Robotic Endoscopic Epicardial 
Isolation of the Pulmonary Veins With Microwave Energy in a Patient in Chronic Atrial Fibrillation. Ann Thorac Surg 2004; 78:e24 -5.

203. Wolf RK, Schneeberger EW, Osterday R, Miller D, Merrill W, Flege JB Jr, Gillinov AM. Video-assisted bilateral pulmonary vein isolation and left atrial appendage exclusion for atrial fibrillation. J. Thorac. Cardiovasc. Surg. 2005; 130(3):797-802.

204. Charokopos N, Rouska E, Styliadis I, Antonitsis P, Papakonstantinou C, Spanos P. Totally endoscopic microwave ablation for lone atrial fibrillation: an alternative method of treatment. Hellenic J Cardiol. 2006;47(6):377-80.

205. Koistinen J, Valtonen M, Savola J, Airaksinen J. Thoracoscopic microwave ablation of atrial fibrillation. Interact Cardiovasc Thorac Surg. 2007; 6(6):695-8.

206. Salenger R, Lahey SJ, Saltman AE . The completely endoscopic treatment of atrial fibrillation: report on the first 14 patients with early results. Heart Surg Forum. 2004; 7(6):E555-8.

207. Sagbas E, Akpinar B, Sanisoglu I, Caynak B, Tamtekin B, Oral K, Onan B.Video-assisted bilateral epicardial pulmonary vein isolation for the treatment of lone atrial fibrillation.Ann Thorac Surg. 2007;83(5):1724-30. 208. Puskas J, Lin E, Bailey D, Guyton R. Thoracoscopic Radiofrequency Pulmonary Vein Isolation and Atrial Appendage Occlusion. Ann Thorac Surg 2007; 83: 1870-2 209. McClelland JH, Duke D, Reddy R Preliminary results of a limited thoracotomy: new approach to treat atrial fibrillation J Cardiovasc Electrophysiol. 2007 ;18(12):1289-95 
210. Wudel JH, Chaudhuri P, Hiller JJ. Video-assisted epicardial ablation and left atrial appendage exclusion for atrial fibrillation: extended followup. Ann. Thorac. Surg.2008; 85, 34-38.

211. Edgerton JR, Edgerton ZJ, Weaver T, Reed K, Prince S, Herbert MA, Mack MJ. Minimally invasive pulmonary vein isolation and partial autonomic denervation for surgical treatment of atrial fibrillation.Ann Thorac Surg. 2008; 86(1):35-8.

212. Sirak J, Jones D, Sun B, Sai-Sudhakar C,Crestanello J Firstenberg, M. Toward a definitive, totally thoracoscopic procedure for atrial fibrillation. Ann. Thorac. Surg.2008; 86:1960-1964.

213. Pruitt JC, Lazzara RR, Dworkin GH, Badhwar V, Kuma C, Ebra G. Totally endoscopic ablation of lone atrial fibrillation: initial clinical experience. Ann Thorac Surg. 2006; 81(4):1325-30.

214. Pruitt JC, Lazzara RR, Ebra G. Minimally invasive surgical ablation of atrial fibrillation: the thoracoscopic box lesion approach. J Interv Card Electrophysiol. 2007; 20(3):83-7.

215. Li H, Li Y, Sun L, Liu X, Xu C, Han J, Meng X. Minimally invasive surgical pulmonary vein isolation alone for persistent atrial fibrillation: preliminary results of epicardial atrial electrogram analysis. Ann Thorac Surg. 2008; 86(4):1219-25.

216. Beyer E, Lee R, Lam BK. Point: minimally invasive bipolar radiofrequency ablation of lone atrial fibrillation: early multicenter results. J. Thorac. Cardiovasc. Surg. 2009; 137: 521-526.

217. Han FT, Kasirajan V, Kowalski M, Kiser R, Wolfe L, Kalahasty G, Shepard RK, Wood MA, Ellenbogen KA. Results of a minimally invasive surgical pulmonary vein isolation and ganglionic plexi ablation for atrial 
fibrillation: single-center experience with 12-month follow-up.Circ Arrhythm Electrophysiol. 2009; 2(4):370-7.

218. Cui YQ, Li Y, Gao F, Xu CL, Han J, Zeng W, Zeng YP, Gurbanov E, Meng X. Video-assisted minimally invasive surgery for lone atrial fibrillation: a clinical report of 81 cases.J Thorac Cardiovasc Surg. 2010; 139(2):326-32.

219. Yilmaz A, Geuzebroek GS, Van Putte BP, Boersma LV, Sonker U, De Bakker JM, Van Boven WJ. Completely thoracoscopic pulmonary vein isolation with ganglionic plexus ablation and left atrial appendage amputation for treatment of atrial fibrillation. Eur J Cardiothorac Surg $2010 ; 38: 356-60$.

220. Sirak J, Jones D, Schwartzman D The five-box thoracoscopic maze procedure. Ann Thorac Surg. 2010 Sep; 90(3):986-9.

221. Jansens JL, Ducart A, Preumont N, Jottrand M, Stefanidis C, Stoupel E, de Cannière D. Pulmonary vein isolation by robotic-enhanced thoracoscopy for symptomatic paroxysmal atrial fibrillation. Heart Surg Forum. 2004; 7(6):E595-8.

222. Gerosa G, Bianco R, Buja G, di Marco F. Totally endoscopic roboticguided pulmonary veins ablation: an alternative method for the treatment of atrial fibrillation. Eur J Cardiothorac Surg. 2004; 26(2):450-2.

223. Balkhy HH, Chapman PD, Arnsdorf SE. Minimally invasive atrial fibrillation ablation combined with a new technique for thoracoscopic stapling of the left atrial appendage: case report. Heart Surg Forum. 2004; 7(6):353-5.

224. Poa, L. Thoracoscopic ablation for treatment of atrial fibrillation: a 2port approach. Heart Surg.Forum2006; 9 (2): e590-e591. 
225. La Meir, M., De Roy, L., Blommaert, D, Buche, M. Treatment of lone atrial fibrillation with a right thoracoscopic approach. Ann. Thorac. Surg. 2007; 83, 2244-2245.

226. Klinkenberg TJ, Ahmed S, Ten Hagen A, Wiesfeld AC, Tan ES, Zijlstra F, Van Gelder IC. Feasibility and outcome of epicardial pulmonary vein isolation for lone atrial fibrillation using minimal invasive surgery and high intensity focused ultrasound. Europace. 2009; 11(12):1624-31. 227. Moten SC, Rodriguez E, Cook RC, Nifong L W, Chitwood WR Jr. New ablation techniques for atrial fibrillation and the minimally invasive cryo-maze procedure in patients with lone atrial fibrillation. Heart Lung Circ. 2007; 66 (Suppl. 3): S88-S93.

228. Cheema FH, Weisberg JS, Khalid I, Roberts HG Jr. Warm beating heart, robotic endoscopic Cox-cryomaze: an approach for treating atrial fibrillation. Ann Thorac Surg. 2009 Mar; 87(3):966-8.

229. Lee AM, Clark K, Bailey MS, Aziz A, Schuessler RB, Damiano RJ. A Minimally Invasive Cox-Maze Procedure: Operative Technique and Results. Innovations (Phila).2010; 5 (4):281-286.

230. Grandmougin D, Tiffet O. Video-assisted thoracoscopic epicardial ablation of left pulmonary veins for lone permanent atrial fibrillation. Interact Cardiovasc Thorac Surg. 2007; 6(1):136-8.

231. Halperin JL, Gomberg-Maitland M. Obliteration of the left atrial appendage for prevention of thromboembolism. J Am Coll Cardiol. 2003; 42:1259-1261.

232. Sievert H, Lesh MD, Trepels T, Omran H, Bartorelli A, Della Bella P, Nakai T,et al. Percutaneous left atrial appendage transcatheter occlusion to 
prevent stroke in high-risk patients with atrial fibrillation: early clinical experience. Circulation. 2002;105:1887-1889.

233. Kanderian AS, Gillinov AM, Pettersson GB, Blackstone E, Klein AL. Success of surgical left atrial appendage closure: assessment by transesophageal echocardiography J Am Coll Cardiol 2008;52:924-929.

234. Slater AD, Foley JL, Phillips L, Francischelli DE Band Occlusion of the Atrial Appendage. J Card Surg. 2010; 25(2): 156-60.

235. Yan BP, Kiernan TJ, Gonzales-Cruz I, Lam YY. Left atrial appendage-occluding devices for stroke prevention in patients with non valvular atrial fibrillation. Expert Rev Med Devices. 2009;6(6):611-20 236. Kamohara K, Fukamachi K, Ootaki Y, Akiyama M, Zahr F, Kopcak MW Jr, Dessoffy R, A novel device for left atrial appendage exclusion. J Thorac Cardiovasc Surg. 2005; 130(6):1639-44.

237. Cappato R, Calkins H, Chen SA, Davies W, Iesaka Y, Kalman J, Kim YH, et al. Worldwide survey on the methods, efficacy and safety of catheter ablation for human atrial fibrillation. Circulation 2005; 111: 110005 .

238. Cappato R, Calkins H, Chen SA, Davies W, Iesaka Y, Kalman J, Kim YH, et al. Updated worldwide survey on the methods, efficacy, and safety of catheter ablation for human atrial fibrillation. Circ Arrhythm Electrophysiol. 2010; 3(1):32-8.

239. La Meir M, De Roy L, Gourdin M. A Hybrid approach for treatment of patients with atrial fibrillation with radiofrequency catheters. In: Hybrid and minimally invasive cardiac intervention. Maessen J and Crijns H Eds. Minerva Medica. Turin 2010. Pages: 9-13. 
240. Shemin RJ, Cox JL, Gillinov AM, Blackstone EH, Bridges CR; Workforce on Evidence-Based Surgery of the Society of Thoracic Surgeons. Guidelines for reporting data and outcomes for the surgical treatment of atrial fibrillation. Ann Thorac Surg. 2007; 83(3):1225-30. 241. De Roy L, Arhie A, Floria M. Hybrid approach for treatment of persistent or long duration paroxysmal atrial fibrillation: medium and longterm follow up. In: Hybrid and minimally invasive cardiac intervention. Maessen J and Crijns H Eds. Minerva Medica. Turin 2010. Pages: 33-39. 242. Pison L, La Meir M. Preliminary results of the tailored hybrid approach.In: Hybrid and minimally invasive cardiac intervention. Maessen J and Crijns H Eds. Minerva Medica. Turin 2010. Pages: 45-48.

243. O'Neill W, Jaïs P, Takahashi Y, Jönsson A, Sacher F, Hocini M, Sanders $\mathrm{P}$, et al.The stepwise ablation approach for chronic atrial fibrillation - evidence for a cumulative effect. J Interv Card Electrophysiol. 2006 Sep; 16(3):153-67.

244. Scherlag BJ, Patterson E, Po SS. The neural basis of atrial fibrillation. Electrocardiol. 2006; 39 (4 Suppl): S180-S183.

245. Roy D, Talajic M, Dorian P, Connolly S, Eisenberg MJ, Green M, Kus T, et al. Amiodarone to prevent recurrence of atrial fibrillation. Canadian Trial of Atrial Fibrillation Investigators. N Engl J Med. 2000; 342(13):913-20.

246. Edgerton JR, Edgerton ZJ, Weaver T, Reed K, Prince S, Herbert MA, Mack MJ. Minimally invasive pulmonary vein isolation and partial autonomic denervation for surgical treatment of atrial fibrillation. Ann Thorac Surg. 2008; 86(1):35-8. 
247. Doll N, Pritzwald-Stegmann P, Czesla M, Kempfert J, Stenzel MA, Borger MA, Mohr FW. Ablation of ganglionic plexi during combined surgery for atrial fibrillation. Ann Thorac Surg. 2008; 86(5):1659-63.

248. Mehall JR, Kohut RM Jr, Schneeberger EW, Taketani T, Merrill WH, Wolf RK.Intraoperative epicardial electrophysiologic mapping and isolation of autonomic ganglionic plexi . Ann Thorac Surg. 2007;83(2):538-41.

249. Schuessler RB, Kay MW, Melby SJ, Branham BH, Boineau JP, Damiano RJ Jr.Spatial and temporal stability of the dominant frequency of activation in human atrial fibrillation. J Electrocardiol. 2006; 39(4 Suppl): S7-12.

250. Berenfeld O, Mandapati R, Dixit S, Skanes AC, Chen J, Mansour M, Jalife J. Spatially distributed dominant excitation frequencies reveal hidden organization in atrial fibrillation in the Langendorff-perfused sheep heart. J Cardiovasc Electrophysiol. 2000; 11(8):869-79.

251. Burnes JE, Taccardi B, Rudy Y: A noninvasive imaging modality for cardiac arrhythmias. Circulation 2000; 102(17):2152-2158.

252. Ghanem RN, Ramanathan C, Jia P, et al: Heart-surface reconstruction and ECG electrodes localization using fluoroscopy, epipolar geometry and stereovision: application to noninvasive imaging of cardiac electrical activity. IEEE Trans Med Imaging.2003; 22(10):1307-1318.

253. Ghosh S, Rudy Y: Accuracy of quadratic versus linear interpolation in noninvasive Electrocardiographic Imaging (ECGI). Ann Biomed Eng . 2005; 33(9):1187-1201. 


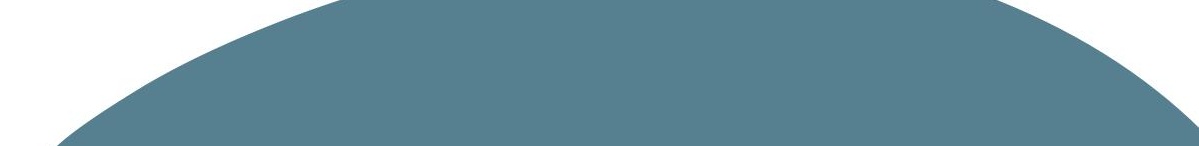

Minimal Invasive Surgery for Atrial Fibrillation: An updated Review

Mark La Meir, Sandro Gelsomino, Fabiana Lucà, Laurent Pison, Andrea Colella, Roberto Lorusso, Elena Crudeli, Gian Franco Gensini, Harry G Crijns and Jos G Maessen. Europace. 2012 Jul 10.

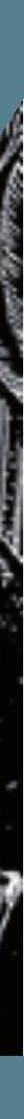




\title{
Introduction: Chapter 2
}

Minimal Invasive Surgery for Atrial Fibrillation: An updated Review

Mark La Meir, Sandro Gelsomino, Fabiana Lucà, Laurent Pison, Andrea Colella, Roberto Lorusso, Elena Crudeli, Gian Franco Gensini, Harry G Crijns and Jos G Maessen.

Europace. 2012 Jul 10.

\begin{abstract}
$\underline{\text { Abstract }}$
Background. Despite its proven efficacy, the Cox-Maze III procedure did not gain widespread acceptance for the treatment of stand-alone atrial fibrillation (SA-AF) because of its complexity and technical difficulty. Surgical ablation for SA-AF can now be successfully performed utilizing minimally invasive surgery (MIS). This article provides an overview of state-of-the-art minimally invasive surgery for the treatment of SA-AF.
\end{abstract}

Methods. Papers selected for this review were identified on PUBMED and exclusion and inclusion criteria were applied to select the publication to be screened. Twenty eight studies were included; 27 (96.4\%) were observational in nature whereas one was prospective non-randomized. The total number of patients was 1,051 (range 14 to 114$)$. Mean age ranged from 45.3 to 67.1 years.

Results. Suboptimal results were obtained when employing microwave and high focused ultrasound energies. In contrast, MIS ablation of SA-AF achieved satisfactory one-year results when the bipolar radiofrequency was employed as energy source, with anti-arrhythmic drugs (AAD)-free success rates comparable to percutaneous catheter ablation (PCA). The success rate in paroxysmal was even higher than in PCA. In contrast, ganglionated plexi (GP) ablation and LAA removal 
seem not to influence the recurrence of $\mathrm{AF}$ and the occurrence of postoperative thrombo-embolic events.

Conclusions. MIS ablation of SA-AF achieved satisfactory one-year results when bipolar radiofrequency was employed. Nonetheless, the relatively high complication rate reported suggest that such techniques require further refinement .Finally, the preliminary results of the hybrid approach are promising but they need to be confirmed.

\section{Introduction}

Over the last 20 years, surgeons and electrophysiologists (EPs) have been making progress toward finding a cure for $\mathrm{AF}$ that offers patients an acceptable risk/benefit profile.

The Cox maze III procedure has been shown to be an effective, but an invasive and complex procedure and, for this reason, it has not been widely accepted as a standalone therapy ${ }^{1,2}$.

Trans-venous pulmonary vein isolation (PVI) has become the cornerstone of catheter ablation for AF and is currently the therapy of first choice if patients warrant rhythm control and failed anti-arrhythmic drugs (AADs) ${ }^{3,4}$. PVI is reported to be effective in $60-85 \%$ of the patients, especially in patients with paroxysmal short lasting episodes of $\mathrm{AF}^{3-5}$. Nonetheless, in about one-third of patients, a second ablation procedure is necessary and complications may occur in up to $6 \%$ of patients ${ }^{6,7}$.

The surgical treatment of atrial fibrillation has undergone dramatic changes over the last decade. New technologies have allowed the creation of transmural lesions on a beating heart through alternative, less-invasive incisions ${ }^{8}$. The introduction of these technologies has greatly simplified the performance of the Maze procedure and allowed for the development of minimally invasive surgery (MIS) ${ }^{8}$. Minimally invasive video-assisted techniques allow pulmonary vein island creation and left 
atrial appendage removal or exclusion, usually with ganglionic plexi evaluation and destruction $^{9}$.

Nonetheless, it is still uncertain whether these procedures are effective in restoring permanent sinus rhythm ${ }^{10}$. We present a systematic literature overview of MIS for the treatment of stand- alone atrial fibrillation (SA-AF) and briefly discuss the hybrid approach which combines, in one-step, off pump epicardial ablation with endocardial mapping and touch-up ablation.

\section{Review criteria}

Papers selected for this review were identified on PUBMED (last search 30/09/2011) using the following search terms: 'stand alone atrial fibrillation", "Mini-Maze", "video-assisted”, “epicardial ablation”, "endoscopic ablation”, "videothoracoscopy”, "minimally invasive", "surgical ablation", "bilateral thoracoscopic surgical ablation", "right thoracoscopic surgical ablation", "left atrial appendage exclusion", and "ganglionic plexi ablation".

Exclusion criteria were: animal studies, reviews, case reports, concomitant surgery, not lone atrial fibrillation, not minimally-invasive surgery, not performed on the beating heart, not English, no full-text availability. These criteria were chosen to make a selection based on title and/or abstract. Inclusion criteria were: studies with $>$ 10 patients, follow-up of $>3$ months, minimal invasive-beating heart surgery and surgery for lone atrial fibrillation.

The search returned a total of 631 papers. A total of 40 articles were selected. Ten met inclusion criteria but were excluded because they had $<10$ patients ${ }^{11-20}$. Two were excluded because ablations were performed on a cardiopulmonary bypass ${ }^{21,22}$. The final selection included 28 studies $^{23-50}$. 


\section{Definitions}

In recent years, it has been hypothesized that $\mathrm{SA}-\mathrm{AF}$ and pathological $\mathrm{AF}$ are different disease processes with contrasting risk predictors ${ }^{51}$. The 2006

ACC/AHA/ESC guidelines stated that there was no standard definition for lone $\mathrm{AF}^{52}$. The guidelines applied the term to "... individuals younger than 60 years without clinical or echocardiographic evidence of cardiopulmonary disease, including hypertension" ${ }^{\prime 1,21}$. A recent international consensus on nomenclature and classification of AF mentions that only AF in the absence of heart disease is termed 'lone' while in the absence of any disease it is termed "idiopathic" "53. Indeed, lone AF does not necessarily mean "idiopathic". By convention, the term "non-valvular AF" is restricted to cases in which the rhythm disturbance occurs in the absence of rheumatic mitral valve disease, a prosthetic heart valve, or mitral valve repair. ${ }^{1}$ However, the reviewed publications were appraised employing a definition of AF as a stand-alone procedure for treating AF without concomitant surgery.

\section{Baseline Characteristics}

An overview of the selected studies is presented in Table 1. Studies were published between 2004 and 2011, and 27/28 (96.4\%) were observational in nature whereas one $^{42}$ was prospective non-randomized. Twenty-six studies $(89.6 \%)$ were performed in a single center, one included 5 centers $^{36}$, one 3 North American Institutions ${ }^{35}$ and one prospectively enrolled patients from two different centers ${ }^{42}$. Three studies of the groups of Edgerton et $\mathrm{al}^{26,31,36}$, Pruitt et $\mathrm{al}^{25,29}$, Sirak et $\mathrm{al}^{32,43}$ and $\mathrm{Cui}^{41,50}$ et al. may report on overlapping patients, thus, when discussing results, we refer to their most recent publications.

The total number of patients was 1,051 (range 14 to 114). Mean age ranged from 45.3 to 67.1 years. Only two studies had a population with mean age $<50$ years ${ }^{28,39}$. Two studies $^{45,31}$ did not report the population's age. AF duration ranged from 0.6 to 12.1 years. Three papers did not report AF duration ${ }^{44,45,49}$ and one paper ${ }^{26}$ classified 
patients on the basis of AF duration: $<6 \mathrm{~m}(\mathrm{n}=3), 6-12 \mathrm{~m}(\mathrm{n}=5),>12 \mathrm{~m}(\mathrm{n}=73)$, and unknown $(\mathrm{n}=2)$.

Only eight papers (34.8\%) distinguished long-standing persistent (LSP) AF as requested by recent Guidelines ${ }^{54}$ and in two studies ${ }^{43,50} 100 \%$ of patients had LSPAF. A total of 443 patients (42.1\%) with paroxysmal AF underwent minimally invasive surgery, 189 (18.0\%) had persistent AF, 123 (11.8\%) LSP and 95 (9.0\%) permanent, whereas 97 (9.2\%) were not clearly defined and one paper reported paroxysmal and persistent AF together $(n=104,9.9 \%)^{49}$.

Finally, 218 patients $(20.7 \%)$ had one or more previous percutaneous catheter ablation (PCA). In one paper ${ }^{40}$ all patients had at least one PCA before surgery.

\section{Surgery}

Video-assisted thoracic surgery was employed in all studies (Table 2) . In their 2006 paper Pruitt and coworkers ${ }^{25}$ performed a robotic-assisted pericardial ablation in 3/50 $(6 \%)$ of patients. Edgerton ${ }^{26,31,36,37,42}$ et al., McClelland and coworkers ${ }^{27}$, Beyer et $^{26}$ al. and Stamou et $\mathrm{al}^{43}$ carried out a small thoracothomy $(4-6 \mathrm{~cm})$ to introduce the endoscopic instruments into the thoracic cavity.

Three studies ${ }^{39,44,49}$ employed a right monolateral approach where in the others a bilateral access was performed. These authors used monopolar radiofrequency ${ }^{44,49}$ or high-intensity focused ultrasound (HIFU). Four studies ${ }^{23,25,28,29}$ employed microwave (MW), whereas in the majority of them the energy source was bipolar radiofrequency. Excluding the three right thoracotomy accesses, patients in all studies but one ${ }^{26}$ underwent excision/ligation of the left atrial appendage (LAA). In 15 studies LAA was stapled/legated in all patients. In four papers ${ }^{23,25,30,36}$ a variable percentage of patients $(16 \%, 8 \%, 39 \%$ and $11 \%$, respectively) did not have LAA stapler/ligation for unexplained reasons. Only a few groups clearly stated the indications for LAA removal: $\mathrm{La} \mathrm{Meir}^{48}$ performed LAA stapler/clip in patients with CHADS2 score $\geq 1$, in the presence of rapid firing coming from the LAA and when 
the procedure was deemed safe $(50 \%)$. Cui et $\mathrm{al}^{41}$ did not perform LAA excision in the first 10 patients $(12.4 \%)$ because of the lack of the appropriate endoscopic equipment and Edgerton et $\mathrm{al}^{42}$ did not remove LAA in 8 patients $(15 \%)$ because the procedure was deemed hazardous.

Seventeen groups (60.7\%) carried out ganglionated plexi (GP) ablation. Additional left atrial lesions are reported in 10 papers. They consisted of a roof line connecting superior pulmonary veins ${ }^{26,31,37,47,48}$, an inferior line connecting inferior pulmonary veins $^{47,48}$, a connecting line between the superior line (or the box) and the left fibrous trigone $26,31,32,37,43,47$, a connecting line from the superior pulmonary vein and the LAA $^{23,25,26,28,29,31,32,37,43}$ and a line from the right inferior pulmonary vein to the coronary sinus $(\mathrm{CS})^{32,43}$.

Additional right lesions are reported in four papers and indications were persistent/long-lasting persistent $\mathrm{AF}$ with LA volume $>58 \mathrm{~mL}^{48}$, permanent/persistent $\mathrm{AF}^{23}$, continuous $\mathrm{AF}^{25}$ or it was not specified ${ }^{29}$. Lesion consisted of a superior vena cava (SVC) to inferior vena cava line $\mathrm{e}^{23,25,29,48}$, a line up to the tip of the right atrial appendage $(\mathrm{RAA})^{23,25,29}$, or a line toward the $\mathrm{CS}^{23}$.

La Meir et $\mathrm{al}^{48}$ added an IVC circumferential isolation in 2 cases (to be sure that the SVC-IVC line would not stop at an area of conduction (in patients with a small portion of intrapericardial IVC). These authors also added a circumferential SVC isolation in case of a rapid firing coming from the SVC $(n=10.7 \%)$. Klinkenberg et al. ${ }^{39}$ added a tricuspid-vena cava-isthmus line ablation in one patient during reoperation for bleeding.

Electrophysiological testing of the lesions was carried out only by Krul and coworkers. ${ }^{47}$ In other groups entry and exit block was checked by baseline and postisolation sensing and pacing ${ }^{26,31-38,40-42,45,46,48-50}$. Speziale et al. ${ }^{44}$ measured the conductance across the lesion and a value $<50 \%$ than predicted defined an adequate lesion. Finally, Mc Clelland et $\mathrm{al}^{27}$ performed ablations guided by epicardial mapping. 


\section{Follow-up, Rhythm Monitoring, Anticoagulation and Anti-arrhythmic}

\section{therapy}

One-thousand-one-hundred-ninety-nine patients $(87.4 \%)$ reached the maximum follow-up which was $100 \%$ complete in 13 papers (46.4\%). In the others the followup completeness ranged from $32 \%$ to $95 \%$ (Table 3 ). The longest follow-up was 36 months ${ }^{48}$ and 9 studies reported a follow up $<12$ months which is the minimum recommended for evaluating procedural efficacy ${ }^{4}$.

Excluding two which did not mention any continuous rhythm monitoring ${ }^{23,45}$ and one which performed electrophysiological studies ${ }^{25}$, all the others papers employed at least one method of long-term monitoring (LTM). Fifteen studies (53.5\%) utilized 24-h Holter Monitoring (HM) at different intervals ${ }^{28,33,35,40,41,44,46,47,49,50}$, two 24-48 h monitoring ${ }^{34,39}$, one 7-day $\mathrm{HM}^{48}$ and one 30 -day $\mathrm{HM}^{27}$ and in one it was not specified. In five (17.8\%) HM was associated with another LTM: 14-21 day event recorder in Edgerton et al. ${ }^{26,31,36,42}$ and Outpatient Telemetry (OT) in Sagbas et al ${ }^{30}$. Among papers which did not utilize HM, $\mathrm{OT}^{24,43}$, event monitoring ${ }^{32,37}$ and trans-telephonic monitoring associated with event monitoring were the methods for rhythm assessment.

Only a few papers clearly described the adopted protocol for anti-arrhythmic drugs (AAD) during the follow-up: AAD were withdrawn in patients in SR after 3 months in 7 papers ${ }^{22,23,40,41,44,47,48}$, at 6 months in two ${ }^{3042}$ and two more papers stated that AAD were stopped after demonstration of stable SR at 3 and 6 month visits ${ }^{44,49,50}$. Sirak et $\mathrm{al}^{32}$ and Yilmaz at al ${ }^{46}$ reported that AAD were withdrawn at the discretion of the referring cardiologist.

Similarly, a standard protocol was not followed for oral anticoagulation (OA) therapy: it was discontinued at three months by Salanger et $\mathrm{al}^{23}$ and La Meir et $\mathrm{al}^{48}$ (if $\mathrm{CHADS}_{2}$ [cardiac failure, hypertension, age, diabetes, stroke (doubled)] score was $<2$ ), at 4 months by Cui et $\mathrm{al}^{41}$, at 6 months by Sagbas et al. ${ }^{30}$, Edgerton et al. ${ }^{37}$, Han 
et al. (if $\mathrm{CHADS}_{2}$ score was $\left.<2\right)^{38}$ and Klinkenberg et al. ${ }^{39}$, at 6 months- 1 year by Castella et $\mathrm{al}^{40}$ and at 1 year by McClelland et $\mathrm{al}^{27}$. Furthermore, in Wudel et al. ${ }^{33}$ and Yilmaz et al. ${ }^{46}$ anticoagulants were discontinued at the discretion of the referring cardiologist; Speziale et al. ${ }^{44}$ and Nasso et al. ${ }^{49}$ kept patients under OA until SR was maintained for 3 months, whereas Krul et al. ${ }^{47}$ discontinued OA when $\mathrm{CHADS}_{2}$ score was $<1$ without AF and AAD . Finally, Wang et $\mathrm{al}^{50}$ continued $\mathrm{OA}$ for at least 3 months.

Patients taking AAD at latest follow up was shown or could be calculated in 22/28 (78.5\%) studies. The range was from $2 \%$ to $53 \%$ (mean $26 \pm 15 \%$ ). Patients still under OA therapy at follow up could be obtained from 15/28 (53.5\%) studies. The range was from $0 \%$ to $63 \%$ (mean $39 \pm 19 \%$ ).

Quality of Life assessment was carried out employing the 36-item short form (SF-36) health survey questionnaire by Speziale et al. ${ }^{44}$ and Nasso et al. ${ }^{49}$, both showing an improvement in all indexes with the exception of vitality score. Pruitt et al ${ }^{25,29}$ explored the perceived health status after surgery: $81.8 \%$ and $52.3 \%$ of patients were pleased with the outcome and $81.8 \%$ and $55.7 \%$ felt the operation had been beneficial, in the two publications, respectively.

\section{$\underline{\text { Results }}$}

Only six papers ${ }^{27,34,38,42,47,50}$, all utilizing RF, clearly defined the primary efficacy endpoint of surgery as suggested by current Guidelines (freedom from AF , off antiarrhythmic drugs at one year [Table 4] $)^{4}$. The follow-up was $93.3 \%$ complete [251/269 pts.]) and the success rate ranged from $51 \%$ to $86 \%$. One study reported a 2 year success rate of $80 \%$.

With specific reference to the different type of AF, AAD-free success rate at 12 months ranged from $65 \%$ to $92 \%$ in paroxysmal AF and from $67 \%$ to $80 \%$ in persistent AF. Only 3 studies $^{27,47,50}$ reported 12-month AAD-free success rate in LSP ( $25 \%$ [4 pts. at follow up], $100 \%$ [1 pt. at follow up] and $80 \%$ [81pts. at follow up]). 
Eight papers ${ }^{26,30,31,32,33,35,36,37}$ reported outcomes as freedom from AF and AAD at 6 months (Table 5) . This rate ranged from $57 \%$ to $91 \%$ in the whole population, from $72 \%$ to $100 \%$ in paroxysmal and from $35 \%$ to $78 \%$ in persistent AF. Two papers ${ }^{36,37}$ showed this outcome

in LS-P patients (32\% [22 pts. at follow up] and 47\% [15 pts. at follow up]) and one ${ }^{30}$ report AAD free- in permanent $\mathrm{AF}(72 \%$ [18pts. at follow up]).

Wolf et $\mathrm{al}^{24}$ Yilmaz et $\mathrm{al}^{46}$ and Nasso et $\mathrm{al}^{49}$ reported freedom from AF-AAD at different intervals (Table 6) : 65\% beyond 3 month-follow up, 65\% at 12.6 monthfollow-up and $51 \%$ at 17.1 -month follow-up, respectively.

Three papers showed outcome as 12-month-freedom from AF (62\% and 75\%, respectively $)^{40,45}$ or 3 month-freedom from AF $(100 \%)^{43}$. Furthermore, in two publications $^{41,44} 80 \%(39 / 49)$ and $87 \%$ (40/46) of patients are in sinus rhythm at 12 and 6 months, respectively.

La Meir et al ${ }^{48}$ employed a method suggested by the Workforce on Evidence-Based Surgery of the Society of Thoracic Surgeons (STS), reporting time related prevalence of $\mathrm{AF}^{55}$.

Four studies employing $\mathrm{MW}^{23,25,28,29}$ reported a freedom from AF success rate of $67 \%$ $79.5 \%, 86 \%$ and $42 \%$, respectively. One group utilizing HIFU ${ }^{39}$ reported a 6 -month AF-AAD-free success rate of $33 \%$.

Krul al. ${ }^{47}$ carried out a roof and inferior line with $86 \%$ one-year freedom from AFAAD (22 pts.). It was 100\% for Sirak et $\mathrm{al}^{43}$ (19 pts all LSP) and 58\% for Edgerton et $\mathrm{al}^{31}(24 \mathrm{pts})$ at 6 months. In three studies utilizing $\mathrm{MW}^{23,25,29}$ an additional line toward LAA was performed. Unfortunately none of these papers reports AAD-free rate.

Groups performing GP ablation reported a 6-month and 12 month AAD-free success rate ranging from $51 \%$ to $86 \%$ and $58 \%$ to $88 \%$, respectively. Two studies employing bipolar $\mathrm{RF}^{30,33}$ without GP ablation reported an $\mathrm{AAD}$-free success rate of $81 \%$ and $91 \%$, respectively. 


\section{Adverse Events}

Three early deaths have been reported (Table 5): one $\mathrm{e}^{26,31,36}$ occurred during the procedure as a consequence of tearing of LAA, one ${ }^{41}$ was due to cerebral infarction and for one death the cause was unknown ${ }^{36}$. Overall, early complications occurred in 125 patients and the complication rate ranged from 0 to $39 \%$. Early complications were as follows: 12 conversions to sternotomy, 15 bleedings, 10 access-port complications, 11 cardiac complications, 8 cerebrovascular events and 28 pulmonary complications. Furthermore, 38 other complications occurred: 4 renal insufficiencies, 16 diaphragmatic-phrenic nerve dysfunctions, one liver damage and 4 brachial plexopathies were observed. Finally, 10 patients required a pacemaker implantation and 2 underwent percutaneous catheter ablation (PCA) within 30 days.

Three deaths occurred during the follow up and none was cardiac related: one unexplained death ${ }^{25}$ occurred in an obese patient who had severe pulmonary disease at the time of operation, one patient died from trauma and one from malignant neoplasm. ${ }^{46}$ Other complications included cerebrovascular accident $(n=4)$, thromboembolic event $(\mathrm{n}=1)$, anticoagulation-related complication ( $\mathrm{n}=1)$ and postpericardiotomy syndrome $(\mathrm{n}=1)$. In addition, during the follow up, 27 patients underwent PCA, 13 surgical Cox-Maze, 5 had pacemaker implantations and one patient was re-hospitalized for congestive heart failure and atrial flutter.

\section{Discussion}

The key purpose of this review is to summarize and discuss published articles about MIS for the treatment of SA-AF. From this overview it is evident that results employing microwave (MW) energy are rather poor. Indeed Pruitt et al. ${ }^{29}$ in the most recent paper report a $42 \%$ rate with $\mathrm{AAD}$ at 12 months. MW is an unfocused heat energy which can create transmural endocardial lesion but it is not capable of creating epicardial lesion on the beating heart ${ }^{56}$, this may explain such unsatisfactory results. 
In addition, results with High Frequency Ultrasound (HIFU) energy were also suboptimal: Klinkenberg et $\mathrm{al}^{39}$ reported a 6-month AAD-free success rate of $33 \%$. Indeed, this energy source appears capable of creating endocardial lesions on the arrested heart but has not been able to create transmural lesion on the beating heart and this explains the poor outcome of this study.

Bipolar radiofrequency is the most commonly adopted energy source for MIS as it has been demonstrated to produce permanent transmural linear lesions on the beating heart $^{56}$. Two groups performed surgery through a monolateral right thoracotomy approach $^{44,49}$ with a success rate without AAD of $51 \%$ and with AAD of $87 \%$ and $89 \%$. The mono-lateral approach should significantly lower the possible complication rates (bleeding, pulmonary complications), should be less painful for patients and allow potentially faster recovery. Nonetheless, only monopolar devices were used because of the lack of maneuverability of bipolar clamps which can hamper the orientation of the probe and constrain the variety of achievable lesion sets when employed from the right side. There is concern about the ability of these devices to create transmural lesion with bidirectional conduction block on the beating heart ${ }^{57}$. Further studies are necessary to establish if this approach may represent a reliable alternative to bilateral bipolar surgical ablation.

Among studies utilizing RF, freedom from AF-AAD at 12 months ranged from 51\% to $86 \%$; this figure was $65 \%-92 \%$ in paroxysmal and $67 \%-80 \%$ in persistent. Wang et $\mathrm{al}^{50}$ reported $80 \%$ AF-AAD freedom with 81 patients reaching 1year-follow-up. These result are comparable to those following $\mathrm{PCA}^{58}$. Indeed, an updated worldwide survey $^{7}$ reported a success rate free of AAD after PCA of $69.9 \%$. It was $71.4 \%$ in paroxysmal, $59.4 \%$ in persistent and $59.7 \%$ in LSP. Similarly, minimally invasive surgery was more effective in paroxysmal and $4 / 7$ studies $^{27,38,42,47}$ showed an AADfree success rate higher than PCA. However, minimally invasive surgery also had better results in persistent in 3/3 studies reporting AAD-free success rates. In contrast, the success rate was lower in $2 / 3$ studies in LSP AF. 
Furthermore, authors performing left additional lines had very high AAD-free success rates in persistent and LSP. This confirms that persistent and LSP AF cannot be successfully treated by PVI alone since the mechanisms for initiation and maintenance of AF lie in the changed left atrial substrate beyond the PVs. From a pathophysiological perspective, this is explained by structural and electrical remodeling of the atrial myocardium, which can then initiate and sustain $\mathrm{AF}$ independent of the PVs in patients with persistent/LSP AF. In these patients, the augmented number and location of drivers for fibrillation necessitates additional linear ablation strategies.

Another interesting finding of this overview is that, from the analysis of the reported results, it seems that GP ablation is not an essential part of the minimally invasive surgery of SA-AF to prevent recurrence of AF. Indeed, groups performing GP ablation reported a 12 month AAD-free success rate lower than studies not performing GP ablation. The long-term efficacy of GP ablation has been questioned ${ }^{59}$ and this was related to the possibility of autonomic ganglia to potentially reconnect or regrow $^{60}$. Nonetheless, these data must be interpreted with caution because of the small number of studies with full results available and the short follow up, and the role of GPs and their destruction in AF must be further investigated.

Mortality was low and comparable to PCA $(0.4 \%)^{54}$. Postoperative complication rates are not negligible and higher than $\mathrm{PCA}^{54}$. Pulmonary problems, bleeding and diaphragm/phrenic nerve dysfunction were the most common complications. Nonetheless, the occurrence of TIA/stroke was very low and less than that reported in catheter based pulmonary vein isolation ${ }^{54}$. Interestingly, the incidence of cardiovascular accident was not different with or without LAA removal and, from these findings, it seems that this procedure is not a critical component of MIS. However, this finding must be interpreted with extreme caution due to the small number of publications and the lack of uniform anticoagulation policy. Certainly, it is necessary to clearly define the role of LAA removal in MIS ablation since the LAA 
exclusion/closure is a potentially dangerous procedure and most of the reported bleedings were related to this maneuver.

Unfortunately no randomized control trials have been published comparing MIS with PCA. At the moment there are two ongoing studies: the SCALAF success trial which compares the efficacy of circumferential pulmonary vein ostia ablation using surgical versus catheter techniques in the treatment of paroxysmal atrial fibrillation, and the FAST II trial that explores whether mini invasive thoracoscopic radiofrequency is more effective compared to a percutaneous catheter based technique in patients with symptomatic paroxysmal atrial fibrillation refractory to at least one anti-arrhythmic drug. The results of these studies will provide a great understanding of the role of both procedures in the treatment of SA-AF.

In our recent paper ${ }^{61}$ we had given an overview of medical and surgical treatments of atrial fibrillation. The present study is mainly focused on providing a more detailed oversight of efficacy and complications of minimally invasive procedure. Krul et $\mathrm{al}^{62}$ have recently published a review on the mini-Maze. They included only papers employing radiofrequency and performed an aggregate patient data (APD) metaanalysis to compare published results. Our approach was different and we choose to give to the readership as much information as possible to allow them to make their own opinion about the effectiveness/safety of these procedures. Furthermore we believe that, although a well-designed meta-analysis can provide valuable information for researchers, there are too many critical caveats in performing and interpreting it which, therefore, can yield misleading information ${ }^{63}$ in particular when individual patient data (IPD) are not available ${ }^{64}$. Indeed, IPD meta-analysis offers advantages and, when feasible, should be considered the best opportunity for summarizing the results of multiple studies. However, the resources, time and cooperation required for such studies will continue to limit their use in many important areas of clinical medicine which can be meaningfully and cost-effectively approached only by APD-based meta-analyses. 


\section{Towards a multi-disciplinary approach: the Hybrid Procedure}

With the development of new tools and advanced techniques, the treatment of SA-AF moves towards a multidisciplinary approach involving cardiac surgeons and electrophysiologists ${ }^{65}$.

The rationale of the so called "hybrid" approach is to combine, in one step, a minimally invasive epicardial technique with a percutaneous endocardial ablation in order to limit the shortcomings of both techniques and, at the same time, to combine their advantages.

The potential for improved outcomes derives from combining levels of expertise. Surgeons are very good at making linear lesions and EPs at mapping for completeness. Lesions are more likely to be transmural when burning from the inside outwards and from the outside inwards simultaneously and the electrophysiologist can add an endocardial "touch-up" in the case of incomplete isolation of one of the pulmonary veins or if the connecting lesions are not transmural.

Furthermore, as discussed above, a more extensive lesion set beyond PVI to include targets along the LA substrate is often necessary in persistent and LSP AF.

Nonetheless, while the other lesions can be performed through the transverse sinus, the biggest challenge in the case of the full beating heart is making the connection to the mitral annulus, and this for different reasons: first, the visualization behind the LA of the full beating heart is very limited; second, there is the risk of collateral damage to the circumflex artery; third, the coronary sinus, which is used as the epicardial landmark for the mitral annulus, is unreliable and may leave a gap ${ }^{66}$. An attempt to address this problem was made by Edgerton et al. ${ }^{37}$ who developed the "Dallas lesion" in which a line was made connecting to the anterior annulus at the junction of the left and non-coronary cusps of the aortic root. Nonetheless, this line might not be transmural due to the inability of radiofrequency energy effectively to penetrate fatty tissue associated with the dome of the left atrium and the superior 
vena cava. This is an indication for mapping conduction block which can be checked by using an hybrid approach.

In contrast, mitral isthmus lesion can easily be carried out (or completed)

endocardially by the EP. Another potential advantage of the hybrid technique is that, from the EP's point of view, there is no longer a risk of phrenic nerve and esophageal injury because these structures can be protected by the surgeon if necessary, as well as no risk of tamponade since the pericardium is open. Furthermore, by reducing the total number of endocardial ablations the risk of emboli during these ablations should be potentially reduced ${ }^{67}$.

A potential drawback of the single-step approach is the patient's heparinisation after the trans-septal puncture which could increase the risk of epicardial bleeding and the risk of measuring a temporary block.

The concept of "hybrid" procedure was first published by Pak and co-workers ${ }^{68}$ who combined percutaneous epicardial catheter ablation (PECA) and endocardial ablation in difficult cases of AF. More recently, Krul et al. ${ }^{47}$ presented their experience with thoracoscopic PV isolation and ganglionated plexus (GP) ablation guided by periprocedural electrophysiological testing.

Mahapatra et al. ${ }^{69}$ have recently published their initial experience with surgical epicardial catheter and endocardial ablation for persistent and long-standing persistent atrial fibrillation carried out in two sequential steps (during the same hospitalization). After a mean follow-up of $20.7 \pm 4.5$ months $86.7 \%$ patients (persistent and LSP) were free of any atrial arrhythmia and off anti-arrhythmic drugs, compared to $56.7 \%$ of patients undergoing repeat catheter ablation. More recently, Pison and coworkers ${ }^{70}$, published results of a one-step hybrid thoracoscopic surgical and transvenous catheter ablation of atrial fibrillation in 26 patients. One-year offAAD success free of AF/AFL/AT was $93 \%$ for patients with paroxysmal AF and $90 \%$ for patients with persistent AF. 
Nonetheless, demonstration of the effectiveness and the safety of this approach awaits the completion of studies currently underway. Figure 1 shows the conversion of AF to sinus rhythm during the one-step hybrid procedure.

\section{Limitations}

This review has some important limitations which must be pointed out. First of all, a meta- analysis could not be carried out because of the heterogeneity of the papers and the lack of individual patient data. Second, the unavailability of data from prospective randomized studies on the minimally invasive surgical treatment of SA-AF vs. PCA was a drawback of this systemic review. Third, not all results are reported following HRS/EHRA/ECAS expert consensus which makes a comparison of the different studies difficult.

\section{Conclusions}

Minimally invasive surgical ablation of SA-AF achieved satisfactory one-year results when bipolar radiofrequency was employed as energy source, with AAD-free success rate comparable to PCA. The success rate in paroxysmal was even higher than in PCA. In persistent and long-standing persistent, results were improved by additional LA ablation lines. In contrast, GP ablation and LAA removal seem not to influence the recurrence of AF and the occurrence of postoperative thrombo-embolic events. Nonetheless, the relatively high complication-rate reported suggests that such techniques require further refinement. Finally, the preliminary results of the hybrid approach are promising but they need to be confirmed. 
Table 1. Minimally Invasive surgery for Lone Atrial Fibrillation: Baseline Characteristics.

\begin{tabular}{|c|c|c|c|c|c|c|c|c|c|c|c|}
\hline First Author & Year & $\mathbf{U} / \mathbf{M}$ & Pts. & Age & AF duration (y) & LA diameter (mm) & PCA & PX & PR & LSP & PM \\
\hline Salenger ${ }^{23}$ & 2004 & $\mathrm{U}$ & 14 & $60 \pm 4$ & 6.9 & $47.3 \pm 7.3$ & 1 & 10 & 1 & - & 3 \\
\hline Wolf $^{24}$ & 2005 & $\mathrm{U}$ & 29 & $57.2 \pm 14.9$ & 7.5 & * & 2 & 18 & 4 & - & 5 \\
\hline Pruitt $^{25}$ & 2006 & $\mathrm{U}$ & 50 & $59 \pm 10$ & 6.1 & $\dot{\dagger}$ & 11 & $\ddagger$ & 末 & $*$ & $\ddagger$ \\
\hline Edgerton $^{26}$ & 2007 & $\mathrm{U}$ & 83 & 60 & $\S$ & 52 & 21 & 72 & ๑ 21 & ๑ 21 & - \\
\hline Mc Clelland $^{27}$ & 2007 & U & 20 & $59 \pm 8$ & 1.4 & $44 \pm 3$ & ns & 11 & 5 & 4 & - \\
\hline Koistinen $^{28}$ & 2007 & $\mathrm{U}$ & 22 & $45.3 \pm 10.2$ & 6.6 & $42.9 \pm 5.2$ & 0 & 10 & 12 & - & - \\
\hline Pruitt $^{29}$ & 2007 & $\mathrm{U}$ & 100 & $60 \pm 9$ & 6.0 & $* *$ & ns & 64 & 11 & - & 25 \\
\hline Sagbas $^{30}$ & 2007 & $\mathrm{U}$ & 26 & $56 \pm 11$ & 2.8 & $42.2 \pm 6.3$ & 6 & 8 & - & - & 18 \\
\hline Edgerton $^{31}$ & 2008 & $\mathrm{U}$ & 74 & $\mathrm{~ns}$ & ns & ns & 20 & 46 & 14 & 14 & - \\
\hline $\operatorname{Sirak}^{32}$ & 2008 & $\mathrm{U}$ & 32 & $61 \pm 10$ & 7.7 & $48.2 \pm 8.2$ & ns & 0 & 3 & 29 & - \\
\hline Wudel $^{33}$ & 2008 & $\mathrm{U}$ & 22 & $62 \pm 9$ & 3.7 & $34.7 \pm 11.5$ & 7 & 14 & 8 & - & - \\
\hline Bagge $^{34}$ & 2009 & $\mathrm{U}$ & 42 & $58[36-71]$ & 7 & 45 [26-62] & 18 & 28 & 6 & - & 9 \\
\hline Beyer $^{35}$ & 2009 & M (3) & 100 & $65 \pm 11$ & 4.9 & $43 \pm 6$ & ns & 39 & 29 & - & 32 \\
\hline Edgerton $^{36}$ & 2009 & M (5) & 114 & $59.5 \pm 10.6$ & $>1(\mathrm{n}=101)$ & $47.2 \pm 8.3$ & 24 & 60 & 32 & 22 & - \\
\hline Edgerton $^{37}$ & 2009 & $\mathrm{U}$ & 30 & $58 \pm 9$ & $>1$ & 52 & ns & - & 10 & 20 & - \\
\hline $\mathrm{Han}^{38}$ & 2009 & U & 45 & $64 \pm 8.7$ & 6.2 & $43 \pm 6$ & 12 & 33 & 12 & - & - \\
\hline Klinkemberg ${ }^{39}$ & 2009 & $\mathrm{U}$ & 15 & $47 \pm 10$ & 5.0 & $38 \pm 5$ & ns & 11 & 4 & - & - \\
\hline Castella $^{40}$ & 2010 & $\mathrm{U}$ & 34 & $54 \pm 8.6$ & 8.1 & $45.3 \pm 5.6$ & $34+\dagger$ & 17 & 12 & 5 & - \\
\hline $\mathrm{Cui}^{41}$ & 2010 & $\mathrm{U}$ & 81 & $58 \pm 10$ & 5.9 & $49.7 \pm 11.4$ & 4 & 49 & 17 & - & 15 \\
\hline Edgerton $^{42}$ & 2010 & M (2) & 52 & $60[42-79]$ & $>1$ & $48[3.7-6.0]$ & 10 & 52 & - & - & - \\
\hline $\mathrm{Sirak}^{43}$ & 2010 & $\mathrm{U}$ & 48 & $60 \pm 6$ & 4.3 & 45 [34-63] & 13 & - & - & 48 & - \\
\hline Speziale $^{44}$ & 2010 & $\mathrm{U}$ & 46 & 54.9 & $\mathrm{~ns}$ & $42 \pm 5$ & 14 & 19 & 27 & - & - \\
\hline Stamou ${ }^{45}$ & 2010 & $\mathrm{U}$ & 20 & $\mathrm{~ns}$ & ns & ns & ns & $\mathrm{ns}$ & ns & ns & $\mathrm{ns}$ \\
\hline Yilmaz $^{46}$ & 2010 & $\mathrm{U}$ & 30 & $55.6 \pm 8.6$ & 6.6 & ns & 18 & 19 & 8 & - & 3 \\
\hline $\mathrm{Krul}^{47}$ & 2011 & $\mathrm{U}$ & 27 & $57 \pm 7$ & 0.6 & $47 \pm 7$ & 14 & 16 & 3 & 2 & - \\
\hline La Meir ${ }^{48}$ & 2011 & U & 28 & $67.1 \pm 9.1$ & 12.1 & $41.6 \pm 5.7$ & 21 & 14 & 5 & 9 & - \\
\hline Nasso $^{49}$ & 2011 & U & 104 & $63.9 \pm 8$ & ns & $21.3 \pm 5$ & 24 & $104^{88}$ & $104^{85}$ & - & - \\
\hline Wang $^{50}$ & 2011 & $\mathrm{U}$ & $83^{19}$ & $57 \pm 11$ & 5.1 & $52.5 \pm 11.5$ & ns & - & - & 83 & - \\
\hline
\end{tabular}

Studies were presented by year of publication and in alphabetical order . Abbreviations: U/M:

Unicentric/Multicentric study; Age expressed as mean \pm SD or [range]; AF duration expressed y: years LA :

Left atrial; LA Diameter expressed a s as mean $\pm \mathrm{SD}$ or median [ Interquartile range]; PCA: Percutaneous catheter Ablation ; PX: Paroxysmal atrial fibrillation; PR: Persistent atrial fibrillation; LSP: Long-standing Persistent atrial fibrillation; PM: Permanent atrial fibrillation; ns: not specified..

Notes: $* \dagger<60 \mathrm{~mm}(\mathrm{n}=26)>60 \mathrm{~mm}(\mathrm{n}=1) ; \dagger *<60 \mathrm{~mm}(\mathrm{n}=26)>60 \mathrm{~mm}(\mathrm{n}=1) ; \uparrow<46 \mathrm{~mm}(\mathrm{n}=23), 46-59$ $\mathrm{mm}(\mathrm{n}=24), \geq 60 \mathrm{~mm}(\mathrm{n}=3 ; \$$ AF classified as intermittent $(\mathrm{n}=33)$ and continuous $(\mathrm{n}=17) ; \S<6 \mathrm{~m}(\mathrm{n}=3), 6-12 \mathrm{~m}$ $(\mathrm{n}=5),>12 \mathrm{~m}(\mathrm{n}=73)$, unknown $(\mathrm{n}=2)$.; $\uparrow$ Persistent and Long-standing persistent reported together). $* *<46 \mathrm{~mm}$ $(\mathrm{n}=42), 46-59 \mathrm{~mm}(\mathrm{n}=53), \geq 60 \mathrm{~mm}(\mathrm{n}=5) ; \dagger$ All patients had PCA by definition; + +indexed by BSA; $\S$ Paroxysmal and persistent reported together; $\uparrow 41$ patients treated with irbesartan. 
Table 2. Minimally Invasive surgery for Lone Atrial Fibrillation: Surgery

\begin{tabular}{|c|c|c|c|c|c|c|}
\hline First Author & Source & Method & Access & GP & LAA & $\mathbf{A L}$ \\
\hline Salenger $^{23}$ & MW & VATS & $\mathrm{B}$ & $\mathrm{N}$ & $\mathrm{Y}(9)$ & $\mathrm{Y}$ \\
\hline Wolf $^{24}$ & $\mathrm{RF}(\mathrm{b}) \mathrm{I}$ & VATS & $\mathrm{B}$ & $\mathrm{N}$ & $\mathrm{Y}$ & $\mathrm{N}$ \\
\hline Pruitt $^{25}$ & MW & VATS (47) /Rob (3) & B & $\mathrm{N}$ & $Y(46)$ & Y \\
\hline Edgerton $^{26}$ & $\mathrm{RF}(\mathrm{b}) \mathrm{I}$ & Thoracotomy /VATS & $\mathrm{B}$ & $\mathrm{Y}$ & $\mathrm{Y}$ & $\mathrm{Y}$ \\
\hline Mc Clelland $^{27}$ & $\mathrm{RF}(\mathrm{b}) \mathrm{I}$ & Thoracotomy /VATS & B & $\mathrm{Y}$ & $\mathrm{N}$ & $\mathrm{N}$ \\
\hline Koistinen $^{28}$ & MW & VATS & $\mathrm{B}$ & $\mathrm{N}$ & $\mathrm{Y}^{\S}$ & $\mathrm{N}$ \\
\hline Pruitt $^{29}$ & MW & VATS & $\mathrm{B}$ & $\mathrm{N}$ & $\mathrm{Y}$ & $\mathrm{Y}$ \\
\hline Sagbas $^{30}$ & $\mathrm{RF}(\mathrm{b}) \mathrm{I}$ & VATS & $\mathrm{B}$ & $\mathrm{N}$ & Y (16) & $\mathrm{N}$ \\
\hline Edgerton $^{31}$ & $\mathrm{RF}(\mathrm{b}) \mathrm{I}$ & VATS & $\mathrm{B}$ & $\mathrm{Y}$ & $\mathrm{Y}$ & Y \\
\hline Sirak $^{32}$ & $\mathrm{RF}(\mathrm{b}) \mathrm{NI}$ & VATS & $\mathrm{B}$ & $\mathrm{Y}$ & $\mathrm{Y}$ & $\mathrm{Y}$ \\
\hline Wudel $^{33}$ & $\mathrm{RF}(\mathrm{b}) \mathrm{NI}$ & VATS & $\mathrm{B}$ & $\mathrm{N}$ & $\mathrm{Y}$ & $\mathrm{N}$ \\
\hline Bagge $^{34}$ & $\mathrm{RF}(\mathrm{b}) \mathrm{I}$ & VATS & $\mathrm{B}$ & $\mathrm{Y}$ & $\mathrm{Y}$ & $\mathrm{N}$ \\
\hline Beyer $^{35}$ & $\mathrm{RF}(\mathrm{b}) \mathrm{I} \mathrm{NI}$ & Thoracotomy /VATS & $\mathrm{B}$ & $\mathrm{Y}$ & $\mathrm{Y}$ & $\mathrm{N}$ \\
\hline Edgerton $^{36}$ & $\mathrm{RF}(\mathrm{b}) \mathrm{I}$ & Thoracotomy /VATS & $\mathrm{B}$ & $\mathrm{Y}$ & $\mathrm{Y}(101)$ & $\mathrm{N}$ \\
\hline Edgerton $^{37}$ & $\mathrm{RF}(\mathrm{b}) \mathrm{I}$ & Thoracotomy /VATS & $\mathrm{B}$ & $\mathrm{Y}$ & $\mathrm{Y}$ & $\mathrm{Y}$ \\
\hline $\operatorname{Han}^{38}$ & $\mathrm{RF}(\mathrm{b}) \mathrm{I}$ & VATS & $\mathrm{B}$ & $\mathrm{Y}$ & $\mathrm{Y}$ & $\mathrm{N}$ \\
\hline Klinkemberg $^{39}$ & HIFU & VATS & $\mathrm{R}$ & $\mathrm{N}$ & $\mathrm{N}$ & $\mathrm{Y}^{*}$ \\
\hline Castella $^{40}$ & $\mathrm{RF}(\mathrm{b}) \mathrm{NI}$ & VATS & B & $\mathrm{Y}$ & $\mathrm{Y}$ & $\mathrm{N}$ \\
\hline $\mathrm{Cui}^{41}$ & $\mathrm{RF}(\mathrm{b}) \mathrm{NI}$ & VATS & B & $\mathrm{N}$ & $Y(71)$ & $\mathrm{N}$ \\
\hline Edgerton $^{42}$ & RF(b)I & Thoracotomy /VATS & B & Y & $Y(44)$ & $\mathrm{N}$ \\
\hline Sirak $^{43}$ & RF(b)I & VATS & B & $\mathrm{Y}$ & $\mathrm{Y}$ & $\mathrm{Y}$ \\
\hline Speziale $^{44}$ & $\mathrm{RF}(\mathrm{m})$ & VATS & $\mathrm{R}$ & $\mathrm{N}$ & $\mathrm{N}$ & $\mathrm{N}$ \\
\hline Stamou $^{45}$ & $\mathrm{RF}(\mathrm{b}) \mathrm{I} \mathrm{NI}$ & Thoracotomy & $\mathrm{B}$ & $\mathrm{Y}$ & $\mathrm{Y}$ & $\mathrm{N}$ \\
\hline Yilmaz $^{46}$ & $\mathrm{RF}(\mathrm{b}) \mathrm{NI}$ & VATS & B & $\mathrm{Y}$ & $\mathrm{Y}$ & $\mathrm{N}$ \\
\hline $\mathrm{Krul}^{47}$ & $\mathrm{RF}(\mathrm{b}) \mathrm{NI}$ & VATS & $\mathrm{B}$ & $\mathrm{Y}$ & $\mathrm{Y}$ & $\mathrm{Y}$ \\
\hline $\mathrm{La} \mathrm{Meir}^{48}$ & $\mathrm{RF}(\mathrm{b}) \mathrm{I}$ & VATS & B & $\mathrm{Y}$ & Y (14) & Y \\
\hline $\mathrm{Nasso}^{49}$ & $\mathrm{RF}(\mathrm{m})$ & VATS & $\mathrm{R}$ & $\mathrm{N}$ & $\mathrm{N}$ & $\mathrm{N}$ \\
\hline Wang $^{50}$ & $\mathrm{RF}(\mathrm{b}) \mathrm{NI}$ & VATS & B & $\mathrm{Y}$ & $\mathrm{Y}$ & $\mathrm{N}$ \\
\hline
\end{tabular}

Studies were presented by year of publication and in alphabetical order

Abbreviations: GP: Ganglionated plexi (ablation); LAA: Left atrial appendage excision/closure; AL: Additional lines; Source: MW: Microwave; RF:

Radiofrequency; Cryo: Cryotherapy; HIFU: High-Intensity Focused Ultrasound b: bipolar; u: unipolar; I. Irrigated; NI: Not irrigated; VATS: video assisted thoracoscopic surgery; Rob: Robotic-assisted surgery; ns: not specified.

Notes: * during reoperation for bleeding a tricuspid-vena cava inferior isthmus ablation was performed in one pt. $\dagger$ Eight underwent additional mitral and tricuspid procedures ; $\$$ Performed on Cardiopulmonary bypass; $\S$ LAA was excised if it was deemed to be significantly enlarged or if the patient had suffered from a thromboembolic event. 
Table 3. Minimally Invasive surgery for Lone Atrial Fibrillation: End-points and Rhythm Monitoring

\begin{tabular}{|c|c|c|c|c|c|c|c|}
\hline First Author & F-Up (m) & End-point & $\mathrm{N}(\%)$ & F-Up type & Rhythm Monitoring & AAD & OA \\
\hline Salenger $^{23}$ & 12 & 1 & $14(100)$ & $\mathrm{OC}$ & ns & ns & ns \\
\hline Wolf2 $^{24}$ & 6 & 1 & $23(79)$ & OC-MR-TI-CV (3-5-6 M) & ECG (10) OT(13) & 9 & ns \\
\hline Pruitt $^{25}$ & 7.6 & 2 & $44(88)$ & OC-TI (ns) & ECG EPS & 20 & 50 \\
\hline Edgerton $^{26}$ & 6 & 3 & $57(69)$ & $\mathrm{OC}(1-3-6 \mathrm{M})$ & ECG, 14-21-day event recorder (24)24HM (24), Pm (9) & 34 & ns \\
\hline Mc Clelland $^{27}$ & $17 \pm 3$ & 4 & $20(100)$ & OC(1-2-3-6-W 3-6 M-every 6M) & *30-day HM (12M) & 25 & ns \\
\hline Koistinen $^{28}$ & $11.5 \pm 6$ & $2-5$ & $22(100)$ & OC $(1-3-6 \mathrm{M})$ & $24 \mathrm{HM}(6 \mathrm{M})$ & 2 & 0 \\
\hline Pruitt $^{29}$ & 23.1 & 6 & $88(88)$ & OR-MR-EPS (ns) & ECG -HM (ns) & 11 & 54 \\
\hline $\operatorname{Sagbas}^{30}$ & $8 \pm 3$ & 2 & $26(100)$ & $\mathrm{OC}(3-6 \mathrm{M})$ & OT; 24HM (ns) & 19 & 54 \\
\hline Edgerton $^{31}$ & 6 & 3 & $66(89)$ & $0 \mathrm{C}(1-3-6 \mathrm{M})$ & ECG; 14-21-day event recorder (ns)24HM (ns) & 47 & ns \\
\hline Sirak $^{32}$ & 6 & 1 & $19(40)$ & $\mathrm{OC}$ & 7-day event recorder (3-6-13-24M) & ns & ns \\
\hline Wudel $^{33}$ & $18 \pm 4$ & 2 & $22(100)$ & OC (3-6-12 M) & 24HM (ns) & 9 & 9 \\
\hline Bagge $^{34}$ & 12 & 1 & $41(78)$ & OC (3-6-12-M) & $24-48 \mathrm{HM}(\mathrm{ns})$ & 32 & 24 \\
\hline Beyer $^{35}$ & $13 \pm 8$ & 7 & $100(100)$ & $0 C(3 \mathrm{M}$ - every Year) & $24 \mathrm{HM}(3 \mathrm{M})$ & 37 & 36 \\
\hline Edgerton $^{36}$ & $17 \pm 3.4$ & 1 & $114(100)$ & OC ( $1-3-6 \mathrm{M})$ & 24 HM (26) 14- 21-day event recorder (68) Pm (15) & 43 & ns \\
\hline Edgerton $^{37}$ & 6 & 8 & $30(100)$ & OC $(1-3-6 \mathrm{M})$ & ECG-Event Recorder Pm & 53 & 47 \\
\hline $\operatorname{Han}^{38}$ & 12 & 9 & $43(95)$ & OC (6-12 M-Yearly) & 30-day event recorder $(6 \mathrm{~m})$ TTM $(12 \mathrm{M})$ & 35 & 33 \\
\hline Klinkemberg ${ }^{39}$ & $1.3 \pm 0.6 \mathrm{y}$ & 10 & $15(100)$ & $\mathrm{OC}(2-6-12--24 \mathrm{M})$ & ECG 24HM (2m) 48 HM (6m) & 40 & $\mathrm{~ns}$ \\
\hline Castella $^{40}$ & $16 \pm 11$ & 11 & $11(32.3)$ & OC (1-4-6-12 M) & ECG 24HM (4-6M-1Y) & $\mathrm{ns}$ & 63 \\
\hline $\mathrm{Cu}^{4+1}$ & 12 & 11 & $49(60)$ & OC (1-3-6-12 M) & ECG, 24-48 HM, Pm, UCG & ns & ns \\
\hline Edgerton $^{42}$ & 12 & 8 & $52(100)$ & $\mathrm{OC}(1-3-6-12 \mathrm{M})$ & 24 HM 14-21-day event recorder Pm & 11 & 19 \\
\hline Sirak $^{43}$ & 6 & 7 & $24(75)$ & $\mathrm{OC}(3-6-13 \mathrm{M})$ & OT & 12 & ns \\
\hline Speziale $^{44}$ & $9.3 \pm 3.2$ & 3 & $46(100)$ & $\mathrm{OC}(3-6-12 \mathrm{M})$ & ECG 24HM (6-12 M) & ns & ns \\
\hline Stamou ${ }^{45}$ & 12 & ns & $12(60)$ & $\mathrm{ns}$ & ns & $\mathrm{ns}$ & $\mathrm{ns}$ \\
\hline Yilmaz $^{46}$ & $11 \pm 4$ & 7 & $30(100)$ & $O C(1-3-6-W 3-6-12 M)$ & ECG 24HM (3-6-12 M) & 35 & 52 \\
\hline $\mathrm{Krul}^{47}$ & 12 & $12-9$ & $22(71)$ & OC ( 3-6-12-15-18-24 M) & ECG 24HM (every 3 M) & 14 & 48 \\
\hline $\mathrm{La} \mathrm{Meir}^{48}$ & 36 & 13 & $24(85.7)$ & OC(2-W 1-6-12M-Yearly) & ECG 7day-HM(2-W 1-6-12M-Yearly) & 11.3 & 15.2 \\
\hline $\mathrm{Nasso}^{49}$ & $17 \pm 6$ & $1-5$ & $104(100)$ & OC ( 3-6 -every $6 \mathrm{M})$ & ECG, $24 \mathrm{HM}(3-6 \mathrm{M})$ & 49 & 60 \\
\hline Wang $^{30}$ & 26 & 11 & $81(97.5)$ & OC (1-3-6-12 M-every $6 \mathrm{M})$ & ECG $24-48$ HM (3M) & 21 & $\mathrm{~ns}$ \\
\hline
\end{tabular}

Studies were presented by year of publication and in alphabetical order . Abbreviations: F-Up: Follow-up; $\mathrm{m}=$ months; $\mathrm{N}(\%)$ : Number (percentage) of patients at follow-up; ADD: (\%patients taking ) Antiarrhythmic Drugs; OA : (\%patients taking ) Oral Anticoagulants. Endpoint: 1= freedom from AF,2=number of patients in sinus rhythm/with no AF; 3: No episodes of AF $>15 \mathrm{sec}$ at 6 months 4: Free of AAD (Class IC and III) and $\mathrm{AF}$, no $>30 \mathrm{sec}$ of AF ; 5: episodes of AF, 6: Absence of AF on all serial ECG, Holter Monitoring or 30-day event - free monitoring $>6$ months after procedure; 7: No episode of AF o left Atrial Tachyarrhythmia (AT) after blanking period of 3 months; 8 :No AT, AF or Atrial Flutter (AFl) $>30$ seconds during monitoring at 6 months; 9: No AT, AF or Atrial Flutter (AFl) lasting >30 seconds off antiarrhythmic drugs, 10: Absence of $\mathrm{AF} \mathrm{AFl}$ and $\mathrm{AT}$ on $96 \mathrm{~h} \mathrm{HM}$ or ECG $>30 \mathrm{sec}$ and no AF compliant; 11: No AF or Atrial Flutter (AFl) $>30$ seconds during ECG or Holter Monitoring:; 12: Freedom from AT, AF or Afl off antiarrhythmic drugs after 12 months; 13: Time-related prevalence of AF ( defined as of AF o left Atrial Tachyarrhythmia after blanking period of 3 months. Follow-Up type: OC: Outpatient Clinic; MR: Medical Records; TI: Telephonic Interviews;; CV: Cardiologic Visits; M: Months; ns: not specified; Rhythm Monitoring: ECG: Electrocardiograms HM: Holter Monitoring;, , OT : Outpatient (Cardiac ) Telemetry; TTM : Trans Telephonic (event) Monitor Pm= Pace-maker; UCG: Ultrasonic Cardiographic evaluation, EPS: Ectrophysiology studies; Notes: * 1 Patient underwent 15-day HM. 


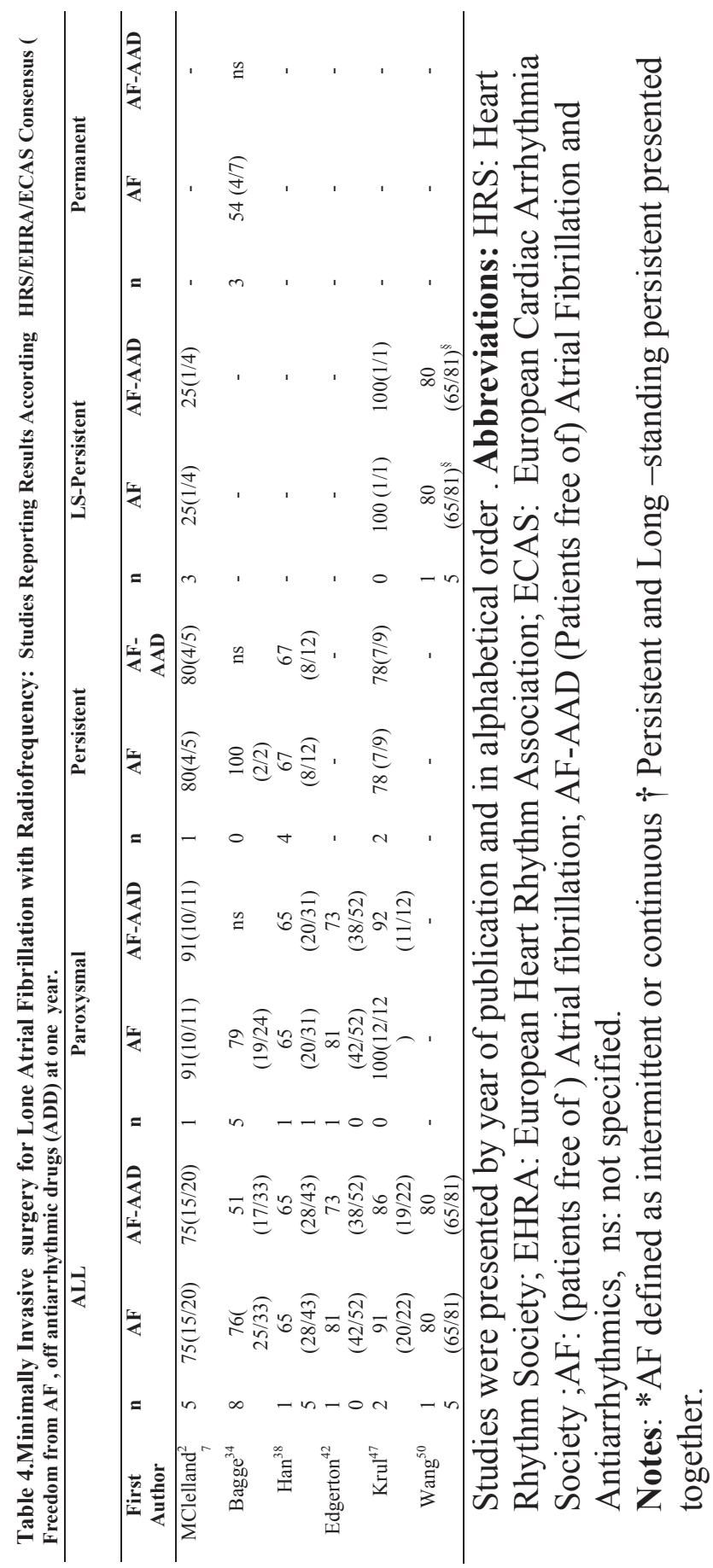




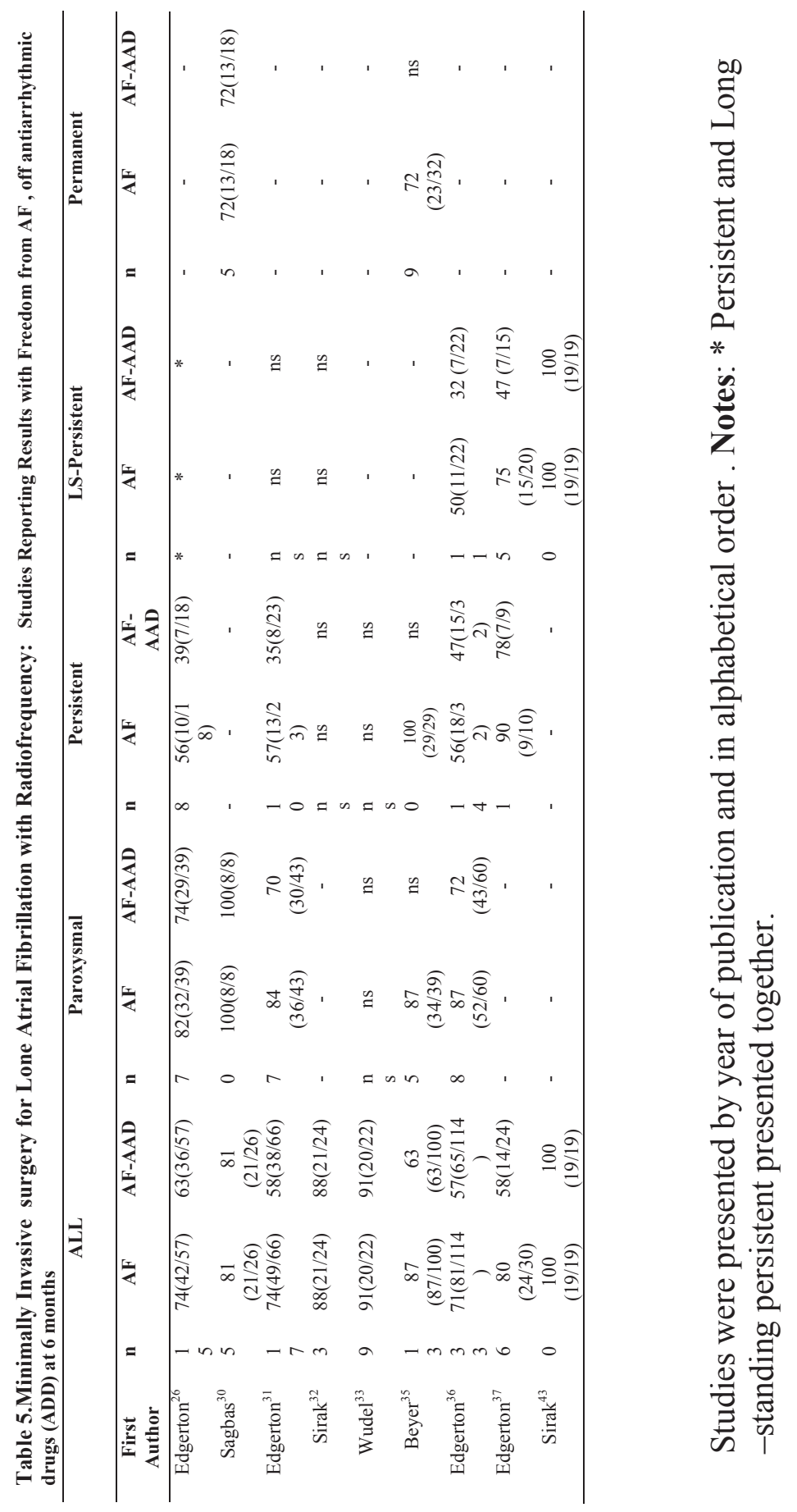




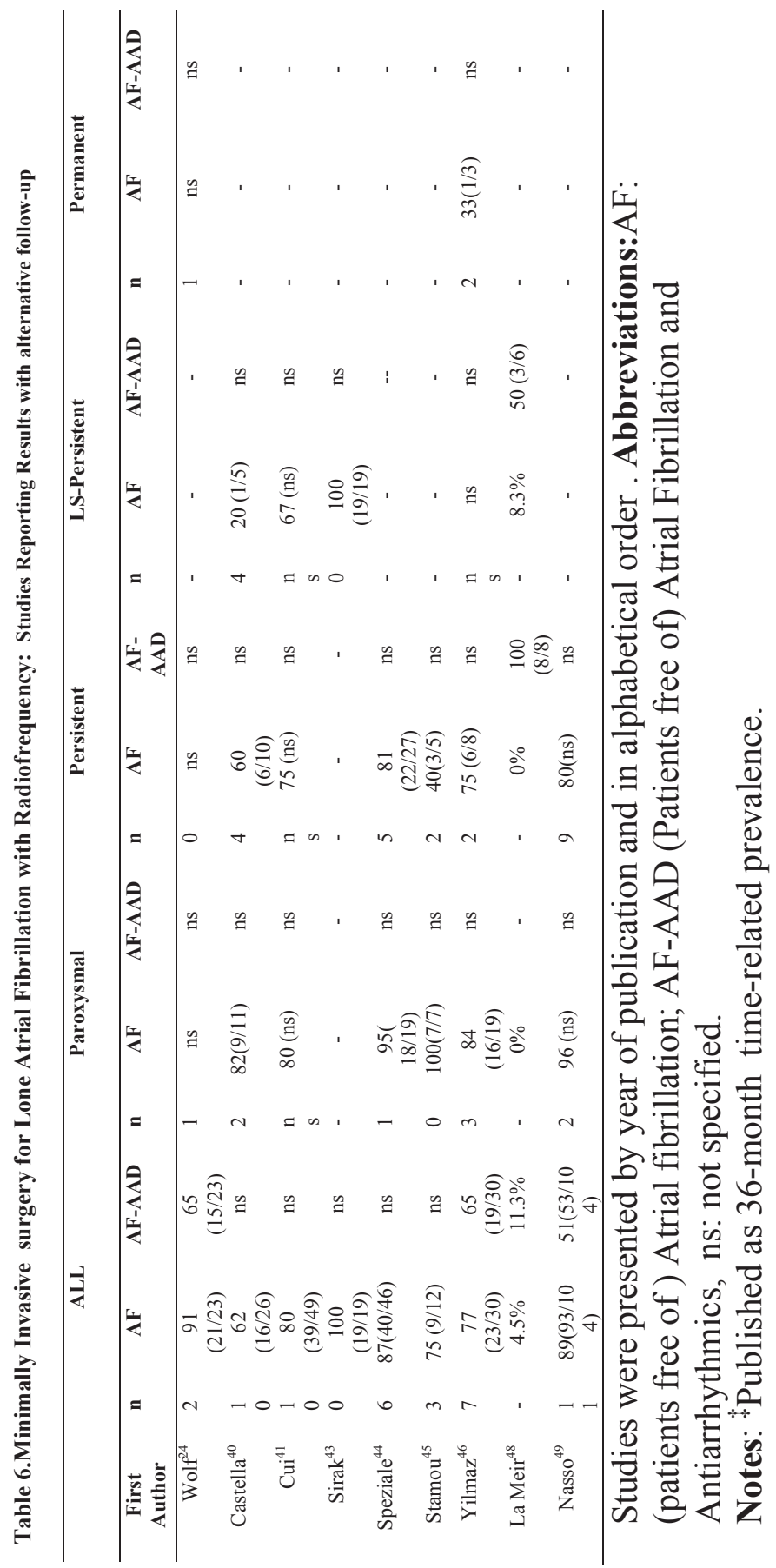




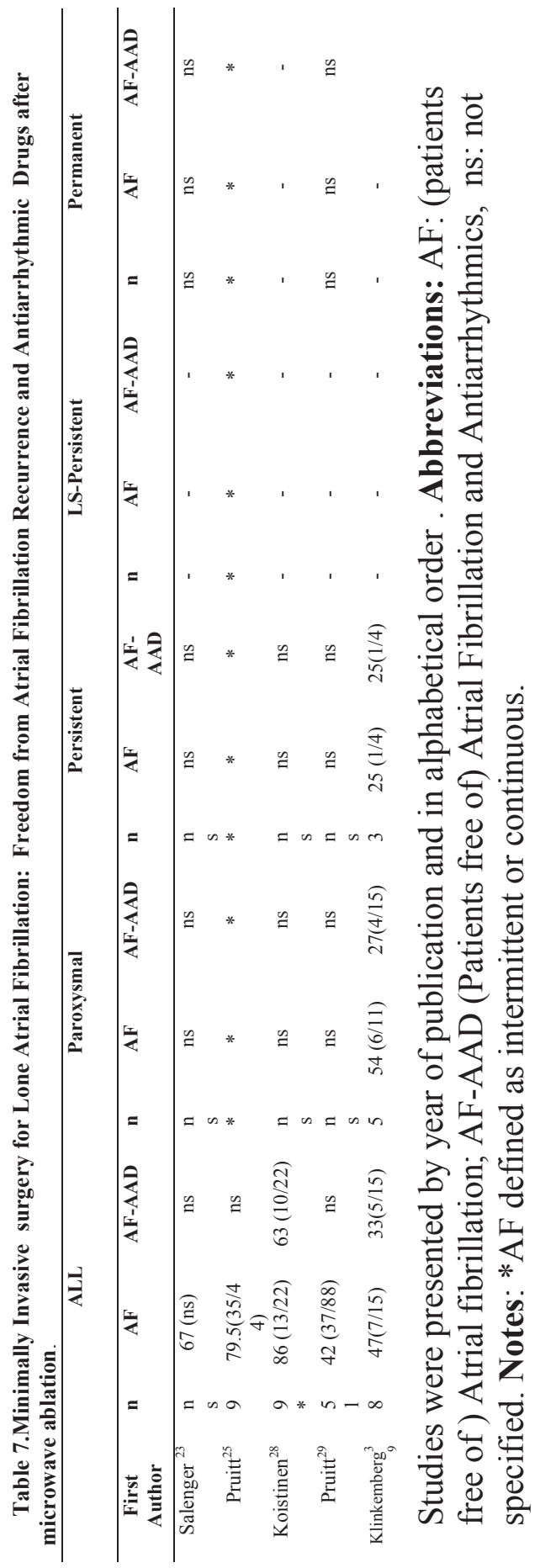


Table 8. Minimally Invasive surgery for Lone Atrial Fibrillation: Adverse events.

\begin{tabular}{|c|c|c|c|c|c|c|c|c|c|c|c|}
\hline First Author & $\mathbf{N}$ & $\%$ & Death & $\begin{array}{l}\text { Conversi } \\
\text { on }\end{array}$ & $\begin{array}{c}\text { Blee } \\
\text { d }\end{array}$ & Port & $\begin{array}{c}\text { Cardia } \\
\text { c }\end{array}$ & $\begin{array}{c}\text { Cerebra } \\
1\end{array}$ & $\begin{array}{c}\text { Pulmona } \\
\text { ry }\end{array}$ & Other & Late \\
\hline Salenger $^{23}$ & 4 & $\begin{array}{c}28 . \\
5\end{array}$ & 0 & 2 & 0 & 0 & 0 & 0 & PN; PE & 0 & $\begin{array}{l}\text { PCA(2[3-6-M]); } \\
\text { PM([9M] })\end{array}$ \\
\hline Wolf $^{24}$ & 3 & $\begin{array}{c}13 . \\
0\end{array}$ & 0 & 0 & 0 & 0 & $\mathrm{Pe}$ & 0 & PX & Phl & RH \\
\hline Pruitt $^{25}$ & 2 & 4 & 0 & 0 & 0 & 0 & 0 & 0 & 0 & $\mathrm{D}(2)$ & Death (1) C-MZ (5) \\
\hline Edgerton $^{26}$ & 4 & 4.8 & $1^{\dagger}$ & 0 & 0 & 0 & 0 & 0 & $\mathrm{H}$ & $\mathrm{RI}$; BP & 0 \\
\hline Mc Clelland ${ }^{27}$ & 1 & 0.5 & 0 & 0 & 0 & 0 & 0 & 0 & $\mathrm{H}$ & 0 & $\operatorname{PCA}(3[\mathrm{~ns}])$ \\
\hline Koistinen $^{28}$ & 5 & 2.2 & 0 & 0 & 2 & 0 & 0 & 0 & 0 & Liv.Dam D (2) & $\mathrm{PM}([\mathrm{ns}])$ \\
\hline Pruitt $^{29}$ & $\begin{array}{l}1 \\
3\end{array}$ & 13 & 0 & 0 & 2 & 0 & 0 & CVA & 0 & $\mathrm{D}(7) \mathrm{PM}(3)$ & 4CVA, ACC C-MZ (9) \\
\hline Sagbas ${ }^{30}$ & 2 & 7.6 & 0 & 0 & 0 & 0 & 0 & 0 & PLE & $\mathrm{D}$ & 0 \\
\hline Edgerton $^{31}$ & 4 & 5.4 & $1^{\dagger}$ & 0 & 0 & 0 & 0 & 0 & $\mathrm{H}$ & $\mathrm{RI}$; BP & 0 \\
\hline $\operatorname{Sirak}^{32}$ & 1 & 3.1 & 0 & 1 & 0 & 0 & 0 & 0 & 0 & 0 & PCA (5 [ within $3 \mathrm{M}])$ \\
\hline Wudel $^{33}$ & 2 & 9 & 0 & 0 & 0 & $\operatorname{Rev}$ & 0 & 0 & PE & 0 & $\operatorname{PCA}(1[7 \mathrm{M}])$ \\
\hline Bagge $^{34}$ & $\begin{array}{l}1 \\
7\end{array}$ & 39 & 0 & 0 & 6 & Rib I (4) & VT PP & $\begin{array}{l}\text { Dis } \\
\text { Stroke }\end{array}$ & $\mathrm{H}(2)$ & 0 & PP INF Esoph $\mathrm{He}$ (ns) \\
\hline Beyer $^{35}$ & $\begin{array}{l}1 \\
3\end{array}$ & 13 & 0 & 0 & 0 & 0 & 0 & TIA & H (3) PE & PM (5) Phre (3) & ns \\
\hline Edgerton $^{36}$ & $\begin{array}{l}1 \\
5\end{array}$ & 13 & $2^{\dagger}$ & 0 & 1 & 0 & $\begin{array}{l}\mathrm{Pe} \text { VT } \\
\text { (2) }\end{array}$ & 0 & $\mathrm{RD}(5)$ & RI (2) Phre BP & ns \\
\hline Edgerton $^{37}$ & 0 & 0 & 0 & 0 & 0 & 0 & 0 & 0 & 0 & 0 & PM(2) PCA (ns) \\
\hline $\operatorname{Han}^{38}$ & 0 & 0 & 0 & 0 & 0 & 0 & 0 & 0 & 0 & 0 & $\begin{array}{c}\text { PCA (8 }[532 \pm 73 \text { days }]) \\
\text { PM }\end{array}$ \\
\hline Klinkemberg $^{39}$ & 3 & 20 & 0 & 0 & $2^{*}$ & 0 & $\mathrm{Pe}$ & 0 & 0 & 0 & PCA (6) \\
\hline Castella $^{40}$ & 5 & $\begin{array}{c}14 . \\
7\end{array}$ & 0 & 0 & 2 & 0 & 0 & Stroke & H PAV & 0 & ns \\
\hline $\mathrm{Cui}^{41}$ & 6 & 7.4 & 1 & 1 & 0 & $\operatorname{Rev}(2)$ & MI & 0 & Reint & 0 & ns \\
\hline Edgerton $^{42}$ & 4 & 7.6 & 0 & 0 & 0 & 0 & 0 & 0 & 0 & $\mathrm{BP}, \mathrm{PM} \mathrm{PCA}(2)$ & 0 \\
\hline $\operatorname{Sirak}^{43}$ & 2 & 4.2 & 0 & 1 & 0 & 0 & 0 & 0 & 0 & PM & PCA \\
\hline Speziale $^{44}$ & 1 & 1.9 & 0 & 1 & 0 & 0 & 0 & 0 & 0 & 0 & 0 \\
\hline Stamou $^{45}$ & 3 & 15 & 0 & 0 & 0 & 0 & $\operatorname{Pe}(3)$ & 0 & 0 & 0 & ns \\
\hline Yilmaz $^{46}$ & 4 & $\begin{array}{c}13 . \\
3\end{array}$ & 0 & 2 & 0 & 0 & 0 & 0 & $\mathrm{PX}(2)$ & 0 & 0 \\
\hline $\mathrm{Krul}^{47}$ & 6 & 22. & 0 & 3 & 0 & 0 & 0 & 0 & H PX PN & 0 & 0 \\
\hline $\mathrm{La} \mathrm{Meir}^{48}$ & 0 & 0 & 0 & 0 & 0 & 0 & 0 & 0 & 0 & 0 & 0 \\
\hline $\mathrm{Nasso}^{49}$ & 3 & 2.9 & 0 & 1 & 0 & 0 & 0 & $\begin{array}{c}\text { TIA } \\
\text { Stroke }\end{array}$ & 0 & 0 & Death (2) TEE \\
\hline Wang $^{50}$ & 4 & 4.8 & 0 & - & - & $\operatorname{Rev}(2)$ & - & Stroke & Reint & - & - \\
\hline
\end{tabular}

Studies were presented by year of publication and in alphabetical order . Abbreviations: N: Number of in-hospital complications; \%: Percentage of in-hospital complications; Bleed: Bleeding; Port (access port complications): Rev: Surgical Revision; Rib: Rib Fracture; Cardiac: VT: Ventricular tachycardia, Pe : Pericarditis/Pericardial effusion; Myocardial Infarction;

Cerebral: CVA: Cerebro-vascular Vascular Accident; Dis: Disorientation/Confusion TIA: Transient Ischemic Attack; Pulmonary: PN: Pneumonia; PE: Pulmonary Embolism; PX: Pneumothorax; PLE: Pleural Effusion; H: Hemothorax; RD: Respiratory Distress; PAV: Prolonged assisted ventilation; Reint: Reintubation. Other: Phl: Phlebitis, D: Diafragmatic dysfunction, RI: Renal insufficiency; BP: brachial plexopathy; PM: Pacemaker implantation, Phre: Phrenic nerve injury, PCA: Percutaneous Catheter Ablation. Late: PM: Pacemaker implantation, RH: Re-hospitalization C-MZ: Cox Maze procedure; CVA: Cerebrovascular Vascular Accident, PCA: Percutaneous Catheter Ablation, ACC : Anticoagulation Complications, PP: Post-perdicardiotomy syndrome, INF: Infection; Esoph: Esophagitis He : Portal hernia, TEE: Thromboembolic event, ns: not specified (n of events [time]).

* during reoperation for bleeding a tricuspid-vena cava inferior isthmus ablation was performed in one of these pts. $\uparrow$ referring to the some patients. 


\section{Figure Legends}

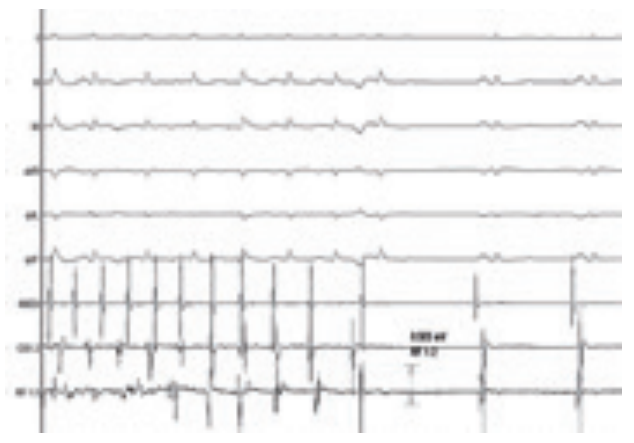

Figure 1. Hybrid procedure: conversion to sinus rhythm during epicardial ablation of the right superior ganglionated plexi (GP). 


\section{References}

1. McCarthy PM, Gillinov AM, Castle L, Chung M, Cosgrove D 3rd.. The Cox-Maze procedure: the Cleveland Clinic experience. Semin Thorac Cardiovasc Surg. 2000; 12: $25-9$.

2. Prasad SM, Maniar HS, Camillo CJ, Schuessler RB, Boineau JP, Sundt TM III et al. The Cox maze III procedure for atrial fibrillation: long-term efficacy in patients undergoing lone versus concomitant procedures. J Thorac Cardiovasc Surg 2003; 126: $1822-8$.

3. Pappone C, Santinelli V. Atrial fibrillation ablation: state of the art. Am J Cardiol 2005; 96: 59L-64L.

4. Calkins H, Brugada J, Packer DL, Cappato R, Chen SA, Crijns HJ et al. HRS/EHRA/ECAS expert Consensus Statement on catheter and surgical ablation of atrial fibrillation: recommendations for personnel, policy, procedures and follow-up. A report of the Heart Rhythm Society (HRS) Task Force on catheter and surgical ablation of atrial fibrillation. Europace 2007; 9: 335-79

5. Jais P, Hocini M, Sanders P, Hsu LF, Takahashi Y, Rotter M et al. Long-term evaluation of atrial fibrillation ablation guided by noninducibility. Heart Rhythm 2006; 3: 140-5.

6. Cappato R, Calkins H, Chen SA, Davies W, Iesaka Y, Kalman J, et al. Worldwide survey on the methods, efficacy and safety of catheter ablation for human atrial fibrillation. Circulation 2005; 111: 1100-05.

7. Cappato R, Calkins H, Chen SA, Davies W, Iesaka Y, Kalman J, et al. Updated worldwide survey on the methods, efficacy, and safety of catheter ablation for human atrial fibrillation. Circ Arrhythm Electrophysiol. 2010; 3:32-8.

8. Lall SC, Damiano RJ Jr .Surgical ablation devices for atrial fibrillation. J Interv Card Electrophysiol. 2007; 20: 73-82. 
9. Lee AM, Melby SJ, Damiano RJ Jr. The Surgical Treatment of Atrial Fibrillation. Surg Clin N Am. 2009; 89: 1001-1020

10. Damiano RJ Jr. Surgical ablation of lone atrial fibrillation on the beating heart: the chaos continues. Europace 2010; 12: 297-298.

11. Gerosa G, Bianco R, Buja G, di Marco F. Totally endoscopic robotic-guided pulmonary vein ablation: an alternative method for the treatment of atrial fibrillation. Eur J Cardiothorac Surg. 2004; 26: 450-2.

12. Balkhy HH, Chapman PD, Arnsdorf SE. Minimally invasive atrial fibrillation ablation combined with a new technique for thoracoscopic stapling of the left atrial appendage: case report. Heart Surg Forum. 2004; 7: 353-5.

13. Poa, L. Thoracoscopic ablation for treatment of atrial fibrillation: a 2-port approach. Heart Surg. Forum 2006; 9: e590-e591.

14. La Meir, M., De Roy, L., Blommaert, D, Buche, M. Treatment of lone atrial fibrillation with a right thoracoscopic approach. Ann. Thorac. Surg. 2007; 83, 2244 2245.

15. Loulmet DF, Patel NC, Patel NU, Frumkin WI, Santoni-Rugiu F, Langan MN, et al. First Robotic Endoscopic Epicardial Isolation of the Pulmonary Veins With Microwave Energy in a Patient in Chronic Atrial Fibrillation. Ann Thorac Surg 2004; 78: e24 -5.

16. Charokopos N, Rouska E, Styliadis I, Antonitsis P, Papakonstantinou C, Spanos P. Totally endoscopic microwave ablation for lone atrial fibrillation: an alternative method of treatment. Hellenic J Cardiol. 2006; 47: 377-80.

17. Puskas J, Lin E, Bailey D, Guyton R. Thoracoscopic Radiofrequency Pulmonary Vein Isolation and Atrial Appendage Occlusion. Ann Thorac Surg 2007; 83: 1870-2 18. Li H, Li Y, Sun L, Liu X, Xu C, Han J, et al. Minimally invasive surgical pulmonary vein isolation alone for persistent atrial fibrillation: preliminary results of epicardial atrial electrogram analysis. Ann Thorac Surg. 2008; 86: 1219-25. 
19. Jansens JL, Ducart A, Preumont N, Jottrand M, Stefanidis C, Stoupel E, et al. Pulmonary vein isolation by robotic-enhanced thoracoscopy for symptomatic paroxysmal atrial fibrillation. Heart Surg Forum. 2004; 7: E595-8.

20. Grandmougin D, Tiffet O. Video-assisted thoracoscopic epicardial ablation of left pulmonary veins for lone permanent atrial fibrillation. Interact Cardiovasc Thorac Surg. 2007; 6: 136-8.

21. Lee AM, Clark K, Bailey MS, Aziz A, Schuessler RB, Damiano RJ Jr. A Minimally Invasive Cox-Maze Procedure: Operative Technique and Results. Innovations (Phila). 2010; 5: 281-286.

22. Moten SC, Rodriguez E, Cook RC, Nifong LW, Chitwood WR Jr. New ablation techniques for atrial fibrillation and the minimally invasive cryo-maze procedure in patients with lone atrial fibrillation. Heart Lung Circ. 2007; 16 (Suppl 3): S88-93.

23. Salenger R, Lahey SJ, Saltman AE. The completely endoscopic treatment of atrial fibrillation: report on the first 14 patients with early results. Heart Surg Forum. 2004; 7: E555-8.

24. Wolf RK, Schneeberger EW, Osterday R, Miller D, Merrill W, Flege JB Jr, et al. Video-assisted bilateral pulmonary vein isolation and left atrial appendage exclusion for atrial fibrillation. J. Thorac. Cardiovasc. Surg. 2005; 130: 797-802.

25. Pruitt JC, Lazzara RR, Dworkin GH, Badhwar V, Kuma C, Ebra G. Totally endoscopic ablation of lone atrial fibrillation: initial clinical experience. Ann Thorac Surg. 2006; 81: 1325-30.

26. Edgerton JR, Jackman WM. Minimally invasive pulmonary vein isolation and partial autonomic denervation for surgical treatment of atrial fibrillation. J Interv Card Electrophysiol. 2007; 20: 89-93.

27. McClelland JH, Duke D, Reddy R .Preliminary results of a limited thoracotomy: new approach to treat atrial fibrillation J Cardiovasc Electrophysiol. 2007; 18: 128995. 
28. Koistinen J, Valtonen M, Savola J, Airaksinen J. Thoracoscopic microwave ablation of atrial fibrillation. Interact Cardiovasc Thorac Surg. 2007; 6: 695-8.

29. Pruitt JC, Lazzara RR, Ebra G. Minimally invasive surgical ablation of atrial fibrillation: the thoracoscopic box lesion approach. J Interv Card Electrophysiol. 2007; 20: 83-7.

30. Sagbas E, Akpinar B, Sanisoglu I, Caynak B, Tamtekin B, Oral K, et al. Videoassisted bilateral epicardial pulmonary vein isolation for the treatment of lone atrial fibrillation. Ann Thorac Surg. 2007; 83: 1724-30.

31. Edgerton JR, Edgerton ZJ, Weaver T, Reed K, Prince S, Herbert MA, et al. Minimally invasive pulmonary vein isolation and partial autonomic denervation for surgical treatment of atrial fibrillation. Ann Thorac Surg. 2008; 86: 35-8.

32. Sirak J, Jones D, Sun B, Sai-Sudhakar C, Crestanello J, Firstenberg, M. Toward a definitive, totally thoracoscopic procedure for atrial fibrillation. Ann. Thorac. Surg. 2008; 86: 1960-1964.

33. Wudel JH, Chaudhuri P, Hiller JJ. Video-assisted epicardial ablation and left atrial appendage exclusion for atrial fibrillation: extended follow-up. Ann. Thorac. Surg. 2008; 85: 34-38.

34. Bagge L, Blomström P, Nillsson L, Einarsson GM, Jidèus L, BlomströmLundqvist C. Epicardial off-pump pulmonary vein isolation and vagal denervation improve long-term outcome and quality of life in patients with atrial fibrillation. $\mathrm{J}$ Thorac Cardiovasc Surg 2009; 137: 1265-71.

35. Beyer E, Lee R, Lam BK. Point: minimally invasive bipolar radiofrequency ablation of lone atrial fibrillation: early multicenter results. J. Thorac. Cardiovasc. Surg. 2009; 137: 521-526.

36. Edgerton JR, McClelland JH, Duke D, Gerdisch MW, Steinberg BM, Bronleewe $\mathrm{SH}$, et al. Minimally invasive surgical ablation of atrial fibrillation: six-month results. J Thorac Cardiovasc Surg. 2009; 138: 109-13. 
37. Edgerton RJ, Jackman WM, Mahoney C, Mack MJ. Totally thoracoscopic surgical ablation of persistent atrial fibrillation and long-standing persistent atrial fibrillation using the "Dallas" lesion set. Heart Rhythm 2009; 6: S64-S70.

38. Han FT, Kasirajan V, Kowalski M, Kiser R, Wolfe L, Kalahasty G, et al. Results of a minimally invasive surgical pulmonary vein isolation and ganglionic plexi ablation for atrial fibrillation: single-center experience with 12-month follow-up. Circ Arrhythm Electrophysiol. 2009; 2: 370-7.

39. Klinkenberg TJ, Ahmed S, Ten Hagen A, Wiesfeld AC, Tan ES, Zijlstra F, et al. Feasibility and outcome of epicardial pulmonary vein isolation for lone atrial fibrillation using minimal invasive surgery and high intensity focused ultrasound. Europace. 2009; 11: 1624-31.

40. Castellá M, Pereda D, Mestres CA, Gómez F, Quintana E, Mulet J. Thoracoscopic pulmonary vein isolation in patients with atrial fibrillation and failed percutaneous ablation. J Thorac Cardiovasc Surg. 2010; 140: 633-8.

41. Cui YQ, Li Y, Gao F, Xu CL, Han J, Zeng W, et al. Video-assisted minimally invasive surgery for lone atrial fibrillation: a clinical report of 81 cases. J Thorac Cardiovasc Surg. 2010; 139: 326-32.

42. Edgerton JR, Brinkman WT, Weaver T, Prince SL, Culica D, Herbert MA, et al. Pulmonary vein isolation and autonomic denervation for the management of paroxysmal atrial fibrillation by a minimally invasive surgical approach. J Thorac Cardiovasc Surg. 2010; 140: 823-8.

43. Sirak J, Jones D, Schwartzman D The five-box thoracoscopic maze procedure. Ann Thorac Surg. 2010; 90: 986-9.

44. Speziale G, Bonifazi R, Nasso G, Bartolomucci F, Caldarola P, Fattouch K, et al. Minimally invasive radiofrequency ablation of lone atrial fibrillation by monolateral right minithoracotomy: operative and early follow-up results. Ann Thorac Surg. 2010; 90: 161-7. 
45. Stamou SC, Khabbaz KR, Mahmood F, Zimetbaum P, Hagberg RC .A multidisciplinary approach to the minimally invasive pulmonary vein isolation for treatment of atrial fibrillation. Ann Thorac Surg. 2010; 89: 648-50. 221.

46. Yilmaz A, Geuzebroek GS, Van Putte BP, Boersma LV, Sonker U, De Bakker $\mathrm{JM}$, et al. Completely thoracoscopic pulmonary vein isolation with ganglionic plexus ablation and left atrial appendage amputation for treatment of atrial fibrillation. Eur J Cardiothorac Surg 2010; 38: 356-60.

47. Krul SP, Driessen AH, van Boven WJ, Linnenbank AC, Geuzebroek GS, Jackman WM, et al. Thoracoscopic video-assisted pulmonary vein antrum isolation, ganglionated plexus ablation, and periprocedural confirmation of ablation lesions: first results of a hybrid surgical-electrophysiological approach for atrial fibrillation. Circ Arrhythm Electrophysiol. 2011; 4: 262-70.

48. La Meir M, Gelsomino S, Luca F, Pison L, Chambille P, Parise O, et al. Timerelated prevalence of postoperative atrial fibrillation after stand-alone minimally invasive radiofrequency ablation. J Card Surg. 2011; 26: 453-9.

49. Nasso G, Bonifazi R, Del Prete A, Del Prete G, Lopriore V, Bartolomucci F, et al. Long-term results of ablation for isolated atrial fibrillation through a right minithoracotomy: toward a rational revision of treatment protocols. J Thorac Cardiovasc Surg. 2011; 142: e41-6.

50. Wang JG, Li Y, Shi JH, Han J, Cui YQ, Luo TG, et al. Treatment of long-lasting persistent atrial fibrillation using minimally invasive surgery combined with irbesartan. Ann Thorac Surg.1011; 91: 1183-90.

51. Chambers PW. Lone atrial fibrillation: Pathologic or not? Med Hypotheses 2007; 68: $281-7$.

52. European Heart Rhythm Association; Heart Rhythm Society, Fuster V, Rydén LE, Cannom DS, Crijns HJ, Curtis AB, Ellenbogen KA, et al. ACC/AHA/ESC 2006 guidelines for the management of patients with atrial fibrillation: a report of the American College of Cardiology/American Heart Association Task Force on Practice 
Guidelines and the European Society of Cardiology Committee for Practice Guidelines (Writing Committee to Revise the 2001 Guidelines for the Management of Patients With Atrial Fibrillation). J Am Coll Cardiol. 2006; 48: 854-906.

53. Lévy S, Camm AJ, Saksena S, Aliot E, Breithardt G, Crijns H, et al. Working group on Arrhythmias, Working group on Cardiac Pacing of the European Society of Cardiology, North American Society of Pacing and Electrophysiology. International consensus on nomenclature and classification of atrial fibrillation; a collaborative project of the Working group on Arrhythmias and the Working group on Cardiac Pacing of the European Society of Cardiology and the North American Society of Pacing and Electrophysiology. Europace 2003; 5: 119-22.

54. Camm AJ, Kirchhof P, Lip GY, Schotten U, Savelieva I, Ernst S, et al. Guidelines for the management of atrial fibrillation: the Task Force for the Management of Atrial Fibrillation of the European Society of Cardiology (ESC) Europace 2010; 12: 1360420.

55. Shemin RJ, Cox JL, Gillinov AM, Blackstone EH, Bridges CR. Workforce on Evidence-Based Surgery of the Society of Thoracic Surgeons. Workforce on Evidence-Based Surgery of the Society of Thoracic Surgeons. Guidelines for reporting data and outcomes for the surgical treatment of atrial fibrillation. Ann Thorac Surg. 2007; 83: 1225-30.

56. Lall SC. Damiano RJ Jr. Surgical ablation devices for atrial fibrillation. J Interv Card Electrophysiol. 2007; 20: 73-82

57. Prasad SM, Maniar HS, Schuessler RB, Damiano RJ Jr. Chronic transmural atrial ablation by using bipolar radiofrequency energy on the beating heart. J Thorac Cardiovasc. Surg. 2002; 124: 708-713.

58. Weerasooriya R, Khairy P, Litalien J, Macle L, Hocini M, Sacher F, et al. Catheter ablation for atrial fibrillation: are results maintained at 5 years of follow-up? J Am Coll Cardiol. 2011; 57: 160-6. 
59. Mounsey JP. Recovery from vagal denervation and atrial fibrillation inducibility: effects are complex and not always predictable. Heart Rhythm. 2006; 3: 709-10. 60. Roy D, Talajic M, Dorian P, Connolly S, Eisenberg MJ, Green M, et al. Amiodarone to prevent recurrence of atrial fibrillation. Canadian Trial of Atrial Fibrillation Investigators. N Engl J Med. 2000; 342: 913-20.

61. Gelsomino S, La Meir M, Lucà F, Lorusso R, Crudeli E, Vasquez L,et al. Treatment of lone atrial fibrillation: a look at the past, a view of the present and a glance at the future. Eur J Cardiothorac Surg. 2012 ; Jun;41(6):1284-94.

62. Krul SP, Driessen AH, Zwinderman AH, van Boven WJ, Wilde AA, de Bakker JM, et al. Navigating the mini-maze: Systematic review of the first results and progress of minimally-invasive surgery in the treatment of atrial fibrillation. Int J Cardiol. 2011.doi10.1016/j.ijcard.2011.10.011

63. Walker E, Hernandez AV, Kattan M W. Meta-analysis its strength and limitations. Clev. Clin. J Med.2008; 75: 431-9.

64. Lyman GH, Kuderer NM. The strengths and limitations of meta-analyses based on aggregate data. BMC Med. Res. Method 2005, 5:14

65. Stamou SC, Khabbaz KR, Mahmood F, Zimetbaum P, Hagberg RC.A multidisciplinary approach to the minimally invasive pulmonary vein isolation for treatment of atrial fibrillation. Ann Thorac Surg. 2010; 89: 648-50.

66. Shinbane JS, Lesh MD, Stevenson WG, Klitzner TS, Natterson PD, Wiener I, et al. Anatomic and electrophysiologic relation between the coronary sinus and mitral annulus: implications for ablation of left-sided accessory pathways. Am Heart J. 1998; 135: 93-8.

67. Sauren LD, La Meir M, De Roy L, Pison L, van der Veen FH, Mess WH, et al. Increased number of cerebral emboli during percutaneous endocardial pulmonary vein isolation versus a thoracoscopic epicardial approach. Eur J Cardiothorac Surg. 2009; 36: 833-7. 
68. Pak HN, Hwang C, Lim HE, Kim JS, Kim YH .Hybrid epicardial and endocardial ablation of persistent or permanent atrial fibrillation: a new approach for difficult cases. J Cardiovasc Electrophysiol. 2007 18: 917-23.

69. Mahapatra S, LaPar DJ, Kamath S, Payne J, Bilchick KC, Mangrum, et al. Initial Experience of Sequential Surgical Epicardial- Catheter Endocardial Ablation for Persistent and Long-Standing Persistent Atrial Fibrillation With Long-Term Follow-Up. Ann Thorac Surg 2011; 91: 1890-8.

70. Pison L, La Meir M, van Opstal J, Blaauw Y, Maessen JG, Crijns HJ. Hybrid Thoracoscopic Surgical and Transvenous Catheter Ablation of Atrial Fibrillation. J Am Coll Cardiol. 2011. "In press" 
- $131-$ 


\section{Chapter 3}

Time-Related Prevalence of Postoperative Atrial Fibrillation After Stand-Alone Minimally Invasive Radiofrequency Ablation.

Mark La Meir, Sandro Gelsomino, Fabiana Lucà, Laurent Pison, Pol Chambille, Orlando Parise, Harry J Crijns and Jos G Maessen.

J Card Surg. 2011 Jul;26(4):453-9.

\section{Abstract}

Background and Aim of the Study. We present our results with minimally invasive surgical treatment of lone atrial fibrillation (LAF) employing a radiofrequency (RF) source through a bilateral thoracoscopy

Methods. Between January 2007 and January 2011 twenty-eight consecutive patients (85.7\% male, mean age 67.1 \pm 9.1 years) with LAF underwent videoassisted bilateral radiofrequency (RF) ablation. Fourteen patients (50\%), had paroxysmal, 5 (17.8\%) persistent and 9 (32.2\%) longstanding persistent LAF. All patients were followed-up according the Heart Rhythm Society/ European Heart Rhythm Association/ European Cardiac Arrhythmia Society (HRS/EHRA/ECA) and success/failure was reported as suggested by Society of Thoracic Surgeon (STS) guidelines. Mean follow-up was $27.8 \pm 8.6$ months.

Results. Time-related prevalence of postoperative AF was $4.5 \%$ at 36 months. Success was much more likely in subjects with paroxysmal (3-year prevalence, $0 \%$ ) or persistent (3-year prevalence, $0 \%$ ) than long-standing persistent LAF (3-year prevalence, $8.3 \%$ ). At 36 months the estimated prevalence of anti- 
arrhythmic drugs was $11.3 \%$ (8.8-13.7). No major thrombo-embolic events were detected during the follow up period and 36-month prevalence of Warfarin use was $15.2 \%$ (11.5-18.1). Finally, no patient underwent electrical cardioversion.

Conclusions. This approach yielded satisfactory results with a high degree of safety. Further larger studies are necessary to confirm our findings.

\section{Introduction}

The surgical treatment of lone atrial fibrillation (LAF) has entered a new era with the development of new tools and advanced endoscopic techniques ${ }^{1}$. Similarly, new energy sources have been adopted in an effort to reduce the invasiveness and technical concerns with the original Maze procedure ${ }^{2,3}$. As a result, a plethora of new surgical approaches have been introduced over the last decade $^{4}$. Nonetheless, despite the high number of published cases, we remain far from a standardized surgical approach ${ }^{5}$. In addition, the wide variability in success rates obtained by different Groups ${ }^{6-8}$ has led to a great deal of confusion among both cardiologists and surgeons because of different AF cohorts, energy sources and lesion sets.

Thus, the adoption of common criteria for reporting clinical results after procedures for AF has been encouraged by The Workforce on Evidence Based Surgery of the Society of Thoracic Surgeons (STS) to facilitate the comparison between experiences of various authors treating different cohorts of AF patients, at different times with different techniques ${ }^{9}$.

Therefore, in the present study we report our results with minimally invasive surgical treatment of LAF employing a radiofrequency (RF) source through a bilateral thoracoscopy in terms of time related prevalence of postoperative AF. 
We also analyzed prevalence of anti-arrhythmic medication use, prevalence of anticoagulant use and the cumulative incidence of postoperative cardioversion following the surgical procedure.

\section{Methods}

\section{Patients}

The study followed the World Medical Association guidelines concerning ethical principles for medical research involving human subjects and was approved by the Institutional Ethics Board. All patients gave their informed consent.

Between January 2007 and January 2011 twenty-eight consecutive patients with LAF underwent video-assisted bilateral radiofrequency (RF) ablation for LAF.

Lone atrial fibrillation was defined following American College of Cardiology/American Heart Association/European Society of Cardiology (ACC/AHA/ESC) guidelines ${ }^{10}$ and updated ESC Guidelines were followed to distinguish type of AF and to score the AF-related symptoms (European Heart Rhythm Association [EHRA] score $)^{11}$.

Exclusion criteria were a presence of atrial or left appendage thrombi at transesophageal echocardiography (TEE), 'giant' left atrium (diameter $>65$ $\mathrm{mm}$ ), coronary artery disease, and previous pulmonary or cardiac surgery. Patient characteristics are shown in Table 1.

\section{Assessment of AF}

Patients underwent in-hospital prolonged continuous telemetry monitoring (mean $187 \pm 48$ hours). In case of AF, any episode was recorded and computed 
with the time of occurrence. In case of sinus rhythm (SR) the absence of the event was recorded at the end of any 24-h time. After hospital discharge patients underwent 7-day Holter monitoring (HM). Seven-day HM was performed at 6 months, 1 year and yearly thereafter. Monitoring was performed with an external loop recorder (Del Mar Reynolds, Spacelabs Healthcare, Issaquah, WA, USA) and analyzed with Lifescreen Software (Del Mar Reynolds, Spacelabs Healthcare, Issaquah, WA, USA). For analysis, three rhythms were considered postoperative AF: AF, atrial flutter or atrial tachycardia lasting more than $30 \mathrm{sec}$ after a 3-month blanking period. In addition, for the analysis of AF postoperative prevalence, all electrocardiograms (ECG) performed at the discretion of referring physicians during follow-up in the time comprised between Holter examinations were included when patients had at least two records available for analysis. Each telemetry record, ECG and Holter was treated as a discrete data (presence/absence of atrial fibrillation). A total of 392 postoperative Holter/ ECG data were retrieved.

Thirteen patients (46.4\%) reached 36-month follow up, 11 (39.3\%) reached 24month and 4 (14.3\%) 12-month follow up. Thus, patients available at follow up at 12, 24 and 36 months were 28, 24 and 13, respectively. Mean Follow-up time was $27.8 \pm 8.6$ months. All patients were followed-up according the Heart Rhythm Society/ European Heart Rhythm Association/ European Cardiac Arrhythmia Society (HRS/EHRA/ECA) expert consensus statement on catheter and surgical ablation of $\mathrm{AF}^{12}$. Data and outcomes were reported following the Society of Thoracic Surgeon (STS) guidelines ${ }^{9}$. 


\section{Anticoagulation and Anti-arrhythmic Therapy}

Anti-arrhythmic drugs were given postoperatively to all patients but, although we recommend discontinuing anti-arrhythmic drugs 3 months after ablation if the patients appears to be AF free, continued use is at the discretion of the referring cardiologists.

Electrical cardioversion was not attempted for patients who remained in $\mathrm{AF}$ after the surgical procedure and was reserved for patients who were still in AF after 3 and 6 months.

Warfarin was administered on postoperative day I with INR target of 2.5.and stopped after 3 months if two following Holter recordings showed a SR or patients had a low thromboembolic risk and a $\mathrm{CHADS}_{2}$ [cardiac failure, hypertension, age, diabetes, stroke (doubled)] score $<2{ }^{12}$.

\section{Echocardiography}

Patients underwent an echocardiography control at follow-up appointments. Measurements were carried out following accepted Guidelines ${ }^{13}$. Left ventricular volume and LV ejection fraction (LVEF) were assessed by the biapical Simpson disk method ${ }^{14}$. Echocardiographic measurements were averaged over three cardiac cycles.

\section{Surgery}

Indication for surgery was based on the HRS/EHRA/ECA Guidelines ${ }^{15}$. The interventions were performed under general anesthesia with a double-lumen endotracheal tube for selective lung ventilation. All operations were performed by the same cardiac surgeon (M.L.M).

The chest was entered in the second, fourth and sixth interspaces using respectively a 5-12-12 $\mathrm{mm}$ port. Thoracoscopy of the right side was done first 
the phrenic nerve on the right and posterior to the phrenic nerve on the left. The technique was as originally described by Yilmaz et $\mathrm{al}^{16}$.

The rhythm was determined by placing a bipolar pen probe (Atricure Inc, Westchester, Ohio, USA) on the left atrium, and recordings were made with a physiological recorder ${ }^{17}$.

Autonomic ganglia were identified by high-frequency stimulation to detect a vagal response at 20 predetermined epicardial sites around the pulmonary vein antra. Ganglionated plexi (GP) mapping was performed by placing the bipolar pen at each site and stimulating with an $18-\mathrm{mV}, 1.5-\mathrm{ms}$ pulse width impulse at 1000 pulses per minute from a temporary external pacemaker. A positive response to GP stimulation was defined as prolongation of the RR interval by $\geq 50 \%$.

Ablation of the right and left PVs was performed using a bipolar radiofrequency clamp (Atricure, Westchester, OH, USA). With the clamp placed on the antrum of the pulmonary veins, 3 to 6 ablations were performed (mean $3.8 \pm 0.9$ ). The end point for pulmonary vein ablation was entrance and exit block into and from the pulmonary veins. Entrance block was defined as failure to capture the pulmonary veins during pacing from the left atrium at 7.5 $\mathrm{V}$ and 1.5-ms pulse width. Exit block was defined by failure to capture the left atrium when pacing from the pulmonary veins distal to the radiofrequency lesions at $7.5 \mathrm{~V}$ and 1.5 -ms pulse width. A proprietary algorithm terminated radiofrequency energy (maximum, $28 \mathrm{~W}$ ) after impedance changes indicated transmural injury. GPs were mapped before and after ablation of the pulmonary venous antrum. Bipolar radiofrequency energy at $15 \mathrm{~W}$ was delivered through the bipolar pen at sites demonstrating a vagal response. The end point for GP ablation was the elimination of a vagal response to stimulation. 
Connecting lesions, the roof and inferior lines, were created using the Coolrail and/or the Max5 Pen (Coolrail, Atricure Inc, Westchester, Ohio, USA).The lesions were tested after completion of both lines by pacing inside the isolated posterior left atrium and confirming exit block.

The ligament of Marshall was ablated with radiofrequency energy or cauterized proximally and distally and then ablated with radiofrequency energy. LAA exclusion/ closure was performed under transesophageal echocardiographic (TEE) guidance in patients with $\mathrm{CHADS}_{2}$ score $\geq 1$, and when it was deemed safe. Indeed, the left atrial appendage (LAA) was excised in 7 patients $(25 \%)$ employing a stapler (Endo GIA, Covidien, Norwalk, CT) or, in 7 patients $(25 \%)$ the base of the LAA was closed employing a clip (Atricure, West Chester, $\mathrm{OH})$. The absence of flow was confirmed by intraoperative transesophageal echocardiography.

The lesion set is shown in Table 2 .

An inferior vena cava (IVC)-to-superior vena cava (SVC) lesion was added when patients had a right atrial volume higher than normal $(58 \mathrm{ml})$ and were persistent or longstanding persistent.

An IVC circumferential isolation was performed in two cases (7.1\%) to be sure that the SVC - IVC line would stop at an area of no conduction - this for patients with a small portion of intra-pericardial IVC. A SVC circumferential isolation was carried out in three cases (10.7\%). The isolation of the SVC and the IVC was confirmed by testing of the conduction block across the ablation line. The completeness of the SVC/IVC line could not be tested in the operating room because of the technical difficulty of proving this without using multipolar electrophysiology (EP) catheters and EP analyzing equipment. Mean operation time was 127 minutes ( range 102 to 174 minutes). 


\section{Data Analysis}

Parametric value was expressed as mean \pm 1 standard deviation (SD), non parametric value as median and interquartile range (IQR) and categorical variables as percentages. Normally distributed variables were compared with paired-t test, non-parametric data were compared with Wilcoxon test while McNemar's test was employed to compare paired categorical data.

Because there is no practical method for continuous lifelong heart rhythm assessment, and self-reported AF underestimates its occurrence ${ }^{18}$, we report prevalence AF which was depicted versus time based on discrete Holter and ECG recordings as suggested by STS Guidelines ${ }^{9}$.We analyzed all of the intermittent data available in terms of time-related prevalence of atrial fibrillation with a multiphase hazard decomposition method ${ }^{19}$. Non-time-related event data and time-related prevalences are presented as percentages with asymmetric $68 \%$ confidence limits (CLs), comparable to \pm 1 standard error. The CLs for AF prevalence were obtained with the bootstrap percentile method ${ }^{20}$. Analyses of prevalence of AF do not account for anti-arrhythmic medications. Prevalence of anti-arrhythmic medication use was estimated by mixed modelling based on medication use at each follow-up assessment ${ }^{21}$.With the same method we estimated the prevalence of Warfarin use at time of each follow-up. Finally, the use of electrical cardioversion was analyzed as repeated event and is presented as cumulative incidence (events per patient) ${ }^{21}$.

Statistical analyses were performed using SPSS release 12.0 (SPSS, Chicago, IL, USA) and Curve Expert Professional release1.0.1 (D.G. Hyams, Chattanooga, TN, USA).

$P$ values less than 0.05 were considered significant. 


\section{Results}

There was no pulmonary vein injury, mortality, stroke or reoperation for bleeding All the procedures could be completed as planned without any conversion to sternotomy, There were no requirement for blood transfusion. Median Intensive care unit (ICU) stay was 6.7 hours (IQR 4.3-13.9) and the median in-hospital length of stay was 8 days (IQR 6-9).

Time-related prevalence of postoperative AF peaked at $33.0 \%(30.7-36.9)$ at two weeks, it was $24.1 \%(21.7-28.3)$ at one month, fell to $6.2 \%(11.6-18.1)$ at 3 months, $6.0 \%(3.2-9.6)$ at 12 months, $5.0(2.9-8.2)$ at 24 months and $4.5 \%$ (2.2-7.6) at 36 months (Figure $1 \mathrm{~A}$ ).

Figure $1 \mathrm{~B}$ shows estimated prevalence of postoperative atrial fibrillation by AF type. In patients with long-standing persistent AF it peaked at $47.8 \%$ (44.7$51.2)$ at two weeks, it was $42.2 \%$ (39.7-45.4) at one month, $29.2 \%$ (26.4-33.6) at 3 months, $14.9 \%(11.6-18.3)$ at 12 months, and it fell to $91 . \%(6.2-12.5)$ at 24 months and to $8.3 \%(5.7-10.9)$ at 36 months (at any interval, $\mathrm{p}<0.001 \mathrm{vs.}$ preoperative AF prevalence).In Persistent and paroxysmal LAF, postoperative AF time-related prevalence peaked at 1 week at $11.3 \%(8.3-13.1)$ and $5.3 \%$ ( $2.8-6.1$ ), respectively. In both groups it and it fell to $0 \%$ thereafter ( $\mathrm{p}<0.001 \mathrm{vs}$. preoperative prevalence).

At 36 months the estimated prevalence of anti-arrhythmic drugs was $11.3 \%$ (8.8-13.7). No major thromboembolic events were detected during the follow up period and 36-month prevalence of Warfarin use was $15.2 \%$ (11.5-18.1). Finally, no patient underwent electrical cardioversion (cumulative incidence, $0 /$ patient).

The echocardiographic control showed a significant reduction in left atrial (LA) size $(41.6 \pm 5.7 \mathrm{~mm}$ vs. $37.7 \pm 7.1 \mathrm{~mm}, \mathrm{p}=0.04)$, LA volume $(68.28 \pm 20.5 \mathrm{ml}$ vs. 
$46.06 \pm 14.6 \mathrm{ml}, \mathrm{p}=0.007)$, right atrial $(\mathrm{RA})$ size $(60.2 \pm 18.7 \mathrm{~mm}$ vs. 45.3 $\pm 18.9 \mathrm{~mm}, \mathrm{p}<0.001)$ and an increment in left ventricular ejection fraction $(52.5$ $\pm 5.1 \%$ vs. $63.2 \pm 43, \mathrm{p}=0.009)$.

\section{Comments}

In the last few years the number of patients with lone AF considered as candidates for a stand-alone surgical procedure has been increasing. Minimally invasive video-assisted thoracoscopic surgical techniques, which enables surgical treatment of AF through an epicardial approach on a beating heart, have been recently introduced.

The MAZE procedure yielded excellent results ${ }^{22,23}$, but the acceptance of this technique for patients with LAF has not been universal because of its invasive nature. Furthermore, percutaneous ablation techniques, which have become the second line strategy for patients with lone AF, have certain disadvantages. Major complications such as pulmonary vein stenosis, thromboembolism, and atrio-esophageal fistula have been reported in more than $6 \%$ of cases, and the need for a second or third procedure is not uncommon ${ }^{24,25}$. Moreover, a worldwide survey on the methods, efficacy and safety of catheter ablation in $\mathrm{AF}$,published in $2005^{26}$ and updated in $2010^{27}$, showed that the success rate without anti-arrhythmic drugs was $75 \%$ for paroxysmal AF, $65 \%$ for persistent and $63 \%$ for permanent $\mathrm{AF}$.

The minimally invasive approach can be a monolateral ${ }^{6-8}$ or bilateral $^{28,29}$ depending on the surgeons' preference as well as the ablation devices chosen. A single-sided approach is less traumatic but only monopolar devices will be used and, due to the properties of these devices on the beating heart, only a significant delay can be obtained and not a bi-directional conduction block. In 
contrast, bipolar radiofrequency clamps guarantee transmural and continuous lesions, and the bipolar approach allows the surgeon to exclude/close the left atrial appendage. On the other hand, the procedure is more invasive and it increases the possibility of complications (bleeding, phrenic nerve lesion, pulmonary complications).

The current literature is extremely difficult to interpret. This confusion is compounded by a lack of consensus on methods and timing of follow-up evaluation as well as the absence of strict definitions of success.

The Workforce on Evidence-Based Surgery of the Society of Thoracic Surgeons ${ }^{9}$ proposed an approach to report success/failure. They suggested analyzing all the intermittent data available in terms of time-related prevalence (burden) of atrial fibrillation.

In the present study we report our results with minimally invasive surgical treatment of LAF employing a radiofrequency (RF) source through a bilateral thoracoscopy in terms of time related prevalence of postoperative AF. Adopting this method, time-related prevalence of postoperative AF after bilateral minimally invasive RF ablation was, in our experience, $4.5 \%$ at 36 months. Success was much more likely in subjects with paroxysmal (3-year prevalence, $0 \%$ ) or persistent (3-year prevalence, $0 \%$ ) than long-standing persistent LAF (3-year prevalence, $8.3 \%$ ).

These results compare favorably with data reported in the literature, although these were obtained with different methods. Indeed, excluding case reports, success expressed as number/percentage of patients in sinus rhythm after videoassisted radiofrequency bilateral pulmonary vein isolation ranged from $72 \%$ to $90 \%$ with a maximum follow up of $18.1 \pm 4.1$ months $^{30-35}$. In two recently published papers, Yilmaz and coworkers ${ }^{36}$ (30 pts.) and Sirak et al ${ }^{8}$ (48 pats.) reported 12 -month freedom from $\mathrm{AF}$ of $77 \%$ and $94 \%$, respectively. 
MacClelland and coworkers ${ }^{31}$ reported, at a mean follow-up of $20.6 \pm 4$ months, a success rate of $91 \%, 80 \%$ and $25 \%$, in subjects with paroxysmal, persistent and long-persistent $\mathrm{AF}$, respectively.

Analysis of prevalence of AF did not account for anti-arrhythmic medications used. Prevalence of anti-arrhythmics was reported separately. This figure was, in our experience, $11.3 \%$ at 36 months. The comparison with published data is problematic. Our figures are in keeping with those published in the literature in which the number of patients taking anti-arrhythmic drugs after bilateral thoracoscopic radiofrequency $\mathrm{AF}$ ablation ranges from $7.4 \%$ to $40 \%{ }^{30-39}$.

This procedure demonstrated, in our experience, a high degree of safety with no major complications and no major thrombo-embolic events detected during the follow up period.

Furthermore, the 36-month estimated prevalence of Warfarin use was very low $(15 \%)$ in comparison with published data ${ }^{24,30,31,33}$. In addition, no patient underwent electrical cardioversion and, at latest follow up, the left atrial volume was reduced by $32.5 \%$, the left atrial size by $9.3 \%$ and the right atrial size by $24.5 \%$. Finally, patients showed an increment in LVEF by $16.9 \%$ from the baseline value.

\section{Limitations of the Study}

This study has several limitations which have to be pointed out. First of all, the patient population is small and the follow up interval is short. Larger series, with long-term follow up and comparing different energy sources, are needed to identify the ideal approach for minimally invasive LAF surgical ablation. Furthermore, $50 \%$ of patients in our cohort had paroxysmal AF and this might have influenced our favorable results. 
To overcome this limitation, we analyzed AF prevalences in paroxysmal, persistent and long-persistent patients and compared pre-procedural and postprocedural AF prevalence by AF type.

Larger studies will help to establish whether the bilateral approach and the advantage of removing the LA appendage outweighs the clear advantages of a less traumatic monolateral approach which may be combined with the endocardial ablation in the so called hybrid procedures. The comparison of these results with those of patients using a monopolar radiofrequency clamp and those undergoing hybrid approach will be the subject of ongoing studies. 


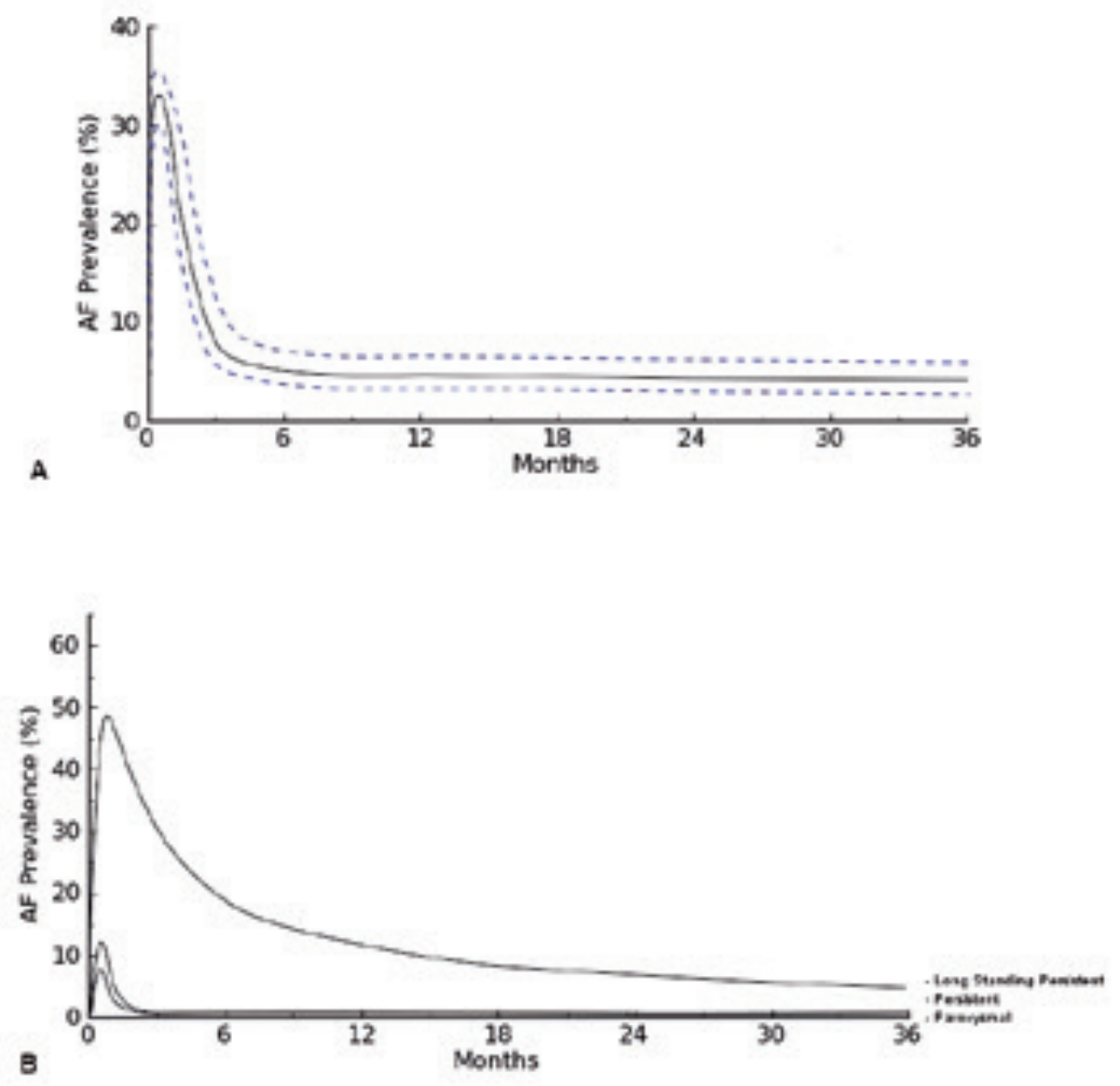

Figure 1.A.Time-related prevalence of Atrial Fibrillation. B. Time-related prevalence of Atrial Fibrillation by AF type .Observations available at each interval ( 1 year, $n=172 ; 2$ years: $n=274 ; 3$ years: $n=392$ ) 

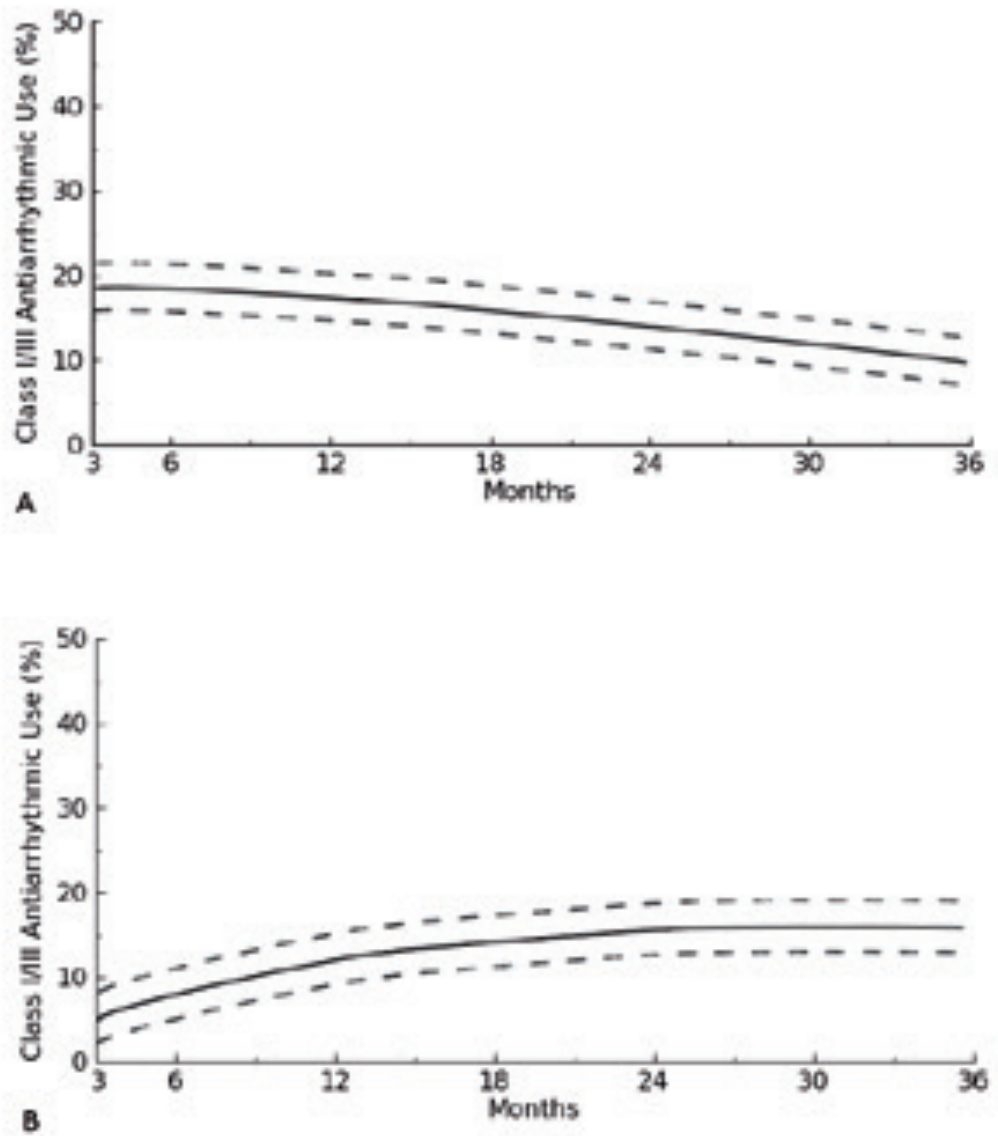

Figure 2. A. Time-related prevalence of class I/III anti-arrhythmic use. B. Time-related prevalence of Warfarin use. 
Table 1. Preoperative Data $(n=28)$

\begin{tabular}{|c|c|}
\hline Age & $67.1 \pm 9.1$ \\
\hline $\mathrm{M} / \mathrm{F}$ & $24 / 11(85.7 / 14.3)$ \\
\hline BMI & $28.6 \pm 3.6$ \\
\hline Diabetes & $0(0)$ \\
\hline Hypertension & $14(50.0)$ \\
\hline \multicolumn{2}{|l|}{ Preoperative catheter ablation } \\
\hline 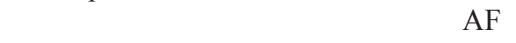 & $13(46.4)$ \\
\hline Flutter & $8(28.5)$ \\
\hline \multicolumn{2}{|l|}{ Type of preoperative AF } \\
\hline Paroxysmal & $14(50.0)$ \\
\hline Persistent & $5(17.8)$ \\
\hline Long-standing persistent & $9(32.2)$ \\
\hline \multicolumn{2}{|l|}{ Prevalence of $\mathrm{AF}^{*}$} \\
\hline Paroxysmal & $21.9\{17.8-24.0\}$ \\
\hline Persistent & $32.7\{28.9-36.2\}$ \\
\hline Long-standing persistent & $68.4\{63.6-72.2\}$ \\
\hline EHRA Score & $3[3-4]$ \\
\hline Duration of preoperative AF (yrs.) & $12.1 \pm 3.7$ \\
\hline \multicolumn{2}{|l|}{ Antiarrhythmic Drugs } \\
\hline Amiodaron & $7(25.0)$ \\
\hline Dysopiramide & $2(7.1)$ \\
\hline Flecainide & $16(57.1)$ \\
\hline Propaphenon & $1(3.5)$ \\
\hline Sotalol & $11(39.2)$ \\
\hline Electrical cardioversion & $14(50.0)$ \\
\hline Medical conversion & $9(32.1)$ \\
\hline \multicolumn{2}{|l|}{ Previous Catheter Ablation } \\
\hline For AF & $13(46.4)$ \\
\hline For Atrial Flutter & $8(28.5)$ \\
\hline Previous Cardiac Surgery & $0(0)$ \\
\hline Previous PTCA & $0(0)$ \\
\hline Preoperative Pace Maker & $2(7.1)$ \\
\hline \multicolumn{2}{|l|}{ Anticoagulant status } \\
\hline Sodium Warfarin & $25(89.2)$ \\
\hline Aspirin & $6(21.4)$ \\
\hline LA diameter & $42.2 \pm 5.2$ \\
\hline LA Volume & $80.9 \pm 25.7$ \\
\hline LVEF & $60.1 \pm 7.1$ \\
\hline
\end{tabular}

Data are presented as mean \pm 1 standard deviation or median [Interquartile ranges]. Discrete data are expressed as numbers (percentages). Abbreviations: M/F: Male/Female; BMI: Body Mass Index; AF: Atrial fibrillation; EHRA: European Heart Rhythm Association; LVEF: Left Ventricular Ejection Fraction.* Reported with 68\% CI. 
Table 2. LAF Surgery: Lesion Set

\section{Left atrium}

$\begin{array}{rc}\text { Right PV Isolation } & 28(100) \\ \text { Left PV Isolation } & 28(100) \\ \text { Connection inferior PVs } & 28(100) \\ \text { Connection superior PVs } & 28(100) \\ \text { Excision of LAA } & 7(25) \\ \text { Closure of LAA with a clip } & 7(25)\end{array}$

Right atrium

SVC to IVC lesion

SVC circumferential isolation

$3(10.7)$

IVC circumferential isolation

$2(7.1)$

Autonomic ganglia

Mapping of autonomic ganglia

Ablation of autonomic Ganglia

28(100)

Data are presented as number (percentage). Abbreviations: PV: Pulmonary vein; LAA: Left atrial appendage; SVC:

Superior Vena Cava; SVC: Superior Vena Cava. 


\section{References}

1. Shen J, Bailey M, Damiano RJ. Surgery for Lone Atrial Fibrillation: Present State-of-the-Art. Innovations (Phila) 2009;4(5):248-255.

2. Shelly C. Lall \& Ralph J. Damiano Jr. Surgical ablation devices for atrial fibrillation. J Interv Card Electrophysiol 2007; 20:73-82

3. Comas GM, Imren Y, Williams MR. An overview of energy sources in clinical use for the ablation of atrial fibrillation. Semin Thorac Cardiovasc Surg 2007 ;19(1):16-24.

4. Khargi K, Hutten BA, Lemke B, et al. Surgical treatment of atrial fibrillation; a systematic review. Eur J Cardiothorac Surg 2005 Feb;27(2):258-65.

5. Damiano RJ. Surgical Ablation of lone atrial fibrillation on the beating heart: the chaos continues. Europace 2010; 12: 297-298.

6. Edgerton JR, Edgerton ZJ, Weaver T, et al. Minimally invasive pulmonary vein isolation and partial autonomic denervation for surgical treatment of atrial fibrillation. Ann Thorac Surg 2008; 86(1):35-8.

7. Pruitt JC, Lazzara RR, Ebra G. Minimally invasive surgical ablation of atrial fibrillation: the thoracoscopic box lesion approach. J Interv Card Electrophysiol. 2007; 20(3):83-7.

8. Sirak J, Jones D, Schwartzman D. The five-box thoracoscopic maze procedure. Ann Thorac Surg. 2010 Sep; 90(3):986-9.

9. Shemin RJ, Cox JL, Gillinov AM, et al. Workforce on Evidence-Based Surgery of the Society of Thoracic Surgeons.Guidelines for reporting data and outcomes for the surgical treatment of atrial fibrillation. Ann Thorac Surg. 2007;83(3):1225-30. 
10. Fuster V, Rydén LE, Cannom DS, et al. ACC/AHA/ESC 2006 guidelines for the management of patients with atrial fibrillation: a report of theAmerican College of Cardiology/American Heart Association Task Force on Practice Guidelines and the European Society of Cardiology Committee for Practice Guidelines (Writing Committee to Revise the 2001 Guidelines for the Management of Patients With Atrial Fibrillation). J Am Coll Cardiol. 2006;48(4):854-90

11. Fuster V, Rydén LE, Cannom DS, et al. ACC/AHA/ESC 2006 guidelines for the management of patients with atrial fibrillation: a report of the American College of Cardiology/American Heart Association Task Force on Practice Guidelines and the European Society of Cardiology Committee for Practice Guidelines (Writing Committee to Revise the 2001 Guidelines for the Management of Patients With Atrial Fibrillation). J Am Coll Cardiol 2006; 48: 854-890.

12. Camm AJ, Kirchhof P, Lip GY, et al. Guidelines for the management of atrial fibrillation: the Task Force for the Management of Atrial Fibrillation of the European Society of Cardiology (ESC). Europace 2010; 12: 1360-1420. 13. Lang RM, Bierig M, Devereux RB, et al. (2006). American Society of Echocardiography's Nomenclature and Standards Committee; Task Force on Chamber Quantification; American College of Cardiology Echocardiography Committee; American Heart Association; European Association of Echocardiography, European Society of Cardiology: Recommendations for chamber quantification.Eur J Echocardiogr 2006; 7: 79-108.

14. Schiller NB, Shah PM, Crawford M, et.al. Recommendations for quantitation of the left ventricle by two-dimensional echocardiography. American Society of Echocardiography Committee on Standards, 
Subcommittee on Quantitation of Two-Dimensional Echocardiograms. J Am Soc Echocardiogr.1989; 2:358-367.

15. Calkins H, Brugada J, Packer DL, et al. HRS/EHRA/ECAS expert consensus statement on catheter and surgical ablation of atrial fibrillation: recommendations for personnel, policy, procedures and follow-up. Heart Rhythm. 2007;4:816-861.

16. Yilmaz A, Van Putte BP, Van Boven WJ. Completely thoracoscopic bilateral pulmonary vein isolation and left atrial appendage exclusion for atrial fibrillation. J Thorac Cardiovasc Surg. 2008;136:521-22.

17. Katritsis D, Ioannidis JP, Anagnostopoulos CE, et al. Identification and catheter ablation of extracardiac and intracardiac components of ligament of Marshall tissue for treatment of paroxysmal atrial fibrillation. J Cardiovasc Electrophysiol. 2001;12:750 -758.

18. Pacifico A, Henry PD. Ablation for atrial fibrillation: are cures really achieved? J Am Coll Cardiol 2004; 43: 1940-1942.

19. Blackstone EH, Naftel DC, Turner ME Jr. The decomposition of timevarying hazard into phases, each incorporating a separate stream of concomitant information. J Am Stat Assoc 1986; 81:615-624.

20. Efron B, Tibshirani RJ. An introduction to the bootstrap. New York, NY: Chapman and Hall/CRC;1998

21. Gillinov AM, Bhavani S, Blackstone EH, et al. Surgery for permanent atrial fibrillation: impact of patient factors and lesion set. Ann Thorac Surg 2006;82: 502-513.

22. Prasad SM, Maniar HS, Camillo CJ, et al. The Cox maze III procedure for atrial fibrillation: long-term efficacy in patients undergoing lone versus concomitant procedures. J Thorac Cardiovasc Surg. 2003;126:1822-1827. 
23. Damiano RJ Jr, Voeller RK. Biatrial lesion sets. J Interv Card Electrophysiol. 2007;20:95-99.

24. Pappone C, Oral H, Santinelli F, et al. Atrio-esophageal fistula as a complication of percutaneous transcatheter ablation of atrial fibrillation. Circulation 2004;109:2724-7.

25. Scanavacca MI, D’Acila A, Parga J, et al. Left atrioesophageal fistula following radiofrequency catheter ablation of atrial fibrillation. J Cardiovasc Electrophysiol 2004;15:960-2.

26. Cappato R, Calkins H, Chen SA, et al. Worldwide survey on the methods, efficacy and safety of catheter ablation for human atrial fibrillation. Circulation 2005; 111: 1100-05.

27. Cappato R, Calkins H, Chen SA, et al. Second worldwide survey on the methods, efficacy and safety of catheter ablation for AF. Updated worldwide survey on the methods, efficacy, and safety of catheter ablation for human atrial fibrillation. Circ Arrhythm Electrophysiol. 2010;3(1):32-8.

28. La Meir M., De Roy L., Blommaert, D, et al. Treatment of lone atrial fibrillation with a right thoracoscopic approach. Ann. Thorac. Surg. 2007; 83, 2244-2245.

29. Gerosa G, Bianco R, Buja G, et al. Totally endoscopic robotic-guided pulmonary veins ablation: an alternative method for the treatment of atrial fibrillation. Eur J Cardiothorac Surg. 2004;26(2):450-2.

30. Sagbas E, Akpinar B, Sanisoglu I, et al.Video-assisted bilateral epicardial pulmonary vein isolation for the treatment of lone atrial fibrillation.Ann Thorac Surg. 2007;83(5):1724-30. 
31. Wudel JH, Chaudhuri P, Hiller JJ. Video-assisted epicardial ablation and left atrial appendage exclusion for atrial fibrillation: extended follow-up. Ann. Thorac. Surg.2008; 85, 34-38.

32. Edgerton JR, Edgerton ZJ, Weaver T, et al. Minimally invasive pulmonary vein isolation and partial autonomic denervation for surgical treatment of atrial fibrillation.Ann Thorac Surg. 2008; 86(1):35-8

33. Li H, Li Y, Sun L, Liu X, et al. Minimally invasive surgical pulmonary vein isolation alone for persistent atrial fibrillation: preliminary results of epicardial atrial electrogram analysis. Ann Thorac Surg. 2008; 86(4):1219-25.

34. Beyer E, Lee R, Lam BK. Point: minimally invasive bipolar radiofrequency ablation of lone atrial fibrillation: early multicenter results. J. Thorac. Cardiovasc. Surg. 2009; 137: 521-526.

35. Cui YQ, Li Y, Gao F, et al. Video-assisted minimally invasive surgery for lone atrial fibrillation: a clinical report of 81 cases. J Thorac Cardiovasc Surg. 2010; 139(2):326-32.

36. Yilmaz A, Geuzebroek GS, Van Putte BP, et al. Completely thoracoscopic pulmonary vein isolation with ganglionic plexus ablation and left atrial appendage amputation for treatment of atrial fibrillation. Eur J Cardiothorac Surg 2010; 38:356-60.

37. McClelland JH, Duke D, Reddy R. Preliminary results of a limited thoracotomy: new approach to treat atrial fibrillation J Cardiovasc Electrophysiol. 2007 ;18(12):1289-95.

38. Wolf RK, Schneeberger EW, Osterday R, et al. Video-assisted bilateral pulmonary vein isolation and left atrial appendage exclusion for atrial fibrillation. J. Thorac. Cardiovasc. Surg. 2005; 130(3):797-802. 
39. Han FT, Kasirajan V, Kowalski M, et al. Results of a minimally invasive surgical pulmonary vein isolation and ganglionic plexi ablation for atrial fibrillation: single-center experience with 12-month follow-up.Circ Arrhythm Electrophysiol. 2009; 2(4):370-7. 


\section{Chapter 4}

The Hybrid Approach for The Surgical Treatment of Lone Atrial Fibrillation: One-year Results Employing a Monopolar Radiofrequency Source.

Mark La Meir, Sandro Gelsomino, Roberto Lorusso, Fabiana Lucà, Laurent Pison, Orlando Parise, Francis Wellens, Gian Franco Gensini and Jos Maessen.

J Cardiothorac Surg. 2012 Jul 19;7:71.

\section{$\underline{\text { Abstract }}$}

Background. The hybrid technique combines a mono or bilateral epicardial approach with a percutaneous endocardial ablation in a single-step procedure. We present our early results with this technique employing a monopolar radiofrequency source through a right thoracoscopy in patients with lone atrial fibrillation (LAF).

Methods. Between June 2009 and December 2010 nineteen consecutive patients (mean $60.8 \pm 8.6$ years, $84.2 \%$ male) underwent right unilateral minimally invasive hybrid procedure for LAF at our Institution. Ten patients (52.6.6\%) had long-standing persistent AF while four (21.1\%) had persistent and five (26.3\%) paroxysmal AF. All patients were followed-up according the Heart Rhythm Society/ European Heart Rhythm Association/ European Cardiac Arrhythmia Society (HRS/EHRA/ECA) and Society of Thoracic Surgeon (STS) guidelines .

Results. There were neither early nor late deaths. It was possible to complete all the procedures as planned without any conversion to cardiopulmonary bypass. No patient died during the follow up. 
At one year, 7/19 (36.8\%) patients were in sinus rhythm with no episode of AF and off anti-arrhythmic drugs (AAD). Time-related prevalence of postoperative AF peaked at $44.4 \%(41.3-47.4)$ at two weeks, was $30.4 \%(27.3-34.9)$ at three months, fell to $14.2 \%(11.6-18.1)$ by 6 months and was $13.3 \%(11.0-17.4)$ at 12 months Among patients with long-standing persistent (LSP) AF, 20\% (2/10) were in Sinus rythm and off AAD . One-year success rates were $50 \%(2 / 4)$ in persistent and $60 \%(3 / 5)$ in paroxysmal AF. At 12 months estimated prevalence of anti-arrhythmic drugs and Warfarin use were 26\% (22.4-33.1) and 48\% (37.253.2), respectively.

Conclusions. One year results combining the percutaneous endocardial with the right thoracoscopic epicardial technique were, in our experience, not satisfactory, particularly in patients with LSP and persistent AF. Our findings need to be confirmed by larger studies.

\section{Background}

Despite being more effective than percutaneous catheter ablation (PCA $)^{1-3}$, the MAZE operation failed to achieve widespread application as a stand-alone procedure because of its complexity and invasiveness. Indeed, the Society for Thoracic Surgeons (STS) database ${ }^{4}$ reported, in 2007, only 700 MAZE operations performed in patients with lone atrial fibrillation (LAF). In addition, along with its suboptimal success rates, PCA showed a non-negligible incidence of major complications ${ }^{3}$.

New technologies have allowed the creation of transmural lesions on a beating heart through alternative, less invasive incisions ${ }^{5}$. Nonetheless, results reported in the literature with these approaches are highly variable ${ }^{6-8}$.

More recently, a sequential one-step surgical / catheter-based approach has been introduced showing satisfactory results in patients with persistent $\mathrm{LAF}^{9}$. This so- 
called hybrid procedure combines the advantages of PCA and video-assisted thoracoscopic epicardial procedures and it is expected to overcome the shortcomings of these techniques ${ }^{10}$.

As originally described, the hybrid technique employs a bilateral thoracoscopic epicardial approach. We have recently introduced a less-invasive hybrid singlesided approach through a right thoracoscopy and, as far as we know, there are no reports in the literature about the effectiveness of this procedure.

Therefore, we present one-year results with minimally invasive hybrid-right thoracoscopic approach employing a monopolar radiofrequency (RF) source for the treatment of LAF.

\section{Methods}

\section{Patients}

Ethical Committee approval was waived according to the National law regulating observational retrospective studies (Dutch WMO law). However, all patients gave their informed consent to access their data for scientific purposes. Between January 2008 and June 2010 nineteen consecutive patients underwent minimally invasive right-thoracoscopic hybrid ablation of LAF employing a monopolar RF source. LAF was defined as suggested by American College of Cardiology/American Heart Association/European Society of Cardiology (ACC/AHA/ESC) Guidelines ${ }^{11}$ and updated ESC Guidelines were followed to distinguish the type of AF and to score the AF-related symptoms (European Heart Rhythm Association [EHRA] score ${ }^{12}$. Indication for minimally invasive surgery was based on the Heart Rhythm Society/ European Heart Rhythm Association/European Cardiac Arrhythmia Society ( HRS/EHRA/ECA) Guidelines ${ }^{13}$. A trans-thoracic echocardiography (TTE) and a computed tomography $(\mathrm{CT})$ scan were carried out preoperatively (pulmonary vein 
anatomy, coronary arteries) and potential candidates for the hybrid procedure underwent a lung function test (spirometry). Exclusion criteria were: 1) Presence of left atrial or left appendage thrombus at transesophageal echocardiography (TEE); 2) "Giant" left atrium (diameter $>6.5 \mathrm{~cm}$ ); 3) Associated coronary artery disease; 4) Previous pulmonary or cardiac surgery.

Patient characteristics are shown in Table 1.

\section{Follow-up and Assessment of AF}

All patients were followed-up according to Heart Rhythm Society/ European Heart Rhythm Association/European Cardiac Arrhythmia Society (HRS/EHRA/ECA) ${ }^{13}$. Main outcomes were also reported following the Society of Thoracic Surgeon (STS) guidelines ${ }^{14}$. After hospital discharge patients underwent 7-day Holter Monitoring (HM) which was repeated at 3 months, 6 months and 1 year. All patients reached 1-year follow up. Monitoring was carried out with an external loop recorder (Del Mar Reynolds, Spacelabs Healthcare, Issaquah, WA,USA) and analyzed with Lifescreen Software (Del Mar Reynolds, Spacelabs Healthcare, Issaquah, WA, USA). For analysis, three rhythms were considered postoperative AF: AF, atrial flutter or atrial tachycardia lasting more than $30 \mathrm{sec}$. In addition, all electrocardiograms (ECG) performed at the discretion of referring physicians/cardiologists during the first three months after surgery and between Holter examinations were included when patients had at least two records available for analysis. Each ECG and Holter was treated as discrete data (presence/absence of atrial fibrillation) to calculate AF estimated prevalence ${ }^{14}$. A total of 222 postoperative Holter/ ECG data were retrieved.

\section{Echocardiography}

Echocardiography was performed preoperatively and at 3 month- and 12 monthfollow-up appointments using a commercially available echocardiographic system (Philips iE33; Philips Medical Systems, Eindhoven, The Netherlands). 
All the parameters were analyzed "off-line" by an experienced echocardiographer (F.L.) using the Xcelera software (Philips Medical Systems Eindhoven, The Netherlands). In the parasternal long-axis views LA maximum antero-posterior (A-P) diameter was measured. LA superior-inferior (S-I) diameter was measured from the mitral annular plane to the posterior wall of the LA in the apical 4-chamber view. In the apical 4-chamber view, LA maximum volume (LA max), at the end of LV systole, just before the opening of the mitral valve and LA minimum volume (LA min) at the end of LV diastole, just after the closure of the mitral valve, were measured ${ }^{15}$. LA emptying fraction $\left(\mathrm{LA}_{\mathrm{EF}}\right)$ was calculated as follows: (LA max-LA min /LA max) x 100.

LA maximum volume was also measured by biplane area-length method ${ }^{16}$ and indexed to body surface area (LAVI). LARR was defined as a reduction in LAVI $\geq 15 \%$ at late follow up ${ }^{17}$.

\section{Anticoagulation and Anti-arrhythmic Therapy}

Anti-arrhythmic drugs (AAD) were given postoperatively to all patients but, although we recommend discontinuing anti-arrhythmics 3 months after ablation if the patients appears to be AF free, continued use is at the discretion of referring cardiologists. Electrical cardioversion was not attempted for patients who remained in $\mathrm{AF}$ after the surgical procedure and was reserved for patients who were still in AF after 6 months. Warfarin was administered on postoperative day II with INR target of 2.5 and stopped after 3 months if the Holter recording showed a sinus rhythm (SR) or patient had a low thromboembolic risk and a $\mathrm{CHADS}_{2}$ [cardiac failure, hypertension, age, diabetes, stroke (doubled)] score $<2$.

\section{Surgical Technique}

The interventions were performed under general anesthesia with a double-lumen endotracheal tube for selective lung ventilation. The chest was entered in the 
second, fourth and sixth interspaces using respectively a 5-12-12mm port. The technique was as previously reported ${ }^{18}$.

High frequency stimulation (HFS) of the right vagal nerve at the level of the mediastinum and at the four major ganglionated plexi (GPS, [right superior GP, right inferior GP, left superior GP and left inferior GP)] was carried out and the vagal response on the atrio-ventricular node was recorded (10V, 1.5-ms pulse width impulse at 1000 pulses per minute from a temporary external pacemaker [Oscor, Oscor INC., Palm Harbor, FL]). The isolation of pulmonary veins was performed with a Cobra ${ }^{\circledR}$ Adhere XL (Estech, Danville, Ca) temperaturecontrolled, monopolar radiofrequency system. The temperature was set at $60^{\circ} \mathrm{C}$, the timing at 120 seconds. The number of ablations performed ranged from 2 to 4 (mean $2.8 \pm 0.4$ ). The ablation catheter was pushed under the superior caval vein $(\mathrm{SCV})$ into the transverse sinus and placed behind the left atrial appendage (LAA) encircling the four PVs to create the box-lesion. Before starting the ablation, the fat pad in the atrial groove was bluntly dissected to provide a better placement of the probe and enhance a higher penetration energy to destroy the GPs located inside this fat pad. After creation of the box lesion the vagal response at level of GPS was tested again. The endpoint for ganglionated plexi (GP) ablation was the elimination of a vagal response to stimulation. In all patients this vagal response could no longer be induced with HFS, except for the right inferior GP which, being located outside the box lesion was not ablated in any patient.

A left femoral vein puncture was made and a HIS bundle catheter (St Jude Medical, Inc, Minnetonka, MN, USA) and a coronary sinus (CS) catheter (Medtronic, Inc, Minneapolis, MN, USA) were placed under fluoroscopic guidance. Through the right femoral vein, a single trans-septal puncture was made using TEE and fluoroscopy and a long sheath 8F (SL0, St. Jude Medical Daig Division, Inc., Minnetonka, MN, USA) was advanced into the LA. The 
patient was heparinzed to keep the activated clotting time $>300$ seconds. During rapid ventricular pacing from the HIS catheter, contrast was injected through the long sheath in order to visualize PVs and the LA. PVs were mapped with a suitably sized circular mapping catheter (Lasso, Biosense Webster, Inc, Diamond. Bar, CA, USA) placed at the ostium of the PVs.

In all patients epicardial pacing and endocardial recordings were utilized to demonstrate entrance and exit block; entrance block was defined as failure to capture the PVs during pacing from the left atrium at $18 \mathrm{~V}$ and 1.5-ms pulse width and the absence of pulmonary vein potentials (PVPs) seen on the Lasso catheter. Exit block was defined by failure to capture the left atrium during the pacing from the PVs and by failure to capture when pacing from each dipole of the Lasso catheter with an output of $10 \mathrm{~mA}$ and $2.0 \mathrm{~ms}$ pulse width.

We identified the conduction gaps from the endocardium which were closed endocardially with a $3.5 \mathrm{~mm}$ tip catheter (ThermoCool, Biosense Webster, Inc., Diamond. Bar, CA, USA) through the sheath in the LA. The precise location of the linear lesions was visualized with the Cobra ${ }^{\circledR}$ Adhere XL (Estech,Danville, $\mathrm{Ca}$ ) in situ and using fluoroscopy. Gaps in linear lesions were defined as low amplitude and fragmented or narrowly split double atrial potentials.

In case of AF persistence, a left isthmus line was made endocardially from the mitral annulus towards the CS employing the ThermoCool catheter (ThermoCool, Biosense Webster, Inc., Diamond. Bar, CA, USA) The endpoint of ablation of the mitral isthmus was the bidirectional block which was achieved when the following criteria were met: 1) proximal-to-distal activation sequence along the CS catheter after pacing lateral to the line in the LA appendage; 2) Late activation on the opposite side after pacing on the septal side of the line through the CS; 3 ) widely separated local double potentials along the whole length of the ablation line. 
Finally, if the patient had a history of typical right atrial flutter or this arrhythmia became apparent during the procedure, we performed a cavotricuspid isthmus line (CTI) endocardially. The endpoint was bidirectional block and the presence of widely separated double potentials along the whole length of the ablation line.

\section{Statistical Analysis}

Normal values were expressed as mean \pm one standard deviation (SD), nonnormal values as median and interquartile range (IQR) and categorical variables as percentages. Student t, Wilcoxon and McNemar's tests were employed where appropriate. We analyzed all the intermittent data available in terms of timerelated prevalence of $\mathrm{AF}^{14}$ with a multiphase hazard decomposition method ${ }^{19}$. Prevalence of AF was presented as percentage with asymmetric $68 \%$ confidence obtained with the bootstrap percentile method $^{20}$.

Analyses of prevalence of AF do not account for anti-arrhythmic medications. Prevalence of anti-arrhythmic medication use was estimated by mixed modeling based on medication use at each follow-up assessment. With the same method we estimated the prevalence of Warfarin use at the time of each follow-up. Finally, the use of electrical cardioversion was analyzed as a repeated event and is presented as cumulative incidence ${ }^{21}$.

Statistical analysis was performed using SPSS release 12.0 (SPSS, Chicago, IL, USA) and Curve Expert Professional release1.0.1 (D.G. Hyams, Chattanooga, TN, USA). P values less than 0.05 were considered significant.

\section{$\underline{\text { Results }}$}

None of the patients showed entrance and/or exit block after the epicardial ablation. Seventeen patients had at least one PV not isolated, which needed an endocardial touch-up (Table 2). After completing endocardial PV isolation the 
entire population had a conduction delay $>200 \mathrm{~ms}$. in the posterior LA but no patient had complete block. Three patients (15.7\%) underwent mitral isthmus line and in all cases a complete block was achieved. A cavo-tricuspid isthmus (CTI) line was carried out in two patients (10.5\%) with successful bidirectional block. All surgical procedures were completed as planned without any conversion to cardiopulmonary bypass. Median operative time was 216 minutes (IQR 132-391). There were neither early deaths nor complications during the postoperative course. Median Intensive care unit (ICU) stay was 6.9 hours [IQR 4.0-14.0] and median in-hospital length of stay was 3.6 days [2.7-4.3].

No patient died during the follow up. There was a significant improvement in median EHRA (European Hear Rhythm Association) score at follow up ( 1[IQR $1-2], \mathrm{p}<0.001$ vs. baseline).

At one year, 7/19 (36.8 \%) patients were in sinus rhythm and off -AAD.

Furthermore, 63.1\% (12/19), patients were free from AF, AFL or AT $>30 \mathrm{~s}$ but still under anti-arrhythmic therapy $(\mathrm{p}=0.1)$.

Time-related prevalence of postoperative AF was $44.4 \%(41.3-47.4)$ at two weeks, $30.4 \%(27.3-34.9)$ at three months, $14.2 \%(11.6-18.1)$ at 6 months and $13.3 \%(11.0-17.4)$ at 12 months (Figure $1 \mathrm{~A})$.

Among patients with long-standing persistent AF, 20\% (2/10) were in SR and off AAD . One-year success rates were $50 \%(2 / 4)$ in persistent and $60 \%(3 / 5)$ in paroxysmal $\mathrm{AF}$.

At 12 months the estimated prevalence of anti-arrhythmic drugs (Figure $2 \mathrm{~A}$ ) was $26 \%$ (22.4-33.1). AAD-prevalences by AF type were $38.1 \%(34.3-43.4)$ for long-standing persistent, $26.3 \%$ (22.2-30.7) for persistent and 14.9\% (9.9-17.8) for paroxysmal AF.

Finally, time-related prevalence of Warfarin (Figure 2 B) at 1 year was $48.2 \%$ (44.2-52.2). This figure was $52.5 \%$ (48.8-55.2) in long-standing persistent, 
$35.3 \%$ (32.5-39.2) in persistent and 19.4\% (16.3-23.3) in paroxysmal AF. The cumulative incidence of electrical cardioversion was $0.05 /$ patient.

\section{LA Function and Remodeling}

Table 3 shows postoperative echocardiographic data. At 3 month- follow-up biplane LAVI was reduced by $16 \%(\mathrm{p}=0.05)$. It further decreased but not significantly at 1 year $(\mathrm{p}=0.09)$. Based on the cut-off value $(\geq 15 \%$ reduction in LAVI) LARR occurred in $47.3 \%(n=9)$ of patients. LA $_{\mathrm{EF}}$ increased not significantly at 3 month- $(p=0.6)$ and at 12 -month- $(p=0.56)$ controls. Finally, LA diameters decreased significantly at 3 months (LA A-P, $p=0.02$; LA S-I $\mathrm{p}=0.03$ ) whereas at one year there was a further reduction which did not reach statistical significance (LA A-P, $p=0.73$; LA S-I $p=0.81$ ).

\section{Discussion}

Minimally invasive surgical epicardial thoracoscopic approaches have gained a growing popularity but data regarding their efficacy are controversial $l^{6-9,22-25}$. The hybrid approach combines, in one step, a thoracoscopic epicardial ablation with a PCA procedure ${ }^{9,26}$.The surgeon, through a thoracoscopy, can isolate the pulmonary veins and the posterior wall of the LA whereas the endocardial "step" offers the possibility of evaluating the endpoints of the ablation and it gives the opportunity to add an endocardial "touch-up" in case of incomplete epicardial PVs isolation. In addition, the electrophysiologist (EP) can make lesions in regions which cannot be reached epicardially. Moreover, this technique may potentially decrease the complication rate of both surgical and catheter ablation procedures. Indeed, from the point of view of the surgeon, the risk of post-operative arrhythmias is reduced since ablation lines and lesion set can be controlled endocardially and the risk of injury is lower, since the EP can make lesions in areas which cannot be easily reached by the surgeon. 
On the other hand, from the EP point of view, there is no risk of phrenic nerve and esophageal injury because these structures can be protected by the surgeon and the possibility of tamponade is low since the pericardium is open. Furthermore, by reducing the total number of endocardial ablations the risk of embolism is potentially reduced ${ }^{27}$.

We present our one-year results with minimally invasive hybrid-right thoracoscopic approach employing a monopolar radiofrequency (RF) source for the treatment of LAF. Little information exists in the literature about the hybrid technique $^{10,29}$ and, to the best of our knowledge, no data exist on the right monolateral monopolar hybrid approach.

The monolateral right-thoracoscopic approach could theoretically reduce the rates of complications (bleeding, pulmonary complications) and significantly shorten patients' recovery time. Nonetheless, only monopolar devices can be used through the right-thoracoscopy because of the lack of maneuverability of bipolar clamps (which can hamper the orientation of the probe and constrain the variety of achievable lesion sets when employed from the right side), but many concerns have been raised regarding the ability of monopolar devices to create transmural lesion with bidirectional conduction block on the beating heart ${ }^{28}$.

This technique demonstrated, in our experience, a high degree of safety with no major complications and no major thrombo-embolic events detected during the follow up period.

Nonetheless, at one year only $36.8 \%(7 / 19)$ patients were in SR and off AAD. Among patients with long-standing persistent AF, 20\% (2/10) were in SR and off AAD .One-year success rates were $50 \%(2 / 4)$ in persistent and $60 \%(3 / 5)$ in paroxysmal AF. Furthermore, at 12 months, the estimated prevalence of antiarrhythmic drugs was $26 \%$ (38.1\% in LSP, $26.3 \%$ in persistent and $14.9 \%$ in paroxysmal AF). The incidence of patients without recurrent AF but with AAD was not significantly lower compared with patients off-AAD $(p=0.1)$ although 
this data must be interpreted taking into account the small number of patients in the study. Therefore, this limitation does not allow us to draw any conclusion about the role of AAD in the development of AF recurrence following minimally invasive surgery.

However, the success rate, in this series, was lower than published papers employing monopolar devices ${ }^{30}$ and it might be explained by the high number of patients with long-standing persistent (LSP) and persistent AF which represent $73.6 \%$ of our cohort. Indeed, LSP and persistent AF may be considered to be advanced stages of the arrhythmia characterized by significant changes in the atrial tissue and muscle (substrate modification) that leads to chaotic electrical activity. Thus, these patients might need more areas in the heart ablated than in the monolateral approach and they might benefit much more from procedures which increase the likelihood that ablation lines are transmural although this aspect may be addressed by the EP who can complete any line by focused endocardial applications. Indeed, in our experience, the incidence of incomplete, non trans-mural gap lesions was high, none of the patients showed entrance and/or exit block after the epicardial ablation and ,after completing PV isolation endocardially, all patients had a conduction delay $>200$ ms. in the posterior LA but no patient had complete block.

With this current knowledge we have stopped using monopolar devices for the surgical treatment of AF, even for patients where a monolateral approach may have a potential advantage i.e. in case of reduced pulmonary function. In these patients we now perform a monolateral approach from the right or left side, depending on the wish to close the LAA, using bipolar devices ${ }^{10}$ and isolating the opposed PVs endocardially with RF energy.

Finally, at latest follow up only $47.3 \%$ of patients experienced LARR and there was no significant improvement in LAVI and LAEF. Due to the small number of patients, we could not compare echocardiographic data by AF type. However, 
again, the high percentage of subjects with LSP or persistent AF reflects a greater extent of substrate modifications and atrial structural remodeling and this could explain the lack of LARR. Indeed, all five patients with paroxysmal AF showed $a \geq 15 \%$ decrease in LAVI.

\section{Limitations of the Study}

This study has some limitations which have to be pointed out. The small patient population and the short follow-up do not allow us to draw definite conclusions . Larger series with long-term follow up are needed.

Second, only a small number of patients in this series underwent right-sided and isthmus lesions and this might have influenced the results.

Third, our study did not compare the hybrid right thoracoscopic approach with the hybrid bilateral thoracoscopic approach to evaluate the real impact of these different techniques on outcome of LAF patients and to evaluate whether the excision of the LAA, besides the management for prevention of thromboembolic events, might have a contribute to different rhythm outcome.

Furthermore we did not compare PCA with surgical thoracoscopic approaches. However, all these aspects will be the subjects of ongoing studies.

Fourth, while data regarding postoperative AF prevalence were obtained from a large number of observations and this allowed us to compare prevalence by $\mathrm{AF}$ type, we could not evaluate LAVI, LAEF and LA diameters in any subgroup of patients.

Finally, atrial function was studied employing only the emptying fraction and neither pulsed-wave Doppler nor Tissue Doppler Imaging (TDI) nor LA strain were employed, which would have given more detailed information about LA function after AF surgical ablation. All these aspects deserve further investigations. 


\section{Conclusions}

One year results combining the percutaneous endocardial with the right thoracoscopic epicardial technique were, in our experience, not satisfactory, particularly in patients with LSP and persistent AF. This approach might still be considered a possible alternative to PCA in selected patients with paroxysmal lone atrial fibrillation and impaired pulmonary function referred to surgery when the LAA excision/ligation is not deemed necessary. Our findings need to be confirmed by larger studies.

\section{Acknowledgments}

We thank Mr. Pol Chambille and Mrs. Monique de Jong for their help in acquisition of data .

\section{List of Abbreviations}

LAF: Lone Atria Fibrillation

PCA: Percutaneous Catheter Ablation

RF: Radiofrequency

LSP: Long-standing persistent

EHRA score: European Heart Rhythm Society score

SCV: Superior caval vein

ICV: Inferior Caval Vein

LAA: Left Atrial Appendage

GP: Ganglionated plexi 
PVs: Pulmonary Veins

CTI: Cavo-tricusoid isthmus (lesions)

CS: Coronary sinus

SR: Sinus Rhythm

EP: Electrophysuologist

LARR: Left Atrial Reverse Remodeling

LAVI: (Biplane) Left atrial volume index

LAMax: Maximum left atrial volume

LAMin: minimum left atrial volume

$\mathrm{LA}_{\mathrm{EF}}$ : Left atrial emptying fraction

LA A-P: Left atrial antero-posterior diameter

LA S-I: Left atrial antero-posterior diameter.

IQR: Interquartile Range

TEE: Transesophageal Echocardiography

TTE: Transthoracic echocardiography 


\section{Figure Legends}
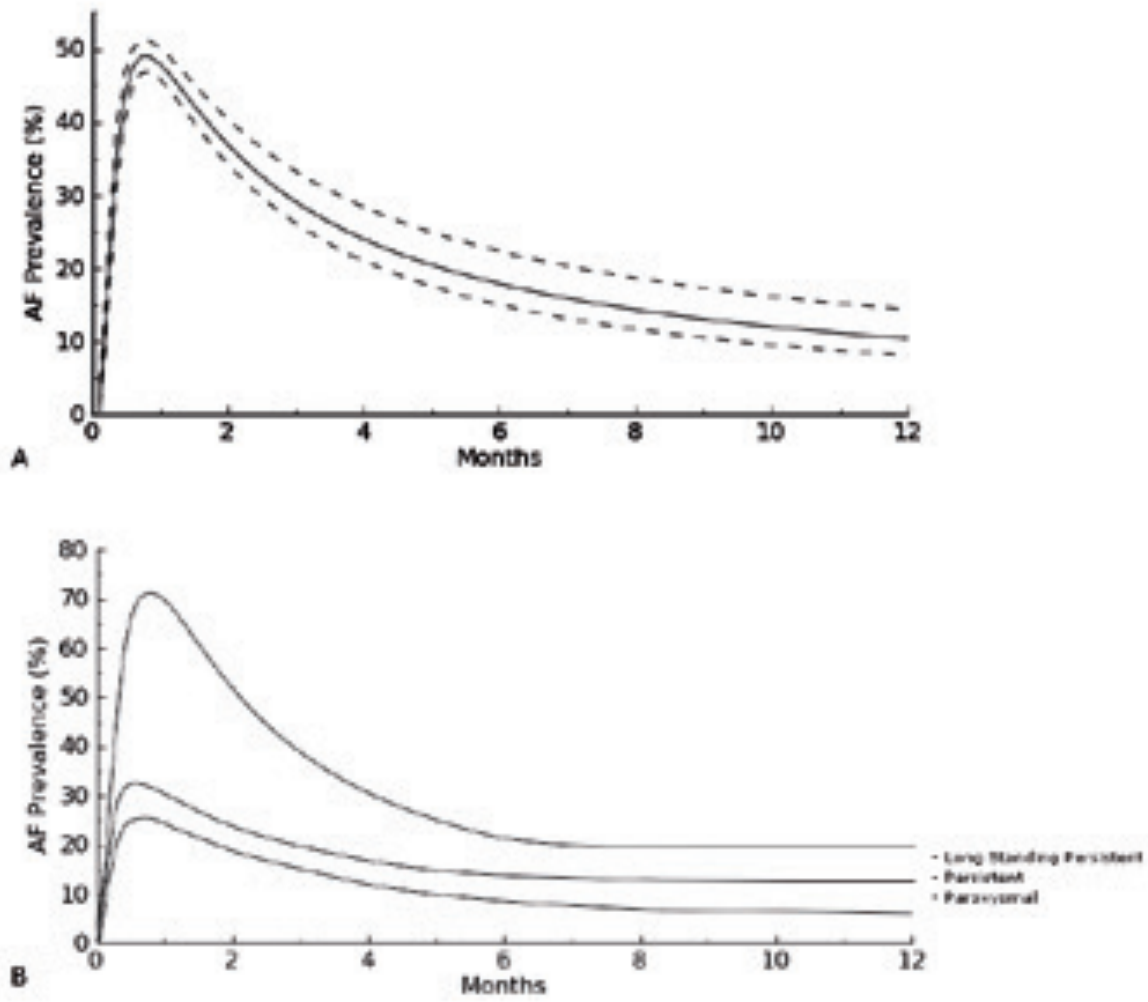

Figure 1A.Time-related prevalence of Atrial Fibrillation after hybrid procedure. B.

Time-related prevalence of Atrial Fibrillation by AF type. 


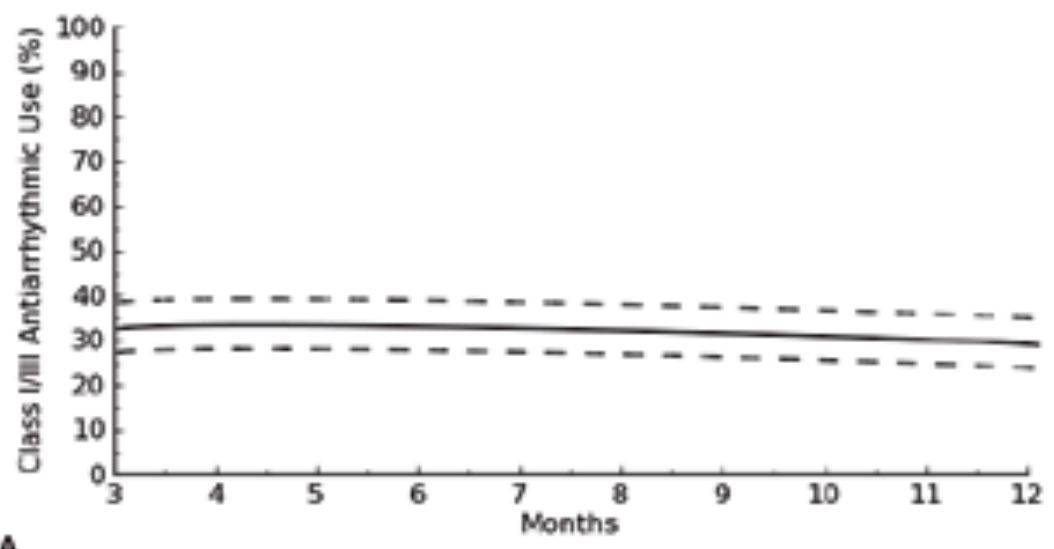

A

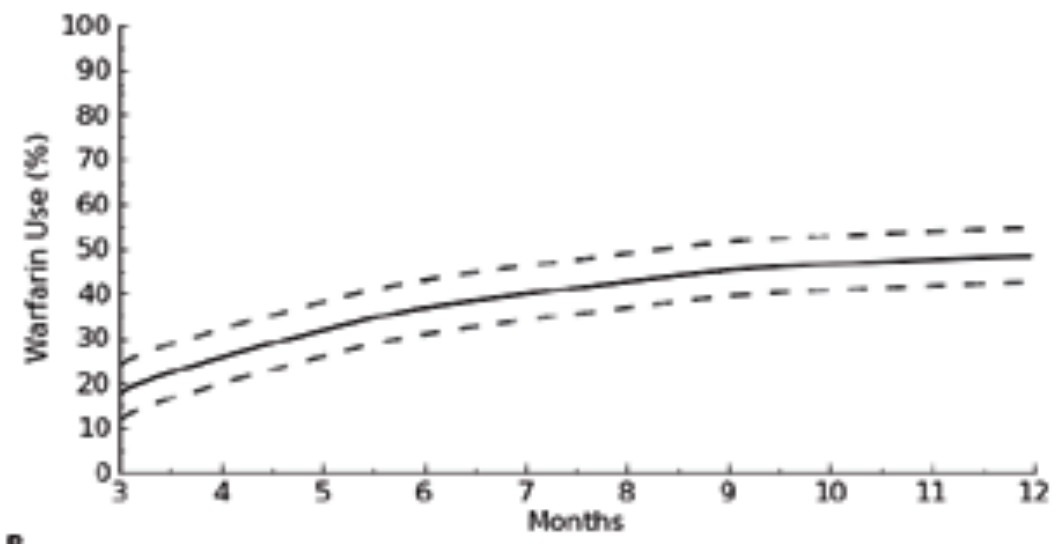

Figure 2A. Prevalence of class I/III anti-arrhythmic use after hybrid procedure. B. Prevalence of Warfarin use hybrid procedure. 
Table 1. Baseline Patient Characteristics $(n=19)$.

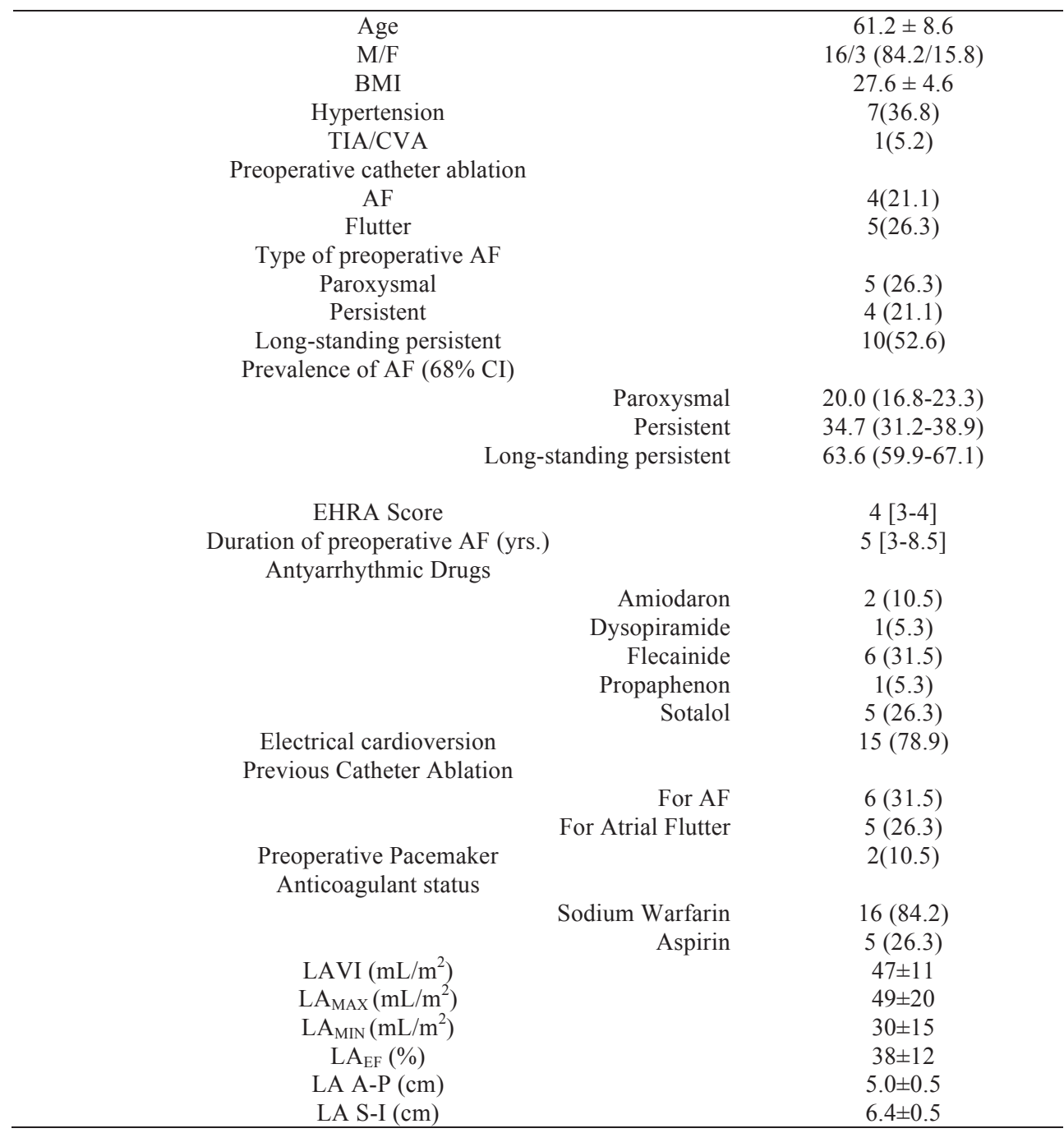

Normal data were presented as mean \pm 1 Standard deviation (SD), non parametric data as Median and [Interquartile Range] and discrete data as percentage (\%).

Abbreviations: M/F: Male/Female; BMI: Body mass index; AF: Atrial fibrillation; CI:

Confidence Interval; EHRA: European Hear Rhythm Association; LAVI: (Biplane) Left

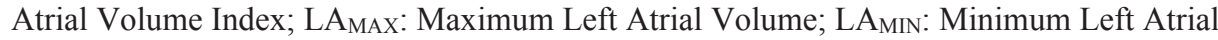
Volume; LA $\mathrm{EF}_{\mathrm{EF}}$ : Left Atrial emptying Fraction; LA A-P: Left Atrial Antero-Posterior Diameter; LA S-I : Left Atrial Superior-Inferior diameter. 
Table 2. Lesions Set

\section{Left atrium}

$\begin{array}{rr}\text { Right PVs Isolation } & 19(100) \\ \text { Left PVs Isolation } & 19(100) \\ \text { Inferior line } & 19(100) \\ \text { Roof line } & 19(100) \\ \text { Isthmus lesion } & 3(15.7) \\ \text { Endocardial gaps closure } & 17(88.4)\end{array}$

\section{Right atrium}

Cavo-tricuspid isthmus line $2(10.5)$

Ablation of autonomic Ganglia 19 (100)

Abbreviations. PVs: Pulmonary Veins; 


\begin{tabular}{|c|c|c|}
\hline \multicolumn{3}{|l|}{ LAVI $\left(\mathrm{mL} / \mathrm{m}^{2}\right)$} \\
\hline & 3 months & $45 \pm 10$ \\
\hline & 12 months & $40 \pm 11$ \\
\hline & $\mathrm{p}$ & 0.09 \\
\hline \multicolumn{3}{|l|}{$\operatorname{LA}_{\text {Max }}\left(\mathrm{mL} / \mathrm{m}^{2}\right)$} \\
\hline & 3 months & $46 \pm 15$ \\
\hline & 12 months & $45 \pm 13$ \\
\hline & $\mathrm{p}$ & 0.7 \\
\hline \multicolumn{3}{|l|}{$\mathbf{L} A_{\operatorname{Min}}\left(\mathrm{mL} / \mathrm{m}^{2}\right)$} \\
\hline & 3 months & $27 \pm 10$ \\
\hline & 12 months & $25 \pm 8$ \\
\hline & $\mathrm{p}$ & 0.86 \\
\hline \multicolumn{3}{|l|}{$L A_{E F}(\%)$} \\
\hline & 3 months & $41 \pm 14$ \\
\hline & 12 months & $43 \pm 14$ \\
\hline & $\mathrm{p}$ & 0.56 \\
\hline \multicolumn{3}{|l|}{ LA A-P (cm) } \\
\hline & 3 months & $3.9 \pm 0.4$ \\
\hline & 12 months & $3.7 \pm 0.4$ \\
\hline & $\mathrm{p}$ & 0.73 \\
\hline \multicolumn{3}{|l|}{ LA S-I (cm) } \\
\hline & 3 months & $5.9 \pm 0.6$ \\
\hline & 12 months & $5.8 \pm 0.6$ \\
\hline & $\mathrm{p}$ & 0.81 \\
\hline
\end{tabular}

Normal data were presented as mean \pm 1 Standard deviation (SD). *Significance vs. Baseline.

Abbreviations: LAVI: (Biplane) Left atrial volume index; LAMax: Maximum left atrial volume; LAMin: minimum left atrial volume; $\mathrm{LA}_{\mathrm{EF}}$ : Left atrial emptying fraction; LA A-P: Left atrial antero-posterior diameter; LA S-I: Left atrial antero-posterior diameter. 


\section{$\underline{\text { References }}$}

1. Cox, JL, Ad N. New surgical and catheter-based modifications of the Maze procedure. Seminars in Thoracic Cardiovascular Surgery.2000, 12:68-73.

2. Shen J, Bailey M, Damiano RJ. Surgery for lone atrial fibrillation. Present state-of-the art. Innovations (Phila) 2009;4(5):248-255.

3. Cappato R, Calkins H, Chen SA, Davies W, Iesaka Y, Kalman J, Kim YH, Klein G, Natale A, Packer D, Skanes A, Ambrogi F, Biganzoli E. Updated worldwide survey on the methods, efficacy, and safety of catheter ablation for human atrial fibrillation. Circ Arrhythm Electrophysiol, 2010;3:32-8.

4. Society of Thoracic surgeons National Adult Cardiac surgery Database.[http://www.sts.org/national-database]

5. Sales VL, McCarthy PM. Minimally invasive surgery for atrial fibrillation. Tex Heart Inst J. 2010, 37: 660-1.

6. Klinkenberg TJ, Ahmed S, Ten Hagen A, Wiesfeld AC, Tan ES, Zijlstra F, Van Gelder IC. Feasibility and outcome of epicardial pulmonary vein isolation for lone atrial fibrillation using minimal invasive surgery and high intensity focused ultrasound. Europace.2009, 11: 1624-31.

7. Pruitt JC, Lazzara RR, Ebra G. Minimally invasive surgical ablation of atrial fibrillation: the thoracoscopic box lesion approach. J Interv Card Electrophysiol 2007, 20:83-7.

8. Beyer E, Lee R, Lam BK. Point: minimally invasive bipolar radiofrequency ablation of lone atrial fibrillation: early multicenter results. J. Thorac.

Cardiovasc. Surg 2009, 137: 521-526.

9. Mahapatra S, LaPar DJ, Kamath S, Payne J, Bilchick KC, Mangrum JM, Ailawadi G. Initial Experience of Sequential Surgical Epicardial- Catheter 
Endocardial Ablation for Persistent and Long-Standing Persistent Atrial Fibrillation With Long-Term Follow-Up. Ann Thorac Surg 2011,91:1890-8.

10. Pison L, La Meir M, van Opstal J, Blaauw Y, Maessen JG, Crijns HJ. Hybrid Thoracoscopic Surgical and Transvenous Catheter Ablation of Atrial Fibrillation. J Am Coll Cardiol, in press.

11. Fuster V, Rydén LE, Cannom DS, Crijns HJ, Curtis AB, Ellenbogen KA, Halperin JL, Le Heuzey JY, Kay GN, Lowe JE, Olsson SB, Prystowsky EN, Tamargo JL, Wann S, Smith SC Jr, Jacobs AK, Adams CD, Anderson JL, Antman EM, Halperin JL, Hunt SA, Nishimura R, Ornato JP, Page RL, Riegel B, Priori SG, Blanc JJ, Budaj A, Camm AJ, Dean V, Deckers JW, Despres C, Dickstein K, Lekakis J, McGregor K, Metra M, Morais J, Osterspey A, Tamargo JL, Zamorano JL. ACC/AHA/ESC 2006 guidelines for the management of patients with atrial fibrillation: a report of the American College of Cardiology/American Heart Association Task Force on Practice Guidelines and the European Society of Cardiology Committee for Practice Guidelines (Writing Committee to Revise the 2001 Guidelines for the Management of Patients With Atrial Fibrillation). J Am Coll Cardiol, 2006; 48: 854-890.

12. Camm AJ, Kirchhof P, Lip GY, Schotten U, Savelieva I, Ernst S, Van Gelder IC, Al-Attar N, Hindricks G, Prendergast B, Heidbuchel H, Alfieri O, Angelini A, Atar D, Colonna P, De Caterina R, De Sutter J, Goette A, Gorenek B, Heldal M, Hohloser SH, Kolh P, Le Heuzey JY, Ponikowski P, Rutten FH; ESC Committee for Practice Guidelines, Vahanian A, Auricchio A, Bax J, Ceconi C, Dean V, Filippatos G, Funck-Brentano C, Hobbs R, Kearney P, McDonagh T, Popescu BA, Reiner Z, Sechtem U, Sirnes PA, Tendera M, Vardas PE, Widimsky P; Document Reviewers, Vardas PE, Agladze V, Aliot E, Balabanski T, Blomstrom-Lundqvist C, Capucci A, Crijns H, Dahlöf B, Folliguet T, Glikson M, Goethals M, Gulba DC, Ho SY, Klautz RJ, Kose S, McMurray J, Perrone Filardi P, Raatikainen P, Salvador MJ, Schalij MJ, 
Shpektor A, Sousa J, Stepinska J, Uuetoa H, Zamorano JL, Zupan I. Guidelines for the management of atrial fibrillation: the Task Force for the Management of Atrial Fibrillation of the European Society of Cardiology (ESC). Europace 2010,12:1360-1420.

13. European Heart Rhythm Association (EHRA); European Cardiac Arrhythmia Scoiety (ECAS); American College of Cardiology (ACC); American Heart Association (AHA); Society of Thoracic Surgeons (STS), Calkins H, Brugada J, Packer DL, Cappato R, Chen SA, Crijns HJ, Damiano RJ Jr, Davies DW, Haines DE, Haissaguerre M, Iesaka Y, Jackman W, Jais P, Kottkamp H, Kuck KH, Lindsay BD, Marchlinski FE, McCarthy PM, Mont JL, Morady F, Nademanee K, Natale A, Pappone C, Prystowsky E, Raviele A, Ruskin JN, Shemin RJ. HRS/EHRA/ECAS expert consensus statement on catheter and surgical ablation of atrial fibrillation: recommendations for personnel, policy, procedures and follow-up. Heart Rhythm 2007, 4:816-861.

14. Shemin RJ, Cox JL, Gillinov AM, Blackstone EH, Bridges CR. Workforce on Evidence-Based Surgery of the Society of Thoracic Surgeons. Workforce on Evidence-Based Surgery of the Society of Thoracic Surgeons. Guidelines for reporting data and outcomes for the surgical treatment of atrial fibrillation. Ann Thorac Surg 2007, 83:1225-1230.

15. Kuppahally SS, Akoum N, Burgon NS, Badger TJ, Kholmovski EG, Vijayakumar S, Rao SN, Blauer J, Fish EN, Dibella EV, Macleod RS, McGann C, Litwin SE, Marrouche NF. Left atrial strain and strain rate in patients with paroxysmal and persistent atrial fibrillation: relationship to left atrial structural remodeling detected by delayed enhancement-MRI. Circ Cardiovasc Imaging $2010 ; 3: 231-9$.

16. Jiamsripong P, Honda T, Reuss CS, Hurst RT, Chaliki HP, Grill DE, Schneck SL, Tyler R, Khandheria BK, Lester SJ. Three methods for evaluation of left atrial volume. Eur J Echocardiogr. 2008, 9:351-5. 
17. Tops LF, Delgado V, Bertini M, Marsan NA, Den Uijl DW, Trines SA, Zeppenfeld K, Holman E, Schalij MJ, Bax JJ. Left atrial strain predicts reverse remodeling after catheter ablation for atrial fibrillation. J Am Coll Cardiol 2011, 57:324-31.

18. La Meir M, De Roy L, Blommaert D, Buche M. Treatment of lone atrial fibrillation with a right thoracoscopic approach. Ann. Thorac. Surg, 2007, 83:2244-2245.

19. Blackstone EH, Naftel DC, Turner ME Jr. The decomposition of timevarying hazard into phases, each incorporating a separate stream of concomitant information. J Am Stat Assoc, 1986;81:615-624.

20. Efron B, Tibshirani RJ. An introduction to the bootstrap. New York: Chapman and Hall/CRC 1998.

21. Gillinov AM, Bhavani S, Blackstone EH, Rajeswaran J, Svensson LG, Navia JL, Pettersson BG, Sabik JF 3rd, Smedira NG, Mihaljevic T, McCarthy PM, Shewchik J, Natale A. Surgery for permanent atrial fibrillation: impact of patient factors and lesion set. Ann Thorac Surg 2006, 82: 502-513.

22. Edgerton JR, Edgerton ZJ, Weaver T, Reed K, Prince S, Herbert MA, Mack MJ. Minimally invasive pulmonary vein isolation and partial autonomic denervation for surgical treatment of atrial fibrillation. Ann Thorac Surg 2008, 86: $35-8$.

23. Li H, Li Y, Sun L, Liu X, Xu C, Han J, Meng X. Minimally invasive surgical pulmonary vein isolation alone for persistent atrial fibrillation: preliminary results of epicardial atrial electrogram analysis. Ann Thorac Surg 2008, 86:1219-1225.

24. Cheema FH, Weisberg JS, Khalid I, Roberts HG Jr. Warm beating heart, robotic endoscopic Cox. Warm beating heart, robotic endoscopic Cox- 
cryomaze: an approach for treating atrial fibrillation. Ann Thorac Surg. 2009, 87: 966-968.

25. Sirak J, Jones D, Schwartzman D. The five-box thoracoscopic maze procedure. Ann Thorac Surg 2010, 90:986-9.

26. La Meir M, De Roy L, Gourdin M. A Hybrid approach for treatment of patients with atrial fibrillation with radiofrequency catheters. In: Hybrid and minimally invasive cardiac intervention. Maessen $\mathrm{J}$ and Crijns H,editors. Turin: Minerva Medica, 2010: 9-13.

27. Sauren LD, la Meir M, de Roy L, Pison L, van der Veen FH, Mess WH, Crijns HJ, Maessen JG. Increaesd number of cerebral emboli during percutaneous endocardial pulmonary vein isolation versus a thoracoscopic epicardial approach. Eur J Cardiothorac Surg. 2009; 36:833-7.

28. van Brakel TJ, Bolotin G, Salleng KJ, Nifong LW, Allessie MA, Chitwood WR Jr, Maessen JG. Evaluation of epicardial microwave ablation lesions: histology versus electrophysiology. Ann Thorac Surg 2004, 78: 1397-1402. 29. Krul SP, Driessen AH, Zwinderman AH, van Boven WJ, Wilde AA, de Bakker JM, de Groot JR. Thoracoscopic Video-Assisted Pulmonary Vein Antrum Isolation, Ganglionated Plexus Ablation and Periprocedural Confirmation of Ablation Lesions. First Results of a Hybrid SurgicalElectrophysiological Approach for Atrial Fibrillation. Circ Arrhythm Electrophysiol 2011, 4:262-70.

30. Nasso G, Bonifazi R, Del Prete A, Del Prete G, Lopriore V, Bartolomucci F, Calafiore AM, Speziale G. Long-term results of ablation for isolated atrial fibrillation through a right minithoracotomy: toward a rational revision of treatment protocols. J Thorac Cardiovasc Surg2011, 142: 41-6. 
Hybrid Thoracoscopic Surgical and

Transvenous Catheter Ablation of Atrial Fibrillation.

Laurent Pison, Mark La Meir, Jurren van Opstal, Yuri Blaauw, Jos Maessen and Harry J. Crijns.

J Am Coll Cardiol. 2012 Jul 3;60(1):54-61.

DR.MARKLAMEIR

. (2) 2. 20.5
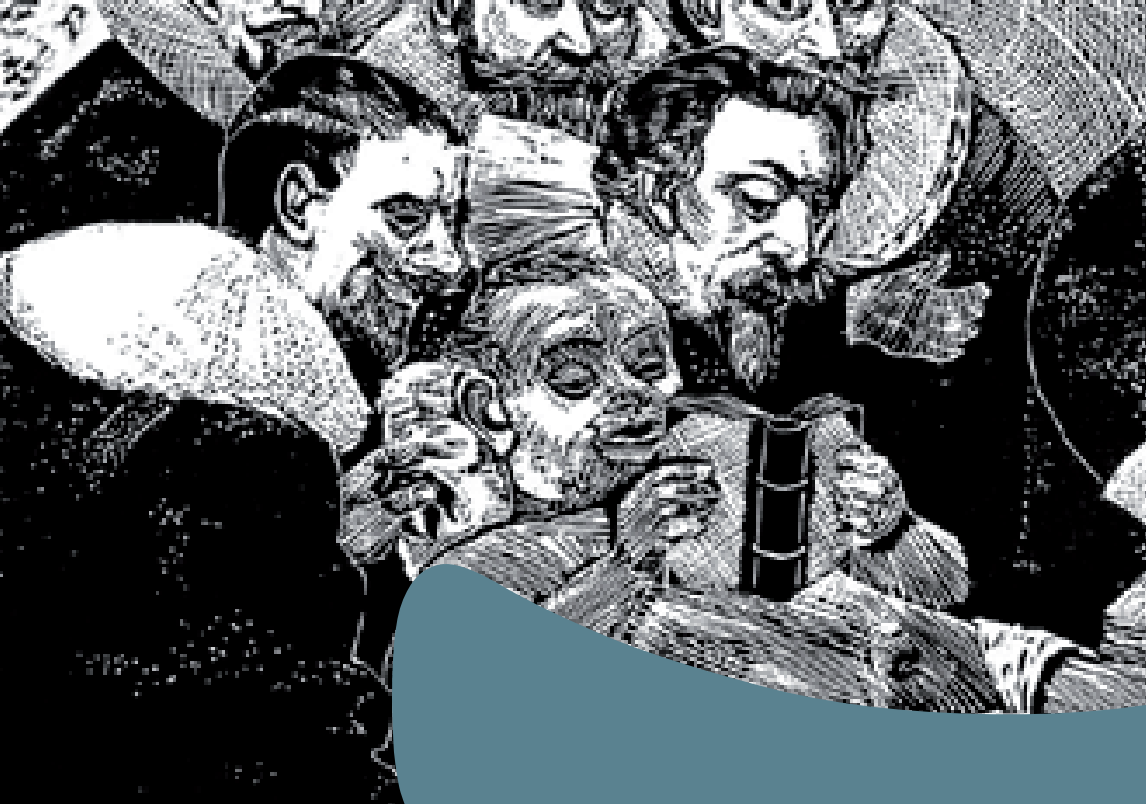

\% 3 ond $-2 x^{2}$

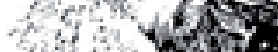

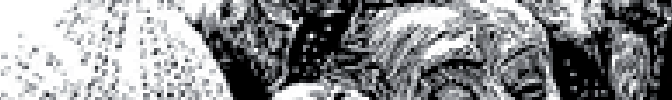

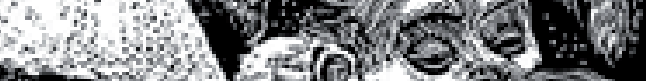

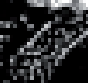

3 .

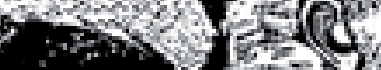

$+48$

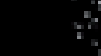

$\therefore$

$\therefore i$
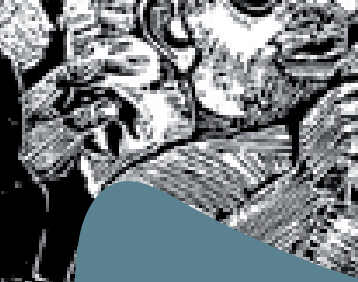
(1)
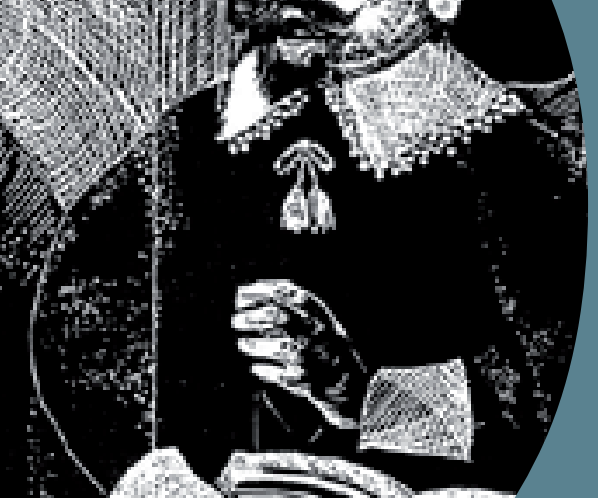


\section{Chapter 5}

Hybrid Thoracoscopic Surgical and Transvenous Catheter Ablation of Atrial Fibrillation.

Laurent Pison, Mark La Meir, Jurren van Opstal, Yuri Blaauw, Jos Maessen and Harry J. Crijns.

J Am Coll Cardiol. 2012 Jul 3;60(1):54-61.

\section{Abstract}

Objectives. The purpose of this study was to evaluate the feasibility, safety, and clinical outcome up to 1 year for patients undergoing a combined simultaneous thoracoscopic surgical and transvenous catheter atrial fibrillation (AF) ablation . Background. The combination of the transvenous endocardial approach with the thoracoscopic epicardial approach in a single AF ablation procedure, overcomes the limitations of both techniques and should result in better outcomes.

Methods. We followed a cohort of 26 consecutive patients with AF who underwent a hybrid thoracoscopic surgical and transvenous catheter ablation (CA) with a follow-up of up to 1 year.

Results. Twenty-six patients (42\% persistent AF) underwent a successful hybrid procedure. There were no complications. Mean follow-up was $470 \pm 154$ days. In $23 \%$ of the patients, the epicardial lesions were not transmural and endocardial touch-up was necessary. One-year success defined according to the Heart Rhythm Society/European Heart Rhythm Association/European Cardiac Arrhythmia Society consensus statement for the catheter and surgical ablation of $\mathrm{AF}$, was $93 \%$ for patients with paroxysmal $\mathrm{AF}$ and $90 \%$ for patients with persistent AF. Two patients underwent $\mathrm{CA}$ for recurrent $\mathrm{AF}$ or left atrial flutter after the hybrid procedure. 
Conclusions. A combined transvenous endocardial and thoracoscopic epicardial ablation procedure for $\mathrm{AF}$, is a feasible and safe procedure with a singleprocedure success rate of $83 \%$ at 1 year.

\section{Introduction}

In paroxysmal atrial fibrillation (AF), success rates of catheter ablation (CA) exceed $80 \%$ and recurrence is mostly associated with pulmonary vein (PV) reconnection $(1,2)$. By combining PV isolation, complex and fractionated atrial electrogram ablation, and linear lesions in persistent AF patients, success rates without anti-arrhythmic drug (AAD) surpass $70 \%(3,4)$. However, multiple procedures are often necessary and creating linear lesions is sometimes challenging.

Surgical AF ablation has evolved from the original Cox-maze procedure towards a minimally invasive video-assisted procedure with new ablation tools to isolate the PVs and create linear lesions without opening the heart (5). Nevertheless, even bipolar radiofrequency (RF) energy cannot guarantee transmural lesions (6). Linear lesions like the mitral isthmus, cannot be created solely from the epicardium, and proving bidirectional block epicardially, can be challenging (7). Combining a transvenous endocardial and thoracoscopic epicardial approach in a single procedure, overcomes these shortcomings.

We report our initial experience with long term follow-up of minimally invasive epicardial bilateral PV isolation and linear lesions in combination with endocardial proof of conduction block and endocardial touch-up if indicated.

\section{Methods}

\section{Patient Selection}

Twenty-six consecutive patients with symptomatic AF underwent a hybrid thoracoscopic surgical and transvenous CA with a follow-up of 1 year. 
Definitions of paroxysmal/persistent/longstanding persistent AF, success and failure of ablation, and follow-up monitoring were based on the Heart Rhythm Society/European Heart Rhythm Association/European Cardiac Arrhythmia Society consensus statement (3). Patients had failed at least 1 AAD. Other selection criteria were previously failed CA, left atrium (LA) volume $\geq 29 \mathrm{ml} / \mathrm{m}^{2}$, persistent or longstanding persistent $\mathrm{AF}$, or patient preference for a hybrid procedure instead of a percutaneous approach. Eleven patients (44\%) had a prior $\mathrm{CA}$ for AF or atrial flutter (AFL). All patients underwent transthoracic echocardiography, cardiac computed tomography, and pulmonary function test preoperatively.

\section{Hybrid procedure}

The procedure was performed under general anesthesia with double-lumen endotracheal tube placement for selective lung ventilation. Transoesophageal echocardiography was used to exclude a thrombus in the LA. On the right side, a $12 \mathrm{~mm}$ cameraport was placed in the 5th intercostal space mid axillary line and in the 6th or 7th intercostal space anterior axillary line. A $5 \mathrm{~mm}$ workingport was placed in the 3 rd intercostal space anterior axillary line. The pericardium was opened anterior to the phrenic nerve. Blunt dissection was used to open the transverse and oblique sinuses.

Via femoral venous approach, a His bundle (St. Jude Medical, St. Paul, MN, USA) and coronary sinus catheter (Medtronic, Minneapolis, MN, USA) were placed under fluoroscopy and transseptal puncture was performed with a long sheath 8F (SL0, St. Jude Medical, St. Paul, MN, USA) into the LA. We then heparinised the patient (1000 units of heparin per 10 kilograms bodyweight and a heparin infusion) with activated clotting time above 300 seconds. During rapid ventricular pacing, we injected contrast through the long sheath to visualize LA anatomy. The PVs were mapped with a circular mapping catheter (Lasso, Biosense Webster, Diamond Bar, USA). Antral isolation of the right PVs as pair, was performed with 4 to 6 applications using a bipolar RF clamp (Atricure, 
West Chester, OH, USA) (Figure 1). Each application had a duration of about 15 seconds with a median output of 10 to 15 Watt. The same port incisions were made on the left side but placed more posteriorly (Figure 2). The pericardium was divided posterior to the phrenic nerve. Left PV isolation was conducted as described above. We did not attempt ablation of the ganglionated plexi. In patients with severe chronic obstructive pulmonary disease, we performed a thoracoscopic epicardial isolation of the PVs only on the right and the left PVs were isolated using a cryothermal energy balloon catheter (Arctic Front, Cryocath, Montreal, Quebec, Canada) endocardially to avoid bilateral sequential lung deflation.

The endpoint for PV ablation, was entrance and exit block. We defined exit block as local capture in the PV during pacing from the Lasso catheter (output $10 \mathrm{~mA}$, pulse width $2 \mathrm{~ms}$ ) without conduction to the LA. In the case of sinus rhythm after PV isolation, reinduction of AF was attempted 5 times by pacing in the coronary sinus for 10 seconds at the shortest cycle length resulting in 1:1 atrial capture. AF was considered inducible if it lasted more than 1 minute. If $\mathrm{AF}$ became noninducible, isoproterenol was infused at rates of 10 to $30 \mu \mathrm{g} / \mathrm{min}$. If AF had not terminated or still was inducible, linear lesions were deployed. A roof line (connecting both superior PVs) and inferior line (connecting both inferior PVs) were made epicardially using a bipolar RF pen or linear pen device (Isolater Pen and Coolrail, Atricure, West Chester, OH, USA). If the right atrium was dilated, two additional ablation lines were placed: one encircling the superior caval vein using the clamp, the other connecting both caval veins using the pen.

By making a roof and inferior line, we isolated the posterior LA (box lesion). If entrance and exit block were not reached, we identified the conduction gaps endocardially and ablated those with a 3.5-mm-tip catheter (ThermoCool, Biosense Webster, Diamond Bar, USA). The location of the linear lesions was visualised with the linear pen device in situ and using fluoroscopy. 
A left isthmus line was made in 3 patients using the bipolar RF pen device. The line was started from the ablation line on the antrum of the left inferior PV towards and crossing the coronary sinus. All patients needed an endocardial touch-up ablation to reach bidirectional block, starting from the mitral annulus towards or inside the coronary sinus. If the patient was known with typical AFL or if this arrhythmia occured during the procedure, the cavotricuspid isthmus (CTI) was ablated endocardially. The endpoint was bidirectional block. In 7 patients the LA appendage was removed using a stapling device.

The pericardium was approximated with a stitch, and a chest tube was placed in both pleural cavities. There was no drain left in the pericardial space.

Low molecular weight heparins were started six hours after the procedure and on the second postoperative day, acenocoumarol was reinitiated. Patients restarted as soon as possible their pre-operative AAD regimen. Acenocoumarol and AADs were discontinued after the 6-month monitor confirmed the absence of atrial arrhythmia.

\section{Long-Term Follow-Up}

Any symptomatic patient not in sinus rhythm was cardioverted before the 3month follow-up visit. One patient had a pacemaker, which was used for monitoring. The remaining patients underwent 7-days continuous Holter monitoring at 3, 6, 9, and 12 months. If 7-days Holter was not available, the patients underwent at least 24 hours Holter monitoring. According to current guidelines, success was defined as no episode of AF, AFL, or any atrial tachycardia (AT) lasting more than 30 seconds off AAD after the three months blanking period.

\section{Statistics}

Data were retrospectively entered into a database. Statistical analysis was performed using SPSS 16.0. Continuous variables are summarized with means and standard deviations. Outcome is displayed with a Kaplan Meier plot and compared with a log-rank test. Any episode of AF, AFL, or AT lasting more 
than 30 seconds detected after the 3-month postprocedural period by ECG, pacemaker interrogation, or 7-days/48 hours/24 hours continuous Holter monitor performed at 6,9, and 12 months, was considered as a failure.

\section{Results}

\section{Perioperative Results}

Twenty-six patients underwent a hybrid procedure between May 29, 2008, to February 25, 2010. Patient baseline characteristics are shown in Table 1. Ten patients had persistent AF and 1 longstanding persistent AF. Eleven patients had 1 or 2 (patient 25) previous CAs. None of the PVs were isolated in those patients and there were no epicardial scars indicative of transmural lesions. Mean followup was $470 \pm 154$ days (221 to 858 days). Mean length of hospital stay was $7 \pm 2$ days (5 to 13 days) and mean ICU stay for postprocedural recovery was $1,0 \pm 0,2$ days ( 1 to 2 days). The median length of the hybrid procedure (from initial skin incision to skin closure) was $280 \pm 84$ minutes (195 to 505 minutes).

Eleven patients were in $\mathrm{AF}$ at the start of the procedure. In all patients we achieved bidirectional block of all the PVs (Figure 3). In 2 patients we did not perform any other lesion, because AF was not inducible. In 1 patient with inducible AF after PV isolation, we performed an additional roof line only. In 1 patient with inducible right AFL after PV isolation, we performed an additional CTI line only. Thereafter, no arrhythmia could be induced. In 22 patients we created a box lesion epicardially. In 17 patients (77\%) we were able to demonstrate endocardial entrance and exit block in the box during sinus rhythm. After endocardial touch-up in 5 patients (23\%), we completed the box lesion. In 3 patients there was a gap at the junction of the right superior PV with the roof of the LA. One patient had a gap in the lateral portion of the roof line and 1 patient in the middle of the inferiorline. Because of ongoing AF or organisation into a mitral isthmus dependent AFL, we performed in 3 patients a mitral isthmus line epicardially. In all cases, it had to be completed from the 
endocardium or coronary sinus with a mean of $1.6 \pm 0.5$ applications of RF energy, resulting in bidirectional block (Figure 4). In 2 patients, a CTI ablation was performed. One patient needed electrical cardioversion at the end of the procedure due to ongoing AF. All the other patients were in sinus rhythm. Twenty-four (92\%) patients were discharged on their pre-operative AAD regimen (amiodarone, 6/24; 25\%). All patients were discharged on acenocoumarol.

\section{Follow-Up}

Twenty-four (92\%) patients reached 1 year follow-up and 96\% underwent 7days Holter monitoring 1 year after the procedure. The remaining $2(8 \%)$ patients, reached 6 months follow-up and there was 100\% compliance with 7 days Holter monitoring (Table 2).

At one year, 22 of 24 (92\%) patients were in sinus rhythm with no episode of AF, AFL or AT lasting longer than 30 seconds on office follow-up, Holter monitoring or pacemaker interrogation (Figure 5). None of those patients was on AAD and 5 (21\%) patients were on acenocoumarol. One-year success defined according to the Heart Rhythm Society/European Heart Rhythm Association/European Cardiac Arrhythmia Society consensus statement (freedom of $\mathrm{AF} / \mathrm{AFL} / \mathrm{AT}$ off $\mathrm{AAD}$ ), was $93 \%$ for patients with paroxysmal $\mathrm{AF}$ and $90 \%$ for patients with persistent AF. Two (9\%) of those 22 patients underwent $\mathrm{CA}$ for recurrent $\mathrm{AF}$ or left AFL after the hybrid procedure (Table 3). There was no statistically significant difference in patients with or without previous CA, regarding the presence of sinus rhythm after one year without $\operatorname{AAD}(\mathrm{p}=1.0)$.

This means a single-procedure success rate (sinus rhythm without AAD and/or redo procedure) of $79 \%$ at 1 year for paroxysmal AF (11 out of 14 patients) and $90 \%$ for persistent AF ( 9 out of 10 patients) and an overall single-procedure success rate of $83 \%$ at 1 year. 
At six months, 2 of $2(100 \%)$ patients were in sinus rhythm with no episode of AF, AFL or AT lasting longer than 30 seconds. One of those patients was taking flecainide and they both were on acenocoumarol. None of those patients had an additional CA procedure.

The management of patients with recurrent supraventricular tachycardia (SVT) after the three months blanking period, is summarized in Table 3. Four (15\%) of 26 patients had SVT recurrence, with a mean of $99 \pm 94$ (range, 29 to 239) SVTfree days after the blanking period. Two of these 4 patients underwent an electrophysiologic study and CA. One patient was found to have AF due to a gap at the junction of the right superior PV with the roof of the LA. The other patient had a left AFL. These 2 patients have been followed for at least five months and have not experienced any SVT anymore off AAD. The remaining 2 patients with SVT recurrence, are treated with AAD for paroxysmal AF.

\section{Complications}

No deaths or conversion to cardiopulmonary bypass were encountered. No patient demonstrated paralysis of the phrenic nerve. One patient had a pleural effusion drained 3 weeks after surgery. One patient stayed hospitalized for 13 days due to difficult to control chestpain at the insertion sites of the workingports without signs of infection.

\section{Discussion}

\section{Main findings}

This report describes for the first time the combined simultaneous thoracoscopic surgical and transvenous CA of paroxysmal and persistent AF. These two complementary techniques performed in combination, bear the potential of treating AF with one single ablation procedure. According to accepted definitions, our overall one-year freedom of arrhythmia without AADs was 92\% with only 2 patients needing a second CA procedure (3). Of note, almost half persistent and over a third of patients had one or more previous CA. The 
robustness of the hybrid approach lies in its complimentary nature as represented by the fact that in almost a quarter of patients CA was needed to finish incomplete epicardial surgical lesions by endocardial touch-up, and additional lesions like the mitral isthmus line can be performed rather fast.

\section{Hybrid procedure versus percutaneous catheter ablation techniques}

Jaïs et al found that if AF was inducible after PV isolation in patients with paroxysmal AF, the addition of linear lesions, with the endpoint of noninducibility, resulted in $91 \%$ of patients free from arrhythmia without AAD during a follow-up of $18 \pm 4$ months (8). To reach that number, however, $31 \%$ of patients needed a second procedure. Using the same endpoint, our success percentage off AAD was comparable but only $9 \%$ of patients needed a second procedure.

The single-procedure, drug-free success rate of the stepwise ablation approach for persistent $\mathrm{AF}$ as described by Haïssaguerre et al, was $62 \%$ at $11 \pm 6$ months (9). Allowing for repeat procedures and the use of AAD, the one year success rate increased to $95 \%$. In our series we followed a comparable ablation strategy and the single-procedure, drug-free success rate at one year was $83 \%$. Allowing for redo-procedures, this number increased to $92 \%$.

The hybrid approach appears to result in better endpoints regarding rhythmcontrol, both for paroxysmal and persistent AF, using the same endpoints and ablation strategy as described in other trials.

Approximately $80 \%$ of patients have at least partial recovery of PV conduction at 4 months after PV isolation with unipolar RF (10). Bipolar RF energy, as used in our series, overcomes the heat-sink by clamping the tissue and excluding the effect of the circulating blood on ablation which seems to result in more persistent lesions (11). But even for such devices, epicardial fat can prevent transmurality. In our series, the box lesion was incomplete after epicardial ablation alone in $23 \%$ of the patients, i.e. endocardial touch-up with unipolar RF 
energy was necessary to achieve bidirectional block. The possibility to perform such an endocardial touch-up, is one of the major advantages of this procedure.

\section{Hybrid procedure versus surgical ablation techniques}

By replacing the incisions of the traditional Cox-maze III procedure with less invasive linear lesions of ablation using bipolar RF, Damiano et al introduced the Cox-maze IV procedure (12). This approach still requires cardiopulmonary bypass and at least one small right thoracotomy. The freedom of AF recurrence was $91 \%$ at 12 months and $67 \%$ of patients off AAD. These figures are comparable with our results although in the case of the hybrid procedure, no cardiopulmonary bypass is needed nor a thoracotomy. None of the existing surgical ablation technologies (even bipolar RF) can guarantee complete transmurality. We solved this issue by applying RF endocardially in the case of incomplete lesions. Another shortcoming of the surgical approach is the inability to precisely locate AF triggers and to map ATs or reentry arrhythmias known to occur during AF ablation (13). In the setting of a hybrid procedure however, it is possible to perform extensive mapping in order to tailor the lesion set. Finally, during an epicardial surgical AF ablation on the beating heart, it is technically not possible to create a linear lesion across the CTI. In our series, this was safely performed endocardially in 3 patients.

\section{Hybrid procedure versus surgical ablation with epicardial mapping}

In 2009, Lockwood et al described techniques for assessing conduction block across surgical lesions based on epicardial mapping (7). Using combinations of a focal and bipolar RF device as in our series, they achieved complete block across linear lesions by the first set of RF applications in only $21 \%$. Several factors like epicardial fat and local myocardial thickness, limit the depth of penetration of RF and thus the creation of transmural lesions (14). After localisation of the gaps, epicardial ablation was repeated until complete bidirectional block across all the linear lesions. 
In our series, pacing manoeuvers and mapping techniques were performed from the endocardial side. In $23 \%$ of our patients we were not able to create a complete box lesion, even after repeating epicardial ablation. To create completely transmural lesions, we applied unipolar RF endocardially at the remaining gaps.

Krul et al described a series of 31 AF patients, treated with thoracoscopic PV isolation and ganglionated plexi ablation (15). In patients with nonparoxysmal AF, LA ablation lines were created and conduction block verified epicardially with custom made catheters. After 1 year, they reported comparable results to our series ( $86 \%$ of patients had no recurrence of SVT off AAD). Although the autonomic nervous system seems to play an important role in AF, there is up to now too little evidence to advocate a systematic ganglionated plexi ablation strategy $(16,17)$. In animal models, return of ganglionated plexi activity was observed 4 weeks after selective ablation and little is known about the electrophysiological impact reinnervation will have on the long term outcome (18). An important conceptual difference between studies is that Krul et al. could only perform epicardial lesions without the possibility of add on endocardial lesions including endocardial touch-ups to improve transmurality, as well as performing CTI and left sided isthmus ablation. In addition, they could only check completeness of ablation lesions from the epicardium which may be insufficient to show complete electrical block.

\section{Limitations}

The low number of patients in this single-center retrospective study prevents definitive conclusions, also in view of the limited power of the log rank test we used to compare groups. However, future larger studies may corroborate our results. 
Although patients with previous CA had at most a PV isolation procedure and none of the PVs appeared to be isolated in any of these patients, it cannot be excluded that previous CA favourably influenced the results.

The single procedure success rate was similar - rather than lower - in patients with persistent compared to those with paroxysmal AF. Although this may be due to low sample size, it may also be considered an expression of the robustness of the hybrid procedure.

In the current series, the overall clinical success may have not recognized some episodes of asymptomatic arrhythmia by the relatively short periods of ambulatory monitoring performed.

The safety of this procedure may be a concern because of the extent of ablation and the full heparinisation during the procedure.

The longer-term impact of this ablation strategy on the atrial systolic function remains unknown.

An ablation strategy based on non-inducibility, could lead to overtreatment of some patients. As demonstrated by Jaïs et al, despite being still inducible after $\mathrm{PV}$ isolation and deployment of linear lesions, some patients remained arrhythmia free without AAD (8).

\section{Conclusions}

A combined transvenous endocardial and thoracoscopic epicardial ablation procedure for paroxysmal and recent persistent $\mathrm{AF}$ resistant to $\mathrm{AAD}$, has a single-procedure success rate of $83 \%$ at one year. Recurrent arrhythmias can be handled with AAD or CA. 


\section{Abbrevations}

$\mathrm{AAD}=$ anti-arrhythmic drug

$\mathrm{AF}=$ atrial fibrillation

$\mathrm{AFL}=$ atrial flutter

$\mathrm{AT}=$ atrial tachycardia

$\mathrm{CA}=$ catheter ablation

$\mathrm{CTI}=$ cavotricuspid isthmus

$\mathrm{LA}=$ left atrium

$\mathrm{PV}=$ pulmonary vein

$\mathrm{RF}=$ radiofrequency

$\mathrm{SVT}=$ supraventricular tachycardia 


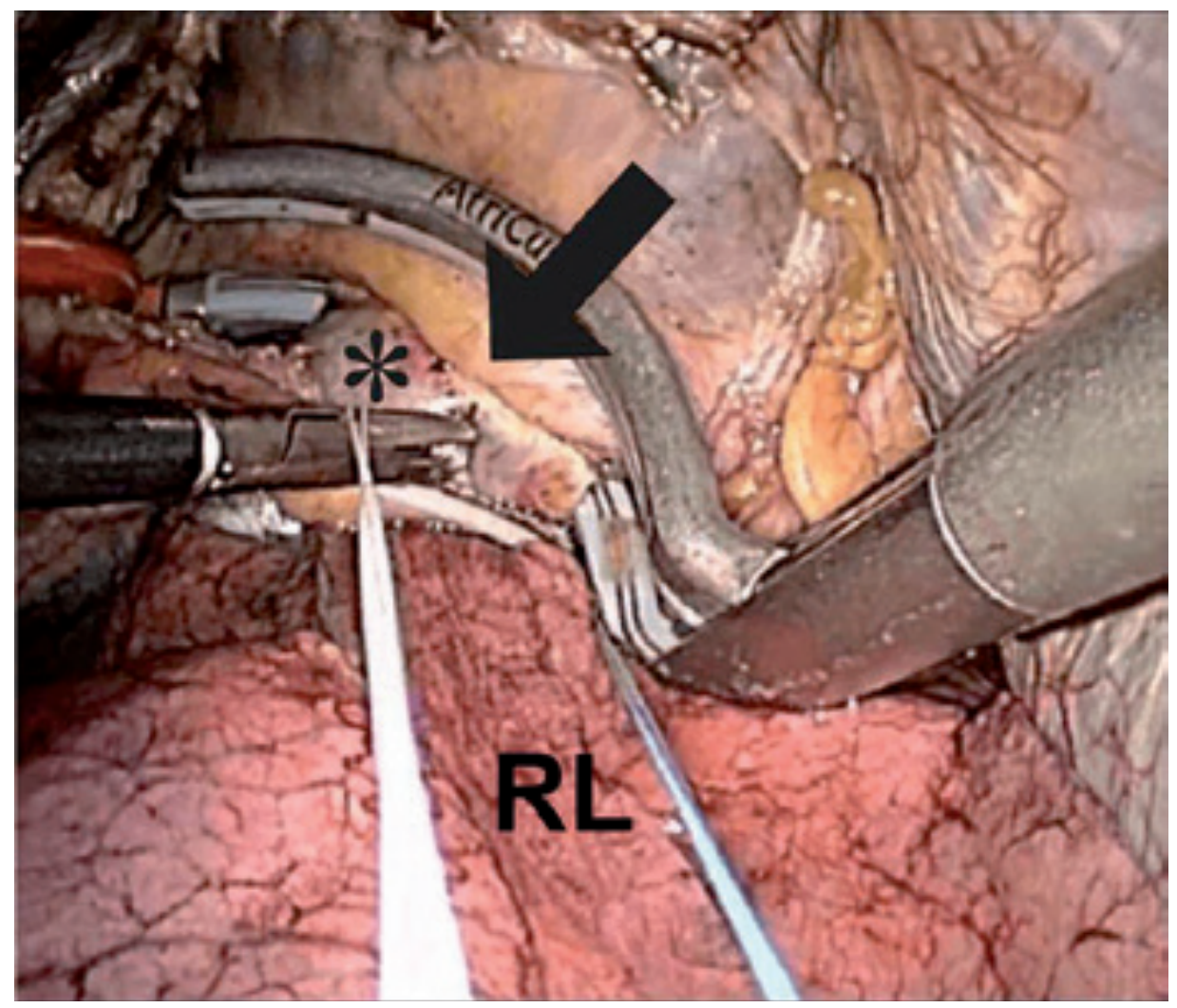

Figure 1. Right Pulmonary Vein Isolation

A large antral lesion (arrow) is created using a bipolar radiofrequency clamp and resulting in complete isolation of the right pulmonary veins (PV). The antrum of the right PVs is clearly visible (*). RL = right lung. 


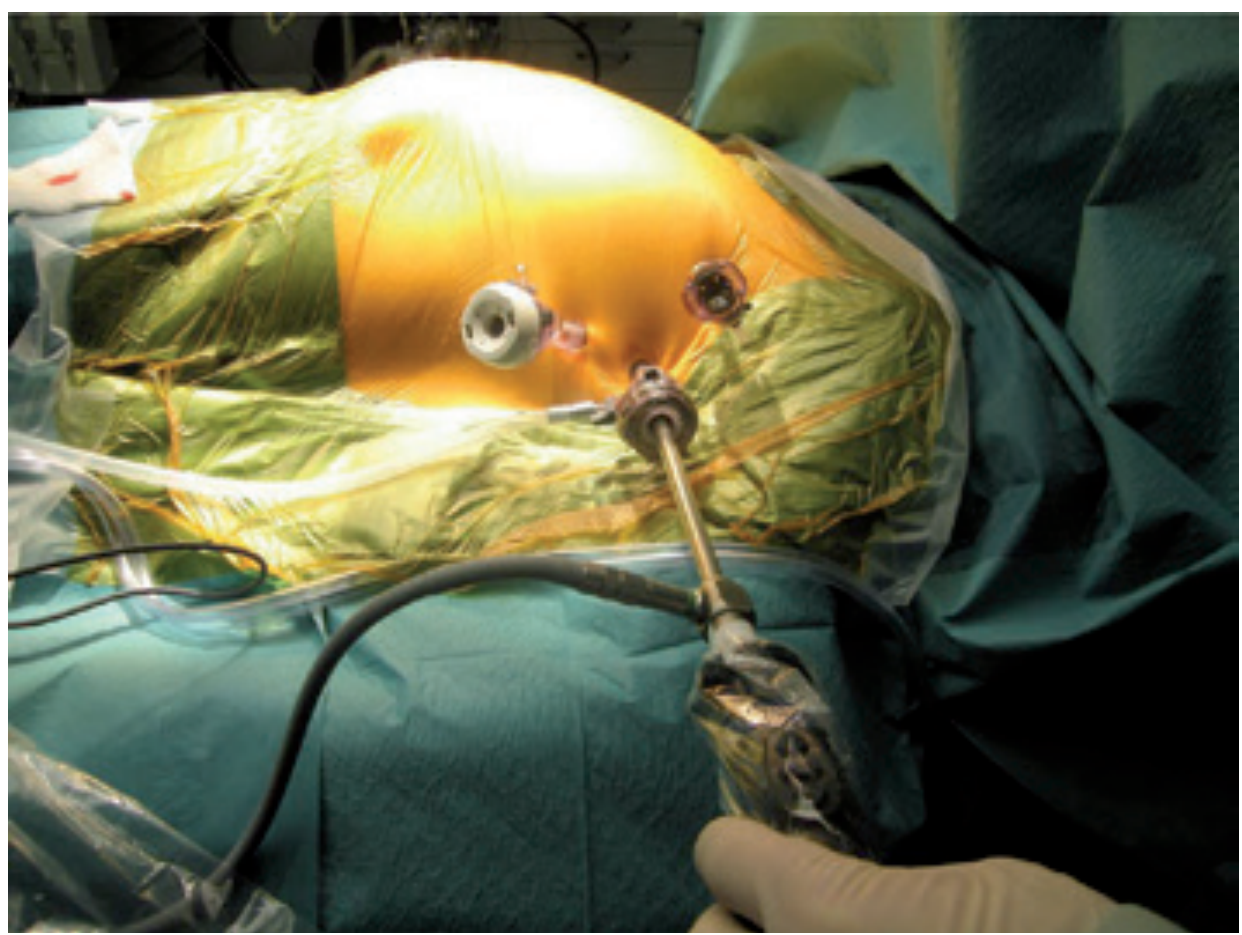

Figure 2. Placement of Ports on Left Side of the Patient 


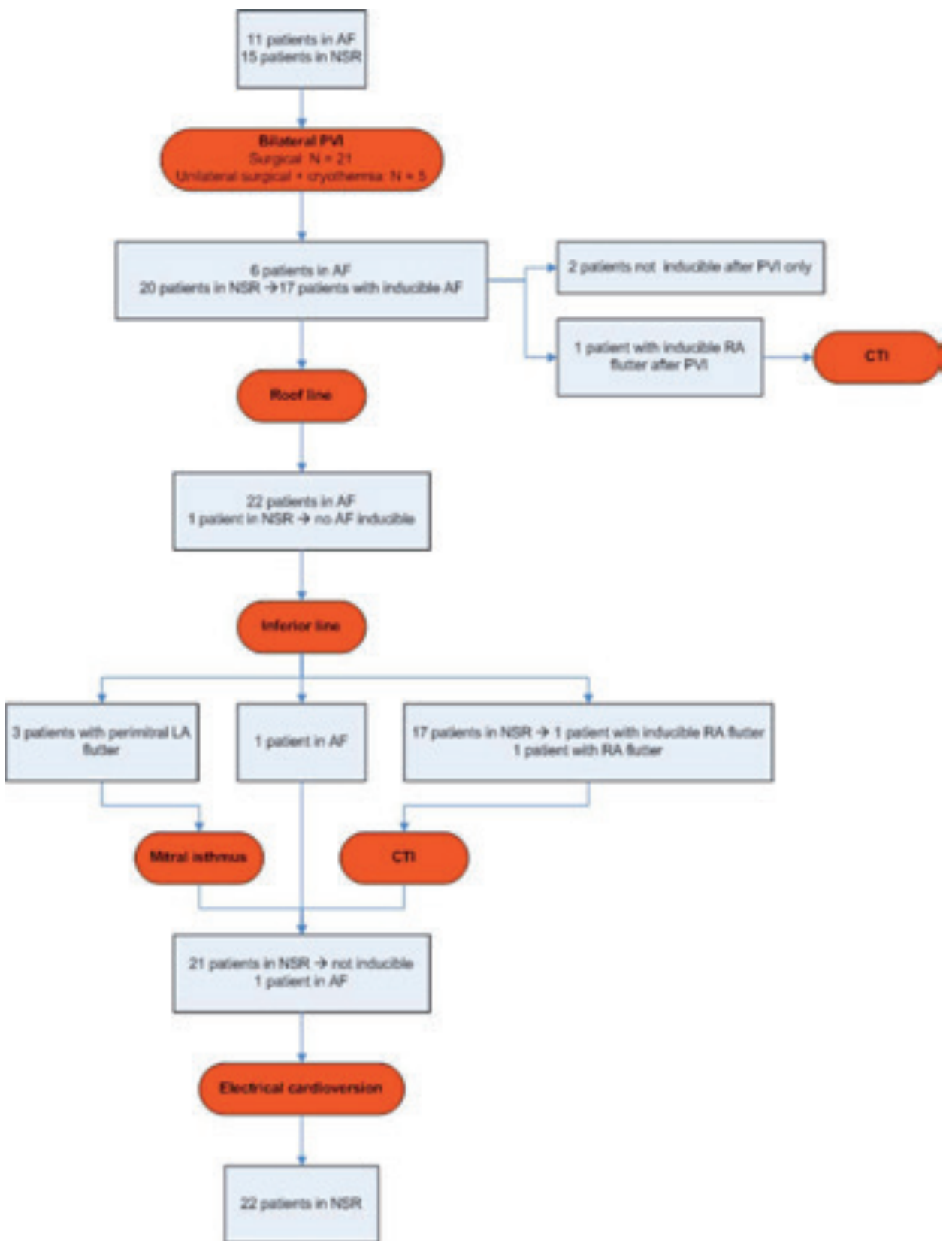

Figure 3. Flow Diagram of the Stepwise Lesion Sets

See text for details. AF $=$ atrial fibrillation, $\mathrm{CTI}=$ cavotricuspid isthmus, $\mathrm{LA}=$ left atrium, $\mathrm{NSR}=$ normal sinus rhythm, $\mathrm{PVI}=$ pulmonary vein isolation, $\mathrm{RA}=$ right atrium. 


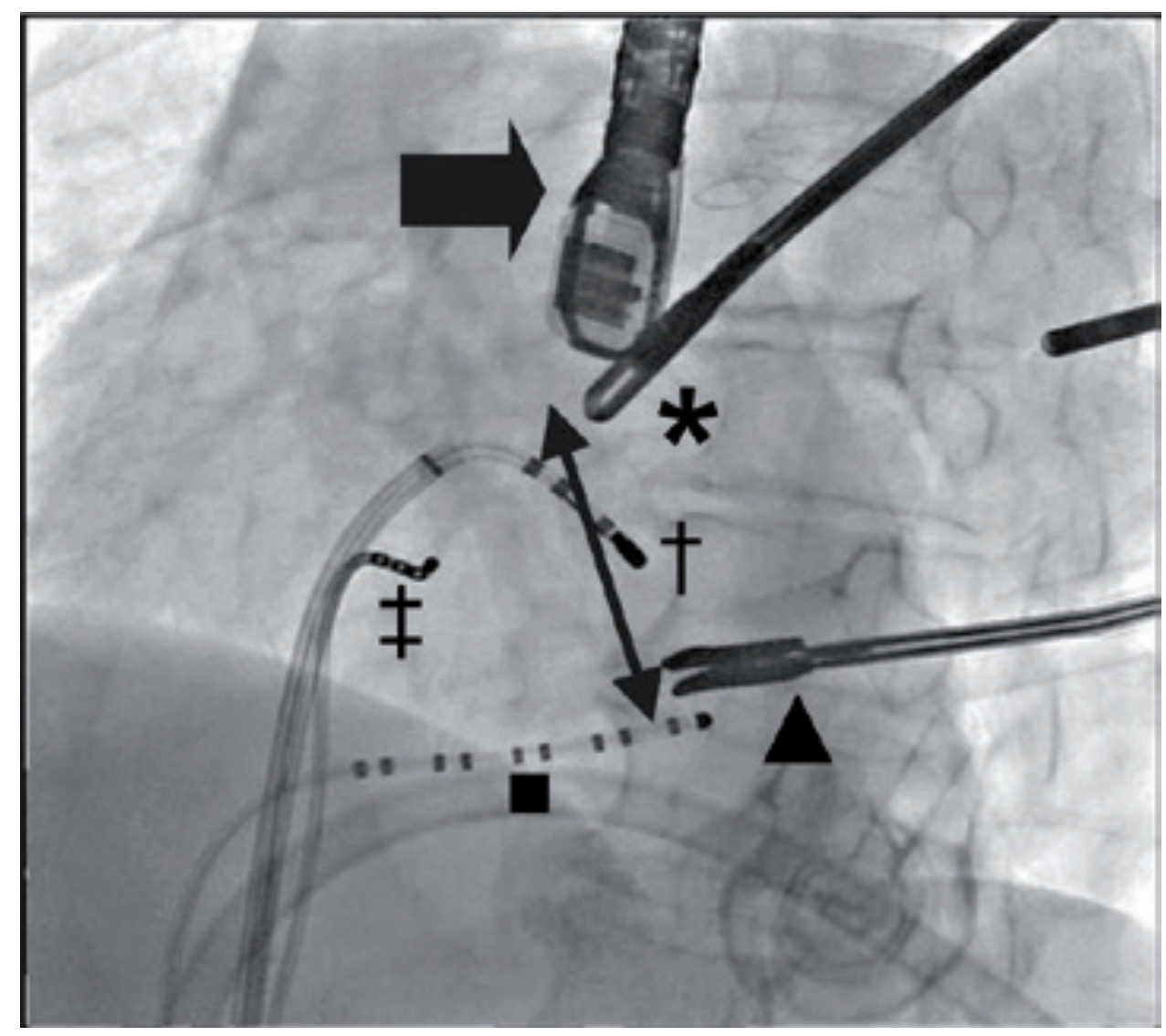

Figure 4. Linear Lesion at the Mitral Isthmus

Two instruments placed epicardially, visualise the location of this linear lesion $(*=$ left inferior pulmonary vein, $\boldsymbol{\Delta}$ = coronary sinus). Bidirectional block across the mitral isthmus was determined using the following criteria: 1) widely separated double potentials along the whole linear lesion $(\leftrightarrow), 2$ ) pacing lateral to the line results in a proximal-to-distal activation sequence in the coronary sinus, 3 ) pacing immediately septal from this linear lesion with the coronary sinus catheter ( $\mathbf{\square})$, results in late activation (170 to $190 \mathrm{~ms}$ ) on the ablation catheter $(\dagger)$ at the lateral side of this line, 4) the conduction time from the septal side of the linear lesion to the lateral side gets shorter as the septal pacing site is moved further from the line. $\$$ $=$ His catheter, $\Rightarrow=$ transesophageal echocardiography probe. 


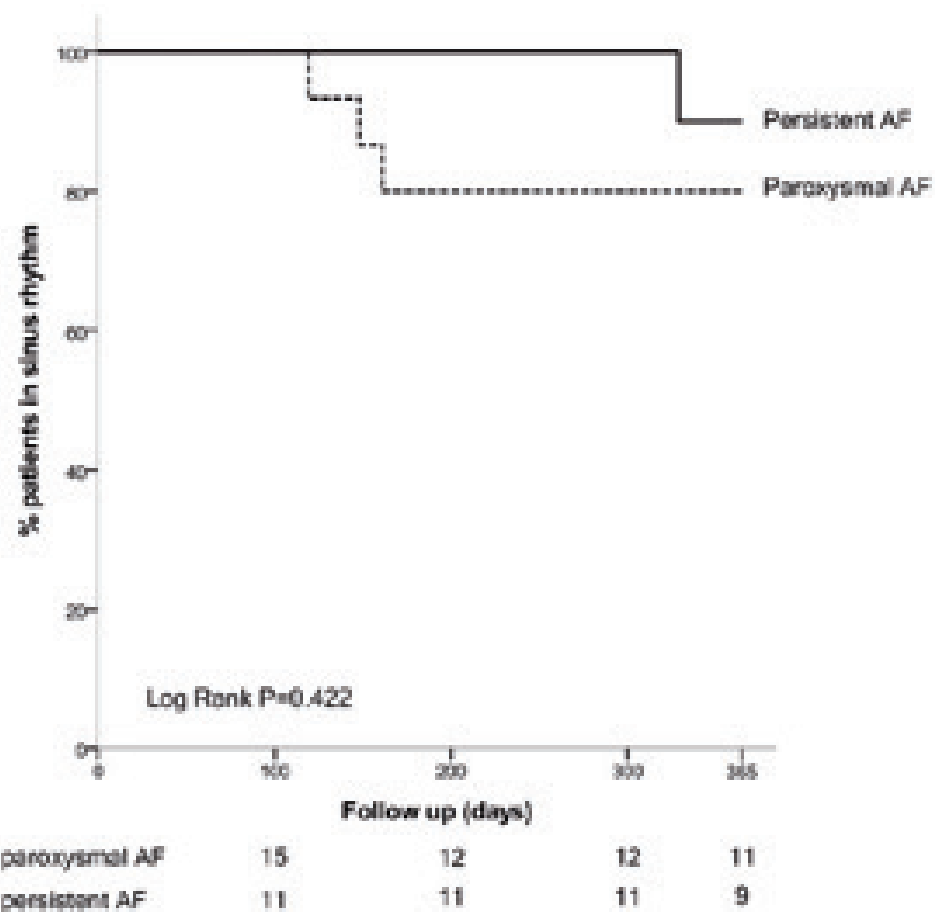

Figure 5. Outcome of Hybrid Ablation Procedure

Kaplan-Meier curve showing the outcomes of hybrid ablation procedure. At 1 year follow-up, hybrid ablation resulted in an overall single-procedure success rate of $83 \%$ (79\% for paroxysmal atrial fibrillation (AF) and 90\% for persistent AF). An event was considered a patient who, at any time, had recurrent supraventricular tachycardia. 


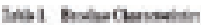

\begin{tabular}{|c|c|c|c|c|c|c|c|c|c|c|c|c|c|c|}
\hline ar & $\Delta$ & Mela & Z & 280 & dF ana & 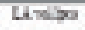 & SUE & hranc C $A$ & Sreces & CDO & CSDON & 600 & Losex & $\sin \theta$ \\
\hline F & ข & u & e & $E=$ & a & Ies & $26:$ & 3 & Te & te & r & Sa & ntianokiandat & the suthan \\
\hline$t$ & $y$ & H & $\omega$ & Bs: & * & $2 *$ & is: & th & is & $y$ & i & It & 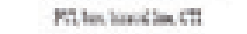 & ijer tat was das \\
\hline 1 & $\mathrm{e}$ & u & 4 & $\mathrm{BN}$ & $y$ & rs & ;i & It & $\pi$ & Is & 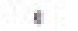 & 34 & pithe & 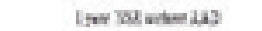 \\
\hline 1 & 6 & u & 4 & $\operatorname{sm}$ & 7 & and & is & In & a & Se & 4 & It & 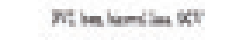 & 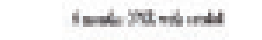 \\
\hline 1 & $t$ & H & e & $B=$ & $x$ & $x *$ & ; 5 & th & 74 & $y$ & 3 & 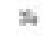 & 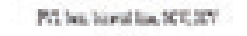 & ther Iat wand das \\
\hline 1 & $y$ & z & $\mathrm{e}$ & De: & w & $\operatorname{las}$ & $\because$ & the & $\mathrm{s}$ & De & 4 & $3 a$ & $\mathrm{~m}$ & 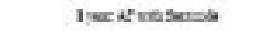 \\
\hline 1 & $\theta$ & te & $\theta$ & An & $u$ & vas & ;t) & 5 & in & 4 & $e$ & $x_{4}$ & 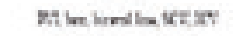 & 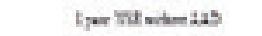 \\
\hline 1 & 4 & t & 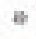 & En & $\boldsymbol{M}$ & De & w & a & $\pi$ & sis & 4 & 3 & ntianocidentat & $2,0 \%$ sut nitm \\
\hline 1 & 4 & t & $*$ & De: & 4 & nes & $s t$ & se & $\pi$ & $\mathrm{sa}$ & 4 & $3 a$ & ntheturalaxery & Lpersendeas \\
\hline$t$ & $\theta$ & $y$ & 4 & $\mathrm{Fm}$ & If & T* & HI & 3 & $\pi$ & Sis & 8 & st & PI k & 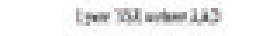 \\
\hline t & 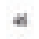 & $\mathbf{x}$ & 4 & Ex & $\varepsilon$ & $\mathrm{ar}$ & 26 & The & $T_{k}$ & sis & 1 & is & 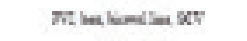 & 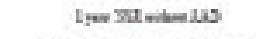 \\
\hline 5 & $a$ & w & 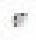 & Pen & st & 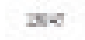 & $w$ & 36 & $\mathrm{Tk}$ & De & t & $\mathrm{sa}$ & nits & tor sae thesacilitere \\
\hline$s$ & 7 & u & $\theta$ & ken & 4 & De & Hi & sat & $V_{r}$ & lis & 1 & St & Mt ks & 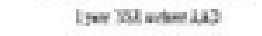 \\
\hline$s$ & $\boldsymbol{c}$ & t & 6 & $x=1$ & $u$ & IIE & s: & s. & $\pi$ & the & 4 & 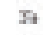 & wilk & 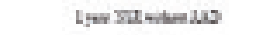 \\
\hline s & $\pi$ & H & E & Ren & 幽 & 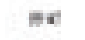 & wb & th & is. & 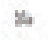 & $i$ & I4 & mas & ires if esatenti \\
\hline 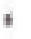 & 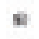 & H & E & Ren & 的 & Nes & iti & 34 & Ye & is & i & ฟธ & mis & tror Xat was das \\
\hline * & 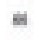 & $\mathrm{t}$ & * & $\mathrm{ken}$ & $i x$ & teat & \#t & 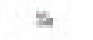 & $\psi$ & tie & 1 & $\%$ & nt be & 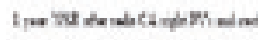 \\
\hline $\mathbf{1}$ & $\mathbf{c}$ & u & e & $x=n$ & 24 & $M 4$ & ses & s. & $\gamma_{k}$ & sis & 1 & 3 & $\mathrm{nt}$ & 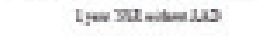 \\
\hline , & 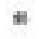 & $\mathbf{x}$ & $\mathrm{E}$ & $\operatorname{Men}$ & $x$ & $\mathbf{c t}$ & $n 2$ & The & $T_{k}$ & sa & 1 & 3 & mertb & Lfer $x e$ nareas \\
\hline$t$ & $a$ & t & et & hen & $1 x$ & 44 & tts & t5. & If & sh & 4 & \pm & nth & 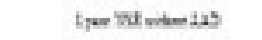 \\
\hline t & 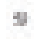 & $y$ & 7 & $\operatorname{men}$ & ix & ne & s! & 3 & $T=$ & Te & $t$ & Ts & mis & L \\
\hline \multirow[t]{2}{*}{8} & $\mathbf{c}$ & t & $\approx$ & Pen & $\pi$ & 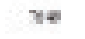 & : & se & $\mathrm{Ts}$ & De & 3 & $\mathrm{Te}$ & 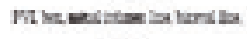 & Lfer $x t$ nate 20 \\
\hline & & & & & & & & & & & & & $\mathbf{K} \mathbf{V}$ & \\
\hline
\end{tabular}

\begin{tabular}{|c|c|c|c|c|c|c|c|c|c|c|c|c|c|}
\hline en & 7 & 2 & hin & 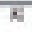 & $8 \pi$ & b. & is & in & 24 & 8 & 9 & Katem inda & 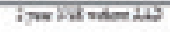 \\
\hline $\mathbf{n}$ & $t$ & ต & his & $\mathbf{x}$ & $9 x$ & $\mathrm{ss}$ & Th & $\mathrm{sa}$ & $\mathrm{sa}$ & 4 & 8 & ral has ca & fand $3 x$ ricks: \\
\hline 4) & u & $\approx$ & $h=$ & 7 & $9 \pi$ & 20 & $T_{h}$ & $m$ & $\pi$ & 3 & No & nit oulle & 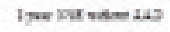 \\
\hline e & t & $\theta$ & $\mathrm{Mm}$ & 6 & $4: 2$ & w? & $\mathrm{x}$ & 8 & 8 & 4 & 8 & mi les Kendian XVV & 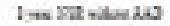 \\
\hline
\end{tabular}


Table 1. Baseline Characteristics

Baseline characteristics of all included patients with lesion set and follow-up results. No patient had previous cardiothoracic surgery or a cerebrovascular accident. Atrial fibrillation duration prior to intervention, is expressed in months.

$\mathrm{BMI}=$ body mass index, $\mathrm{CA}=$ catheter ablation, $\mathrm{CAD}=$ coronary artery disease, $\mathrm{COPD}=$ chronic obstructive pulmonary disease, $\mathrm{EF}=$ ejection fraction, $\mathrm{F}=$ female, $\mathrm{M}=$ male, $\mathrm{NSR}=$ normal sinus rhythm, Parox $=$ paroxysmal, Pers $=$ persistent, $\mathrm{PVI}=$ pulmonary vein isolation. 
Tuls : Delein

\begin{tabular}{|c|c|c|c|c|c|c|c|c|}
\hline ine & Ave & Dondiapinis & 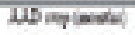 & Dofism: & gidefonts & andentert & 7.minas & Rom \\
\hline $\mathrm{t}$ & $\mathrm{BE}$ & $x \in \mathbb{1}$ & 4 & $76.35 \%$ & $72 \times 8$ & 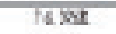 & 71308 & - \\
\hline 2 & An & wents & 6 & itasne. & faxt & $\mathrm{sia}$ & $7+3 \times 2$ & 74382 \\
\hline$j$ & to: & nater & 4 & saske & fasest & fasent & $74 \times 2$ & - \\
\hline * & m & Brack & st यक्या & $30 \times 2$ & $74 \times 2$ & . & . & , \\
\hline 5 & Bm & milnive & 6 & $74 \times 0$ & $74 \times 58$ & 76,398 & $79 \times 2$ & * \\
\hline$i$ & $\mathrm{De}$ & Ansted & 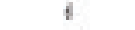 & thase & fast & $76 \mathrm{sen}$ & 74.02 & - \\
\hline 7 & m & assober & 5 & $72 \times 0$ & $74 \times 8$ & $74 \times 82$ & $74 \times 08$ & \\
\hline 3 & Bos & dengiela & 6 & $72 \times 0$ & $74 \times 58$ & $\mathrm{xa}$ & $74 \times 12$ & 74302 \\
\hline 1 & As & sonipat & 6 & $42 \times 2$ & $74 \times 8$ & $\mathrm{xi}$ & $74 \times 2$ & $=$ \\
\hline 12 & be: & antax & 6 & $76 \mathrm{ne}$ & $72 \times 8$ & fos $x$ & faxg & - \\
\hline $\mathrm{E}$ & Ron & nitw & 6 & $74 \times 0$ & $74 \times 58$ & $76 \times 9$ & $74 \times 8$ & - \\
\hline $\mathrm{E}$ & $\operatorname{man}$ & Bund & 4 & 74.56 & 74.47 & $76 \times 8$ & $74 \times 2$ & , \\
\hline b & $\mathrm{hat}$ & botmat & 4 & tosne & ate $x e$ & fest & 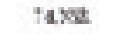 & - \\
\hline Li & $\mathrm{mar}$ & nents & 6 & ats $x e$ & taxt & fest & $74 \times 2$ & " \\
\hline 15 & $\operatorname{mas}$ & wads & want & 7424 & 74052 & $76 \times 8$ & 7220 & $=$ \\
\hline Id & Past & max & 1 & 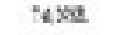 & fasest & fast & faxd & - \\
\hline 1) & $\mathrm{mar}$ & unthos & 6 & $7 e \times 0$ & $\mathrm{sa}$ & teske & taxa & . \\
\hline It & $h=$ & Botud & $t$ & Resta & Deste. & Bessis. & ntsuz. & - \\
\hline 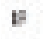 & $\mathrm{Pax}$ & Brient & 6 & $42 \times 7$ & $74 \times 58$ & Taxo & $74 \times 0$. & , \\
\hline 2 & her & Buth & 6 & $72 \times 0$ & $74 \times a$ & $76 \times 5$ & $74 \times 8$ & - \\
\hline t & $\mathrm{har}$ & anplat & 6 & 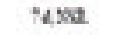 & faxst & $\mathrm{xa}$ & tased & * \\
\hline in & $\operatorname{man}$ & nest & 6 & $r e m a$ & 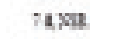 & $74 \times 0$ & $74 \times 8$ & . \\
\hline 3 & hat & fortus & 6 & $74 \mathrm{xa}$ & $7 \mathrm{xas}$ & $\mathrm{sa}$ & $74 \times 8$ & $74 \mathrm{xg}$ \\
\hline$x$ & haik & burgied & 6 & $72 \times 00$ & $74 \times 58$ & , & . & * \\
\hline$y$ & Rat & wat & 4 & iese & faxt & faxat & taxe & - \\
\hline$\pi$ & $\operatorname{man}$ & Brived & , & $7 a \times 0$ & raxs & $x$ & $74 \times 82$ & . \\
\hline
\end{tabular}

Table 2. Monitoring

Anti-arrhythmic drug (AAD) use, type and result of monitoring in all included patients. The duration of AAD intake after the hybrid procedure (AAD stop) is given for each patient.

Patient 6, 12, 15, and 17 had arrhythmia recurrence.

$\mathrm{NA}=$ not available, $\mathrm{NSR}=$ normal sinus rhythm, Parox $=$ paroxysmal, Pers $=$ persistent, $\mathrm{PM}$

= pacemaker, $24 \mathrm{~h} / 48 \mathrm{~h} / 7 \mathrm{~d}=24$ hours $/ 48$ hours/7 days continuous Holter monitoring. 


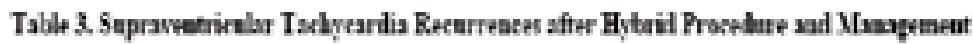

\begin{tabular}{|c|c|c|c|c|c|c|c|}
\hline Pahent & $\begin{array}{l}\text { Tine to SVT } \\
\text { Recurrence, } \\
\text { dery }\end{array}$ & Type of SVI & \begin{tabular}{|l|} 
Mede of \\
angrosits
\end{tabular} & $\begin{array}{l}\text { Danzenent } \\
\text { of returyetet }\end{array}$ & $\begin{array}{l}\text { Recunzace } \\
\text { aftr } \\
\text { adtsixad } \\
\text { Guagy }\end{array}$ & $\begin{array}{l}\text { Follon-wy } \\
\text { atter } \\
\text { additioesl } \\
\text { therayy }\end{array}$ & $A A D$ after $C A$ \\
\hline 6 & 329 & $\lambda F$ & $E C G$ & Inctates & PAF & 4 moxt. & \\
\hline 12 & 119 & $\begin{array}{l}\text { Xet strial } \\
\text { futer }\end{array}$ & $\Xi C Q$ & $\mathrm{CA}$ & bete & Smoxt: & towet \\
\hline 15 & 148 & $A F$ & $\begin{array}{l}48 \text { bettrs } \\
\text { Holiter }\end{array}$ & sctalo? & $\begin{array}{l}\text { tore ad } \\
\text { brief PAF }\end{array}$ & 13 matus & \\
\hline 17 & $16]$ & $\overline{\lambda F}$ & $\overline{E C G}$ & $\overline{C A}$ & Dete & S anoxts & ENat \\
\hline
\end{tabular}

Table 3. Supraventricular Tachycardia Recurrences after Hybrid Procedure and Management $\mathrm{PAF}=$ paroxysmal atrial fibrillation . 


\section{References}

1. Nault I, Miyazaki S, Forclaz A, et al. Drugs vs. ablation for the treatment of atrial fibrillation: the evidence supporting catheter ablation. Eur Heart J 2010;31:1046-1054.

2. Callans DJ, Gerstenfeld EP, Dixit S, et al. Efficacy of repeat pulmonary vein isolation procedures in patients with recurrent atrial fibrillation. J Cardiovasc Electrophysiol 2004;15:1050-1055.

3, Calkins H, Brugada J, Packer DL, et al. HRS/EHRA/ECAS expert consensus statement on catheter and surgical ablation of atrial fibrillation:

recommendations for personnel, policy, procedures, and follow-up: a report of the Heart Rhythm Society Task Force on Catheter and Surgical Ablation of Atrial Fibrillation. Heart Rhythm 2007;4:816-861.

4. Oral H, Knight BP, Tada $\mathrm{H}$, et al. Pulmonary vein isolation for paroxysmal and persistent atrial fibrillation. Circulation 2002;105:1077-1081.

5. Wolf RK, Schneeberger EW, Osterday R, et al. Video-assisted bilateral pulmonary vein isolation and left atrial appendage exclusion for atrial fibrillation. J Thorac Cardiovasc Surg 2005;130:797-802.

6. Bugge E, Nicholson IA, Thomas SP. Comparison of bipolar and unipolar radiofrequency ablation in an in vivo experimental model. Eur J Cardiothorac Surg 2005;28:76-82.

7. Lockwood D, Nakagawa H, Peyton MD, et al. Linear left atrial lesions in minimally invasive surgical ablation of persistent atrial fibrillation: Techniques for assessing conduction block across surgical lesions. Heart Rhythm 2009;6:S50-63.

8. Jaïs P, Hocini M, Sanders P, et al. Long-term evaluation of atrial fibrillation ablation guided by noninducibility. Heart Rhythm 2006;3:140-145. 
9. Haïssaguerre M, Hocini M, Sanders P, et al. Catheter ablation of long-lasting persistent atrial fibrillation : clinical outcome and mechanisms of subsequent arrythmias. J Cardiovasc Electrophysiol 2005;16:1138-1147.

10. Cappato R, Negroni S, Pecora D, et al. Prospective assessment of late conduction recurrence across radiofrequency lesions producing electrical disconnection at the pulmonary vein ostium in patients with atrial fibrillation. Circulation 2003;108:1599-1604.

11. Melby SJ, Gaynor SL, Lubahn JG, et al. Efficacy and safety of right and left atrial ablations on the beating heart with irrigated bipolar radiofrequency energy: a long-term animal study. J Thorac Cardiovasc Surg 2006;132:853-860.

12. Shen J, Bailey MS, Damiano RJ. The surgical treatment of atrial fibrillation. Heart Rhythm 2009;6:S45-50.

13. Jaïs $P$, Matsuo $S$, Knecht $S$, et al. A deductive mapping strategy for atrial tachycardia following atrial fibrillation ablation: Importance of localized reentry. J Cardiovasc Electrophysiol 2009:20;480-491.

14. Thomas SP, Guy DJ, Boyd AC, Eipper VE, Ross DL, Chard RB. Comparison of epicardial and endocardial linear ablation using handheld probes. Ann Thorac Surg 2003;75:543-548.

15. Krul SP, Driessen AH, van Boven WJ, et al. Thoracoscopic video-assisted pulmonary vein antrum isolation, ganglionated plexus ablation, and periprocedural confirmation of ablation lesions. Circ Arrhythm Electrophysiol 2011;4:262-270.

16. Schauerte P, Scherlag BJ, Patterson E, et al. Focal atrial fibrillation: experimentel evidence for pathophysiologic role of the autonomic nervous system. J Cardiovasc Electrophysiol 2001;12:592-599.

17. De Ferrari GM, Schwartz PJ. Autonomic nervous system and arrhythmias. Ann N Y Acad Sci 1990;601:247-262. 
18. Sakamoto S, Schuessler RB, Lee AM, Aziz A, Lall SC, Damiano RJ. Vagal denervation and reinnervation after ablation of ganglionated plexi. J Thorac Cardiovasc Surg 2010;139:444-452. 


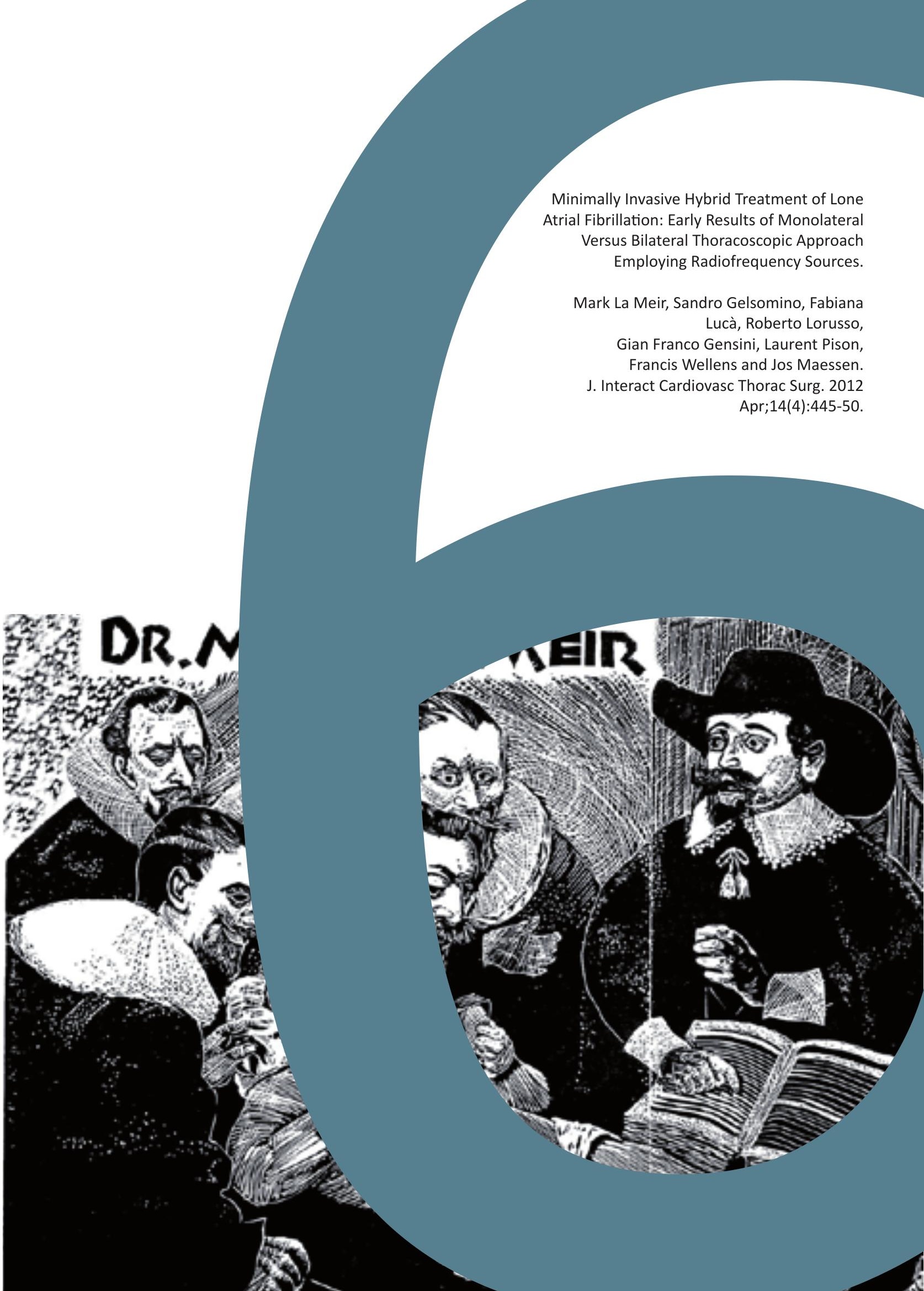




\section{Chapter 6}

Minimally Invasive Hybrid Treatment of Lone Atrial Fibrillation: Early Results of Monolateral Versus Bilateral Thoracoscopic Approach Employing Radiofrequency Sources.

Mark La Meir, Sandro Gelsomino, Fabiana Lucà, Roberto Lorusso, Gian Franco Gensini,, Laurent Pison, Francis Wellens and Jos Maessen.

J. Interact Cardiovasc Thorac Surg. 2012 Apr;14(4):445-50.

\section{$\underline{\text { Abstract }}$}

Objectives. We compare results of hybrid monolateral versus hybrid bilateral thoracoscopic approach employing radiofrequency $(\mathrm{RF})$ sources for the surgical treatment of lone atrial fibrillation (LAF).

Methods. Between January 2008 and June 2010 fifty-four consecutive patients with LAF underwent hybrid minimally invasive surgical ablation.Nineteen patients (35.1\%) underwent monolateral monopolar RF ablation whereas $35(64.9 \%)$ had a bilateral thoracoscopic approach employing a bipolar RF clamp.Seven-day Holter Monitoring (HM) was performed at, 3, 6 months and 1 year.

Results. One-year time-related prevalence of postoperative AF in patients undergoing monolateral thoracoscopic approach or bilateral thoracoscopic ablation were $13.3 \%$ (11.0-17.4) and $5.2 \%$ (4.2-6.7), respectively $(\mathrm{p}<0.001)$. 
It was $21.1 \%(17.6-24.9)$ and $8.2 \%(5.1-11.6)$ in long standing persistent $(\mathrm{p}<0.001), 13.2 \%(10.6-17.8)$ and $3.8 \%(1.4-6.9)$ in persistent $(\mathrm{p}<0.001)$ and $5.6 \%(2.8-8.3)$ and 3.2(1.0-6.5) in paroxysmal AF $(\mathrm{p}=0.64)$ in monolateral and bilateral group, respectively.At 12 months estimated prevalence of antiarrhythmic drugs were $26 \%(22.4-30.1)$ and $18.0 \%(15.5-21.7, \mathrm{p}=0.04)$ whereas prevalence of Warfarin use were $48.2 \%$ (44.2-52.2) and $29.0 \%$ $(26.2-33.1, \mathrm{p}<0.001)$ in monolateral and bilateral group, respectively.LA reverse remodeling occurred in $47.3 \%(n=9)$ of monopolar patients $(n=9)$ and in $77.1 \%(\mathrm{n}=27)$ of bipolar patients $(\mathrm{p}=0.03)$.

Conclusions. Hybrid bilateral approach with a bipolar device for the treatment of LAF showed a good one-year success rate independently of the AF type and a seems to be the better choice for LAF fibrillation more than paroxysmal. In contrast, the hybrid monolateral approach when combined with an endocardial touch-up may represent a reliable alternative in selected paroxysmal LAF patients.

\section{Introduction}

With the development of new tools and advanced endoscopic techniques the surgical treatment of lone atrial fibrillation (LAF ) moves towards increasingly less invasive techniques ${ }^{1}$. Because these minimally invasive approaches are performed on the beating heart they have the potential to promote a multidisciplinary approach involving cardiac surgeons and electrophysiologists (EPs) ${ }^{2}$. A so called hybrid procedure has been recently introduced to overcome the shortcomings of percutaneous catheter ablation and video-assisted thoracoscopic epicardial procedure and, together, to combine their advantages ${ }^{3}$. The hybrid technique originally described 
combines a bilateral thoracoscopic epicardial approach followed by a percutaneous trans-septal procedure ${ }^{3,4}$. In order to reduce the invasiveness of the procedure, we have recently introduced, in selected patients, a hybrid single-sided approach employing a monopolar radiofrequency source through a right thoracoscopy.

Nonetheless, no information exist whether, in hybrid procedures, theoretical advantages of a right thoracoscopic approach outweigh the clear advantages of employing bipolar radiofrequency clamps (transmural and continuous lesions, ligation/excision of the LAA) in bilateral thoracoscopic approach. Therefore, we present our short-term experience with the hybrid procedure in LAF and compare results of hybrid monolateral versus a hybrid bilateral thoracoscopic surgical ablation employing radiofrequency (RF) sources in terms of early and late complications, prevalence of postoperative atrial fibrillation, antiarrhythmic medications and anticoagulant use. Furthermore, we explore whether any difference exists between the two approaches in terms of left atrial (LA) function and LA reverse remodeling (LARR).

\section{Methods}

\section{Patients}

The study followed the World Medical Association guidelines concerning ethical principles for medical research involving human subjects and was approved by Institutional Ethics Board. All patients gave their informed consent.

Between January 2008 and June 2010 fifty-four consecutive patients with LAF underwent a single step hybrid minimally invasive surgical treatment of LAF combined with a percutaneous endocardial step employing a 
radiofrequency (RF) source. Nineteen patients (35.1\%) underwent monolateral right-side thoracoscopic ablation whereas 35 (64.9\%) had a bilateral thoracoscopic procedure. All operations were performed by the same cardiac surgeon (M.L.M).

Lone atrial fibrillation was defined following American College of Cardiology/American Heart Association/European Society of Cardiology (ACC/AHA/ESC) guidelines 5 and updated ESC Guidelines were followed to distinguish type of AF and to score the AF-related symptoms (European Heart Rhythm Association [EHRA] score $)^{6}$.

Indication for minimally invasive surgery was based on the HRS/EHRA/ECA Guidelines ${ }^{7}$. Patients were referred for hybrid procedure in case of paroxysmal, persistent or long-standing persistent AF with left atrial (LA) dilatation $(>4.5 \mathrm{~cm})$, after one or more failed catheter ablations, or on patient's preference. The indication was based on the history of AF and LA size. A transthoracic echocardiography and a computed tomography (CT) scan were carried out preoperatively (pulmonary vein anatomy, coronary arteries) and potential candidates for a hybrid procedure underwent lung function test (Spirometry). The right thoracoscopic approach was preferred for patients with $\geq$ moderate chronic obstructive pulmonary disease (COPD) following European Respiratory Society (ERS) diagnostic criteria ${ }^{8}$ Exclusion criteria were a presence of atrial or left appendage thrombi at transesophageal echocardiography (TEE), 'giant' left atrium (diameter $>6.5$ $\mathrm{cm}$ ), coronary artery disease, and previous pulmonary or cardiac surgery. Patient characteristics are shown in Table 1.No significant difference was detected between groups. 


\section{Follow-up and Assessment of AF}

All patients were followed-up according the Heart Rhythm Society/ European Heart Rhythm Association/ European Cardiac Arrhythmia Society (HRS/EHRA/ECA) expert consensus statement on catheter and surgical ablation of $\mathrm{AF}^{6}$. Data and outcomes were reported following the Society of Thoracic Surgeon (STS) guidelines ${ }^{9}$.

Seven-day Holter Monitoring (HM) was performed at 3, 6 months and 1 year. All patients reached 1-year follow up. Monitoring was carried out with an external loop recorder (Del Mar Reynolds, Spacelabs Healthcare, Issaquah, WA, USA) and analyzed with Lifescreen Software (Del Mar Reynolds, Spacelabs Healthcare, Issaquah, WA, USA). For analysis, three rhythms were considered postoperative AF: AF, atrial flutter or atrial tachycardia lasting more than $30 \mathrm{sec}$. In addition, all electrocardiograms (ECG) performed at the discretion of referring physicians/cardiologists during the first three months after surgery and in the time comprised between Holter examinations were included when patients had at least two records available for analysis. Each ECG and Holter was treated as a discrete data (presence/absence of atrial fibrillation) to calculate estimated prevalence ${ }^{9}$. A total of 628 postoperative Holter/ ECG data were retrieved (bilateral thoracoscopy, $\mathrm{n}=408$; right thoracoscopy, $\mathrm{n}=222$ ).

\section{Anticoagulation and Anti-arrhythmic Therapy}

Anti-arrhythmic drugs (AAD) were given postoperatively to all patients but, although we recommend discontinuing AAD three months after ablation if the patients appear to be AF free, their continued use was at the discretion of referring cardiologists. 
Electrical cardioversion was not attempted for patients who remained in AF after the surgical procedure and was reserved for patients who were still in AF after 3 months and 6 months.

Warfarin was administered on postoperative day 2 with INR target of 2.5 and stopped after 3 months if the Holter recording showed a sinus rhythm (SR) or patients had a low thromboembolic risk $\left(\mathrm{CHADS}_{2}\right.$ score $\left.<2\right)$.

\section{Echocardiography}

Echocardiography was performed preoperatively and at 3 month- and 12 month- follow-up appointments using a commercially available echocardiographic system (Philips iE33; Philips Medical Systems, Eindhoven, The Netherlands). All the parameters were analyzed "off-line" by an experienced echocardiographer (F.L.) using the Xcelera software (Philips Medical Systems Eindhoven, The Netherlands).

In the parasternal long-axis views LA maximum antero-posterior (A-P) diameter was measured.

LA superior-inferior (S-I) diameter was measured from the mitral annular plane to the posterior wall of the LA in the apical 4-chamber view. In the apical 4-chamber view, LA maximum volume (LA max), at the end of LV systole, just before the opening of the mitral valve and LA minimum volume (LA min) at the end of LV diastole, just after the closure of the mitral valve, were measured $^{10}$. LA emptying fraction $\left(\mathrm{LA}_{\mathrm{EF}}\right)$ was calculated as ([La maxLA $\min ] /$ La max) x 100. LA maximum volume was also measured by biplane area-length method ${ }^{11}$ and indexed to body surface area (LAVI). LARR was defined as a reduction in LAVI $\geq 15 \%$ at late follow up $^{12}$. 


\section{Surgery}

The interventions were performed under general anesthesia with a doublelumen endotracheal tube for selective lung ventilation. The chest was entered in the second, fourth and sixth interspaces using respectively a $5-12-12 \mathrm{~mm}$ port. Thoracoscopy of the right side was done first and, in case of bilateral approach, it was followed by the left side. The technique for the monolateral approach was as previously reported ${ }^{13}$. The bilateral procedures were carried out as originally described by Yilmaz et. $\mathrm{al}^{14}$.

In all patients (monolateral and bilateral) high frequency stimulation (HFS) of the right vagal nerve at the level of the mediastinum and at the four major ganglionated plexi $\left(\mathrm{GP}_{\mathrm{S}}\right.$, [right superior GP, right inferior GP, left superior GP and left inferior GP)] was carried out and the vagal respone on the atrioventricular node was recorded (10V , 1.5-ms pulse width impulse at 1000 pulses per minute from a temporary external pacemaker [Oscor, Oscor INC., Palm Harbor, FL])

In patients undergoing a monolateral approach, the isolation of pulmonary veins was performed with a Cobra ${ }^{\circledR}$ Adhere XL (Estech, Danville, Ca) temperature-controlled, monopolar radiofrequency system. The temperature was set at $60^{\circ} \mathrm{C}$, the timing at 120 seconds. The number of ablations performed ranged from 2 to 4 (mean 2.8 0.4 ). The ablation catheter was pushed under the superior caval vein (SCV) into the transverse sinus and placed behind the left atrial appendage (LAA) encircling the four PVs to create the box-lesion. Before starting, the ablation the fat pad in the atrial groove was bluntly dissected to provide a better placement of the ablation probe and enhance higher penetration energy to destroy the GPs located inside this fat pad. 
sheath 8F (SL0, St. Jude Medical Daig Division, Inc., Minnetonka, MN, USA) was advanced into the LA. The patient was heparinised to keep the activated clotting time $>300$ seconds. During rapid ventricular pacing from the His catheter, contrast was injected through the long sheath in order to visualize PVs and the LA. PVs were mapped with suitably sized circular mapping catheter (Lasso, Biosense Webster, Inc, Diamond. Bar, CA, USA) placed at the ostium of the PVs.

In all patients, epicardial pacing and endocardial recordings were utilized to demonstrate entrance and exit block; entrance block was defined as failure to capture the PVs during pacing from the left atrium at $18 \mathrm{~V}$ and $1.5-\mathrm{ms}$ pulse width and the absence of pulmonary veins potentials (PVPs) seen on the Lasso catheter. Exit block was defined by failure to capture the left atrium during the pacing from the PVs. by failure to capture when pacing from each dipole of the Lasso catheter with an output of $10 \mathrm{~mA}$ and $2.0 \mathrm{~ms}$ pulse width. In case of sinus rhythm after PV ablation, induction of AF was attempted 5 times by pacing in the coronary sinus for 10 second at the shortest cycle length resulting in 1:1 atrial capture. AF was considered inducible if it lasted more than 1 minute. If $\mathrm{AF}$ was not inducible isoproterenol was infused at rates of $10-20 \mu \mathrm{g} / \mathrm{min}$. If AF was still inducible (or was not terminated) linear lesions were carried out.

We identified the conduction gaps from the endocardium and ablated those with a $3.5 \mathrm{~mm}$ tip-catheter (ThermoCool, Biosense Webster, Inc., Diamond. Bar, CA, USA) trough the sheath in the LA. The precise location of the linear lesions was visualized with the Cobra ${ }^{\circledR}$ Adhere XL (Estech, Danville, Ca) and with the Coolrail probe (Atricure Inc, Westchester, Ohio, USA) in situ and using fluoroscopy. Gaps in linear lesions were defined as low amplitude and fragmented or narrowly split double atrial potentials. 
In case of persistence of $\mathrm{AF}$, a left isthmus line was made starting from the ablation line on the antrum of the left inferior PV and crossing the CS, using the the Max 3 pen. (Atricure Inc, Westchester, Ohio, USA) on the epicardial side. This line was completed by the EP endocardially from the mitral annulus towards the CS with the ThermoCool catether (ThermoCool, Biosense Webster, Inc., Diamond. Bar, CA, USA)

The endpoint of ablation of the mitral isthmus was the bidirectional block which was achieved when the following criteria were met: 1) proximal-todistal activation sequence along the CS catheter after pacing lateral to the line in the LA appendage; 2) Late activation on the opposite side after pacing on the septal side of the line through the CS; 3) widely separated local double potentials along the whole length of the ablation line.

In the bilateral group, an inferior vena cava (IVC)-to-SVC and SVC circumferential lesions were added when patients with persistent and longstanding persistent $\mathrm{AF}$ had a right atrial volume $\geq 58 \mathrm{ml}$. IVC circumferential isolation was performed in patients with a small portion of intrapericardial IVC to be sure that the SVC-IVC line would stop at an area of no conduction. The isolation of the SVC and the IVC was confirmed by testing of conduction block across the ablation lines.

In both groups, if the patient had a history of typical right atrial flutter or this arrhythmia became apparent during the procedure, we performed a cavotricuspid isthmus line (CTI) endocardially. The endpoint was bidirectional block and the presence of widely separated double potentials along the whole length of the ablation line.

In the bilateral group, in patients with CHADS2 score $\geq 1$, or in presence of a rapid firing coming from the LAA, and when the procedure was deemed safe, LAA exclusion/ closure was performed under transesophageal 
echocardiographic (TEE) guidance employing a stapler (Endo GIA, Covidien, Norwalk, CT) or a clip (Atricure, West Chester, OH). The absence of flow was confirmed by intraoperative transesophageal echocardiography. The lesion set in the two Groups is shown in Table 2.

\section{Statistical Analysis}

Normal values were expressed as mean \pm one standard deviation (SD), nonnormal values as median and interquartile range (IQR) and categorical variables as percentages. T test, Wilcoxon and McNemar's tests were employed where appropriate.

We analyzed all of the intermittent data available in terms of time-related prevalence of atrial fibrillation with a multiphase hazard decomposition $\operatorname{method}^{15}$.Non-time-related event data and time-related prevalences are presented as percentages with asymmetric $68 \%$ confidence limits (CLs), comparable to \pm one standard error. The CLs for AF prevalence were obtained with the bootstrap percentile method $^{16}$.

Analyses of prevalence of AF do not account for antiarrhythmic medications. Prevalence of antiarrhythmic medication use was estimated by mixed modeling based on medication use at each follow-up assessment. With the same method we estimated the prevalence of Warfarin use at time of each follow-up. Finally, the use of electrical cardioversion was analyzed as repeated event and is presented as cumulative incidence (events per patient) ${ }^{9}$ and the Gray's test ${ }^{17}$ was employed to compare two different cumulative incidence curves.

Statistical analyses were performed using SPSS release 12.0 (SPSS, Chicago, IL, USA) and Curve Expert Professional release1.0.1 (D.G. Hyams, Chattanooga, TN, USA).P values less than 0.05 were considered significant. 


\section{Results}

\section{Early Results}

In the monolateral group none of the patients showed entrance and/or exit block after the epicardial ablation. Seventeen patients had at least one PV not isolated, which needed an endocardial touch-up. After completing PV isolation endocardially all these patients had a conduction delay superior to 200 msec. at the level of the posterior wall of the LA but none had block. In the bilateral group, two patients with paroxysmal AF had no extra lesions besides PVs antral ablation because AF was no longer inducible. In three patients with inducible AF after PVs ablation, we performed an additional roof line and no more arrhythmias were seen. A roof and an inferior line were carried out in the other 30 patients of the bilateral group. During endocardial mapping 30 patients (86\%) showed entrance and exit block whereas in 3 patients $(8.5 \%)$ there was a clear gap at the junction of the right superior PV with the roof of the left atrium, one patient (2.8\%) showed a gap in the lateral portion of the roof line and one patient $(2.8 \%)$ had a gap in the middle of the inferior line. These gaps were closed endocardially.

Three patients (15.7\%) in the monolateral and $7(20.0 \%)$ in the bilateral Group had a mitral isthmus line and in all case a complete block was achieved. In the bilateral group 10 patients $(28.5 \%)$ had an IVC-to-SVC lesion, 8 (22.8\% a circumferential SVC lesion and 3 $(8.5 \%)$ a IVC circumferential isolation.

A cavo-tricuspid isthmus (CTI) line was carried out in two (10.5\%) and 3 patients (8.5\%), of the monolateral and bilateral group, respectively, with successful bidirectional block. 
All the procedures could be completed as planned without any conversion to cardiopulmonary bypass. Median operative time was 216 minutes (IQR 132391 ) in the monolateral and 268 minutes (IQR 186-477) in the bilateral procedure $(\mathrm{p}<0.001)$. There were neither early deaths nor complications during the postoperative course. Median Intensive care unit (ICU) and median in-hospital length of stay were comparable in the two groups (6.9 hours [IQR 4.0-14.0] vs. 6.2 hours [5.5-13.4], $\mathrm{p}=0.61$; 3.6 days [2.7-4.3] vs. 3.4 days [2.6-4.1], $\mathrm{p}=0.8)$.

No patient died during the follow up. There was a significant improvement in median EHRA (European Hear Rhythm Association) score in both groups (both, 1[IQR 1-2], p $<0.001$ vs. baseline). Finally, no thromboembolic event occurred during the follow-up.

\section{AF Recurrence}

Time-related prevalence of postoperative AF (Figure $1 \mathrm{~A}-\mathrm{B}$ ) in patients undergoing monolateral thoracoscopic approach or bilateral thoracoscopic ablation were $44.4 \%(41.3-47.4)$ and $35.5 \%$ (33.2-38.2) at two weeks $(\mathrm{p}=0.06), 30.4 \%(27.3-34.9)$ and $27.4 \%(24.5-31.4)$ at three months $(\mathrm{p}=0.08), 14.2 \%(11.6-18.1)$ and $6.6 \%(5.8-8.3)$ at 6 months $(\mathrm{p}=0.001), 13.3$ $\%(11.0-17.4)$ and $5.2 \%(4.2-6.7)$ at 12 months $(\mathrm{p}<0.001)$, respectively.

Figure $1 \mathrm{C}$-D shows estimated prevalence of postoperative atrial fibrillation by AF type. At 1 year it was 21.1\% (17.6-24.9) and 8.2\% (5.1-11.6) in long standing persistent $(\mathrm{p}<0.001), 13.2 \%(10.6-17.8)$ and $3.8 \%(1.4-6.9)$ in persistent $(\mathrm{p}<0.001)$ and $5.6 \%(2.8-8.3)$ and $3.2(1.0-6.5)$ in paroxysmal AF $(\mathrm{p}=0.64)$ in monolateral and bilateral group, respectively

At 12 months estimated prevalence of AAD were $26 \%$ (22.4-30.1) and 18.0\% $(15.5-21.7, \mathrm{p}=0.04)$ 
When comparing prevalence of AAD by AF type, it was significantly lower in the bilateral group in patients in long-standing persistent AF (26.2\% [17.6-30.4] vs.38.1\% [34.3-43.4], p<0.001) and in persistent $(16.0 \%$ [13.4$20.6]$ vs. $26.3 \%$ [22.2-30.7], $\mathrm{p}<0.001)$ where it was comparable in paroxysmal AF (12.2\% [9.7-15.4] vs.14.9\% [9.9-17.8], $\mathrm{p}=0.7)$.

One-year prevalence of Warfarin use were 48.2\% (44.2-52.2) in the monolateral and $29.0 \%(26.2-33.1, \mathrm{p}<0.001)$ in the bilateral group, respectively (Figure $2 \mathrm{~A}-\mathrm{D})$.

This difference was still observed in long standing-persistent (52.5\% [48.8$55.2]$ vs.35.5 \% [29.7-38.2] vs., $\mathrm{p}<0.001)$ and persistent (35.3\% [32.5-39.2] vs.22.7 \% [16.1-24.8], $\mathrm{p}<0.001)$ whereas in paroxysmal AF data were comparable (19.4\% [16.3-23.3] vs.17.3 \% [15.4-21.2], $\mathrm{p}=0.6)$

Finally, the cumulative incidence of electrical cardioversion was $0.05 /$ patient in monolateral Group and 0.04/patient in bilateral group $(\mathrm{p}=0.841)$.

In the bilateral group, four patients ( 2 long-standing persistent, 1 persistent and 1 paroxysmal) had a supraventricular tachycardia (SVT) occurring more than three months after the hybrid procedure. Two patients underwent an electrophysiological study and catheter ablation. One patient was found to have AF due to a remaining gap at the junction of the right superior PV with the roof of the LA. The other patient had a left atrial flutter. These 2 patients have been followed for at least five months and have not experienced any SVT anymore off AAD. The other two patients with SVT were medically treated.

In the monolateral group 5 patients with long-standing persistent LAF had SVT recurrence occurring more than three months after the hybrid procedure. One patient underwent electrophysiological study which showed incomplete 
isolation of the 4 PVs and a gap in the ablation line infero-posterior at the right side. This patient had a catheter ablation whereas the other patients were treated by rate control.

\section{Echocardiographic results}

Table 3 shows echocardiographic data. At 3 month- follow-up biplane LAVI was significantly reduced only in patients undergoing bipolar hybrid procedure ( $\mathrm{p}=0.05$ and $\mathrm{p}=0.03$ in monopolar and bipolar, respectively). It further decreased in both groups without reaching statistical significance but it was lower in the bilateral group. Based on the cut-off value $(\geq 15 \%$ decrease in LAVI) LARR occurred in $47.3 \%(\mathrm{n}=9)$ of patients in the monolateral group and in $85.7 \%(n=30)$ of patients in the bilateral group $(\mathrm{p}<0.001)$.

$\mathrm{LA}_{\mathrm{EF}}$ raised only in patients undergoing bipolar hybrid procedure ( $\mathrm{p}=0.6$ and $\mathrm{p}=0.02$ in monopolar and bipolar, respectively). It further increased not significantly in both groups at 12-month- control. Nonetheless, LA $\mathrm{EF}_{\mathrm{EF}}$ was significantly higher in the bilateral group at each control.

Both LA diameters decreased significantly at 3 months (LA A-P, $p=0.02$; LA S-I $p=0.03$ ) and one year (LA A-P, $p=0.04$; LA S-I p=0.008) in patients undergoing bipolar hybrid procedure. In patients who underwent monopolar hybrid ablation LA diameters decreased significantly at 3 months (LA A-P, $\mathrm{p}=0.02$; LA S-I $\mathrm{p}=0.03$ ) whereas at one year there were a further nostatistically-significant reduction (LA A-P, $\mathrm{p}=0.73$; LA S-I $\mathrm{p}=0.81$ ).

\section{Comment}

Percutaneous ablation techniques have become the second line strategy to cure patients with lone AF. Nonetheless, a worldwide survey on the methods, efficacy and safety of catheter ablation in AF showed that the success rate without $\mathrm{AAD}$ was suboptimal and major complications were not infrequent ${ }^{18}$. 
In the last few years the number of patients with lone AF considered as candidates for a stand-alone surgical procedure have been increasing although a standard surgical method for the treatment for LAF has not been established yet ${ }^{1}$. Minimally invasive, off-pump, video-assisted thoracoscopic surgical techniques enabling surgical treatment of AF through an epicardial approach on a beating heart are being employed worldwide but success rates reported in literature are highly variable ${ }^{19,20}$.

Thus, we introduced a dual endocardial and epicardial single-step approach to reduce the complication rate and improve the results ${ }^{3}$. The surgeon who has epicardial access on the beating heart through a thoracoscopy, isolates the pulmonary veins, makes a roof line (connecting left and right superior pulmonary veins) and inferior line (connecting inferior left and right pulmonary veins).In addition he/she has the possibility of making a left isthmus line from left inferior pulmonary vein to the coronary sinus (which can to be completed endocardially towards the mitral annulus) and to isolate the SVC. The endocardial "step" gives the possibility of evaluating the end points of the ablation as well as the opportunity to add an endocardial "touchup" in case of incomplete isolation of one of the pulmonary veins or if the connecting lesions are not transmural. Furthermore the EP can make lesions in regions which cannot be reached epicardially.

In addition, this procedure should potentially reduce the complication rate of standard surgical and catheter ablation procedures. Indeed, from point of view of the surgeon, the risk of post-operative arrhythmias is reduced since the lines and lesion set are controlled endocardially and also the risk of injury is lower, since the surgeon is no longer forced to perform ablations in areas which are difficult to reach, which can be ablated by the EP. 
On the other hand, from the EP point of view, there is no more risk for tamponade since the pericardium is open and the phrenic nerve and the esophagus can be protected by the surgeon if necessary. Furthermore, by reducing the total number of endocardial ablations the risk of emboli during these ablations should be potentially reduced ${ }^{21}$.

A potential drawback of the single-step approach is heparinization after the transseptal puncture which could increase the risk of epicardial bleeding and the risk of measuring a temporary block.

In this study we presented our short-term experience with the hybrid procedure in LAF and compare results of hybrid monolateral and hybrid bilateral thoracoscopic approach employing radiofrequency (RF) sources. To the best of our knowledge no data exist in the literature on the right thoracoscopic single-step hybrid procedure. The single-sided right thoracoscopic approach was preferred in patients with $\geq$ moderate COPD in order to reduce the invasiveness of the procedure and the pulmonary complication rate. A device specifically designed for a monolateral right thoracoscopic off-pump procedure was used (Cobra ${ }^{\circledR}$ Adhere XL) which has been proven to provide safe and effective cardiac ablation ${ }^{22}$. This device enables focused energy delivery through suction technology which allows constant contact throughout the procedure between probe and tissue. In addition, the precise energy delivery also prevents collateral tissue damage. This device was chosen because of the lack of maneuverability of bipolar clamps which can hamper the orientation of the probe and constrain the variety of achievable lesion sets when employed from the right side. In the absence of significant pulmonary disease a bilateral thoracoscopic approach was chosen following the technique originally described by Yilmaz et. $\mathrm{al}^{14}$. The current literature is extremely difficult to interpret. This confusion is 
compounded by a lack of consensus on methods and timing of follow-up evaluation as well as the absence of strict definitions of success. The workforce on evidence-based surgery of the Society of Thoracic Surgeons ${ }^{9}$ proposed an approach to report success/failure. They suggested analyzing all the intermittent data available in terms of time-related prevalence (burden) of atrial fibrillation ${ }^{9}$ In the present study we report our results as time-related prevalence of postoperative AF, ADD use and Warfarin use.

Time-related prevalence of AF at one year was significantly lower in the bilateral group $(\mathrm{p}<0.001)$ in long-standing persistent and persistent $A F$. Accordingly, these patients showed a lower 12-month- prevalence of AAD and Warfarin use (all, $\mathrm{p}<0.001$ ) in long-standing persistent and persistent AF whereas in paroxysmal AF there was no statistically significant difference. Longer duration of $\mathrm{AF}$ is known to cause progressive remodeling and increased LA volume and long-standing persistent and persistent AF may be considered to be advanced stages of the arrhythmia characterized by significant changes in the atrial tissue and muscle (substrate modification) that leads to chaotic electrical activity. Thus, these patients might need more areas in the heart ablated than what is done in the monolateral approach and they might benefit much more from the bilateral/bipolar procedure which increases the likelihood that ablation lines are transmural. Indeed it has been demonstrate that monopolar sources are unable to create transmural lesions when used from the epicardial surface on the beating heart ${ }^{23}$ especially when the wall thickness is greater than $4 \mathrm{~mm}^{24}$. Nonetheless, Wong and coworkers ${ }^{25}$ describe a combined technique where irrigated unipolar RF is sequentially applied endocardially and then epicardially along the same linear line of block gaining satisfactory results in terms of conduction block. 
In any case, these shortcomings should be addressed by EP who can check for possible incomplete transmurality of the epicardial lines endocardially and can complete any line by focused endocardial applications. In our experience with the hybrid monolateral approach with a monopolar device all the PVs where isolated after the endocardial touch-up, but all patients had only conduction delay and no block from the box lesion. So the transient success could be related to the recovery of conduction from the roof and inferior line.

However, in both groups, the prevalence of Warfarin use was not low and this may be related to the fact that $63.1 \%(\mathrm{n}=12)$ of patients in the monopolar group and $51.4 \%(\mathrm{n}=18)$ had a preoperative $\mathrm{CHADS}_{2}$ score $>2$. However, However, although we recommend stopping Warfarin after 3 months if the patient has a CHADS2 score $<2$ and she/he is in SR at the Holter recording, this is often at the discretion of referring cardiologists.

In addition, only patients undergoing bilateral approach showed a significant improvement in LA function as well as a significant reduction in LA dimensions and LAVI and, based on the cut-off value $(\geq 15 \%$ decrease in LAVI) LARR occurred in $47.3 \%$ of patients in the monolateral group and in $85.7 \%$ of patients in the bilateral group $(\mathrm{p}<0.001)$. Due the small number of patients in the monolateral group we could not compare $\mathrm{LA}_{\mathrm{EF}}$, LA diameters and LA volumes by AF type. However, a high percentage of patients (73.7 $\%)$ in this group had a long-standing persistent or persistent AF with and higher extent of substrate modifications and atrial structural remodeling and this could explain the lack of LARR in this group. Indeed, all the five patients with paroxysmal $\mathrm{AF}$ in the monopolar group showed $\mathrm{a} \geq 15 \%$ decrease in LAVI. 
Finally, no difference was detected in early and late clinical outcomes, EHRA score and freedom from thrombo-embolism. The latter finding suggest that, in our experience, the excision /closure of LA appendage did not have any repercussion on the incidence of postoperative embolic events even though the small number of patient and the limited follow-up time of our study suggests extreme caution in interpreting these data.

\section{Limitations of the Study}

This study has some limitations which have to be pointed out. The small patient population does not allow to draw any conclusion about effectiveness of this technique. Furthermore, the follow-up was limited. Larger series with long-term follow up are needed to confirm the effectiveness of the hybrid approach and to establish whether the right-sided thoracoscopic hybrid procedure may represent a suitable less-invasive choice for all LAF patients referred to surgery.

Furthermore, while data regarding postoperative AF prevalence were obtained from a high number of observations and this allowed us to compare prevalence by AF type, we could not compare echocardiographic parameters in subgroup of patients.

Moreover, our study did not compare results of the hybrid approach to catheter ablation. However, this will be the subject of ongoing studies.

Finally, atrial function was studied employing only the emptying fraction and neither pulsed-wave Doppler nor Tissue Doppler Imaging (TDI) and LA strain were employed which would have given more detailed information about LA function after AF surgical ablation. All these aspects deserve further investigations 


\section{Conclusions}

Even with the above mentioned limitations, we can conclude that the hybrid bilateral approach with a bipolar device for the treatment of LAF showed a good one-year success rate independently of the AF type and a seems to be the better choice for LAF fibrillation referred to surgery. In contrast, the hybrid monolateral approach was ineffective in long-standing persistent and persistent LAF. Nonetheless, it had comparable one-year results in paroxysmal AF thus, when combined with an endocardial touch-up, it may represent a suitable less-invasive alternative in these patients. Our findings need to be confirmed by further larger studies.

Acknowledgments

We gratefully acknowledge Mr.Pol Chambille and MRS.Monique De Jong for their invaluable help. We Thank Dr Orlando Parise for statistical analysis. 
Table 1. Hybrid Procedures: Preoperative Data $(n=54)$

\begin{tabular}{|c|c|c|c|}
\hline & $\begin{array}{c}\text { Right } \\
\text { Thoracoscopy } \\
(\mathrm{n}=19)\end{array}$ & $\begin{array}{c}\text { Bilateral } \\
\text { Thoracoscopy } \\
(\mathbf{n}=35)\end{array}$ & $\mathbf{p}$ \\
\hline Age & $61.2 \pm 8.6$ & $57.1 \pm 9.5$ & 0.073 \\
\hline $\mathrm{M} / \mathrm{F}$ & $16 / 3(84.2 / 15.8)$ & $24 / 11(68.5 / 31.4)$ & 0.23 \\
\hline BMI & $27.6 \pm 4.6$ & $26.8 \pm 3.6$ & 0.84 \\
\hline Diabetes & $0(0)$ & $1(2.8)$ & 0.71 \\
\hline Hypertension & $7(36.8)$ & $15(42.8)$ & 0.55 \\
\hline TIA/CVA & $1(5.2)$ & $0(0)$ & 0.28 \\
\hline \multicolumn{4}{|l|}{ Type of preoperative AF } \\
\hline Paroxysmal & $5(26.3)$ & $16(45.7)$ & \\
\hline Persistent & $4(21.1)$ & $8(22.8)$ & 0.054 \\
\hline Long-standing persistent & $10(52.6)$ & $11(31.5)$ & \\
\hline \multicolumn{4}{|l|}{ Prevalence of AF ( $68 \% \mathrm{CI})$} \\
\hline Paroxysmal & $20.0[16.8-23.3]$ & $22.3[19.2-257]$ & \\
\hline Persistent & $34.7[31.2-38.9]$ & $32.6[29.1-36.9]$ & 0.74 \\
\hline Long-standing persistent & $63.6[59.9-67.1]$ & $61.3[57.4-65.0]$ & \\
\hline EHRA Score & $4[3-4]$ & $4[3-4]$ & $>0.9$ \\
\hline Duration of preoperative AF (yrs.) & $5[3-8.5]$ & $5[4.2-9.0]$ & 0.66 \\
\hline \multicolumn{4}{|l|}{ Antyarrhythmic Drugs } \\
\hline Amiodaron & $2(10.5)$ & $7(20.0)$ & \\
\hline Dysopiramide & $1(5.3)$ & $2(5.7)$ & \\
\hline Flecainide & $6(31.5)$ & $15(42.8)$ & 0.08 \\
\hline Propaphenon & $1(5.3)$ & $2(5.7)$ & \\
\hline Sotalol & $5(26.3)$ & $11(31.4)$ & \\
\hline Electrical cardioversion & $15(78.9)$ & $17(48.5)$ & 0.06 \\
\hline \multicolumn{4}{|l|}{ Previous Catheter Ablation } \\
\hline For AF & $6(31.5)$ & $12(34.3)$ & 0.65 \\
\hline For Atrial Flutter & $5(26.3)$ & $9(25.7)$ & \\
\hline Preoperative Pace Maker & $2(10.5)$ & $2(7.1)$ & 0.88 \\
\hline \multicolumn{4}{|l|}{ Anticoagulant status } \\
\hline Sodium Warfarin & $16(84.2)$ & $30(85.7)$ & 0.76 \\
\hline Aspirin & $5(26.3)$ & $10(28.5)$ & \\
\hline $\operatorname{LAVI}\left(\mathrm{mL} / \mathrm{m}^{2}\right)$ & $47 \pm 11$ & $50 \pm 12$ & 0.08 \\
\hline $\mathrm{LA}_{\mathrm{Max}}\left(\mathrm{mL} / \mathrm{m}^{2}\right)$ & $49 \pm 20$ & $52 \pm 25$ & 0.63 \\
\hline $\mathrm{LA}_{\mathrm{Min}}\left(\mathrm{mL} / \mathrm{m}^{2}\right)$ & $30 \pm 15$ & $32 \pm 18$ & 0.90 \\
\hline $\mathrm{LA}_{\mathrm{EF}}(\%)$ & $38 \pm 12$ & $38 \pm 11$ & 0.90 \\
\hline LA A-P $(\mathrm{cm})$ & $5.0 \pm 0.5$ & $5.2 \pm 0.5$ & 0.77 \\
\hline LA S-I $(\mathrm{cm})$ & $6.4 \pm 0.5$ & $6.3 \pm 0.7$ & 0.60 \\
\hline
\end{tabular}

Normal data were presented as mean \pm 1 Standard deviation (SD), non parametric data as Median and [Interquartile Range]and discrete data as percentage (\%).Abbreviations: M/F: Male/Female; BMI: Body mass index; AF: Atrial fibrillation; CI: Confidence Interval; EHRA: European Hear Rhythm Association; LAVI: (Biplane) Left atrial volume index; $\mathrm{LA}_{\mathrm{Max}}$ : Maximum left atrial volume; $\mathrm{LA}_{\mathrm{Min}}$ : minimum left atrial volume; $\mathrm{LA}_{\mathrm{EF}}$ : Left atrial emptying fraction; LA A-P: Left atrial antero-posterior diameter; LA S-I: Left atrial antero-posterior diameter. 
Table 2. Hybrid Procedures: Lesion set $(n=54)$

\begin{tabular}{|c|c|c|}
\hline & $\begin{array}{c}\text { Right } \\
\text { Thoracoscopy } \\
(n=19) \\
\end{array}$ & $\begin{array}{c}\text { Bilateral } \\
\text { Thoracoscopy } \\
(\mathbf{n}=\mathbf{3 5})\end{array}$ \\
\hline \multicolumn{3}{|l|}{ Left atrium } \\
\hline Right PVs Isolation & $19(100)$ & $35(100)$ \\
\hline Left PVs Isolation & $19(100)$ & $35(100)$ \\
\hline Inferior line & $19(100)$ & $31(88.5)$ \\
\hline Roof line & $19(100)$ & $32(91.4)$ \\
\hline Isthmus lesion & $3(15.7)$ & $7(20.0)$ \\
\hline Endocardial gaps closure & $17(88.4)$ & $5(14.2)$ \\
\hline Excision of LA appendage & - & $8(22.8)$ \\
\hline Closure of LA Appendage with a clip & - & $7(20.0)$ \\
\hline \multicolumn{3}{|l|}{ Right atrium } \\
\hline Superior vena cava to inferior vena cava lesion & - & $10(28.5)$ \\
\hline Superior vena cava circumferential isolation & - & $8(22.8)$ \\
\hline Inferior vena cava circumferential isolation & - & $3(8.5)$ \\
\hline Cavo-tricuspid isthmus line & $2(10.5)$ & $3(8.5)$ \\
\hline Ablation of autonomic Ganglia & $19(100)$ & $35(100)$ \\
\hline
\end{tabular}

$\overline{\text { Discrete data were presented as number (percentage). Abbreviations. PVs: Pulmonary Veins; LA: Left }}$ atrium 


\section{Figure Legends}
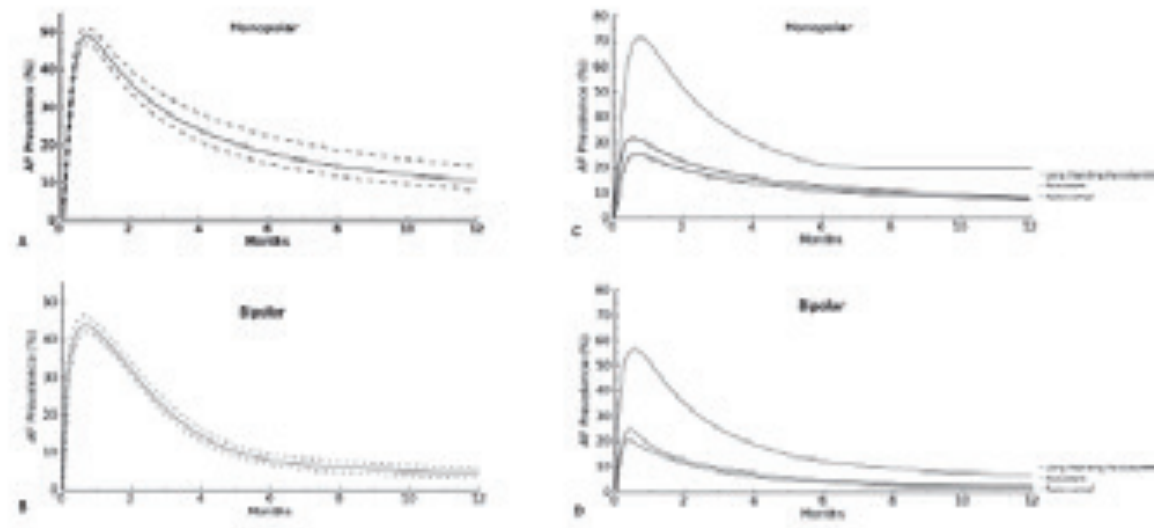

Figure 1.A Time-related prevalence of atrial fibrillation (solid line) and $68 \%$ confidence limits (broken lines) after hybrid monolateral approach with a monopolar device. B Time-related prevalence of atrial fibrillation (solid line) and 68\% confidence limits (broken lines) after hybrid bilateral approach with bipolar device. C Time-related prevalence of atrial fibrillation by AF type after hybrid monolateral approach with a monopolar device. D Time-related prevalence of atrial fibrillation by AF type after hybrid bilateral approach with a bipolar device. 

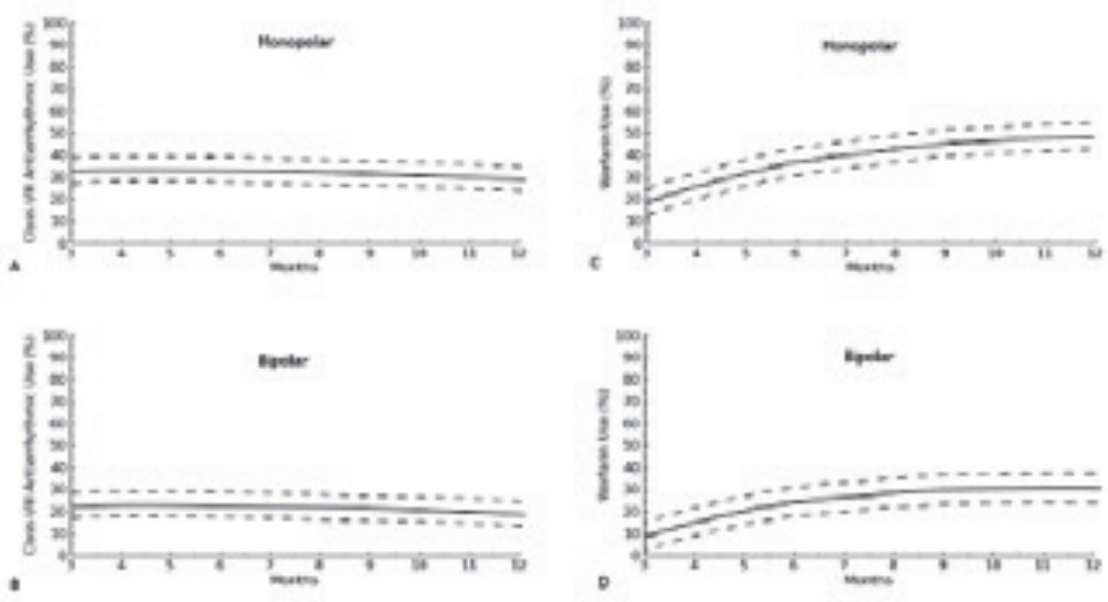

Figure 2. A. Time-related prevalence of class I/III anti-arrhythmic use a after hybrid monolateral approach with a monopolar device.. B. Time-related prevalence of class I/III antiarrhythmic use after hybrid bilateral approach with bipolar device. C Time-related prevalence of Warfarin use after after hybrid monolateral approach with a monopolar device. D Timerelated prevalence of Warfarin use after hybrid bilateral approach with bipolar device. 
References

1. Shen J, Bailey M, Damiano RJ. Surgery for Lone Atrial Fibrillation: Present State-of-the-Art. Innovations (Phila). 2009:248-255.

2. Stamou SC, Khabbaz KR, Mahmood F, Zimetbaum P, Hagberg RC.A multidisciplinary approach to the minimally invasive pulmonary vein isolation for treatment of atrial fibrillation. Ann Thorac Surg. 2010;89:64850.

3. La Meir M, De Roy L, Gourdin M. A Hybrid approach for treatment of patients with atrial fibrillation with radiofrequency catheters. In: Hybrid and minimally invasive cardiac intervention. Maessen J and Crijns H,editors. Turin: Minerva Medica,2010: 9-13.

4. Krul SP, Driessen AH, van Boven WJ, Linnenbank AC, Geuzebroek GS, Jackman WM, Wilde AA, de Bakker JM, de Groot JR.Thoracoscopic VideoAssisted Pulmonary Vein Antrum Isolation, Ganglionated Plexus Ablation and Periprocedural Confirmation of Ablation Lesions. First Results of a Hybrid Surgical-Electrophysiological Approach for Atrial Fibrillation. Circ Arrhythm Electrophysiol. 2011;4:262-70.

5. Fuster V, Rydén LE, Cannom DS, Crijns HJ, Curtis AB, Ellenbogen KA, Halperin JL, Le Heuzey JY, Kay GN, Lowe JE, Olsson SB, Prystowsky EN, Tamargo JL, Wann S, Smith SC Jr, Jacobs AK, Adams CD, Anderson JL, Antman EM, Halperin JL, Hunt SA, Nishimura R, Ornato JP, Page RL, Riegel B, Priori SG, Blanc JJ, Budaj A, Camm AJ, Dean V, Deckers JW, Despres C, Dickstein K, Lekakis J, McGregor K, Metra M, Morais J, Osterspey A, Tamargo JL, Zamorano JL; American College of Cardiology/American Heart Association Task Force on Practice Guidelines; 
European Society of Cardiology Committee for Practice Guidelines; European Heart Rhythm Association; Heart Rhythm Society. ACC/AHA/ESC 2006 Guidelines for the Management of Patients with Atrial Fibrillation: a report of the American College of Cardiology/American Heart Association Task Force on Practice Guidelines and the European Society of Cardiology Committee for Practice Guidelines (Writing Committee to Revise the 2001 Guidelines for the Management of Patients With Atrial Fibrillation): developed in collaboration with the European Heart Rhythm Association and the Heart Rhythm Society.Circulation. 2006;114: 257-354.

6. European Heart Rhythm Association; European Association for CardioThoracic Surgery, Camm AJ, Kirchhof P, Lip GY, Schotten U, Savelieva I, Ernst S, Van Gelder IC, Al-Attar N, Hindricks G, Prendergast B, Heidbuchel H, Alfieri O, Angelini A, Atar D, Colonna P, De Caterina R, De Sutter J, Goette A, Gorenek B, Heldal M, Hohloser SH, Kolh P, Le Heuzey JY, Ponikowski P, Rutten FH; ESC Committee for Practice Guidelines, Vahanian A, Auricchio A, Bax J, Ceconi C, Dean V, Filippatos G, Funck-Brentano C, Hobbs R, Kearney P, McDonagh T, Popescu BA, Reiner Z, Sechtem U, Sirnes PA, Tendera M, Vardas PE, Widimsky P; Document Reviewers, Vardas PE, Agladze V, Aliot E, Balabanski T, Blomstrom-Lundqvist C, Capucci A, Crijns H, Dahlöf B, Folliguet T, Glikson M, Goethals M, Gulba DC, Ho SY, Klautz RJ, Kose S, McMurray J, Perrone Filardi P, Raatikainen P, Salvador MJ, Schalij MJ, Shpektor A, Sousa J, Stepinska J, Uuetoa H, Zamorano JL, Zupan I. Guidelines for the management of atrial fibrillation: the Task Force for the Management of Atrial Fibrillation of the European Society of Cardiology (ESC).Europace 2010; 12: 1360-1420.

7. European Heart Rhythm Association (EHRA); European Cardiac Arrhythmia Scoiety (ECAS); American College of Cardiology (ACC); 
American Heart Association (AHA); Society of Thoracic Surgeons (STS), Calkins H, Brugada J, Packer DL, Cappato R, Chen SA, Crijns HJ, Damiano RJ Jr, Davies DW, Haines DE, Haissaguerre M, Iesaka Y, Jackman W, Jais P, Kottkamp H, Kuck KH, Lindsay BD, Marchlinski FE, McCarthy PM, Mont JL, Morady F, Nademanee K, Natale A, Pappone C, Prystowsky E, Raviele A, Ruskin JN, Shemin RJ. HRS/EHRA/ECAS expert consensus statement on catheter and surgical ablation of atrial fibrillation: recommendations for personnel, policy, procedures and follow-up. Heart Rhythm. 2007;4:816-861.

8. Nathell L, Nathell M, Malmberg P, Larsson K. COPD diagnosis related to different guidelines and spirometry techniques. Respir Res 2007; 8: 89.

9. Shemin RJ, Cox JL, Gillinov AM, Blackstone EH, Bridges CR; Workforce on Evidence-Based Surgery of the Society of Thoracic Surgeons.Workforce on Evidence-Based Surgery of the Society of Thoracic Surgeons.Guidelines for reporting data and outcomes for the surgical treatment of atrial fibrillation. Ann Thorac Surg. 2007;83:1225-30.

10. Kuppahally SS, Akoum N, Burgon NS, Badger TJ, Kholmovki EG, Vijayakumar MS, Rai SW, Blauer J, Fish EN, Di Bella EVR, MacLeod RS, McGann C, Litwin SE, Marrouche NF. Left atrial strain and strain rate in patients with paroxysmal and persistent atrial fibrillation: relationship to left atrial structural remodeling detected by delayed enhancement-MRI. Circ Cardiovasc Imaging 2010; 3:231-9.

11. Jiamsripong P, Honda T, Reuss CS, Hurst RT, Chaliki HP, Grill DE, Schneck SL, Tyler R, Khandheria BK, Lester SJ. Three methods for evaluation of left atrial volume. Eur J Echocardiogr. 2008; 9: 351-5. 
12. Tops LF, Delgado V, Bertini M, Marsan NA, Den Uijl DW, Trines SA, Zeppenfeld K, Holman E, Schalij MJ, Bax JJ. Left atrial strain predicts reverse remodeling after catheter ablation for atrial fibrillation. J Am Coll Cardiol. 2011; 57:324-31.

13. La Meir M, De Roy L, Blommaert D, Buche M. Treatment of lone atrial fibrillation with a right thoracoscopic approach> Ann Thorac Surg. 2007 Jun;83:2244-5.

14. Yilmaz A, Van Putte BP, Van Boven WJ. Completely thoracoscopic bilateral pulmonary vein isolation and left atrial appendage exclusion for atrial fibrillation. J Thorac Cardiovasc Surg. 2008;136:521-22.

15. Blackstone EH, Naftel DC, Turner ME Jr. The decomposition of timevarying hazard into phases, each incorporating a separate stream of concomitant information. J Am Stat Assoc,1986; 81: 615-624.

16. Efron B, Tibshirani RJ..An introduction to the bootstrap. New York: Chapman and Hall/CRC 1998.

17. Gray RJ. A class of K-sample tests for comparing the cumulative incidence of a competing risk. Ann Stat 1988; 16: 1140-54.

18. Cappato R, Calkins H, Chen SA, Davies W, Iesaka Y, Kalman J, Kim YH, Klein G, Natale A, Packer D, Skanes A, Ambrogi F, Biganzoli E. Updated worldwide survey on the methods, efficacy, and safety of catheter ablation for human atrial fibrillation. Circ Arrhythm Electrophysiol. 2010;3:32-8.

19. Pruitt JC, Lazzara RR, Ebra G. Minimally invasive surgical ablation of atrial fibrillation: the thoracoscopic box lesion approach. J Interv Card Electrophysiol. 2007; 20(3):83-7. 
20. Beyer E, Lee R, Lam BK. Point: minimally invasive bipolar radiofrequency ablation of lone atrial fibrillation: early multicenter results. J. Thorac. Cardiovasc. Surg. 2009; 137: 521-526.

21. Sauren LD, La Meir M, De Roy L, Pison L, van der Veen FH, Mess WH, Crijns HJ, Maessen JG. Increaesd number of cerebral emboli during percutaneous endocardial pulmonary vein isolation versus a thoracoscopic epicardial approach. Eur J Cardiothorac Surg. 2009;36:833-7.

22. Klinkenberg TJ, Ahmed S, Ten Hagen A, Wiesfeld AC, Tan ES, Zijlstra F, Van Gelder IC. Feasibility and outcome of epicardial pulmonary vein isolation for lone atrial fibrillation using minimal invasive surgery and high intensity focused ultrasound. Europace. 2009; 11:1624-31.

23. Speziale G, Bonifazi R, Nasso G, Bartolomucci F, Caldarola P, Fattouch K, Martines G, Tavazzi L, Chierchia SL. Minimally invasive radiofrequency ablation of lone atrial fibrillation by monolateral right minithoracotomy: operative and early follow-up results.Ann Thorac Surg. 2010;90:161-7.

24. van Brakel TJ, Bolotin G, Salleng KJ, Nifong LW, Allessie MA, Chitwood WR Jr, Maessen JG. Evaluation of epicardial microwave ablation lesions: histology versus electrophysiology. Ann Thorac Surg.2004; 78:13971402.

25. Wong JW Ensuring transmurality using irrigated radiofrequency modified maze in surgery for atrial fibrillation--a simple and effective way. Heart Lung Circ. 2004;13:302-8. 
Minimally Invasive Surgical Treatment of Lone Atrial Fibrillation: Early Results of Hybrid Versus Standard Minimally Invasive Approach Employing Radiofrequency Sources.

Mark La Meir, Sandro Gelsomino, Laurent Pison, Roberto Lorusso, Fabiana Lucà, Orlando Parise, Gian Franco Gensini, Harry Crijns, Francis Wellens and Jos Maessen. Int J Cardiol. 2012 May 2.

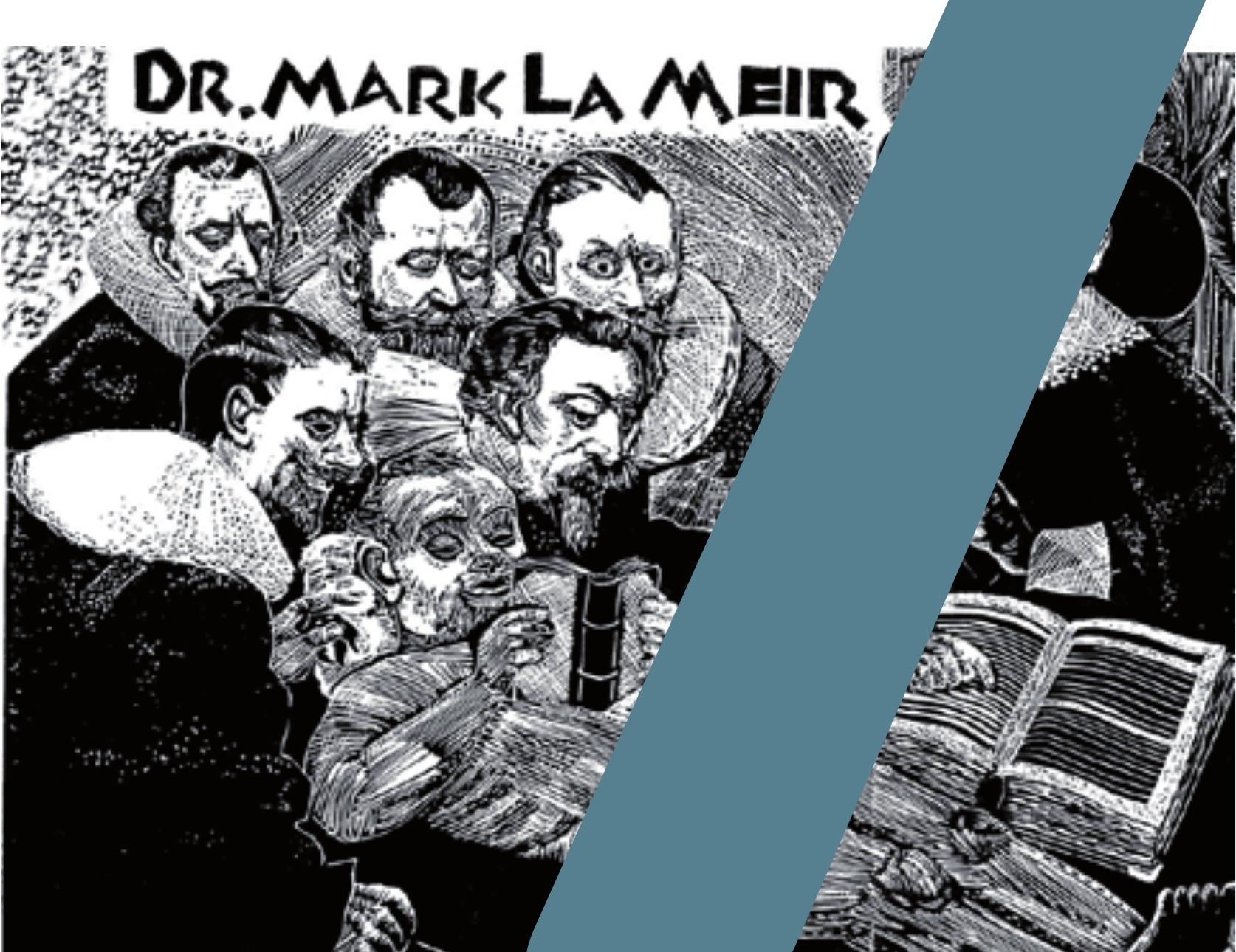




\section{Chapter 7}

Minimally Invasive Surgical Treatment of Lone Atrial Fibrillation: Early Results of Hybrid Versus Standard Minimally Invasive Approach Employing Radiofrequency Sources.

Mark La Meir, Sandro Gelsomino, Laurent Pison, Roberto Lorusso, Fabiana Lucà, Orlando Parise, Gian Franco Gensini, Harry Crijns, Francis Wellens and Jos Maessen.

Int J Cardiol. 2012 May 2.

\section{Abstract}

Background. We compared short-term results of hybrid versus standard surgical bilateral thoracoscopic approach employing radiofrequency (RF) sources in the surgical treatment of lone atrial fibrillation (LAF)

Methods and Results. Between January 2008 and July 2010 sixty-three consecutive patients with LAF underwent minimally invasive surgery. Thirty-five (55.5\%) had hybrid approach whereas 28 (45.5\%) underwent bilateral thoracoscopic standard procedure (no-hybrid group). All patients underwent continuous 7-day Holter Monitoring (HM) at 3, 6 months and 1 year. Time-related prevalence of postoperative AF at 12 months in hybrid and no-hybrid procedure were $5.2 \%$ (68\% CI 4.2-6.7), and $6.0 \%(3.2-9.6)$, respectively $(\mathrm{p}=0.56)$,. The hybrid group yielded better results in long standing persistent AF (8.2\% [5.1-11.6] and 14.9\% [11.6-18.3].One-year estimated prevalence of anti-arrhythmic drugs $(A A D)$ were $18.0 \%(15.5-21.7)$ and $16.7 \%([13.9-21.5] \mathrm{p}=0.65)$ in 
hybrid and no hybrid group, respectively. When comparing prevalence of AAD by AF type, it was significantly lower in hybrid patients in longstanding persistent AF (26.2 \% [17.6-30.4] vs. 38.7\% [32.9-42.7], $\mathrm{p}<0.001)$. One-year prevalence of Warfarin use was significantly higher in hybrid (29.0\% [26.2-33.1] and 13.4\% [9.9-16.3] with no difference by AF type. LA reverse remodeling occurred in $81.7 \%(n=30)$ of hybrid patients and $67.8 \%(\mathrm{n}=19)$ of no-hybrid patients at latest control $(p=0.02)$. Left atrial emptying fraction increased in both groups $(50 \pm 14 \%, \mathrm{p}<0.001$ and $52 \pm 12 \%, \mathrm{p}=0.004$ in hybrid and no-hybrid, respectively) without differences between groups $(p=0.6)$.

Conclusions. The hybrid procedure yielded excellent results in longstanding persistent AF. Our findings need to confirmed by further larger studies.

\section{Introduction}

The introduction of different energy sources ${ }^{1}$ and the development of minimally invasive procedures as an alternative to the original "cut-andsew" technique ${ }^{2,3}$ allowed a new dawn in the surgical treatment of atrial fibrillation. Meanwhile, electrophysiologists (EPs) developed more complex ablation systems that allowed the creation of linear lesions, similar to the surgical ones, while mapping the atria with threedimensional (3D) navigation systems ${ }^{4}$. Nevertheless, the reported success rate is suboptimal in both fields ${ }^{5,6}$ and the most beneficial ablation methodology for patients with lone atrial fibrillation (LAF) still remains a matter of debate. 
In the attempt to improve results obtained by standard procedures, the so called "hybrid approach" has recently been introduced, which combines a thoracoscopic epicardial ablation with a percutaneous trans-septal procedure. Nonetheless, no information exists whether this technique has clear advantages over standard thoracoscopic video-assisted surgery.

The aim of this study was, therefore, to compare short-term results of hybrid versus standard surgical bilateral thoracoscopic approach employing radiofrequency (RF) sources in terms of early and late complications, prevalence of postoperative atrial fibrillation, prevalence of antiarrhythmic medications and anticoagulant use, left atrial (LA) remodeling and LA function.

\section{Methods}

\section{Patients}

The study followed the World Medical Association guidelines concerning ethical principles for medical research involving human subjects and was approved by Institutional Ethics Board. All patients gave their informed consent.

Between January 2008 and July 2010 sixty-three consecutive patients with LAF underwent minimally invasive surgical treatment of LAF employing a radiofrequency (RF) source.

Thirty-five (55.5\%) had a hybrid approach whereas 28 (45.5\%) underwent bilateral thoracoscopic standard procedure (no-hybrid group).

Lone atrial fibrillation was defined following American College of Cardiology/American Heart Association/European Society of Cardiology (ACC/AHA/ESC) guidelines ${ }^{7}$. 
Indication for minimally invasive surgery was based on the HRS/EHRA/ECA Guidelines ${ }^{8}$. Patients were referred for hybrid procedure in case of paroxysmal, persistent or long-standing persistent AF with LA dilatation $(>4.5 \mathrm{~cm})$, after one or more failed catheter ablations, or on patient's preference. The indication was based on the history of AF and LA size. A transthoracic echocardiography and a computed tomography (CT) scan were carried out preoperatively (pulmonary vein anatomy, coronary arteries) and potential candidates to a hybrid procedure underwent lung function test (Spirometry). Exclusion criteria were a presence of atrial or left appendage thrombi, 'giant' left atrium (diameter $>6.5 \mathrm{~cm}$ ), coronary artery disease, and previous pulmonary or cardiac surgery. Table 1 shows patients baseline characteristics. Patients in the hybrid group had larger LA volumes and dimensions and a significantly higher $\mathrm{CHADS}_{2}$ [cardiac failure, hypertension, age, diabetes, stroke (doubled)] score. The other variables were comparable between groups.

\section{Follow-up and Assessment of AF}

All patients were followed-up according the Heart Rhythm Society/ European Heart Rhythm Association/ European Cardiac Arrhythmia Society (HRS/EHRA/ECA) expert consensus statement on catheter and surgical ablation of $\mathrm{AF}^{9}$. Data and outcomes were reported following the Society of Thoracic Surgeon (STS) guidelines ${ }^{10}$.

Seven-day Holter Monitoring (HM) was performed at 3, 6 months and 1 year. All patients reached 1-year follow up. Monitoring was carried out with an external loop recorder (Del Mar Reynolds, Spacelabs Healthcare, Issaquah, WA, USA) and analyzed with Lifescreen Software (Del Mar Reynolds, Spacelabs Healthcare, Issaquah, WA, USA). For analysis, 
three rhythms were considered postoperative AF: AF, atrial flutter or atrial tachycardia lasting more than $30 \mathrm{sec}$. In addition, all electrocardiograms (ECG) performed at the discretion of referring physicians/cardiologists during the first three months after surgery and in the time comprised between Holter examinations were included when patients had at least two records available for analysis. Each ECG and Holter was treated as a discrete data (presence/absence of atrial fibrillation) to calculate the estimated prevalence of $\mathrm{AF}^{10}$. A total of 785 postoperative Holter/ ECG data were retrieved (no-hybrid procedure, $\mathrm{n}=377$ hybrid procedure, $\mathrm{n}=408$ ).

\section{Anticoagulation and Anti-arrhythmic Therapy}

Anti-arrhythmic drugs (AAD) were given postoperatively to all patients but, although we recommend discontinuing AAD three months after ablation if the patient appears to be AF free, their continued use was at the discretion of referring cardiologists.

Electrical cardioversion was not attempted for patients who remained in AF after the surgical procedure and was reserved for patients who were still in AF after 3 months and 6 months.

Warfarin was administered on postoperative day 2 with INR target of 2.5 and stopped after 3 months if the Holter recording showed a sinus rhythm $(\mathrm{SR})$ or patients had a low thromboembolic risk $\left(\mathrm{CHADS}_{2} \quad\right.$ score $\left.<2\right)$.

\section{Echocardiography}

Echocardiography was carried out preoperatively and at 3 month- and 12 month- follow-up appointments using a commercially available echocardiographic system (Philips iE33; Philips Medical Systems, Eindhoven, The Netherlands). All the parameters were analyzed "off- 
line" by an experienced echocardiographer (F.L.) using the Xcelera software (Philips Medical Systems Eindhoven, The Netherlands).Left atrial A-P diameter was measured in parasternal long-axis view In the apical 4-chamber view, LA maximum volume (LA max), at the end of LV systole, just before the opening of the mitral valve and LA minimum volume (LA min) at the end of LV diastole, just after the closure of the mitral valve, were measured and LA emptying fraction $\left(\mathrm{LA}_{\mathrm{EF}}\right)$ was calculated as ([La max-LA min]/La max) x 100. LA maximum volume was also measured by biplane area-length method $^{12}$ and indexed to body surface area (LAVI). Left atrial reverse remodeling (LARR) was defined as a reduction in LAVI $\geq 15 \%$ at late follow up ${ }^{13}$.

\section{Surgery}

All operations were performed by the same cardiac surgeon (M.L.M) All hybrid procedures were carried out at the hybrid operative room of the Department of Cardiology, Maastricht University Medical Center, Maastricht, The Nederlands involving the same electrophisiologist (L.P.)

The interventions were performed under general anesthesia with a double-lumen endotracheal tube for selective lung ventilation. The chest was entered in the second, fourth and sixth interspaces using respectively a 5-12-12mm port. Thoracoscopy of the right side was done first followed by the left side. The technique was as originally described by Yilmaz et $\mathrm{al}^{14}$.

High frequency stimulation (HFS) of the right vagal nerve at the level of the mediastinum and at the four major ganglionated plexi $\left(\mathrm{GP}_{\mathrm{S}}\right.$, [right superior GP, right inferior GP, left superior GP and left inferior GP)] was carried out and the vagal respone on the atrio-ventricular node was recorded $(10 \mathrm{~V}, 1.5-\mathrm{ms}$ pulse width impulse at 1000 pulses per minute 
from a temporary external pacemaker [Oscor, Oscor INC., Palm Harbor, FL]). The isolation of pulmonary veins was performed with the Atricure bipolar radiofrequency clamp (Atricure Inc, Westchester, Ohio, USA). With the clamp placed on the antrum of the pulmonary veins (first from the right side and then from the left side) a mean of $3.0 \pm 0.4$ and $3.8 \pm 0.9$ ablations were performed in hybrid and no-hybrid group, respectively $(\mathrm{p}=0.44)$. A roof and inferior line were created using the Coolrail linear pen (Atricure Inc, Westchester, Ohio, USA) or the Max 3 unidirectional bipolar pen. (Atricure Inc, Westchester, Ohio, USA) connecting PVs from the right side, trough the transverse and oblique sinuses, with the PVs from the left side. The endpoint was entrance and exit block for the created "box". Entrance block was defined as the absence of atrial potentials inside the area of the lesions. Exit block was defined as failure to capture the remaining LA when pacing from the posterior LA with proven local capture with an output of $18 \mathrm{~V}$ and $1.5 \mathrm{~ms}$ pulse width. After creation of the box lesion (PVs isolation-roof-inferior line) the vagal response at level of $\mathrm{GP}_{\mathrm{S}}$ was tested again. The end point for ganglionated plexi (GP) ablation was the elimination of a vagal response to stimulation. In all patients this vagal response could no longer be induced with HFS, except for the right inferior GP which, being located outside the box lesion resulted not to be ablated in any patient. Thus the inferior GP was ablated with the Max 3 pen. (Atricure Inc, Westchester, Ohio, USA).

In the hybrid Group a left femoral vein puncture was made and a His bundle catheter (St Jude Medical, Inc, Minnetonka, MN, USA) and a coronary sinus (CS) catheter (Medtronic, Inc, Minneapolis, MN, USA) were placed under fluoroscopic guidance. Through the right femoral 
vein, a single trans-septal puncture was made using TEE and fluoroscopy and a long sheath 8F (SL0, St. Jude Medical Daig Division, Inc., Minnetonka, MN, USA) was advanced into the LA. The patient was heparinised to keep the activated clotting time $>300$ seconds.

During rapid ventricular pacing from the His catheter, contrast was injected through the long sheath in order to visualize PVs and the LA. PVs were mapped with suitably sized circular mapping catheter (Lasso, Biosense Webster, Inc, Diamond. Bar, CA, USA) placed at the ostium of the PVs.

In all patients epicardial pacing was utilized to demonstrate entrance and exit block; entrance block was defined as failure to capture the PVs during pacing from the left atrium at $18 \mathrm{~V}$ and 1.5 -ms pulse width and exit block was defined by failure to capture the left atrium during the pacing from the PVs.

In hybrid patients endocardial recordings at the PVs were also employed to demonstrate entrance and exit block for each PV. Entrance block was defined as the absence of pulmonary veins potentials (PVPs). Exit block was defined by failure to capture when pacing from each dipole of the Lasso catheter with an output of $10 \mathrm{~mA}$ and $2.0 \mathrm{~ms}$ pulse width. In these patients, in case of sinus rhythm after PV ablation, induction of AF was attempted 5 times by pacing in the coronary sinus for 10 second at the shortest cycle length resulting in 1:1 atrial capture. AF was considered inducible if it lasted more than 1 minute. If AF was not inducible isoproterenol was infused at rates of $10-20 \mu \mathrm{g} / \mathrm{min}$. If $\mathrm{AF}$ was still inducible (or was not terminated) linear lesions were carried out. We identified the conduction gaps from the endocardium and ablated those with a $3.5 \mathrm{~mm}$ tip-catheter (ThermoCool, Biosense Webster, Inc., 
Diamond. Bar, CA, USA) trough the sheath in the LA. The precise location of the linear lesions was visualized with the Coolrail probe (Atricure Inc, Westchester, Ohio, USA) in situ and using fluoroscopy. Gaps in linear lesions were defined as low amplitude and fragmented or narrowly split double atrial potentials.

In case of persistence of AF, a left isthmus line was made in hybrid procedures starting from the ablation line on the antrum of the left inferior PV and crossing the CS, using the the Max 3 pen. (Atricure Inc, Westchester, Ohio, USA) on the epicardial side. This line was completed by the EP endocardially from the mitral annulus towards the CS with the ThermoCool catether (ThermoCool, Biosense Webster, Inc., Diamond. Bar, CA, USA)

The endpoint of ablation of the mitral isthmus was the bidirectional block which was achieved when the following criteria were met:

1) proximal-to-distal activation sequence along the CS catheter after pacing lateral to the line in the LA appendage;

2) Late activation on the opposite side after pacing on the septal side of the line through the CS; 3 ) widely separated local double potentials along the whole length of the ablation line.

An inferior vena cava (IVC)-to-superior vena cava (SVC) and SVC circumferential lesions were added when patients with persistent and long-standing persistent $\mathrm{AF}$ had a right atrial volume $\geq 58 \mathrm{ml}$. IVC circumferential isolation was performed in patients with a small portion of intrapericardial IVC to be sure that the SVC-IVC line would stop at an area of no conduction. The isolation of the SVC and the IVC was confirmed by testing of conduction block across the ablation lines. 
In hybrid patients, if the patient had a history of typical right atrial flutter or this arrhythmia became apparent during the procedure, we performed a cavo-tricuspid isthmus line (CTI) endocardially. The endpoint was bidirectional block and the presence of widely separated double potentials along the whole length of the ablation line.

In patients with CHADS2 score $\geq 1$, or in presence of a rapid firing coming from the left atrial appendage (LAA), and when the procedure was deemed safe, LAA exclusion/ closure was performed under transesophageal echocardiographic (TEE) guidance employing a stapler (Endo GIA, Covidien, Norwalk, CT) or a clip (Atricure, West Chester, $\mathrm{OH})$. The absence of flow was confirmed by intraoperative transesophageal echocardiography.

The lesion set in the two Groups is shown in Table 2.

Median operative time were 268 minutes (IQR 186-477) in hybrid operations and 127 minutes (IQR 97-188) in standard minimally invasive procedures $(\mathrm{p}=0.001)$.

\section{Statistical Analysis}

Normal values were expressed as mean \pm one standard deviation (SD), non-normal values as median and interquartile range (IQR) and categorical variables as percentages. T test, Wilcoxon and McNemar's tests were employed where appropriate.

We analyzed all of the intermittent data available in terms of time-related prevalence of atrial fibrillation with a multiphase hazard decomposition method $^{10,15}$. Time-related prevalences are presented as percentages with asymmetric $68 \%$ confidence limits (CLs), comparable to \pm one standard 
error. The CLs for AF prevalence were obtained with the bootstrap percentile method.

Analyses of prevalence of AF do not account for anti-arrhythmic medications thus prevalence of anti-arrhythmic medication use was estimated by mixed modeling based on medication use at each follow-up assessment ${ }^{16}$.With the same method we estimated the prevalence of Warfarin use at time of each follow-up.

Statistical analyses were performed using SPSS release 12.0 (SPSS, Chicago, IL, USA) and Curve Expert Professional release1.0.1 (D.G. Hyams, Chattanooga, TN, USA).P values less than 0.05 were considered significant.

\section{$\underline{\text { Results }}$}

\section{Clinical outcome and Recurrence of AF}

There was no pulmonary vein injury, mortality, stroke or reoperation for bleeding in the two groups. Furthermore, all the procedures could be completed as planned without any conversion to sternotomy and there were no requirements for blood transfusion.

Median Intensive care unit (ICU) and median in-hospital length of stay were comparable in the two groups (6.2 hours [IQR 5.5-13.4] vs. 6.7 hours [4.3 to 13.9$]$ vs. $\mathrm{p}=0.9 ; 3.4$ days [2.6-4.1

vs. 3.8 days [2.9-4.4], $\mathrm{p}=0.87$, in hybrid and no-hybrid procedures, respectively).No patient died during the follow up. There was a significant improvement in median EHRA (European Hear Rhythm Association) score in both groups (both, 1[1-2], $\mathrm{p}<0.001$ vs. baseline). 
Time-related prevalence of postoperative AF at 12 months (Figure 1 AB) in patients undergoing hybrid procedure or standard thoracoscopic approach were $5.2 \%$ (4.2-6.7), and $6.0 \%$ (3.2-9.6), respectively $(\mathrm{p}=0.56)$.

Figure $1 \mathrm{C}$-D shows estimated prevalence of postoperative atrial fibrillation by AF type. At 1 year it was $8.2 \%(5.1-11.6)$ and $14.9 \%$ (11.6-18.3) in long standing persistent $(\mathrm{p}=0.04), 3.8 \%(1.4-6.9)$ and $0 \%$ in persistent $(\mathrm{p}<0.001)$ and $3.2 \%(1.0-6.5)$ and $0 \%$ in paroxysmal AF $(p<0.001)$ in hybrid and no hybrid and group, respectively

At 12 months estimated prevalence of AAD (Figure 2 A-B) were $18.0 \%$ $(15.5-21.7)$ and $16.7 \%([13.9-21.5] \mathrm{p}=0.65)$ in hybrid and no hybrid group, respectively (Figure $2 \mathrm{~A}-\mathrm{B}$ ). When comparing prevalence of AAD by AF type, it was significantly lower in hybrid patients in long-standing persistent $\mathrm{AF}(26.2 \%$ [17.6-30.4] vs. $38.7 \%$ [32.9-42.7], $\mathrm{p}<0.001)$ whereas it was higher in this group in persistent (16.0\% [13.4-20.6] vs. $6.1 \%$ [3.9-9.2], $\mathrm{p}<0.001)$ and paroxysmal AF (12.2\% [9.7-15.4] vs. $4.7 \%$ [2.9-7.7], $\mathrm{p}<0.001)$.

One-year prevalence of Warfarin use (Figure 2 C-D) were and $29.0 \%$ (26.2-33.1) and 13.4\% (9.9-16.3) in hybrid and no hybrid group respectively $(\mathrm{p}<0.001)$. This difference was observed in long standingpersistent (35.5\% [29.7-38.2] vs. 20.9\% [16.9-20.6], p<0.001), persistent (22.7\% [16.1-24.8] vs. $13.0 \%$ [9.9-17.1], $\mathrm{p}<0.001)$ and paroxysmal AF $(17.3 \%$ [15.4-21.2] vs. $7.9 \%$ [4.8-10.5], $<<0.001)$.No thromboembolic event occurred during the follow-up in the two groups Finally, two patients in the hybrid group required electrical cardioversion (both 3 months after surgery). In contrast, none in the no-hybrid group underwent electrical cardioversion $(\mathrm{p}=0.57)$. 


\section{Echocardiographic Results}

At 3 month- LAVI was significantly reduced in both Groups $(35 \pm 8$ $\mathrm{mL} / \mathrm{m}^{2}, \mathrm{p}<0.001$ vs. 3 months and $40 \pm 9 \mathrm{~mL} / \mathrm{m}^{2}, \mathrm{p}=0.03$ vs. 3 months, in hybrid and no-hybrid, respectively) with a further significant improvement at 12 months $\left(30 \pm 7 \mathrm{~mL} / \mathrm{m}^{2}, \mathrm{p}<0.001\right.$ and $35 \pm 3 \mathrm{~mL} / \mathrm{m}^{2}$, $\mathrm{p}=0.03$ ). However, biplane LAVI was significantly lower in the hybrid group at each control ( $\mathrm{p}=0.03$ and $\mathrm{p}=0.02$ at 3 and 12 months, respectively). In long-standing persistent AF LAVI reduced significantly only in hybrid procedures at postoperative controls. In contrast it was reduced in both groups without statistical significance in long-standing persistent and paroxysmal patients (Figure 3 A-C).

Based on the cut-off value ( $\geq 15 \%$ decrease in LAVI) LARR occurred in $81.7 \%(\mathrm{n}=30)$ of hybrid patients and $67.8 \%(\mathrm{n}=19)$ of no-hybrid patients at 12 -month control $(\mathrm{p}=0.02)$. In patients with long-standing LAF, LARR occurred in $81.8 \%(9 / 11)$ of patients in hybrid group and $0 \%(0 / 9)$ in no hybrid $(\mathrm{p}<0.001)$. The percentage of patients with persistent $(87.5 \%[7 / 8]$ vs. $100 \%$ [5/5]) and paroxysmal LAF (87.5\% [14/16] vs. 100\% [14/14]) was comparable ( $\mathrm{p}=0.3$ and $\mathrm{p}=0.1$, respectively).

At 3 months $\mathrm{LA}_{\mathrm{EF}}$ raised only in no-hybrid patients $(47 \pm 15 \%, \mathrm{p}=0.002)$ whereas it reduced in hybrid without reaching statistical significance $\left(35 \pm 9 \%, p=0.7, p<0.001\right.$ vs. no-hybrid). At 1 year $L_{E F}$ increased in both groups $(50 \pm 14 \%$ [p $<0.001$ vs. 3 months $]$ and $52 \pm 12 \%$ [p=0.004 vs. 3 months], in hybrid and no-hybrid, respectively) without differences between groups $(\mathrm{p}=0.6)$. Figure $4 \mathrm{~A}-\mathrm{C}$ shows $\mathrm{LA}_{\mathrm{EF}}$ by $\mathrm{AF}$ type: at oneyear control LA $\mathrm{EF}_{\mathrm{EF}}$ was significantly higher in the hybrid group in long- 
standing persistent patients and in the no-hybrid group in paroxysmal. In persistent AF data were comparable between groups..

LA diameters decreased significantly at 3 months in hybrid $(3.5 \pm 0.3$ $\mathrm{cm}, \mathrm{p}<0.001$ vs. baseline) as well as in no hybrid patients $(3.6 \pm 0.4 \mathrm{~cm}$, $\mathrm{p}=0.003$ ). Both diameters further reduced at one year (hybrid, $3.3 \pm 0.3$ $\mathrm{cm}$; no-hybrid, $3.4 \pm 0.3 \mathrm{~cm}$ ) without reaching statistical significance $(\mathrm{p}=0.5$ and $\mathrm{p}=0.4$, respectively). Among long-standing persistent patients LA diameters reduced, in hybrid procedures, at 3 months $(4.0 \pm 0.4 \mathrm{~cm}$, $\mathrm{p}<0.001$ vs. baseline) and 12 months $(3.6 \pm 0.3 \mathrm{~cm}, \mathrm{p}=0.01$ vs. 3 months $)$ whereas in no-hybrid did not vary from baseline ( 3 months, $4.4 \pm 0.4 \mathrm{~cm}$, $\mathrm{p}=0.08$ vs. baseline; one year, $4.4 \pm 0.4 \mathrm{~cm}, \mathrm{p}=0.9$ vs. 3 months). In persistent LA diameters decreased significantly at 3 months in hybrid $(3.2 \pm 0.3 \mathrm{~cm}, \mathrm{p}<0.001)$ as well as in no hybrid patients $(3.2 \pm 0.3 \mathrm{~cm}$, $\mathrm{p}=0.001$; between groups $\mathrm{p}=0.9$ ). Finally, in paroxysmal AF there was a significant reduction in both groups at 3 months (hybrid $3.0 \pm 0.3 \mathrm{~cm}$, $\mathrm{p}=0.01$; no-hybrid, $2.9 \pm 0.2 \mathrm{~cm}, \mathrm{p}<0.001$; between groups $\mathrm{p}=0.74$ ) with values remaining stable at one year (hybrid $3.0 \pm 0.3 \mathrm{~cm}, \mathrm{p}=0.9$; nohybrid, $2.9 \pm 0.2 \mathrm{~cm}, \mathrm{p}=0.09$; between groups $\mathrm{p}=0.7$ ).

\section{Discussion}

With the development of new tools and advanced techniques, the treatment of LAF moves toward a multidisciplinary approach involving cardiac surgeons and electrophysiologists ${ }^{17}$. Although catheter ablation is considered an effective treatment for $\mathrm{AF}^{18}$, its success rate without antiarrhythmic drugs resulted to be suboptimal ${ }^{5}$. Failures of percutaneous catheter ablation are most often due to recurrence of pulmonary vein conduction, due to a lack of transmural lesions ${ }^{19}$. In addition, recent data 
suggests the importance of the left atrial appendage (LAA) ${ }^{20}$, ligament of Marshall (LOM) ${ }^{21}$, and epicardial ganglia ${ }^{22}$ which remain difficult to target endocardially.

Surgical epicardial ablation, can isolate the superior vena cava (SVC) without phrenic nerve injury, eliminate the LOM, remove the LAA, target the ganglia and create transmural lesions around the $\mathrm{PVs}^{, 2}$, ${ }^{3,6,14}$.Nonetheless, surgical ablation is limited by post-ablation flutters, often due to gaps in linear lesions made by unipolar devices ${ }^{23}$. In addition, typical right-sided atrial flutter complicates up to $12 \%$ of minimally invasive surgical ablation, and it could likely be prevented by a cavo-tricuspid isthmus (CTI) line, which is easily created by endocardial catheters ${ }^{24}$.

Hybrid ablation is a dual approach in which an electrophysiologist ablates from inside the heart and a cardiac surgeon ablates on the outside of the heart in order to limit the shortcomings of both techniques and, at the same time, to combine their advantages.

The concept of "hybrid procedure" was first published by Pak and coworkers $^{25}$ who combined percutaneous epicardial catheter ablation (PECA) and endocardial ablation in difficult cases of AF. More recently, Krul et al. ${ }^{26}$ presented their experience with thoracoscopic PV isolation and ganglionated plexus (GP) ablation guided by peri-procedural electrophysiological testing resulting in a single-procedure success rate of $86 \%$. Mahapatra et al. ${ }^{27}$ have recently published their initial experience with surgical epicardial-catheter and endocardial ablationfor persistent ts

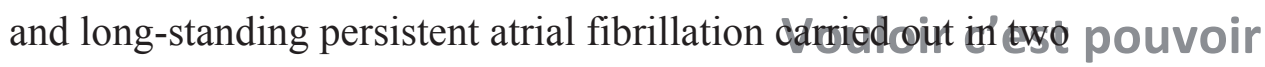
sequential steps. After a mean follow-up of $20.7 \pm 4.5$ months, $86.7 \%$ patients were free of any atrial arrhythmia and off of antyarrhythmic 
drugs (AAD). This figure was $53.3 \%$ in patients undergoing catheteralone procedure $(\mathrm{p}=0.04)$. Nonetheless, no data have been published comparing the hybrid technique to standard thoracoscopic video-assisted surgery. The purpose of this study was, therefore, to investigate whether the combined approach has clear advantages over standard minimally invasive surgical AF ablation.

The current literature is extremely difficult to interpret. This confusion is compounded by a lack of consensus on methods and timing of follow-up evaluation as well as the absence of strict definitions of success. The workforce on evidence-based surgery of the Society of Thoracic Surgeons ${ }^{10}$ proposed an approach to report success/failure. They suggested analyzing all the intermittent data available in terms of timerelated prevalence (burden) of atrial fibrillation ${ }^{10,15,16}$. In the present study we report our results as time-related prevalence of postoperative AF, ADD use and Warfarin use. To the best of our knowledge, this is the first study which compares standard minimally invasive technique with the hybrid approach.

The main findings of this study can be summarized as follows:

First, although both techniques yielded satisfactory and comparable results in terms of 1-year related prevalence of postoperative AF (5.2\% and $6.0 \%)$ and prevalence of AAD (18.0\% vs.16.7\% ), both these figures ( $8.2 \%$ vs. $14.9 \%$ and $26.2 \%$ vs.. $38.7 \%$, respectively) were lower in hybrid patients in case of long-standing persistent AF. This may be explained with the fact that, unlike paroxysmal AF, which is caused by triggers that most often are inside the pulmonary veins, long-standing persistent $\mathrm{AF}$ is characterized by changes in the atrial tissue and muscle (substrate modification) that leads to chaotic electrical activity ${ }^{28}$. Thus, 
these patients might need more areas in the heart ablated than what is done in PV isolation. In contrast, the no-hybrid technique gained lower12-month related AF prevalence and prevalence of AAD in paroxysmal AF ( $0 \%$ vs. $3.2 \%$ and $4.7 \%$ vs. $12.2 \%)$ and, surprisingly, in persistent AF ( $0 \%$ vs. $3.8 \%$ and $6.1 \%$ vs. $16.0 \%$, respectively). We might postulate that the smaller preoperative LA volume $\left(54 \pm 12 \mathrm{ml} / \mathrm{m}^{2}\right.$ vs. $50 \pm 15 \mathrm{ml} / \mathrm{m}^{2}$ ) in patients with persistent AF in no-hybrid group reflects a lesser extent of substrate modifications and this could explain the better results obtained with the epicardial ablation in these patients.

Second, we observed an higher percentage of LA reverse remodeling after hybrid procedure in long-standing AF patients ( $81.8 \%$ vs. $0 \%)$ whereas it was comparable in persistent ( $87.5 \%$ vs. $100 \%)$ and paroxysmal LAF ( $87.5 \%$ vs. 100\%). Atrial size and LAVI reduced in both groups in persistent and paroxysmal AF whereas, in long-standing persistent patients these values were reduced only in patients undergoing a hybrid procedure. Atrial structural remodeling, with LA enlargement is a hallmark of AF and reverse remodeling is considered an important target of any AF treatment. Indeed, LA volume showed a strong correlation with the extent of fibrosis at 3D delayed-enhancement and the stretching of the LA myocites increases the intercellular matrix, collagen production and fibrosis ${ }^{29}$. Longer duration of AF is known to cause progressive remodeling and increased LA volume and long-persistent AF is considered to be an advanced stage of the arrhythmia as compared to paroxysmal AF. Our findings demonstrate that these patients may benefit from the epicardial-endocardial approach which increases the likelihood that ablation lines are transmural. In contrast, epicardial PVs isolation was more effective, in terms of La remodeling, in patients with 
paroxysmal AF. Minimally invasive epicardial ablation resulted in significant reverse remodeling also in patients with persistent AF with small atria in whom remodeling may be still reversible.

Third, after a transient, even not significant, reduction presumably related to the scar tissue produced by radiofrequency endocardial catheter ablation, we observed, in the hybrid group, a significant increase in atrial function, expressed as LA emptying fraction $\left(\mathrm{LA}_{\mathrm{EF}}\right)$. Atrial function was comparable in the two groups at one year. Nonetheless, when considering $\mathrm{LA}_{\mathrm{EF}}$ by $\mathrm{AF}$ type, it improved at latest follow up much more in hybrid patiens when the AF was long-standing persistent while $\mathrm{LA}_{\mathrm{EF}}$ was significantly higher in the no-hybrid group in case of paroxysmal AF. In persistent AF data were comparable. The recovery of LA function after ablation is a complex phenomenon and currently there is no standardization in the measurement of LA function. Transmitral flow velocity with pulsed Doppler imaging shows the flow velocity due to atrial contraction. This can be used to measure atrial force, an indirect measure of atrial contraction. Unfortunately, the A wave is highly depending on loading condition (i.e. LA and LV pressures) and it is absent in AF. We employed the emptying fraction as measure of LA function. During the initial part of ventricular diastole, the LA has a passive conduit function, whereas it has an active pump or booster function during the later part of ventricular diastole, as the atrium contracts. In sinus rhythm atrial emptying comprises both passive and active phases whereas in AF there is only a passive phase, hence the term "emptying fraction" rather than "ejection fraction". $\mathrm{LA}_{\mathrm{EF}}$ mirrors the structural changes in LA and preoperative $\mathrm{LA}_{\mathrm{EF}}$ was shown to be a powerful predictor of successful MAZE procedure ${ }^{30}$ 
Fourth, one-year prevalence of Warfarin use was higher in hybrid patients independently of the type of atrial fibrillation and this can explained by an higher preoperative thrombo-embolic risk in these patients, expressed by an higher $\mathrm{CHADS}_{2}$ score and larger LA volumes and diameters. However, although we recommend stopping Warfarin after 3 months if the patient has a $\mathrm{CHADS}_{2}$ score $<2$ and she/he is in SR at the Holter recording, this is often at the discretion of referring cardiologists.

\section{Limitations of the Study}

Some limitations of the present study warrant consideration. The small number of patients and the short follow up does not allow to draw any conclusion about the effectiveness of these techniques. Furthermore, while data regarding postoperative AF prevalence were obtained from a high number of observations, some caution should be exercised before generalizing the results of left atrial remodeling by AF type due to the small number of patients in each group. In addition our study did not compare results of the hybrid approach to catheter ablation. However, this will be the subject of ongoing studies.

Finally, atrial function was studied employing only the emptying fraction and neither pulsed-wave Doppler nor Tissue Doppler Imaging (TDI) and LA strain were employed which would have given more detailed information about LA function after AF surgical ablation. All these aspects deserve further investigations. 


\section{Conclusion}

Even with the above mentioned limitations we can conclude that both minimally invasive procedures resulted to be effective in the treatment of LAF. The hybrid procedure yielded better results in long-standing persistent $\mathrm{AF}$ and, in these patients it might represent a suitable option to treat LAF. Our findings need to be confirmed by further larger studies.

Acknowledgments

We gratefully acknowledge Mr. Pol Chambille and Mss. Monique De Jong for their invaluable help. 


\begin{tabular}{|c|c|c|c|}
\hline & $\begin{array}{c}\text { Hybrid } \\
(\mathrm{n}=35)\end{array}$ & $\begin{array}{c}\text { No-Hybrid } \\
(\mathrm{n}=28)\end{array}$ & $\mathbf{p}$ \\
\hline Age & $57.1 \pm 9.5$ & $67.1 \pm 9.1$ & 0.06 \\
\hline $\mathrm{M} / \mathrm{F}$ & $24 / 11(68.5 / 31.4)$ & $17 / 11(60.7 / 39.3)$ & 0.1 \\
\hline BMI & $26.8 \pm 3.6$ & $28.6 \pm 3.6$ & $>0.9$ \\
\hline Diabetes & $1(2.8)$ & $0(0)$ & 0.87 \\
\hline Hypertension & $15(42.8)$ & $14(50.0)$ & 0.31 \\
\hline TIA/CVA & $0(0)$ & $1(3.5)$ & 0.85 \\
\hline \multicolumn{4}{|l|}{ Type of preoperative AF } \\
\hline Paroxysmal & $16(45.7)$ & $14(50.0)$ & \\
\hline Persistent & $8(22.8)$ & $5(17.8)$ & 0.44 \\
\hline Long-standing persistent & $11(31.5)$ & $9(32.2)$ & \\
\hline \multicolumn{4}{|l|}{ Prevalence of AF } \\
\hline Paroxysmal & $22.3[19.2-257]$ & $21.9[17.8-24.0]$ & \\
\hline Persistent & $32.6[29.1-36.9]$ & $32.7[28.9-36.2]$ & 0.86 \\
\hline Long-standing persistent & $61.3[57.4-65.0]$ & $68.4[63.6-72.2]$ & \\
\hline EHRA Score & $4[3-4]$ & $3[3-4]$ & 0.08 \\
\hline $\mathrm{CHADS}_{2}$ Score & $1.6 \pm 0.5$ & $0.9 \pm 0.3$ & $<0.001$ \\
\hline Duration of preoperative AF (yrs.) & $5[4.2-9.0]$ & $7[5.9-11.4]$ & 0.06 \\
\hline \multicolumn{4}{|l|}{ Antiarrhythmic Drugs } \\
\hline Amiodaron & $7(20.0)$ & $7(25.0)$ & \\
\hline Dysopiramide & $2(5.7)$ & $2(7.1)$ & \\
\hline Flecainide & $15(42.8)$ & $16(57.1)$ & 0.12 \\
\hline Propaphenon & $2(5.7)$ & $1(3.5)$ & \\
\hline Sotalol & $11(31.4)$ & $11(39.2)$ & \\
\hline Electrical cardioversion & $17(48.5)$ & $14(50.0)$ & 0.83 \\
\hline Previous Catheter Ablation & $21(60.0)$ & $21(75.0)$ & 0.06 \\
\hline Preoperative Pace Maker & $2(10.5)$ & $2(7.1)$ & 0.07 \\
\hline \multicolumn{4}{|l|}{ Anticoagulant status } \\
\hline Sodium Warfarin & $30(85.7)$ & $25(89.2)$ & 0.67 \\
\hline Aspirin & $10(28.5)$ & $6(21.4)$ & \\
\hline LAVI $\left(\mathrm{mL} / \mathrm{m}^{2}\right)$ & $50 \pm 12$ & $45 \pm 15$ & 0.03 \\
\hline $\mathrm{LA}_{\mathrm{EF}}(\%)$ & $38 \pm 11$ & $36 \pm 10$ & 0.66 \\
\hline LA diameter $(\mathrm{cm})$ & $5.2 \pm 0.5$ & $4.2 \pm 0.4$ & 0.01 \\
\hline
\end{tabular}

Normal data were presented as mean \pm 1 Standard deviation (SD), non parametric data as Median and [Interquartile Range] and discrete data as percentage (\%).Abbreviations: M/F: Male/Female; BMI: Body mass index; AF: Atrial fibrillation; CI: Confidence Interval; EHRA: European Hear Rhythm Association; CHADS2 : cardiac failure, hypertension, age, diabetes, stroke (doubled)]; PTCA: Percutaneous transluminal coronary angioplasty; LA: Left Atrium; RA: Right Atrium LVEF: Left ventricular ejection fraction LAVI: (Biplane) Left atrial volume index; $\mathrm{LA}_{\mathrm{Max}}$ : Maximum left atrial volume; $\mathrm{LA}_{\mathrm{Min}}$ : minimum left atrial volume; $\mathrm{LA}_{\mathrm{EF}}$ : Left atrial emptying fraction. 
Table 2 Lesion set $(\mathrm{n}=63)$

\begin{tabular}{|c|c|c|}
\hline & $\begin{array}{c}\text { Hybrid } \\
(\mathrm{n}=35)\end{array}$ & $\begin{array}{c}\text { No-Hybrid } \\
(n=28)\end{array}$ \\
\hline \multicolumn{3}{|l|}{ Left atrium } \\
\hline Right PVs Isolation & $35(100)$ & $28(100)$ \\
\hline Left PVs Isolation & $35(100)$ & $28(100)$ \\
\hline Inferior line & $31(88.5)$ & $28(100)$ \\
\hline Roof line & $32(91.4)$ & $28(100)$ \\
\hline Isthmus lesion & $7(20.0)$ & - \\
\hline Endocardial gap closures & $5(14.2)$ & - \\
\hline Excision of LA appendage & $8(22.8)$ & $7(25)$ \\
\hline Closure of LA Appendage with a clip & $7(20.0)$ & $7(25)$ \\
\hline \multicolumn{3}{|l|}{ Right atrium } \\
\hline Superior vena cava to inferior vena cava lesion & $10(28.5)$ & $8(28.5)$ \\
\hline Superior vena cava circumferential isolation & $8(22.8)$ & $3(10.7)$ \\
\hline Inferior vena cava circumferential isolation & $3(8.5)$ & $2(7.1)$ \\
\hline Cavo-tricuspid isthmus line & $3(8.5)$ & - \\
\hline Ablation of autonomic Ganglia & $35(100)$ & $28(100)$ \\
\hline
\end{tabular}

Discrete data were presented as number (percentage). Abbreviations. PVs:

Pulmonary Veins; LA: Left atrium. 


\section{Figure Legends}
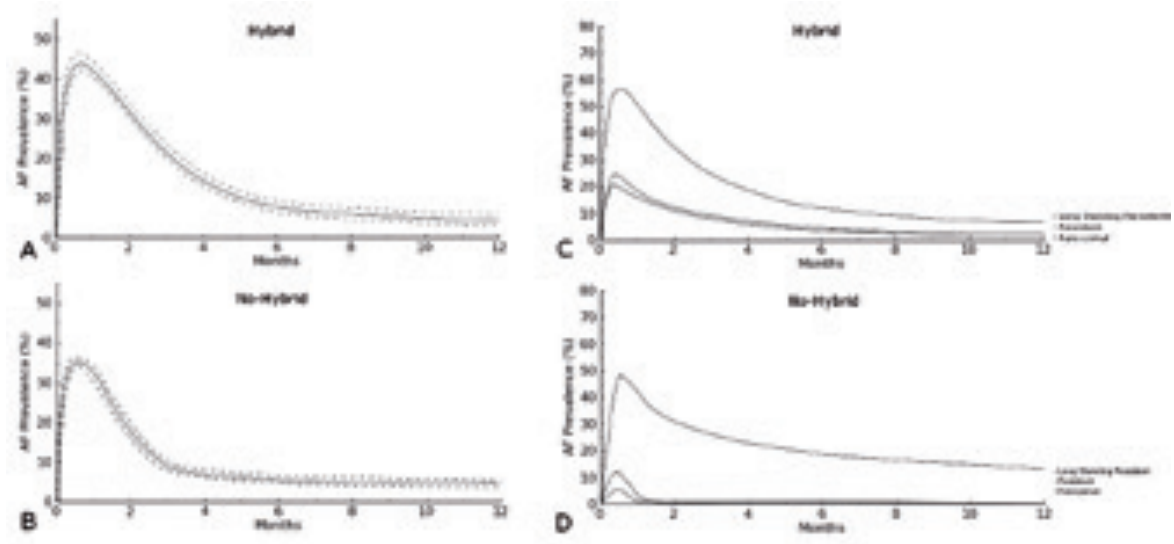

Figure 1. A. Time-related prevalence of atrial fibrillation (solid line) and $68 \%$ confidence limits (broken lines) after minimally invasive hybrid procedure. B. Time-related prevalence of atrial fibrillation (solid line) and 68\% confidence limits (broken lines) after minimally invasive standard bilateral thoracoscopic procedure. C. Time-related prevalence of atrial fibrillation by AF type after minimally invasive hybrid procedure. D Time-related prevalence of atrial fibrillation by AF type after minimally invasive standard bilateral thoracoscopic procedure. 

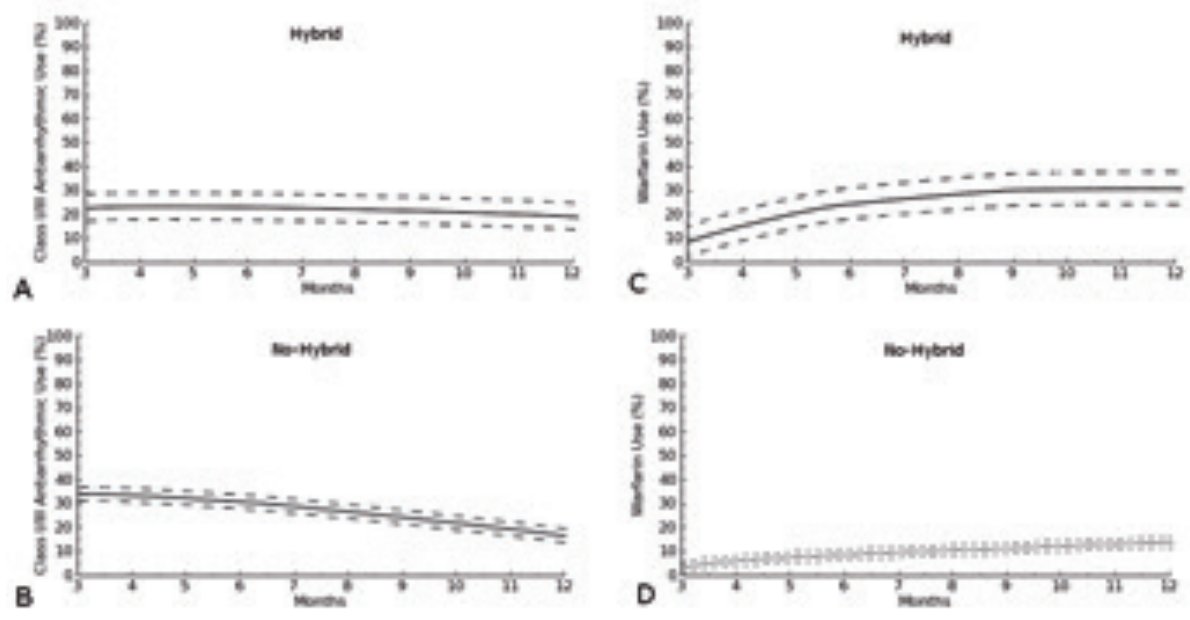

Figure 2. A. Time-related prevalence of class I/III anti-arrhythmic use after minimally invasive hybrid procedure B. Time-related prevalence of class I/III anti-arrhythmic use after minimally invasive standard bilateral thoracoscopic procedure. C Time-related prevalence of Warfarin use after minimally invasive hybrid procedure. D Time-related prevalence of Warfarin use after minimally invasive standard bilateral thoracoscopic procedure. 

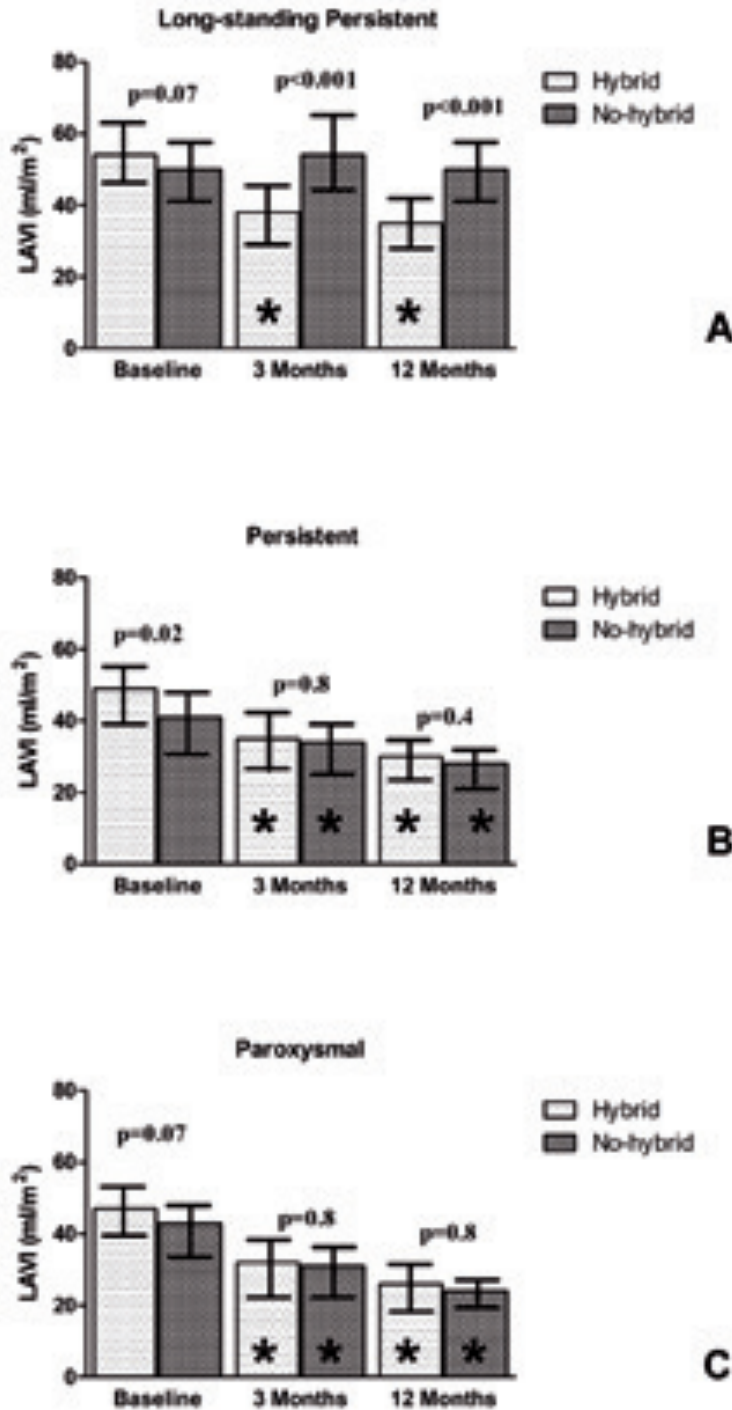

Figure 3. A-C. Left Atrial Volume Index (LAVI) and 95\% Confidence interval (error bars) by atrial fibrillation type. ${ }^{*} p<0.05$ vs. baseline values. 


\section{Long-standing Persistent}
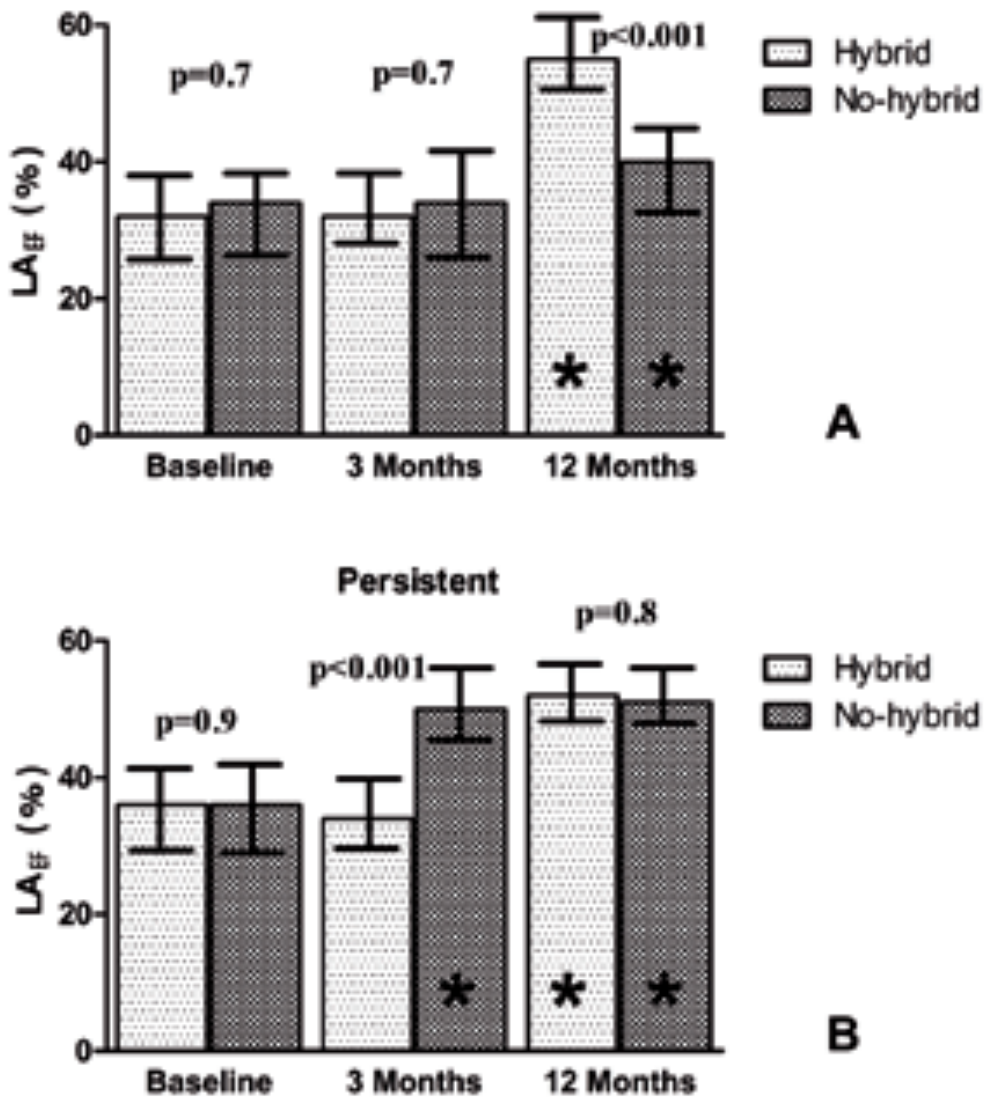

Paroxysmal

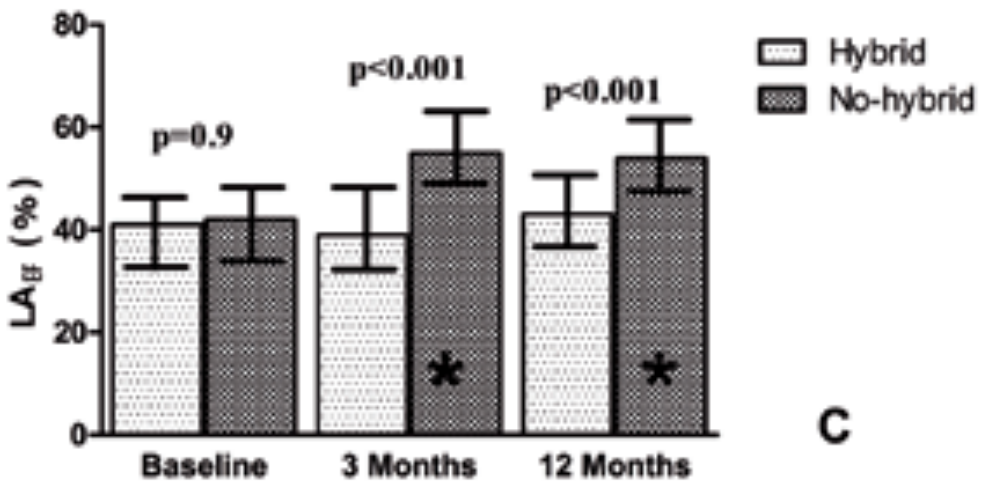


Figure4. A-C. Left Atrial Emptying Fraction $\left(\mathrm{LA}_{\mathrm{EF}}\right)$ and $95 \%$ Confidence interval (error bars) by atrial fibrillation type. ${ }^{*} \mathrm{p}<0.05$ vs. baseline values. 


\section{References}

1. Shelly CL, Damiano RJ. Surgical Ablation devices for atrial fibrillation. J Interv. Card Electrophysiol.2007; 20:73-82

2. Yilmaz A, Geuzebroek GS, Van Putte BP, Boersma LV, Sonker U, De Bakker JM, Van Boven WJ. Completely thoracoscopic pulmonary vein isolation with ganglionic plexus ablation and left atrial appendage amputation for treatment of atrial fibrillation. Eur J Cardiothorac Surg. 2010;38(3):356-60.

3. Pruitt JC, Lazzara RR, Ebra G. Minimally invasive surgical ablation of atrial fibrillation: the thoracoscopic box lesion approach. J Interv Card Electrophysiol. 2007 ;20(3):83-7.

4. Ernst S. The future of atrial fibrillation ablation: new technologies and indications. Heart 2009;95:158-163.

5. Cappato R, Calkins H, Chen SA, Davies W, Iesaka Y, Kalman J, Kim YH, Updated worldwide survey on the methods, efficacy, and safety of catheter ablation for human atrial fibrillation. Circ Arrhythm Electrophysiol. 2010; 3:32-8.

6. Khargi K, Hutten BA, Lemke B, Deneke T. Surgical treatment of atrial fibrillation; a systematic review. Eur J Cardiothorac Surg. 2005; 27:25865.

7. Fuster V, Rydén LE, Cannom DS, Crijns HJ, Curtis AB, Ellenbogen KA, Halperin JL, Le Heuzey JY, Kay GN, Lowe JE, Olsson SB, Prystowsky EN, Tamargo JL, Wann S, Smith SC Jr, Jacobs AK, Adams CD, Anderson JL, Antman EM, Halperin JL, Hunt SA, Nishimura R, Ornato JP, Page RL, Riegel B, Priori SG, Blanc JJ, Budaj A, Camm AJ, 
Dean V, Deckers JW, Despres C, Dickstein K, Lekakis J, McGregor K, Metra M, Morais J, Osterspey A, Tamargo JL, Zamorano JL; American College of Cardiology/American Heart Association Task Force on Practice Guidelines; European Society of Cardiology Committee for Practice Guidelines; European Heart Rhythm Association; Heart Rhythm Society. ACC/AHA/ESC 2006 Guidelines for the Management of Patients with Atrial Fibrillation: a report of the American College of Cardiology/American Heart Association Task Force on Practice Guidelines and the European Society of Cardiology Committee for Practice Guidelines (Writing Committee to Revise the 2001 Guidelines for the Management of Patients With Atrial Fibrillation): developed in collaboration with the European Heart Rhythm Association and the Heart Rhythm Society. Circulation. 2006;114: 257-354.

8. European Heart Rhythm Association (EHRA); European Cardiac Arrhythmia Scoiety (ECAS); American College of Cardiology (ACC); American Heart Association (AHA); Society of Thoracic Surgeons (STS), Calkins H, Brugada J, Packer DL, Cappato R, Chen SA, Crijns HJ, Damiano RJ Jr, Davies DW, Haines DE, Haissaguerre M, Iesaka Y, Jackman W, Jais P, Kottkamp H, Kuck KH, Lindsay BD, Marchlinski FE, McCarthy PM, Mont JL, Morady F, Nademanee K, Natale A, Pappone C, Prystowsky E, Raviele A, Ruskin JN, Shemin RJ. HRS/EHRA/ECAS expert consensus statement on catheter and surgical ablation of atrial fibrillation: recommendations for personnel, policy, procedures and follow-up. Heart Rhythm. 2007;4:816-861.

9. European Heart Rhythm Association; European Association for Cardio-Thoracic Surgery, Camm AJ, Kirchhof P, Lip GY, Schotten U, Savelieva I, Ernst S, Van Gelder IC, Al-Attar N, Hindricks G, 
Prendergast B, Heidbuchel H, Alfieri O, Angelini A, Atar D, Colonna P, De Caterina R, De Sutter J, Goette A, Gorenek B, Heldal M, Hohloser SH, Kolh P, Le Heuzey JY, Ponikowski P, Rutten FH; ESC Committee for Practice Guidelines, Vahanian A, Auricchio A, Bax J, Ceconi C, Dean V, Filippatos G, Funck-Brentano C, Hobbs R, Kearney P, McDonagh T, Popescu BA, Reiner Z, Sechtem U, Sirnes PA, Tendera M, Vardas PE, Widimsky P; Document Reviewers, Vardas PE, Agladze V, Aliot E, Balabanski T, Blomstrom-Lundqvist C, Capucci A, Crijns H, Dahlöf B, Folliguet T, Glikson M, Goethals M, Gulba DC, Ho SY, Klautz RJ, Kose S, McMurray J, Perrone Filardi P, Raatikainen P, Salvador MJ, Schalij MJ, Shpektor A, Sousa J, Stepinska J, Uuetoa H, Zamorano JL, Zupan I. Guidelines for the management of atrial fibrillation: the Task Force for the Management of Atrial Fibrillation of the European Society of Cardiology (ESC).Europace 2010; 12: 13601420.

10. Shemin RJ, Cox JL, Gillinov AM, Blackstone EH, Bridges CR; Workforce on Evidence-Based Surgery of the Society of Thoracic Surgeons.Workforce on Evidence-Based Surgery of the Society of Thoracic Surgeons.Guidelines for reporting data and outcomes for the surgical treatment of atrial fibrillation. Ann Thorac Surg. 2007;83:122530.

11. Kuppahally SS, Akoum N, Burgon NS, Badger TJ, Kholmovki EG, Vijayakumar MS, Rai SW, Blauer J, Fish EN, Di Bella EVR, MacLeod RS, McGann C, Litwin SE, Marrouche NF. Left atrial strain and strain rate in patients with paroxysmal and persistent atrial fibrillation: relationship to left atrial structural remodeling detected by delayed enhancement-MRI. Circ Cardiovasc Imaging 2010; 3:231-9. 
12. Jiamsripong P, Honda T, Reuss CS, Hurst RT, Chaliki HP, Grill DE, Schneck SL, Tyler R, Khandheria BK, Lester SJ. Three methods for evaluation of left atrial volume. Eur J Echocardiogr. 2008; 9: 351-5.

13. Tops LF, Delgado V, Bertini M, Marsan NA, Den Uijl DW, Trines SA, Zeppenfeld K, Holman E, Schalij MJ, Bax JJ. Left atrial strain predicts reverse remodeling after catheter ablation for atrial fibrillation. $\mathrm{J}$ Am Coll Cardiol. 2011; 57:324-31.

14. Yilmaz A, Van Putte BP, Van Boven WJ. Completely thoracoscopic bilateral pulmonary vein isolation and left atrial appendage exclusion for atrial fibrillation. J Thorac Cardiovasc Surg. 2008;136:521-22.

15. Blackstone EH, Naftel DC, Turner ME Jr. The decomposition of time-varying hazard into phases, each incorporating a separate stream of concomitant information. J Am Stat Assoc, 1986; 81: 615-624.

16. Gillinov AM, Bhavani S, Blackstone EH, Rajeswaran J, Svensson LG, Navia JL, Pettersson BG, Sabik JF 3rd, Smedira NG, Mihaljevic T, McCarthy PM, Shewchik J, Natale A.. Surgery for permanent atrial fibrillation: impact of patient factors and lesion set. Ann Thorac Surg 2006;82: 502-513.

17. Stamou SC, Khabbaz KR, Mahmood F, Zimetbaum P, Hagberg RC.A multidisciplinary approach to the minimally invasive pulmonary vein isolation for treatment of atrial fibrillation. Ann Thorac Surg. 2010;89:648-50.

18. Oral H, Pappone C, Chugh A, Good E, Bogun F, Pelosi F Jr, Bates ER, Lehmann MH, Vicedomini G, Augello G, Agricola E, Sala S, Santinelli V, Morady F. Circumferential pulmonary-vein ablation for chronic atrial fibrillation. N Engl J Med. 2006 ;354:934-41. 
19. Jaïs P, Cauchemez B, Macle L, Daoud E, Khairy P, Subbiah R, Hocini M, Extramiana F, Sacher F, Bordachar P, Klein G, Weerasooriya R, Clémenty J, Haïssaguerre M. Catheter ablation versus antiarrhythmic drugs for atrial fibrillation: the A4 study. Circulation. 2008;118:2498505.

20. Sievert H, Lesh MD, Trepels T, Omran H, Bartorelli A, Della Bella P, Nakai T, Reisman M, DiMario C, Block P, Kramer P, Fleschenberg D, Krumsdorf U, Scherer D. Percutaneous left atrial appendage transcatheter occlusion to prevent stroke in high-risk patients with atrial fibrillation: early clinical experience. Circulation. 2002;105:1887-1889.

21. Tan AY, Chou CC, Zhou S, Nihei M, Hwang C, Peter CT, Fishbein MC, Chen PS. Electrical connections between left superior pulmonary vein, left atrium, and ligament of Marshall: implications for mechanisms of atrial fibrillation. Am J Physiol Heart Circ Physiol. 2006 , 290:312-22.

22. Zhou J SB, Edwards J, Jackman WM, Lazzara R, Po SS. Gradients of atrial refractoriness and inducibility of atrial fibrillation due to stimulation of ganglionated plexi. J Cardiovasc Electrophysiol 2007;18:83-90.

23. Liu X, Dong J, Mavrakis HE, Zheng B, Long D, Yu R, Tang R, Tian Y, Vardas PE, Ma C. Mechanisms of arrhythmia recurrence after videoassisted thoracoscopic surgery for the treatment of atrial fibrillation: insights from electrophysiological mapping and ablation. J Cardiovasc Electrophysiol. $2009 ; 20: 1313-20$.

24. Prasad SM, Maniar HS, Schuessler RB, Damiano RJ Jr. Chronic transmural atrial ablation by using bipolar radiofrequency energy on the beating heart. J Thorac Cardiovasc.2002; Surg 124(4):708-713. 
25. Pak HN, Hwang C, Lim HE, Kim JS, Kim YH .Hybrid epicardial and endocardial ablation of persistent or permanent atrial fibrillation: a new approach for difficult cases. J Cardiovasc Electrophysiol. 2007 18(9):917-23.

26. Krul SP, Driessen AH, van Boven WJ, Linnenbank AC, Geuzebroek GS, Jackman WM, Wilde AA, de Bakker JM, de Groot JR. Thoracoscopic video-assisted pulmonary vein antrum isolation, ganglionated plexus ablation, and periprocedural confirmation of ablation lesions: first results of a hybrid surgical-electrophysiological approach for atrial fibrillation. Circ Arrhythm Electrophysiol. 2011;4:262-70. 27. Mahapatra S, LaPar DJ, Kamath S, Payne J, Bilchick KC, Mangrum, Ailawadi G. Initial Experience of Sequential Surgical EpicardialCatheter Endocardial Ablation for Persistent and Long-Standing Persistent Atrial Fibrillation With Long-Term Follow-Up. Ann Thorac Surg 2011; 91:1890-8.

28. Haïssaguerre M, Hocini M, Sanders P, Sacher F, Rotter M, Takahashi Y, Rostock T, Hsu LF, Bordachar P, Reuter S, Roudaut R, Clémenty J, Jaïs P. Catheter ablation of long-lasting persistent atrial fibrillation: clinical outcome and mechanisms of subsequent arrhythmias. J Cardiovasc Electrophysiol. 2005;16:1138-47.

29. Kuppahally SS, Akoum N, Badger TJ, Burgon NS, Haslam T, Kholmovski E, ET AL. Echocardiographic left atrial reverse remodelling after catether ablation of atrial fibrillation is predicted by preablation delayed enhancement of left atrium by magnetic resonance imaging. Am Heart J 2010; 160: 877-84 . 
30. Aikawa M, Watanabe H, Shimokawa T, Inoue K, Takamisawa I, Seki A, et al.Preoperative left atrial emptying fraction is a powerful predictor of successful maze procedure. Circ J. 2009; 73:269-73. 
- $283-$ 
- $284-$ 



\section{Chapter 8}

Improvement of Left Atrial Function And Left Atrial Reverse Remodeling After Minimally Invasive Radiofrequency Ablation Evaluated By Two-Dimensional Speckle Tracking Echocardiography.

Mark La Meir, Sandro Gelsomino, Fabiana Lucà, Laurent Pison, Carmelo Massimiliano Rao, Francis Wellens and Jos G Maessen.

J Thorac Cardiovasc Surg. 2012 Jun 17.

\section{Abstract}

Objective. The present study was aimed at demonstrating the beneficial effect of minimally invasive radiofrequency surgical ablation on left atrial remodeling employing Two-dimensional speckle-tracking echocardiography 2D-STE.

Methods. The study population consisted of 33 patients (mean age $64.6 \pm 6.9$, $84.8 \%$ male) with paroxysmal lone atrial fibrillation undergoing minimally invasive radiofrequency surgical ablation at our Institution (Cardiothoracic Surgery, University Hospital, Maastricht, The Netherlands) between 2007 and 2011.Twenty age- and gender-matched healthy adults represented the control group. LA peak systolic strain $\left(\varepsilon_{\mathrm{P}}\right)$, peak strain rate $\left(\mathrm{SR}_{\mathrm{P}}\right)$, peak early diastolic strain rate $\left(\mathrm{SR}_{\mathrm{E}}\right)$ and peak negative strain rate $\left(\mathrm{SR}_{\mathrm{A}}\right)$ were measured. Left atrial reverse remodeling (LARR) was defined as a reduction in Left atrial volume Index (LAVI) $\geq 15 \%$. 
Results. Peak systolic strain was lower in patients with AF compared with controls $(p<0.001)$. It increased significantly at 3 months $(p<0.001)$ and 1 year $(p=0.01)$. Similarly, $\operatorname{SR}_{P}(p<0.001)$ and $\mathrm{SR}_{E}(\mathrm{p}<0.001)$ increased after surgery at 3 months $(p=0.004)$ and 12 months $(p=0.001)$. Finally, $S_{A}$ was lower at baseline when compared with controls $(p<0.001)$ but it increased significantly at follow-up $(p=0.02$ and $p=0.01$ at 3 and 12 months, respectively). LA reverse remodeling occurred in $60.6 \%$ of patients at 3 months and $72.7 \%$ at 12 month-control.

Conclusions. Minimally invasive radiofrequency ablation resulted in significant LARR as well as in a significant improvement of LA compliance and function after restoration of sinus rhythm as demonstrated by 2D-STE analysis. Our findings need to be confirmed by further larger prospective studies.

\section{Introduction}

Two-dimensional speckle-tracking echocardiography (2D-STE) is a nonDoppler based technique that has been used recently to evaluate dynamic left atrial (LA) function ${ }^{1}$. It has been demonstrated that 2D-STE is an easy and reproducible tool for the assessment of atrial mechanics in atrial fibrillation $(\mathrm{AF})^{2}$ and to be a predictor of stroke risk and cardiovascular outcomes in AF patients ${ }^{3}$.

Electrical remodeling (shortening of atrial refractoriness), structural remodeling (alterations in atrial collagen content and atrial geometry) and contractile remodeling (loss of contractility) are hallmarks of electrophysiological and cellular changes occurring in $\mathrm{AF}^{4-6}$. All these changes are partly reversible with a recovery of function, morphology, and 
to some extent of electrophysiological properties of the LA tissue (left atrial reverse remodeling, LARR $)^{7}$. Reverse remodeling has been shown after restoration of sinus rhythm after cardioversion ${ }^{8}$. In addition LARR has been demonstrated to occur in a significant number of patients after successful catheter ablation for AF and it has been shown that baseline LA strain was an independent predictor of LARR after this procedure ${ }^{9,10}$. Nonetheless, little information exists about LA function and LA strain after AF surgical ablation and, to the best of our knowledge, no data has been published on this topic regarding minimally invasive procedures.

Therefore, the present study was aimed at demonstrating the beneficial effect of minimally invasive radiofrequency surgical ablation on left atrial function after restoration of sinus rhythm employing 2D-STE.

\section{Methods}

\section{Study population}

The study followed the World Medical Association guidelines concerning ethical principles for medical research involving human subjects and was approved by the Institutional Ethics Board. All patients gave their informed consent.

Patients were included in our study according to the following inclusion criteria: 1) Paroxysmal AF treated successfully by radiofrequency bipolar surgical ablation for lone atrial fibrillation (LAF) 2) Old history ( $>6$ months) of paroxysmal recurrent AF with symptoms but in stable sinus rhythm in the $48 \mathrm{~h}$ preceding the ablation therapy in order to perform a dedicated echocardiography. Exclusion criteria were: 1) Previous ablation procedures; 2) presence of intracardiac thrombi at transesophageal 
echocardiography (TEE); 3) patent foramen ovale or atrial septal defect; 4) 'giant' left atrium (diameter $>65 \mathrm{~mm}$ ); 5) coronary artery disease; 6) previous pulmonary or cardiac surgery.

LAF was defined following American College of Cardiology/American Heart Association /European Society of Cardiology (ACC/AHA/ESC) guidelines ${ }^{11}$ and updated ESC Guidelines were employed to distinguish type of AF and to score the AF-related symptoms (European Heart Rhythm Association [EHRA] score) ${ }^{12}$.

Among 72 patients undergoing minimally invasive radiofrequency surgical ablation at our Institution (Cardiothoracic Surgery, University Hospital, Maastricht, The Netherlands) between 2007 and 2011, 33 met the inclusion criteria and were, therefore, the subjects of this study.

Patient characteristics are shown in Table 1

Twenty age- and gender-matched healthy adults without cardiovascular disease and/or history or cardiovascular risk factors and who did not use cardiovascular medication, were selected as the control group as reference for the LA atrial function assessment by echocardiography.

\section{Surgery}

Indication for surgery was based on the HRS/EHRA/ECA Guidelines ${ }^{13}$. All operations were performed by the same cardiac surgeon (M.L.M).The chest was entered in the second, fourth and sixth interspaces using respectively a $5-12-12 \mathrm{~mm}$ port. Thoracoscopy of the right side was done first and was then followed by the left side. The pericardium was opened anterior to the phrenic nerve on the right and posterior to the phrenic nerve on the left. The technique was as originally described by Yilmaz et $\mathrm{al}^{14}$. The 
rhythm was determined by placing a bipolar pen probe (Atricure Inc, Westchester, Ohio, USA) on the left atrium, and recordings were made with a physiological recorder ${ }^{15}$. Autonomic ganglia were identified by high-frequency stimulation to detect a vagal response at 20 predetermined epicardial sites around the pulmonary vein antra.

Ablation of right and left PVs was performed using a bipolar radiofrequency clamp (Atricure, Westchester, OH, USA). With the clamp placed on the antrum of the pulmonary veins, 3 to 6 ablations were performed (mean $3.8 \pm 0.9$ ). The end point for pulmonary vein ablation was complete entrance and exit block into and from the pulmonary veins. Entrance block was defined as failure to capture the pulmonary veins during pacing from the left atrium at $7.5 \mathrm{~V}$ and $1.5-\mathrm{ms}$ pulse width. Exit block was defined by failure to capture the left atrium when pacing from the pulmonary veins distal to the radiofrequency lesions at $7.5 \mathrm{~V}$ and 1.5$\mathrm{ms}$ pulse width. A proprietary algorithm terminated radiofrequency energy (maximum, $28 \mathrm{~W}$ ) after impedance changes indicated transmural injury. In 19 patients $(57.5 \%)$ entrance and exit block were checked endocardially by the electrophysiologist through a catheter (Lasso catheter, Biosense Webster Inc, Diamond Bar, USA) placed at the ostium of the PVs to assess the presence of pulmonary vein potentials.

Ganglionated plexi (GP) mapping was performed by placing the bipolar pen at each site and stimulating with an $18-\mathrm{mV}, 1.5-\mathrm{ms}$ pulse width impulse at 1000 pulses per minute from a temporary external pacemaker. A positive response to GP stimulation was defined as prolongation of RR interval $\geq 50 \%$. Bipolar radiofrequency energy at $15 \mathrm{~W}$ was delivered through the bipolar pen.The end point for GP ablation was the elimination of a vagal response to stimulation. 
Connecting lesions, the roof and inferior lines, were created using the Coolrail and/or the Max5 Pen (Coolrail, Atricure Inc, Westchester, Ohio, USA).The lesions were tested after completion of both lines by pacing inside the isolated posterior left atrium and confirming exit block.

Left atrial appendage (LAA) exclusion/ closure was performed under TEE guidance in patients with CHADS2 score $\geq 1^{16}$, in the presence of a rapid firing coming from the LAA and when it was deemed safe. Indeed, the left atrial appendage (LAA) was excised in 4 patients (12.1\%) employing a stapler (Endo GIA, Covidien, Norwalk, CT) or, in 6 patients (18.1\%) it was closed by employing a clip (Atricure, West Chester, $\mathrm{OH}$ ). The absence of flow was confirmed by intraoperative transesophageal echocardiography.

\section{Echocardiographic assessments}

Echocardiography was performed preoperatively, 3 months and 12 months postoperatively using a commercially available echocardiographic system (Philips iE33; Philips Medical Systems, Eindhoven, The Netherlands). All the parameters were analysed by two experienced echocardiographists (F.L. and C.M.R) using the Xcelera software (Philips Medical Systems Eindhoven, The Netherlands). Left ventricular ejection fraction (LVEF) was assessed by the bi-apical Simpson disk method ${ }^{17}$.

In the parasternal long-axis views LA maximum antero-posterior (A-P) diameter was measured.

LA superior-inferior (S-I) diameter was measured from the mitral annular plane to the posterior wall of the LA in the apical 4-chamber view. In the apical 4-chamber view, LA maximum volume ( $\left.\mathrm{LA}_{\max }\right)$, at the end of LV 
systole, just before the opening of the mitral valve and LA minimum volume $\left(\mathrm{LA}_{\mathrm{min}}\right)$ at the end of LV diastole, just after the closure of the mitral valve, were measured ${ }^{3}$. LA emptying fraction $\left(\mathrm{LA}_{\mathrm{EF}}\right)$ was calculated as $\left(\left[\mathrm{La}_{\max }-\mathrm{LA}_{\min }\right] / \mathrm{La}_{\max }\right) \times 100$. LA maximum volume was also measured by biplane area-length method ${ }^{18}$ and indexed to body surface area (LAVI). LARR was defined as a reduction in LAVI $\geq 15 \%{ }^{10}$. Responders were defined as patients who exhibited $\geq 15 \%$ reduction in LAVI, non responders the others.

Pulsed-wave Doppler at the tips of mitral valve leaflets allowed us to measure early (E) and late (A) diastolic filling velocities, diastolic E/A ratio, and E deceleration time (DT). For The Tissue Doppler Imaging (TDI) peak early diastolic tissue velocity (E') and peak late diastolic velocity (A') were recorded from a four chamber view at the lateral and septal border of the mitral annulus. Septal and lateral measures were averaged according to Guidelines ${ }^{19}$.

We used A' as a reproducible measure of LA function ${ }^{20}$. Finally, E/E' ratio was calculated and used as a reliable index of LV filling pressure ${ }^{21}$.

\section{Speckle Tracking}

Longitudinal LA strain was computed by speckle-tracking echocardiography (2D Cardiac Performance Analysis; TomTec Imaging Systems, Munich, Germany). Data from a total of 12 LA segments (annular, mid, and superior segments along the septal, lateral, anterior, and inferior LA walls using apical four-chamber and two-chamber images) were averaged to determine global LA peak systolic strain $\left(\varepsilon_{\mathrm{P}}\right)$ during LV ejection (LA reservoir phase). Peak strain rate $\left(\mathrm{SR}_{\mathrm{P}}\right)$ was measured during 
LV ejection (LA reservoir phase) whereas peak early diastolic strain rate $\left(\mathrm{SR}_{\mathrm{E}}\right)$ was measured during LV early diastole (LA conduit phase) and peak negative strain rate $\left(\mathrm{SR}_{\mathrm{A}}\right)$ was measured during $\mathrm{LV}$ diastole occurring after the P-wave (active contraction phase).

Assessment of LV strain was regarded as suboptimal when either (1)

speckle tracking could not be obtained for at least four of the six myocardial segments in each view or (2) a theoretically unacceptable value or values were obtained.

\section{Primary Endpoint and Assessment of AF}

The primary efficacy endpoint was freedom from AF and atrial flutter/tachycardia off ADD following the blanking period ${ }^{13,22}$.

Patients underwent 7-day Holter monitoring (HM) at 3 months and 1 year $^{23}$. Monitoring was performed with an external loop recorder (Del Mar Reynolds, Spacelabs Healthcare, Issaquah, WA, USA) and analyzed with Lifescreen Software (Del Mar Reynolds, Spacelabs Healthcare, Issaquah, WA, USA). For analysis, three rhythms were considered postoperative AF: $\mathrm{AF}$, atrial flutter or atrial tachycardia lasting more than $30 \mathrm{sec}$ after a 3month blanking period. Anticoagulation and Anti-arrhythmic Therapy Anti-arrhythmic drugs were given postoperatively and were discontinued 3 months after surgery if the patients appeared to be AF free. Electrical cardioversion was not attempted for patients who remained in AF after the surgical procedure and was reserved for patients who were still in AF after 3 and 6 months. Warfarin was administered on postoperative day I with INR target of 2.5.and stopped after 3 months if two following Holter recordings showed SR or patients had a low thrombo-embolic risk and a 
$\mathrm{CHADS}_{2}$ [cardiac failure, hypertension, age, diabetes, stroke (doubled)] score $<2{ }^{12}$.

\section{Statistical analysis}

Parametric value was expressed as mean \pm 1 standard deviation (SD), non parametric value as median and interquartile range (IQR) and categorical variables as percentages. Normally distributed variables were compared with paired-t test while Fisher's and McNemar's tests were employed to compare unpaired and paired categorical data, respectively.

Echocardiographic variables over time were analyzed by means of ANOVA repeated measures followed by Tukey's post hoc test to detect differences at different study points.

Interobserver and intraobserver variability were examined using Pearson bivariate correlation. Intraobserver and interobserver correlations were: $\varepsilon_{\mathrm{P}}$ $(\mathrm{r}=0.90, \mathrm{p}<0.001$ and $\mathrm{r}=0.77, \mathrm{p}=0.002), \mathrm{SR}_{\mathrm{P}}(\mathrm{r}=0.89, \mathrm{p}<0.001$ and $\mathrm{r}=0.80$, $\mathrm{p}=0.001), \mathrm{SR}_{\mathrm{E}}(\mathrm{r}=0.92, \mathrm{p}<0.001$ and $\mathrm{r}=0.70, \mathrm{p}=0.01), \mathrm{SR}_{\mathrm{A}}(\mathrm{r}=0.88, \mathrm{p}<0.001$ and $\mathrm{r}=0.75, \mathrm{p}=0.006)$.

Analyses were performed using SPSS release 12.0 (SPSS, Chicago, IL, USA). $P$ values less than 0.05 were considered significant.

\section{$\underline{\text { Results }}$}

\section{Clinical Results}

No patient died within the first 30 days postoperatively. There was no pulmonary vein injury, mortality, stroke or reoperation for bleeding. All the procedures could be completed as planned without any conversion to 
sternotomy. There were no requirement for blood transfusion. Median Intensive care unit (ICU) stay was 5.7 hours (IQR 3.7-11.6) and the median in-hospital length of stay was 6 days (IQR 5-7).

No patient died during follow up. The EHRA score improved significantly from baseline (1 [IQR1-2], p<0.001). All patients were in sinus rhythm and off-AAD at 3 month- and 12 month follow-up .No major thromboembolic events were detected during the follow up period and no patient was taking Warfarin. Finally, no patient underwent electrical cardioversion.

\section{LA Reverse Remodeling}

Baseline morphological analysis (Table 2) revealed a significant LA enlargement in AF patients as compared with controls (LA A-P, $p=0.006$; LA S-I $p=0.001$ ). This enlargement was accompanied by an increase in $\mathrm{LA}_{\mathrm{MAX}}(\mathrm{p}=0.001), \mathrm{LA}_{\mathrm{MIN}}(\mathrm{p}<0.001)$, and biplane LAVI $(\mathrm{p}=0.02)$.

LA diameters decreased significantly at 3 months (LA A-P, $p=0.04$; LA S-I $p=0.004)$ and 1 year (both, $p=0.04)$. $\mathrm{LA}_{\mathrm{MAX}}(\mathrm{p}=0.02$ and $\mathrm{p}=0.03), \mathrm{LA}_{\mathrm{MIN}}$ $(\mathrm{p}=0.02$ and $\mathrm{p}=0.03)$, and biplane LAVI $(\mathrm{p}=0.03$ and $\mathrm{p}=0.04)$ was significantly reduced at 3 months and 1 year, respectively.

Based on the cut-off value ( $\geq 15 \%$ decrease in LAVI) LA reverse remodeling occurred in $60.6 \%$ of patients $(\mathrm{n}=20)$ at 3 months and $72.7 \%$ $(\mathrm{n}=24)$ at 12 month-control $(\mathrm{p}=0.31)$. At 3 months LAVI in non-responders was reduced by $10 \%$ or more in 7 patients $(21.2 \%)$, less than $10 \%$ in 3 (9.1\%), and it was relatively stable $( \pm 1 \%)$ in 3 patients $(9.1 \%)$. At 1 year LAVI in non-responders was reduced by $10 \%$ or more in 6 patients (18.2\%), less than $10 \%$ in $2(6.1 \%)$, and it was relatively stable $( \pm 1 \%)$ in 1 $(3.0 \%)$. 


\section{LA Function and Strain analysis}

Compared to controls, LA emptying fraction was significantly lower at baseline $(p<0.001$, Table 3$)$. It increased significantly at 3 months $(p=0.04)$ and 12 months $(\mathrm{p}=0.02)$.

Of the total of 1,428 segments analyzed in 33 patients (baseline, 3-month and 12-month follow up) and 20 controls, analysis of regional strain was feasible in 1313 segments (91.9\%).

Global peak systolic strain $\varepsilon_{\mathrm{P}}$ was reduced in patients with AF compared with controls (Table $3, \mathrm{p}<0.001$ ). It increased significantly at 3 months $(\mathrm{p}<0.001)$ and 1 year $(\mathrm{p}=0.01)$. Similarly, peak systolic strain rate $\mathrm{SR}_{\mathrm{P}}$ $(p<0.001)$ and early diastolic strain rate $\operatorname{SR}_{E}(p<0.001)$ were lower in patients with AF but increased after surgery at 3 months $(\mathrm{p}=0.004)$ and 12 months $(p=0.001)$. Finally, late diastolic strain rate $\mathrm{SR}_{\mathrm{A}}$ was lower at baseline when compared with controls $(p<0.001)$ but it increased significantly at follow-up controls $(\mathrm{p}=0.02$ and $\mathrm{p}=0.01$ at 3 and 12 months, respectively).

\section{Pulsed-wave Doppler and Tissue Doppler Imaging (TDI)}

Peak E wave velocity, E wave deceleration time and E/A ratio (Table 4) in AF patients were not significantly different from controls at baseline and all these indices did not vary during the follow up. Contrastingly, A wave velocity was lower than in controls at baseline $(p=0.03)$ and increased significantly at e $3(p=0.03)$ and 12 months $(p=0.04)$.

Baseline TDI A' was lower compared with controls ( $p>0.001)$ and it increased at 3 months $(p=0.01)$ and 1 year $(p=0.008)$. Finally no difference was detected at baseline in $\mathrm{E}^{\prime}$ wave and $\mathrm{E} / \mathrm{E}^{\prime}$ between controls and $\mathrm{AF}$ 
patients. These indices did not show any significant modification during follow up.

\section{Discussion}

In recent years, due to the development of a variety of ablative energy sources as well as to an increasing knowledge about the pathophysiology of $\mathrm{AF}$ and the development of new ablation devices, minimally invasive surgical ablation of LAF has been performed with satisfactory results ${ }^{24}$. Atrial structural remodeling, with altered LA compliance, LA enlargement and impaired contractility, is a hallmark of AF, and reverse remodeling as well as recovery of atrial function are considered important targets of any $\mathrm{AF}$ treatment ${ }^{10}$. Left atrial reverse remodeling (LARR) has been demonstrated with drug therapy, after restoration of sinus rhythm with cardioversion and after successful catheter ablation for $\mathrm{AF}^{10}$. Nonetheless, reverse remodeling and atrial function in response to successful surgical $\mathrm{AF}$ ablation have been poorly investigated ${ }^{25}$ and little is known about morphological and functional changes following minimally invasive AF surgical ablation. It was for this reason that we conducted this study to evaluate left atrial function after restoration of sinus rhythm by minimally invasive methods

Currently, there is no standardization in the measurement of LA function. Transmitral flow velocity with pulsed Doppler imaging shows the flow velocity due to atrial contraction. This can be used to measure the atrial force but, unfortunately, the A wave is highly dependent on loading conditions and diastolic function ${ }^{3}$. Tissue Doppler imaging (TDI) has the advantage of increased spatial resolution and the ability to evaluate 
multiple segments in a single view and TDI A' wave is a reproducible measure of LA function ${ }^{21}$. Another way of assessing atrial function is to measure the LA emptying fraction $\left(\mathrm{LA}_{\mathrm{EF}}\right)$. In sinus rhythm, atrial emptying comprises both passive and active phases. In AF there is only a passive phase, hence the term "emptying fraction" rather than "ejection fraction" 3 .Preoperative $\mathrm{LA}_{\mathrm{EF}}$ was shown to be a powerful predictor of successful MAZE procedure ${ }^{26}$.

Myocardial mechanics by strain imaging, which is widely used to asses ventricular function, has been recently employed to evaluate atrial function ${ }^{1}$. Nonetheless, strain by Doppler techniques has inherent limitations caused by angle dependency and the influence of loading conditions.

Two-dimensional speckle-tracking echocardiography (2D-STE) is a novel non-Doppler-based method for the angle-independent and objective quantification of myocardial deformation which has recently been introduced to evaluate LA function ${ }^{1}$ in order to overcome many of the limitations of Doppler-based methodologies ${ }^{2,3}$.

To our knowledge, this is the first study that substantiates the changes in LA structure and function after minimally invasive surgery for lone atrial fibrillation employing 2D-STE.

In our experience, patients showed preoperatively a significant impairment in LA compliance (reservoir function) estimated by global peak systolic strain $\varepsilon_{\mathrm{P}}$ and peak systolic strain rate $\mathrm{SR}_{\mathrm{P}}$.

Kuppahally et $\mathrm{al}^{3}$ found that LA fibrosis detected by 3D delayedenhancement MRI had significant correlation with systolic strain and strain rate and Tops and coworkers ${ }^{10}$ demonstrated that LA strain at baseline was 
an independent predictor of LA reverse remodeling. Although the exact mechanism remains to be elucidated, the impairment in atrial compliance represented plays an important role in the ability to reverse LA enlargement and to maintain sinus rhythm during the follow up ${ }^{10}$. Both $\varepsilon_{\mathrm{P}}$ and $\mathrm{SR}_{\mathrm{P}}$ increased significantly after surgery and this suggests that this postoperative improvement in atrial compliance might be due to a still reversible LA functional changes in these patients. The improvement in atrial compliance is also demonstrated by a postoperative significant increase in $\mathrm{LA}_{\mathrm{EF}}$. Furthermore, baseline LA conduit function (during LV passive filling) was also significantly altered, as shown by $\mathrm{SR}_{\mathrm{E}}$ values. We observed a significant improvement in the conduit phase as demonstrated by an increase in $\mathrm{SR}_{\mathrm{E}}$, which was maintained also at the late control.

Moreover, we showed an improvement in left atrial function after restoration of sinus rhythm reflected either by a mechanical reverse remodeling process or by enhancement in LA function. A traditional and widely used method of assessing structural remodeling is to measure LA A$\mathrm{P}$ diameter. Nonetheless, the utility of this approach is limited because the LA may enlarge in an asymmetrical way. Hence we examined the LA-S-I diameter which is more strongly correlated with LA strain than LA A-P ${ }^{3}$ However, we found a significant reduction in both diameters at 3-monthand at 1 year- controls.

The increment in LA volume is one of the most important structural pathological changes in AF. Indeed, the stretching of the LA myocites increases the intercellular matrix, collagen production and fibrosis. LA volume showed a strong correlation with the extent of fibrosis at 3D delayed-enhancement $\mathrm{MRI}^{3,7}$ and it was associated with higher mortality in patients with $\mathrm{AF}^{2}$. Thus reverse remodeling of the left atrium is considered 
an important target of AF treatment. In our experience, based on the cut-off value ( $\geq 15 \%$ decrease in LAVI) LA reverse remodeling occurred in $60.6 \%$ of patients at 3 months and $72.7 \%$ at 12 month-control.

Finally, an important finding in our study is, in our opinion, the postoperative significant improvement in LA pump function demonstrated by an increase, at 3 and 12 months, of $\mathrm{SR}_{\mathrm{A}}$ which was severely affected preoperatively and which reflects the LA "active pump" or "booster" function during the later part of the ventricular diastole, as the atrium contracts. This atrial contraction phase depends on the LV filling pressure (LA afterload), and E/E' ratio has been shown to represent a reliable index of LV filling pressure ${ }^{21}$. Interestingly, E/E' did not change during the postoperative period and it was, at all times, comparable to controls. This demonstrates that the improvement in LA function is not secondary to a reduction in LV filling pressure but to a "true" improvement in LA contraction as is also confirmed by a parallel increase in A and A' wave velocities and $\mathrm{LA}_{\mathrm{EF}}$.

LA mechanical function is an independent and powerful risk factor for thromboembolic stroke ${ }^{27}$. Therefore, strain-analysis of atrial function should be accounted for when considering anticoagulation treatment for post minimally invasive ablation patients, especially with high CHADS score $^{11-13}$.

\section{Limitations}

Our study presents some important limitations which have to be pointed out. First of all the small number of patients does not allow any definite conclusion about LA morphological and functional improvements 
following minimally invasive surgery. Second, AF is also known to cause significant changes in the right atrium (RA). Unfortunately we were not able to carry out 2D-STE of the RA because of the small number of goodquality images suitable for this analysis. Third, due to the small sample we did not compare LA reverse remodeling and LA function between patients who had LAA exclusion / closure and those who did not. This may have an incremental value on indicating LAA exclusion/ closure and deserves further investigations. Finally, we did not compare results of minimally invasive surgery with patients converted to SR on drugs and following catheter ablation. This will be object of an ongoing study.

\section{Conclusions}

Even with the above mentioned limitations, minimally invasive radiofrequency ablation resulted, in our experience, in significant LA reverse remodeling as well as in improvement in LA compliance and LA function after restoration of sinus rhythm as demonstrated by 2D-STE analysis. Our findings need to be confirmed by further larger prospective studies.

Acknowledgments

We gratefully acknowledge Dr Orlando Parise for statistical analysis. 
Table 1. Preoperative Data $(n=33)$

\begin{tabular}{|c|c|}
\hline Age & $64.6 \pm 6.9$ \\
\hline $\mathrm{M} / \mathrm{F}$ & $28 / 5(84.8 / 15.2)$ \\
\hline BMI & $27.9 \pm 3.3$ \\
\hline Hypertension & $18(54.5)$ \\
\hline Prevalence of $\mathrm{AF}^{*}$ & $20.8\{16.5-23.6\}$ \\
\hline EHRA Score & $3[3-4]$ \\
\hline Duration of preoperative AF (yrs.) & $6.3 \pm 2.1$ \\
\hline \multicolumn{2}{|l|}{ Antiarrhythmic Drugs } \\
\hline Amiodaron & $2(6.0)$ \\
\hline Flecainide & $20(60.6)$ \\
\hline Propaphenon & $7(21.2)$ \\
\hline Ibutilide & $1(3.0)$ \\
\hline Electrical cardioversion & $17(51.5)$ \\
\hline Sodium Warfarin & $33(100)$ \\
\hline LVEF & $60.1 \pm 7.1$ \\
\hline
\end{tabular}

Data are presented as mean \pm 1 standard deviation or median [Interquartile ranges]. Discrete data are expressed as numbers (percentages). Abbreviations: M/F: Male/Female; BMI: Body Mass Index; AF: Atrial fibrillation; EHRA: European Heart Rhythm Association; LVEF: Left Ventricular Ejection Fraction.*Reported with 68\% CI. 
Table 2. Left Atrial Remodeling and Reverse Remodeling ( $n=33)$

\begin{tabular}{|c|c|c|c|c|}
\hline & Controls & Baseline & 3 months & 12 months \\
\hline LAVI $\left(\mathrm{mL} / \mathrm{m}^{2}\right)$ & $32 \pm 7$ & $42 \pm 12^{*}$ & $37 \pm 10^{* \dagger}$ & $34 \pm 9^{* *}$ \\
\hline $\mathrm{LA}_{\operatorname{Max}}\left(\mathrm{mL} / \mathrm{m}^{2}\right)$ & $35 \pm 14$ & $52 \pm 25^{*}$ & $46 \pm 20^{* \dagger}$ & $39 \pm 16^{*}$ \\
\hline $\mathrm{LA}_{\mathrm{Min}}\left(\mathrm{mL} / \mathrm{m}^{2}\right)$ & $12 \pm 8$ & $32 \pm 18^{*}$ & $26 \pm 10^{* \dagger}$ & $21 \pm 11^{* \vdots}$ \\
\hline LA A-P $(\mathrm{cm})$ & $3.1 \pm 0.4$ & $4.2 \pm 0.5^{*}$ & $3.8 \pm 0.4^{* \dagger}$ & $3.4 \pm 0.4^{* \ddagger}$ \\
\hline LA S-I $(\mathrm{cm})$ & $4.3 \pm 0.6$ & $6.3 \pm 0.7^{*}$ & $5.7 \pm 0.5^{* \dagger}$ & $5.3 \pm 0.5^{* \ddagger}$ \\
\hline
\end{tabular}

Abbreviations: LAVI: (Biplane) Left atrial volume index; $\mathrm{LA}_{\mathrm{Max}}$ : Maximum left atrial volume; $\mathrm{LA}_{\text {Min }}$ : minimum left atrial volume; LA A-P: Left atrial antero-posterior diameter; LA S-I: Left atrial antero-posterior diameter; ${ }^{*}$ Significance vs. controls; ${ }^{\dagger}$ Significance vs. baseline ${ }^{\ddagger}$ Significance vs. 3-months 
Table 3. LA Function and Strain analysis

\begin{tabular}{ccccc}
\hline & Controls & Baseline & 3 months & 12 months \\
\hline $\mathrm{LA}_{\mathrm{EF}}(\%)$ & $65 \pm 13$ & $38 \pm 14^{*}$ & $42 \pm 16^{* \dagger}$ & $49 \pm 18^{* \dagger}$ \\
$\varepsilon_{\mathrm{P}}(\%)$ & $35.8 \pm 15$ & $17.9 \pm 9.5^{*}$ & $23.6 \pm 9.8^{* \dagger}$ & $28.7 \pm 15.7^{* \dagger}$ \\
$\mathrm{SR}_{\mathrm{P}}\left(\mathrm{s}^{-1}\right)$ & $1.42 \pm 0.70$ & $0.78 \pm 0.33^{*}$ & $0.96 \pm 0.46^{* \dagger}$ & $1.23 \pm 0.55^{* \dagger}$ \\
$\mathrm{SR}_{\mathrm{E}}\left(\mathrm{s}^{-1}\right)$ & $1.75 \pm 0.83$ & $1.02 \pm 0.53^{*}$ & $1.23 \pm 0.66^{* \dagger}$ & $1.47 \pm 0.66^{* \dagger}$ \\
$\mathrm{SR}_{\mathrm{A}}\left(\mathrm{s}^{-1}\right)$ & $-2.3 \pm 0.5$ & $-1.41 \pm 0.67^{*}$ & $-1.63 \pm 0.76^{* \dagger}$ & $-1.87 \pm 0.86^{* \dagger}$
\end{tabular}

Abbreviations: $\mathrm{LA}_{\mathrm{EF}}$ : Left atrial empting fraction; $\varepsilon_{\mathrm{P}}$ : Peak systolic strain; $\mathrm{SR}_{\mathrm{P}}$ : Peak systolic strain rate; $\mathrm{SR}_{\mathrm{E}}$ Peak early diastolic strain rate; $\mathrm{SR}_{\mathrm{A}}$ : peak late diastolic strain rate;

${ }^{*}$ Significance vs. controls; ${ }^{\dagger}$ Significance vs. baseline ${ }^{\ddagger}$ Significance vs. 3-months 
Table 4. Pulsed-wave Doppler and Tissue Doppler Imaging (TDI)

\begin{tabular}{ccccc}
\hline & Controls & Baseline & 3 months & 12 months \\
\hline $\mathrm{E}(\mathrm{cm} / \mathrm{sec})$ & $86.3 \pm 10.7$ & $82.0 \pm 9.2$ & $85.6 \pm 15.9$ & $86.9 \pm 16.1$ \\
$\mathrm{~A}(\mathrm{~cm} / \mathrm{sec})$ & $65.5 \pm 7.2$ & $56.6 \pm 5.3^{*}$ & $60.8 \pm 8.9^{* \dagger}$ & $63.7 \pm 12.1$ \\
$\mathrm{E} / \mathrm{A}$ & $1.38 \pm 0.33$ & $1.40 \pm 0.35$ & $1.40 \pm 0.35$ & $1.34 \pm 0.37$ \\
$\mathrm{DT}(\mathrm{ms})$ & $206 \pm 41$ & $202 \pm 37$ & $200 \pm 34$ & $202 \pm 39$ \\
$\mathrm{E}^{\prime}$ & $11.2 \pm 2.7$ & $10.8 \pm 2.2$ & $11.1 \pm 2.0$ & $11.4 \pm 2.1$ \\
$\mathrm{E} / \mathrm{E}^{\prime}$ & $8.1 \pm 1.6$ & $7.8 \pm 1.7$ & $7.7 \pm 1.6$ & $7.7 \pm 1.5$ \\
$\mathrm{~A}^{\prime}$ & $10.5 \pm 3.0$ & $7.0 \pm 2.1^{*}$ & $8.2 \pm 2.9^{* *}$ & $9.4 \pm 2.0^{* \dagger}$
\end{tabular}

Abbreviations: E: Early diastolic filling velocity; A: late diastolic filling velocity; DT: Deceleration time; E': (Tissue Doppler) early diastolic filling velocity; A': (Tissue Doppler) late diastolic filling velocity; ${ }^{*}$ Significance vs. controls; ${ }^{\dagger}$ Significance vs. baseline ${ }^{\ddagger}$ Significance vs. 3 -months 


\section{References}

1. Vianna-Pinton R, Moreno CA, Baxter CM, Lee KS, Tsang TS, Appleton CP. Two-dimensional speckle-tracking echocardiography of the left atrium: feasibility and regional contraction and relaxation differences in normal subjects. J Am Soc Echocardiogr. 2009; 22(3):299-305.

2. Saha SK, Anderson PL, Caracciolo G, Kiotsekoglou A, Wilansky S, Govind S, et al. Global Left Atrial Strain Correlates with CHADS(2) Risk Score in Patients with Atrial Fibrillation. J Am Soc Echocardiogr. 2011; 24(5):506-12 .

3. Kuppahally SS, Akoum N, Burgon NS, Badger TJ, Kholmovki EG, Vijayakumar MS, et al. Left atrial strain and strain rate in patients with paroxysmal and persistent atrial fibrillation: relationship to left atrial structural remodeling detected by delayed enhancement-MRI. Circ Cardiovasc Imaging 2010; 3:231-9.

4. Chimenti C, Russo MA, Carpi A, Frustaci A. Histological substrate of human atrial fibrillation. Biomed Pharmacother. 2010; 64(3):177-83.

5. Nguyen BL, Fishbein MC, Chen LS, Chen PS, Masroor S.

Histopathological substrate for chronic atrial fibrillation in humans. Heart Rhythm. 2009; 6(4):454-60.

6. Allessie M, Ausma J, Schotten U Electrical, contractile and structural remodeling during atrial fibrillation. Cardiovascular Research 2002;54(2): 230-246

7. Kuppahally SS, Akoum N, Badger TJ, Burgon NS, Haslam T, Kholmovski E, ET AL. Echocardiographic left atrial reverse remodelling after catether ablation of atrial fibrillation is predicted by preablation 
delayed enhancement of left atrium by magnetic resonance imaging. Am Heart J 2010; 160: 877-84 .

8. Casaclang-Verzosa G, Gersh BJ, Tsang TS. Structural and functional remodeling of the left atrium: clinical and therapeutic implications for atrial fibrillation. J Am Coll Cardiol. 2008; 51(1):1-11.

9. Tops LF, Bax JJ, Zeppenfeld K, Jongbloed MR, van der Wall EE, Schalij MJ Effect of radiofrequency catheter ablation for atrial fibrillation on left atrial cavity size. Am J Cardiol. 2006; 97(8):1220-2.

10. Tops LF, Delgado V, Bertini M, Marsan NA, Den Uij1 DW, Trines SA, Zeppenfeld K, Holman E, Schalij MJ, Bax JJ. Left atrial strain predicts reverse remodeling after catheter ablation for atrial fibrillation. J Am Coll Cardiol. 2011; 57(3):324-31.

11. Fuster V, Rydén LE, Cannom DS, Crijns HJ, Curtis AB, Ellenbogen $\mathrm{KA}$, et al .. ACC/AHA/ESC 2006 guidelines for the management of patients with atrial fibrillation: a report of the American College of Cardiology/American Heart Association Task Force on Practice Guidelines and the European Society of Cardiology Committee for Practice Guidelines (Writing Committee to Revise the 2001 Guidelines for the Management of Patients With Atrial Fibrillation). J Am Coll Cardiol, 2006; 48: 854-890.

12. Camm AJ, Kirchhof P, Lip GY, Schotten U, Savelieva I, Ernst S, et al. Guidelines for the management of atrial fibrillation: the Task Force for the Management of Atrial Fibrillation of the European Society of Cardiology (ESC) Europace.2010;12(10):1360-420.

13. Calkins H, Brugada J, Packer DL, Cappato R, Chen SA, Crijns HJ, et al. HRS/EHRA/ECAS expert consensus statement on catheter and surgical 
ablation of atrial fibrillation: recommendations for personnel, policy, procedures and follow-up. Heart Rhythm. 2007; 4:816-861.

14. Yilmaz A, Van Putte BP, Van Boven WJ. Completely thoracoscopic bilateral pulmonary vein isolation and left atrial appendage exclusion for atrial fibrillation. J Thorac Cardiovasc Surg. 2008; 136: 521-22.

15. Katritsis D, Ioannidis JP, Anagnostopoulos CE, et al. Identification and catheter ablation of extracardiac and intracardiac components of ligament of Marshall tissue for treatment of paroxysmal atrial fibrillation. J Cardiovasc Electrophysiol. 2001; 12: 750 -758.

16. European Heart Rhythm Association; European Association for CardioThoracic Surgery, Camm AJ, Kirchhof P, Lip GY, Schotten U, Savelieva I, Ernst S, Van Gelder IC, et al. Guidelines for the management of atrial fibrillation: the Task Force for the Management of Atrial Fibrillation of the European Society of Cardiology (ESC). Eur Heart J. 2010; 31(19): 2369429.

17. Schiller NB, Shah PM, Crawford M, DeMaria A, Devereux R, Feigenbaum H, et al. Recommendations for quantitation of the left ventricle by two dimensional echocardiography. American Society of Echocardiography Committee on Standards, Subcommittee on Quantitation of Two-Dimensional Echocardiograms. J Am Soc Echocardiogr 1989; 2: 358-67.

18. Jiamsripong P, Honda T, Reuss CS, Hurst RT, Chaliki HP, Grill DE, et al.Three methods for evaluation of left atrial volume. Eur J Echocardiogr. 2008; 9(3): 351-5.

19. Nagueh SF, Appleton CP, Gillebert TC, Marino PN, Oh JK, Smiseth $\mathrm{OA}$, et al. Recommendations for the Evaluation of Left Ventricular 
Diastolic Function by Echocardiography. Eur J Echocardiogr. 2009; 10: 165-93.

20. Verma A, Kilicaslan F, Adams JR, Hao S, Beheiry S, Minor S, et al. Extensive ablation during pulmonary vein antrum isolation has no adverse impact on left atrial function: an echocardiography and cine computed tomography analysis. J Cardiovasc Electrophysiol. 2006; 17(7):741-6.

21. Ommen SR, Nishimura RA, Appleton CP, Miller FA, Oh JK, Redfield MM, et al..Clinical utility of Doppler echocardiography and tissue Doppler imaging in the estimation of left ventricular filling pressures: A comparative simultaneous Doppler-catheterization study. Circulation. 2000; 102(15):1788-94.

22. Gillinov AM, Argenziano M, Blackstone EH, Iribarne A,. DeRose, Jr. JJ, Ailawadi G, et al. Designing comparative effectiveness trials of surgical ablation for atrial fibrillation: Experience of the Cardiothoracic Surgical Trials Network . J. Thorac. Cardiovasc. Surg. 2011; 142: 257 - 264.e2.

23. Edgerton JR, Mahoney C, Mack MJ, Roper K, Herbert MA.Long-term monitoring after surgical ablation for atrial fibrillation: How much is enough? J. Thorac. Cardiovasc. Surg. 2011; 142: 162-65.

24. Nasso G, Bonifazi R, Del Prete A, Del Prete G, Lopriore V, Bartolomucci F, et al. Long-term results of ablation for isolated atrial fibrillation through a right minithoracotomy: Toward a rational revision of treatment protocols. J Thorac Cardiovasc Surg. 2011 Aug;142(2):e41-6.

25. Santarpino G, Rubino AS, Onorati F, Curcio A, Torella D, Tucci L, et al. Atrial fibrillation ablation induces reverse remodelling and impacts cardiac function. Minerva Cardioangiol. 2011; 59(1):17-29. 
26. Aikawa M, Watanabe H, Shimokawa T, Inoue K, Takamisawa I, Seki A, et al.Preoperative left atrial emptying fraction is a powerful predictor of successful maze procedure. Circ J. 2009; 73(2):269-73.

27. Buber J, Luria D, Sternik L, Raannani E, Finberg MS, Goldemberg I et al. Left atrial contractile function following a successful modified Maze procedure at surgery and the risk of subsequent thromboembolic stroke. $\mathrm{J}$ Am Coll Cardiol. 2001; 58: 1614-21 
- $312-$ 


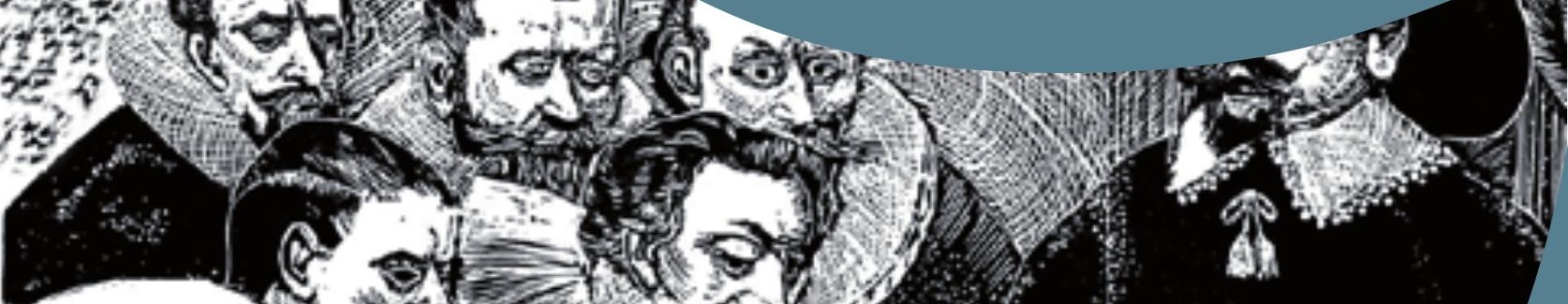




\section{Chapter 9: General discussion}

A combined endocardial and epicardial procedure for the treatment of atrial fibrillation is an impartial way the cardiac surgeon and the electrophysiologist could explore as a team to reach a common goal, a high long-term cure rate achieved with a single-session procedure.

The basic concepts of cardiac surgery and electrophysiology in AF treatment is obscured by different strategies, leading to conflicting trends and therefore misunderstanding. On the EP side isolation of the PVs with proof of an acute complete electrical isolation is the cornerstone of most ablation strategies. On the surgical side the classical idea of a successful AF procedure is still a Cox Maze procedure on the arrested heart with no electrophysiological confirmation of the effect and the quality of the lesion set. These distinctive characteristics of different treatment platforms can only be changed if we are willing to accept our individual and technical limitations. If we are able to confront this, than the necessity of a direct link between the two disciplines will become clear. The energy that is needed to realize this multi-disciplinary approach is a reflection of the difficulty to define the parameters of energy delivery in the left and right atrium. The effect of this multidisciplinary approach will depend upon the power delivered, and the accuracy of the visualization and mapping of the ablated tissue in both atria. Fundamental questions like the necessity of a continuous and transmural lesion will no longer be unanswered if we can map triggers and substrate at the endocardium and epicardium, improve our 
understanding of the mechanism of AF and confirm lesion transmurality at both sides with one single combined procedure.

Recent EP literature shows that long-lasting endocardial catheter isolation of the PVs, whether it is achieved with RF energy or cryo, remains challenging ${ }^{1}$. Because of this limitation it is not clear whether complete circumferential antral ablation is necessary for successful PV isolation in patients with PAF. Non-circumferential antral ablation could achieve similar success rates with shorter procedure and ablation times than circumferential ablation. Therefore, attention could be focused on producing permanent lesions rather than on completing antral encirclement after isolation is achieved $^{2-4}$.

This basic philosophy was the rationale of our initial experience with the minimally invasive surgical treatment of lone AF. In 2005 we developed a technique of a monolateral right thoracoscopic approach. The procedure consisted of the creation of a box lesion with a catheter that used microwave energy to ablate left atrial tissue. At that time this catheter was the only commercially available thoracoscopic minimal invasive surgical ablation tool ${ }^{5-6}$. The concept of the box lesion as a minimal lesion set was based on several factors, but most importantly, a consequence of the absence of electrophysiological mapping during the surgical procedure. The rationale was to exclude a maximum of triggers, by isolating the four PVs, to try to obtain an important substrate modification by isolating the posterior wall of the left atrium, to reduce the critical mass, to denervate the four major ganlionated plexi and to ablate the ligament of Marshall. A potential major drawback for a monolateral right-sided 
approach was the lack of opportunity to exclude or occlude the left atrial appendage safely. Since the LAA is largely responsible for thrombo-embolic events in patients with $\mathrm{AF}$, and can be part of the substrate responsible for $\mathrm{AF}$, it could be preferable to occlude the LAA in a sub-group of patients. We therefore developed a technique of a monolateral left-sided approach for patients when isolation of the LAA was deemed necessary. Freedom of AF at one year was $73 \%$ for the combined group of right and left-sided interventions. A complementary endocardial approach was performed at 6 months in 18 patients ${ }^{7}$. Since the success rate at two year follow-up was unsatisfactory ${ }^{8}$ we changed the energy source from microwave to monopolar RF. Realizing that the concept of the epicardial box lesion was difficult to achieve epicardialy on the beating heart (epicardial fat, heat-sink effect, power delivery of a monopolar ablation device) we combined the surgical procedure with a simultaneous endocardial electrophysiology procedure. A single-session hybrid AF procedure was born. For the first time we could study the effect of an epicardial ablation on the endocardium in a human being during the same procedure and vice versa. Using this approach we could demonstrate that after epicardial creation of a box lesion with microwave or radiofrequency there was a conduction delay from the PVs and the posterior wall of the left atrium, but no exit or entrance block. The incomplete epicardial surgical ablation line necessitated a complementary endocardial isolation of one or more PVs, the roof and inferior line.

The importance of these findings was twofold: first we proved the concept that combining a percutaneous endocardial approach with a thoracoscopic epicardial 
approach was technically feasible and safe, secondly creation of a continuous transmural box lesion from the epicardium with a monopolar energy source was not possible. Even with satisfactory clinical results, transmurality and continuity of epicardial lesions could not be assumed. This could probably explain the low success rate at long-term follow-up. Again we had to change our strategy and decided to first focus on antral epicardial isolation of the PVs. In order to be an alternative for an endocardial ablation, it was mandatory to achieve a long-lasting antral isolation of the PVs. Since microwave and monopolar RF energy were inconsistent, we had to search for an alternative. Prasad et al. showed in an animal model the potential of a bipolar RF clamp to isolate PVs ${ }^{9}$. Damiano et al. studied the results of a Cox Maze IV using a bipolar RF clamp and found that they where similar to the "cut and sew" Cox Maze III ${ }^{10}$. Thus it was assumed that a bipolar RF clamp is able to isolate the PVs on the beating heart. However, endocardial redo procedures in patients with recurrence of AF who had had a thoracoscopic bipolar PV isolation showed that in 50\% there was failure to isolate of one or more PVs ${ }^{11}$. We demonstrated that clamping-induced ischemia could be responsible for these failures ${ }^{12}$. Therefore, combining a bilateral thoracoscopic approach with antral isolation of the PVs followed by an endocardial mapping at least 30 minutes after the epicardial ablation should avoid incomplete isolation of the PVs. Building upon this antral isolation of the PVs we then could focus on the creation of linear lesions connecting the superior PVs and the inferior PVs using a bipolar unidirectional linear pen. 
The group of Damiano demonstrated in an animal model the potential risk of incomplete lesions using these devices ${ }^{13}$. Our clinical experience confirmed their findings, in $23 \%$ of patients the epicardial lines created with these linear ablation devices were not transmural and necessitated an endocardial touch-up, demonstrating the importance of power application and mapping during catheter treatment of $\mathrm{AF}^{14}$. The possibility to perform such an endocardial touch-up to render epicardial lesions completely transmural, is one of the major advantages of this dual epicardial endocardial approach.

It also appeared to be an advantage during a redo procedure by offering the possibility to first map the patient endocardialy. An important percentage of patients that will be send for an epicardial treatment of AF will have had a previous endocardial procedure, mostly PV isolation. Knowing which veins have been isolated, and which not, will have important consequences for the treatment strategy. If all PVs have been isolated, the epicardial procedure should be focused on linear lesions and (mostly) exclusion of the LAA. In these cases the thoracoscopic procedure can be limited to the left side. If the PVs have been isolated on one side, the thoracoscopic procedure will be limited to the other side.

Starting from a single-sided thoracoscopic procedure with a monopolar energy source on the beating heart we were confronted with the surgical and technical limitations of the ablation devices. A simultaneous endocardial approach seemed mandatory to understand the limitations of our minimal approach. Setting up this collaboration with the EP was challenging. Trying to understand our common goals, organizing the 
availability of the different teams, selection of the patients, deciding where the procedure should be performed, the sequences, where some of many challenges we had to confront. Evaluation of our findings acutely and over time made several changes of approach and choice of ablation technologies and devices necessary. This could only be achieved by a real open-minded team approach that stayed critical regarding the achieved progress and willing to look back and compare this new approach with other more standard procedures.

\section{Single-session hybrid procedure versus percutaneous catheter ablation}

The reported success rate of percutaneous catheter ablation of paroxysmal AF with a single procedure ranges between $50 \%$ to $80 \%$, and is independent of operator experience. These results are even lower for patients with persistent AF (30\% to $50 \%$ ). The differences in success rates could be explained by a variety of reasons including the experience of the centre, the ablation strategy, the technology, the follow-up and other variables. A major concern is a significant recurrence rate after initial complete PV isolation necessitating a repeat intervention to achieve long-term cure of AF (even in high volume centres). Recovered PV conduction after initial acute circumferential PV isolation is the dominant reason for recurrent AF and atrial tachyarrhythmias ${ }^{15}$. The problem of durability of contiguous and transmural ablation lines in percutaneous transvenous endocardial procedures is related to different factors. The procedure is performed with the help of virtual imaging (fluoroscopy and 
3-D mapping) limiting the anatomical accuracy, the permanent tissue effects will depend on adequate and stable catheter tip-tissue contact, and the necessary parameters of energy delivery are difficult to define in an environment of circulating blood. These issues can be addressed by epicardial application of a bipolar RF clamping device and should therefore result in more persistent antral lesions of the PVs. With an epicardial approach direct anatomical visualisation and stable catheter tip-tissue contact are obtained. Furthermore, clamping the tissue between two jaws excludes the effect of the circulating blood on delivery of power thereby eliminating the heat-sink effect. However, anatomical limitations and epicardial fat can still prevent transmurality. The epicardial approach which is anatomical and fast, which creates long contiguous lines, which partially eliminates the ganglionated plexi and through which the left atrial appendage can be more safely excluded is complementary to the endocardial approach which can confirm the quality of the lesion set, which can make a left and right isthmus line and which can eliminate CAFEs. This complementarities by itself also have the potential to reduce complications related to both individual procedures. On the epicardial side the combined approach avoids the necessity for a more invasive surgical procedure and the very limited endpoints of acute exit and entry block can be improved by a more complete endocardial mapping. On the endocardial side the combined approach will avoid the risk for tamponade, oesophageal fistula, phrenic nerve injury and prolonged fluoroscopy. The risk of thrombo-embolic events with an epicardial approach is close to zero. By replacing a number of endocardial ablations to the epicardium, the total amount of thrombo- 
embolic events will be reduced ${ }^{16}$. In short, the possibility to perform an endocardial mapping of the epicardial lesion set and the ability to touch-up endocardialy an incomplete lesion is what makes the hybrid procedure successful.

\section{Sequential hybrid procedure versus percutaneous catheter ablation}

Mahapatra et al. published their initial experience with surgical epicardial catheter and endocardial ablation for atrial fibrillation carried out in two sequential steps, but during the same hospitalization ${ }^{17}$. Fifteen patients with persistent or long-standing persistent $\mathrm{AF}$ who failed at least one catheter ablation and one AAD were treated. This group was matched to 30 patients who had previously failed at least one catheter ablation and underwent a repeat catheter ablation. Five sequential hybrid patients had seven inducible flutters that were mapped and ablated. After a mean follow-up of $20.7 \pm 4.5$ months, $86.7 \%$ of patients of the sequential group were free of any atrial arrhythmia and off AAD, compared to $53.3 \%$ of the catheter-alone patients. The authors concluded that for patients with atrial fibrillation who have failed catheter ablation, sequential minimally invasive epicardial surgical ablation, followed by endocardial catheter-based ablation, has a higher early success rate than repeat catheter ablation alone.

This staged approach may have logistical advantages over a combined, single-session hybrid procedure. A potential drawback could be oedema off the tissue post-ablation with difficulty to re-ablate the same area after a short waiting period. A second 
problem could be the increase of complication rates since the two procedures are performed separately.

\section{Hybrid procedure versus surgical ablation}

By replacing the incisions of the traditional Cox-maze III procedure with less invasive linear lesions of ablation using bipolar RF, Damiano et al. introduced the Cox-maze IV procedure. This procedure requires cardiopulmonary bypass and at least one small right thoracotomy. The freedom of AF recurrence was $84 \%$ at 2 years for patients off $\mathrm{AAD}^{10}$. These figures are comparable with our results although in the case of the hybrid procedure, no cardiopulmonary bypass is needed neither a thoracotomy. We know that none of the existing surgical ablation technologies (even bipolar RF) can guarantee complete transmurality ${ }^{11}$. We solved this issue by endocardial mapping and in the case of incomplete lesions applying RF endocardialy. Another shortcoming of the surgical approach is the inability to precisely locate AF triggers and to map ATs or reentry arrhythmias known to occur during AF ablation. In the setting of a hybrid procedure it is possible to perform extensive mapping in order to tailor the lesion set. Finally, if the surgical procedure is performed epicardialy on the beating heart, it is technically impossible to create a linear lesion across the left and right isthmus. Both these lesions can be performed with a hybrid approach. Nonetheless only a randomized study with a significant number of patients will be 
able to demonstrate a preferred technique according to the classification of AF and its complication rate.

\section{Hybrid procedure versus surgical ablation with epicardial mapping}

Lockwood et al. described a technique for assessing conduction block across surgical lesions based on epicardial mapping ${ }^{18}$. They identified gaps in linear lesions by pacing the atrium epicardialy on one side of the ablation line and mapping the direction of atrial activation on the opposite side. Transmurality of linear lesions was also assessed by reduction of atrial potential amplitude along the linear lesion and the development of double atrial potentials along the ablation line. Using RF devices, they achieved complete block across linear lesions by the first set of RF applications in only $21 \%$. Several factors like epicardial fat and local myocardial thickness limited the depth of penetration of RF and thus the creation of transmural lesions. After identification and localisation of the gaps, epicardial ablation was repeated until complete bidirectional block across all the linear lesions. During a hybrid procedure pacing manoeuvres and mapping techniques are performed from the endocardial side. In our series, in $23 \%$ of patients we were not able to create a complete box lesion, even after identification of remaining gaps and repeating epicardial ablation. In these patients all PVs were isolated (bipolar bidirectional clamping) and the gaps were found in the connecting lesions at the roof or inferior line (bipolar unidirectional linear pen). To create contiguous transmural lesions in these areas, we had to apply 
endocardial unipolar RF. Since the connecting lesions are created with a non-clamping device, epicardial fat, tissue thickness and the heat-sink effect are still a concern. Krul et al. described a series of 31 patients with AF which was treated with thoracoscopic PV isolation and ganglionated plexus (GP) ablation ${ }^{19}$. In patients with non-paroxysmal AF, LA ablation lines were created and conduction block verified epicardialy with custom made catheters. After 1 year, they reported comparable success rates to our series ( $86 \%$ of patients had no recurrence of SVT off AAD), but had a significantly higher complication rate. Three patients had a sternotomy because of uncontrolled bleeding during thoracoscopic surgery. An important conceptual difference between both studies is that Krul et al. could only perform epicardial lesions without the possibility of add on endocardial lesions including endocardial touch-ups to improve transmurality, as well as performing CTI and left sided isthmus ablation. In addition, they could only check completeness of ablation lesions from the epicardium which may be insufficient to show complete electrical block. In these small patient groups it is difficult to make hard conclusions when comparing two studies. More than half of the patients in Krul's study had PAF and all patients had a 24-hour Holter monitoring after one year. In our series most patients had persistent or long-lasting persistent AF and had a 7-day Holter monitoring at 1 year. 


\section{What is the future of hybrid procedures in ablation of AF?}

Even with the best and most experienced hands stand-alone catheter ablations for the treatment of AF have a significant recurrence rate, even after initial complete PV isolation. The need for one or more repeat interventions to achieve long-term cure of $\mathrm{AF}$ is cost ineffective and increases the potential complication rate unnecessarily. The majority of patients would prefer a single procedure if this can be achieved safely and with minimal invasiveness. There will not be one single standard approach for PV isolation, and the EP will have to choose among the available techniques and technologies.

The lack of endpoints and of understanding which patients benefit most could be improved by a combined endocardial epicardial procedure. In the patient population where "AF begets AF" it seems that "catheter ablation begets catheter ablation". A single-session hybrid procedure, although initially more complex and more costly, may lead to a higher cost-efficiency and lower complication rate because of a higher cure rate. Understanding that treatment of AF is mandatary because of the high costs associated with the persistence of AF despite medication, invasive therapies will become a serious economical burden. Reducing the surgical invasiveness and improving the quality of the endocardial ablation lines will increase success rates, the number of patients available for interventional procedures and the willingness of social security providers to accept the costs related to these invasive treatments. 
Hybrid AF treatment will change the working relationship between electrophysiologist, cardiac surgeon and patient and could become a treatment option for symptomatic patients with persistent or long-lasting persistent AF. With increased experience it could also become the treatment of choice for patients with PAF, after failed catheter ablation, or with increased LA size and important substrate modification.

\section{Conclusion}

The ideal approach for AF should be patient-tailored, employing a procedure which is adapted to the origin of the patient's AF, and should take into consideration triggers and substrate. Therefore, the current classification of AF in four categories going from PAF to permanent AF is limiting when considering an ablation strategy. Defining AF only within a time scale is insufficient to understand the complexity of the atrial pathology responsible. Our group has demonstrated in the lab that AF is not a disease coming from the endocardium or epicardium, but a disease involving the three dimensional structure of the atria. The study and treatment of the atria can only be complete if we have simultaneous access to the endocardium and epicardium of the beating heart. This can be achieved through a close collaboration between the surgeon and the electrophysiologist.

The potential benefits of a hybrid procedure as a single-step or sequential ablation are important. The endocardial and epicardial approach gives us a perfect platform to 
study the mechanisms of AF and thereby could improve our understanding of the difficulties to treat this disease. Two complementary techniques performed in conjunction could increase long-term success rate, reduce complication rate, morbidity and mortality related to AF. In a single-session procedure, the reduction of complication rates is not only because of the reduction in the number of procedures, but more importantly through the simultaneous access during the procedure. The robustness of the approach lies in its complimentary nature. In our experience almost a quarter of single-step hybrid AF procedures needed a touch-up with an endocardial catheter ablation to finish incomplete epicardial surgical lesions. In addition, the mitral isthmus line and CTI line can only be performed when combined with an endocardial approach. In redo procedures knowledge of the effect of the previous endocardial procedure(s) will guide the epicardial technique.

The efficacy of this procedure as well as its superiority over catheter ablation or standard surgical techniques has to be proven by large comparative studies with longterm follow-up. 


\section{References}

1. Kottkamp H, Hindricks G. Beyond Pulmonary Vein Isolation: The Issue of Reconduction. J Cardiovasc Electrophysiol. 2009 Dec;20(12),1388-90.

2. Sy RW, Gula LJ, Leong-Sit P, Klein GJ, Yee R, Krahn AD, Bentley C, Razak S, Skanes AC. Complete antral encirclement is not required for pulmonary vein isolation. Heart Rhythm. $2011 \mathrm{Jan} ; 8(1): 16-22$.

3. Stabile G, Turco P, Nocerino P, Stabile E and De Simone A. Is pulmonary vein isolation necessary for curing atrial fibrillation? Circ. $2003 ; 108$;657-660.

4. van Brakel TJ, Bolotin G, Nifong LW, Dekker AL, Allessie MA, Chitwood WR Jr, Maessen JG. Robot-assisted epicardial ablation of the pulmonary veins: is a completed isolation necessary? Eur Heart J. 2005 Jul;26(13):1321-6.

5. La Meir M, De Roy L, Blommaert D, Buche M. Treatment of lone atrial fibrillation with a right thoracoscopic approach. Ann. Thorac. Surg. 2007; 83, 2244-2245.

6. La Meir M. Unilateral approach for thoracoscopic AF ablation : technical considerations. Maessen J. Eds. Minerva Medica. Turin 2009. Pages: 25-32.

7. La Meir M, De Roy L, Gourdin M. A Hybrid approach for treatment of patients with atrial fibrillation with radiofrequency catheters. In: Hybrid and minimally invasive cardiac intervention. Maessen J and Crijns H. Eds.

Minerva Medica. Turin 2010. Pages: 9-13.

8. Pruitt JC, Lazzara RR, Ebra G. Minimally invasive surgical ablation of atrial 
fibrillation: the thoracoscopic box lesion approach. J Interv Card Electrophysiol. 2007;20(3):83-7.

9. Prasad SM, Maniar HS, Schuessler RB, Damiano RJ Jr. Chronic transmural atrial ablation by using bipolar radiofrequency energy on the beating heart. J Thorac Cardiovasc Surg. 2002 Oct;124(4):708-13.

10. Weimar T, Schena S, Bailey MS, Maniar HS, Schuessler RB, Cox JL, Damiano RJ Jr. The cox-maze procedure for lone atrial fibrillation: a singlecenter experience over 2 decades. Circ Arrhythm Electrophysiol. 2012 Feb $1 ; 5(1)$.

11. Kron J, Kasirajan V, Wood MA, Kowalski M, Han FT, Ellenbogen KA. Management of recurrent atrial arrhythmias after minimally invasive surgical pulmonary vein isolation and ganglionic plexi ablation for atrial fibrillation. Heart Rhythm. 2010 Apr;7(4):445-51.

12. Pison L, La Meir M, van Opstal J, Crijns HJ. Transient clamp-induced mechanical block of pulmonary vein potentials. J Thorac Cardiovasc Surg. 2011 Feb;141(2):e15-6.

13. Lee AM, Aziz A, Clark KL, Schuessler RB, Damiano RJ Jr. Chronic performance of a novel radiofrequency ablation device on the beating heart: Limitations of conduction delay to assess transmurality. J Thorac Cardiovasc Surg. 2012 Feb 1. 
14. Pison L, La Meir M, van Opstal J, Blaauw Y, Maessen JG, Crijns HJ. Hybrid thoracoscopic surgical and transvenous catheter ablation of atrial fibrillation. J Am Coll Cardiol. 2012. "In press"

15. Gerstenfeld EP, CallansDJ, Dixit S, Zado E, Marchlinski FE: Incidence and location of focal atrial fibrillation triggers in patients undergoing repeat pulmonary vein isolation: Implications for ablation strategies. $\mathrm{J}$

Cardiovasc Electrophysiol 2003;14:685-690.

16. Sauren LD, la Meir M, de Roy L, Pison L, van der Veen FH, Mess WH, Crijns HJ, Maessen JG. Increased number of cerebral emboli during percutaneous endocardial pulmonary vein isolation versus a thoracoscopic epicardial approach. Eur J Cardiothorac Surg. 2009 Nov;36(5):833-7.

17. Mahapatra S, LaPar DJ, Kamath S, Payne J, Bilchick KC, Mangrum, Ailawadi G. Initial Experience of Sequential Surgical Epicardial- Catheter Endocardial Ablation for Persistent and Long-Standing Persistent Atrial Fibrillation With Long-Term Follow-Up. Ann Thorac Surg 2011; 91: 1890-8.

18. Lockwood D, Nakagawa H, Peyton MD, Edgerton JR, Scherlag BJ, Sivaram CA, Po SS, Beckman KJ, Abedin M, Jackman WM. Linear left atrial lesions in minimally invasive surgical ablation of persistent atrial fibrillation: Techniques for assessing conduction block across surgical lesions. Heart Rhythm 2009;6: S50-63.

19. Krul SP, Driessen AH, van Boven WJ, Linnenbank AC, Geuzebroek GS, Jackman WM, Wilde AA, de Bakker JM, de Groot JR. Thoracoscopic video-assisted pulmonary vein antrum isolation, ganglionated plexus ablation, and periprocedural 
confirmation of ablation lesions: first results of a hybrid surgical-electrophysiological approach for atrial fibrillation. Circ Arrhythm Electrophysiol. 2011; 4: 262-70. 
Samenvatting voor niet medici

De behandeling van hartritmestoornissen in de voorkamers blijft een uitdaging die vraagt naar nieuwe oplossingen. Toediening van medicatie om het hart te resinusaliseren, of de hartfrequentie te normaliseren, en medicatie om stolselvorming in de voorkamers te vermijden, heeft een aantal negatieve effecten, zeker bij een langdurige behandeling . Een alternatief bestaat uit het maken van een aantal littekens met catheters aan de binnenzijde of aan de buitenzijde van de beide voorkamers. De resultaten van deze technieken zijn bevredigend voor patiënten met boezemfibrilleren dat spontaan binnen de zeven dagen beëindigt, maar minder voor patiënten bij dewelke een elektrische shock of extra medicatie nodig is voor het stoppen van dit boezemfibrilleren. De doelstelling van dit proefwerk was om te bestuderen welke de mogelijkheden en mogelijke voordelen zijn indien we de beide voorkamers simultaan vanuit de buitenzijde en de binnenzijde benaderen. De buitenzijde van de voorkamers wordt benaderd via een kijkoperatie tussen de ribben waarbij met speciale catheters brandlijntjes worden gemaakt. Aan de andere kant wordt de binnenzijde van het hart benadert via een ader in de lies. Via deze weg kunnen signalen in het hart gemeten worden en een eventuele incomplete brandlijn aan de buitenzijde van de voorkamers vervolledigd worden. Deze gecombineerde ingreep noemen we een hybride thoracoscopische epicardiale en endoveneuze endocardiale behandeling van boezemfibrilleren.

Hoofdstuk 1 is een algemene introductie. De geschiedenis, soorten, oorzaken en de mogelijke behandelingsopties worden beschreven. Hierop volgend geeft hoofdstuk 2 een overzicht van de huidige chirurgische minder invasieve mogelijkheden. In hoofdstuk 3 beschrijven we onze ervaring voor het behandelen van boezemfibrilleren met een kijkoperatie alleen. De resultaten van deze studie liggen aan de basis van onze hybride benadering. Hoofdstuk 4 is de beschrijving van een vereenvoudigde heelkundige techniek, waarbij de operatie 
gebeurt enkel via de rechterzijde van de ribbenkast, in combinatie met een procedure via een ader in de lies. Deze ervaring maakte duidelijk dat deze procedure doenbaar was en veilig kon gebeuren. Gezien de resultaten na 1 jaar suboptimaal waren, werd besloten om de catheters die tijdens de chirurgie werden gebruikt te veranderen door mogelijks efficiëntere catheters. Deze nieuwe catheters betekenden wel dat nu een benadering via zowel de rechter als de linker ribbenkast noodzakelijk was. Hoofdstuk 5 geeft onze resultaten met deze techniek. Hoofdstuk 6 vergelijkt de hybride techniek met een kijkoperatie via een zijde of via beide zijden van de ribbenkast. In hoofdstuk 7 vergelijken we de hybride techniek met een benadering via beide zijden met een niet hybride techniek. In hoofdstuk 8 bestuderen we de positieve effecten van de chirurgische benadering op de functie van de linkervoorkamer d.m.v. echografie van het hart. In hoofdstuk 9 worden tenslotte de bevindingen van al deze studies gekaderd binnen het onderzoek naar en de behandeling van boezemfibrilleren. 


\section{Dankwoord}

Ik wil met dit dankwoord duidelijk maken dat dit proefschrift niet het werk is van een individu, maar het gevolg is van een nauwe samenwerking tussen vele personen die voor altijd verbonden zullen blijven aan de woorden in deze tekst. De kracht van dit proefschrift ligt zeker in de samenwerking die in alle openheid en zonder vooroordelen, zonder een jacht naar een individueel voordeel, werd verwezenlijkt. We waren allen op zoek naar een vorm van waarheid, in de geneeskunde en de mensheid. Het complexe gedrag van eenieder werd verenigd in een verbluffende arbeidsverdeling, een inspiratiebron voor het echte teamwerk, belichaamd alhier.

Niets is zo vervelend als bladvulling door een meestal onvolledige lijst van personen aan wie we dank verschuldigd zijn. Bovendien overstijgt de individuele erkenning nooit de collectieve voldoening. Vandaar dat ik mijn dank richt aan de verschillende organen die betrokken waren met dit project: UCL Mont-Godinne, AZM Maastricht, Careggi Hospital Florence en UZ Brussel. Buiten al de namen die in de verschillende teksten te lezen zijn, is er nog een veelvoud van andere namen die ondanks hun anonimiteit even belangrijk zijn. Ik dank $u$ allen oprecht met deze enkele woorden. Jullie steun is wat dit werk voldoening geeft.

Niemand begrijpt beter de tekortkomingen van dit proefschrift, de verantwoordelijkheid ligt volledig bij mijzelf. 


\section{CURRICULUM VITAE}

Dr Mark La Meir

Cardiothoracic surgery

UZ Brussels

Laarbeeklaan 101

1090 Brussels

Belgium

Tel. : +32 24776008

Fax : +32 24776851

E-mail : mark.lameir@uzbrussel.be

Cardiothoracic surgery

AZM (University hospital Maastricht)

P. Debyelaan 25

P.O. Box 5800

6200 AZ Maastricht

The Netherlands

Tel. : +31 433875070

Fax : +31 433875075

E-mail : m.la.meir@mumc.nl 


\title{
PERSONALIA
}

\author{
Name - Firstname : $\quad$ La Meir Mark
}

Date - Place of Birth : 19/11/1967 - Gent, Belgium

Private Address : $\quad$ Hertogenweg 18

B-3080 Tervuren

Tel.: +32495264911

E-mail : lameir@yahoo.com

\section{STUDIES}

10/92 - 09/98 : Assistant Surgery, Vrije Universiteit Brussel, Belgium

10/85 - 06/92 : Medecine, Vrije Universiteit Brussel, Belgium

\section{PROFESSIONAL ACTIVITIES}

08/09 - $\quad$ : Cardiothoracic surgeon

Department of Cardiac Surgery

Prof. F. Wellens, UZ Brussels - ASZ Aalst, Belgium

Special interests : minimal invasive surgery, arrhythmia surgery, valve surgery, hybrid procedures

: Cardiothoracic surgeon

Department of Cardiothoracic Surgery

Prof. J. Maessen, AZM, Maastricht, The Netherlands

: Consultant cardiothoracic and vascular surgeon

Department of Cardiovascular and Thoracic Surgery

Prof. M. Buche, UCL Mont-Godinne, Yvoir, Belgium

10/05-07/09 : Cardiothoracic surgeon

Department of Cardiothoracic Surgery

Prof. J. Maessen, AZM, Maastricht, The Netherlands

Special interests : minimal invasive surgery, arrhythmia surgery, valve surgery, hybrid procedures

: Consultant cardiothoracic and vascular surgeon

Department of Cardiovascular and Thoracic Surgery 
Prof. M. Buche, UCL Mont-Godinne, Yvoir, Belgium

03/04 - 09/05 : Cardiothoracic and vascular surgeon

Department of Cardiovascular and Thoracic Surgery

Prof. M. Buche, UCL Mont-Godinne, Yvoir, Belgium

Special interests : minimal invasive surgery, arrhythmia surgery, valve surgery, lung transplantation

03/02 - 02/04 : Cardiothoracic and vascular surgeon

Department of Cardiovascular and Thoracic Surgery

Dr. H. Vanermen, OLV-ziekenhuis, Aalst, Belgium

Special interests : minimal invasive valve surgery, arrhythmia surgery, lung surgery, stentgrafts

10/99-02/02 : Cardiothoracic surgeon

Department of Cardiothoracic Surgery

Prof. B. Mochtar, AZM, Maastricht, The Netherlands

Special interests : off-pump CABG, arrhythmia surgery, aortic surgery, lung surgery

10/98 - 09/99 : General and vascular surgeon

MCNOL Bree - Maaseik, Belgium

\section{SURGICAL TRAINING}

10/96 - 09/98 : OLV-ziekenhuis, Aalst, Belgium

10/94 - 09/96 : Aalsters Stedelijk Ziekenhuis, Aalst, Belgium

10/92 - 09/94 : Bracopsziekenhuis, Brussels, Belgium

\section{TRAINING PERIODS ABROAD}

10/99 - 02/02 : Department of Cardiothoracic Surgery

Prof. B. Mochtar, AZM, Maastricht, The Netherlands

10/84 - 02/85 : Vascular Surgery, Tygerbergziekenhuis

Cape Town, South-Africa 


\section{PUBLICATIONS}

The Hybrid Approach for The Surgical Treatment of Lone Atrial Fibrillation: One-year Results Employing a Monopolar Radiofrequency Source. La Meir M, Gelsomino S, Lorusso R, Lucà F, Pison L, Parise O, Wellens F, Gensini GF, Maessen JG. J Cardiothorac Surg. 2012 Jul 19;7:71.

Minimal Invasive Surgery for Atrial Fibrillation: An updated Review. La Meir M, Gelsomino S, Lucà F, Pison L, Colella A, Lorusso R, Crudeli E, Gensini GF, Crijns HG, Maessen JG. Europace. 2012 Jul 10.

Extracardiac minimal invasive implantation of cardioverter defibrillator in young children. Czapla J, La Meir M, Verbessem D, Brugada P, Wellens F. Acta Chir Belg. 2012 MayJun;112(3):185-8.

Hybrid Thoracoscopic Surgical and Transvenous Catheter Ablation of Atrial Fibrillation. Pison L, La Meir M, van Opstal J, Blaauw Y, Maessen JG, Crijns HJ. J Am Coll Cardiol. 2012 Jul 3;60(1):54-61.

Minimally Invasive Surgical Treatment of Lone Atrial Fibrillation: Early Results of Hybrid Versus Standard Minimally Invasive Approach Employing Radiofrequency Sources. La Meir $\mathrm{M}$, Gelsomino S, Pison L, Lorusso R, Lucà F, Parise $\mathrm{O}$, Gensini GF, Crijns HG, Wellens F and Maessen JG. Int J Cardiol. 2012 May 2.

Negative-pressure wound therapy and laparoscopic omentoplasty for deep sternal wound infections after median sternotomy. De Brabandere K, Jacobs-Tulleneers-Thevissen D, Czapla J, La Meir M, Delvaux G, Wellens F. Tex Heart Inst J. 2012;39(3):367-71.

Improvement of Left Atrial Function And Left Atrial Reverse Remodeling After Minimally Invasive Radiofrequency Ablation Evaluated By Two-Dimensional Speckle Tracking Echocardiography. La Meir M, Gelsomino S, Lucà F, Pison L, Rao CM, Wellens F, Maessen JG. J Thorac Cardiovasc Surg. 2012 Jun 17.

The apple does not fall far from the tree: epicardial ventricular tachycardia due to blunt chest trauma. Casado-Arroyo R, Namdar M, Bayrak F, Sarkozy A, La Meir M, Brugada P. Eur Heart J. 2012 Jun;33(12):1430.

Treatment of lone atrial fibrillation: a look at the past, a view of the present and a glance at the future. Gelsomino S, La Meir M, Lucà F, Lorusso R, Crudeli E, Vasquez L, Gensini GF, Maessen J. Eur J Cardiothorac Surg. 2012. Jun;41(6):1284-94. 
Minimally invasive thoracoscopic hybrid treatment of lone atrial fibrillation: early results of monopolar versus bipolar radiofrequency source. La Meir $\mathrm{M}$, Gelsomino $\mathrm{S}$, Lucà $\mathrm{F}$, Lorusso R, Gensini GF, Pison L, Wellens F, Maessen J. Interact Cardiovasc Thorac Surg. 2012 Apr;14(4):445-50.

Left atrial flutter due to incomplete left fibrous trigone linear lesion. Pison L, La Meir M, Crijns HJ. J Thorac Cardiovasc Surg. 2011 Nov;142(5):e149-51.

Time-related prevalence of postoperative atrial fibrillation after stand-alone minimally invasive radiofrequency ablation. La Meir M, Gelsomino S, Luca F, Pison L, Chambille P, Parise O, Crijns HJ, Maessen JG. J Card Surg. 2011 Jul;26(4):453-9.

Complete Epicardial Resynchronization Device Implantation in a Patient Who Underwent a Replacement of Mitral and Tricuspid Valve. Ricciardi D, de Asmundis C, Czapla J, La Meir M, Brugada P, Wellens F. Pacing Clin Electrophysiol. 2011 Jun 8. [Epub ahead of print]

Pharmacological Management of Atrial Fibrillation: One, None, One Hundred Thousand Lucà F, La Meir M, Rao CM, Parise O, Vasquez L, Carella R, Lorusso R, Daniela B, Maessen J, Gensini GF, Gelsomino S. Cardiol Res Pract. 2011; 2011: 874802. Published online 2011 April 26.

Transient clamp-induced mechanical block of pulmonary vein potentials. Pison L, La Meir M, van Opstal J, Crijns HJ. J Thorac Cardiovasc Surg. 2011 Feb;141(2):e15-6.

Cryoballoon ablation for paroxysmal atrial fibrillation in septuagenarians: a prospective study. Chierchia GB, Capulzini L, de Asmundis C, Sarkozy A, Sorgente A, Yazaki Y, Muller-Burri SA, Paparella G, La Meir M, Bayrak F, De Ponti R, Brugada P. Indian Pacing Electrophysiol J. 2010 Sep 5;10(9):393-9.

Seeing is Believing: Unmasking Left Atrial Appendage Activity Recorded in the Left Superior Pulmonary Vein Without Stimulation. Pison L, LA Meir M, Maessen J, Crijns H. J Cardiovasc Electrophysiol. 2010 Jun 25. [Epub ahead of print]

Atrial Fibrillation After Cardiac Surgery: Incidence, Risk Factors, and Economic Burden. Rostagno C, La Meir M, Gelsomino S, Ghilli L, Rossi A, Carone E, Braconi L, Rosso G, Puggelli F, Mattesini A, Stefàno PL, Padeletti L, Maessen J, Gensini GF.

J Cardiothorac Vasc Anesth. 2010 Dec;24(6):952-8.

Extracardiac ice formation during cryoballoon technique for atrial fibrillation.

Pison L, La Meir M, Maessen J, Crijns H. Heart Rhythm. 2010 Oct;7(10):1518.

Increased number of cerebral emboli during percutaneous endocardial pulmonary vein isolation versus a thoracoscopic epicardial approach. Sauren L, La Meir M, de Roy L, Pison L, Van der Veen E, Mess WH, Crijns HJ, Maessen J. Eur J Cardiothorac Surg. 2009; Nov;36(5):833-7.

The EmBlocker: efficiency of a new ultrasonic embolic protection device adjunctive to heart valve surgery. Sauren L, La Meir M, Bolotin G, Van der Veen E, Heijmans JH, Mess WH, Maessen J. Eur J Cardiothorac Surg. Ann Thorac Surg. 2009; 88(1): 253-7. 
Transcranial Measurement of Cerebral Microembolic Signals During Endocardial Pulmonary Vein Isolation: Comparison of Three Different Ablation Techniques. Sauren L, Van Belle Y, De Roy L, Pison L, La Meir M, Van der Veen E, Crijns HJ, Jordaens L, Mess WH, Maessen J. J Cardiovasc Electrophysiol. 2009 Oct;20(10):1102-7.

Surgical treatment of atrial fibrillation. De Roy L., Floria Mariana, Blommaert D, Collet B, Dormal F, Alsteen G, Deceuninck O, Colard E, La Meir M. Arch Mal Coeur $2008 ; 101: 116$.

Endoscopic mitral and tricuspid valve surgery after previous cardiac surgery.

Casselman FP, La Meir M, Jeanmart H, Mazzaro E, Coddens J, Van Praet F, Wellens F, Vermeulen Y, Vanermen H. Circ. 2007 Sep11;116(11 Suppl):I270-5.

Minimal invasive surgical ablation for persistent atrial fibrillation associated with ganglionated plexi isolation. Floria M., De Roy L., Blommaert D., Deceuninck O., Dormal F., Collet B., Freches D., Jamart J., Collard E., La Meir M. Romanian Journal of Cardiology, Vol XXII, 2007: A 276-277.

Treatment of lone atrial fibrillation with a right thoracoscopic approach. M. La Meir, De Roy L., Blommaert D., Buche M. Ann Thorac Surg. 2007; 83: 2244-5.

New ultrasonic radiation reduces cerebral emboli during extracorporeal circulation. Sauren L., La Meir M., Palmen M, Severdija E., Van der Veen E, Mess W., Maessen J. Eur J Cardiothorac Surg. 2007;32(2):274-80.

Contralateral Replacement of Pacemaker and Leads Following Laser Sheath Extraction and Concomitant Stenting for Superior Vena Cava Syndrome. Ihsan Bakir MD, Mark La Meir MD, Ivan Degrieck MD, Cathérine Marien MD, Kristof Van Den Hauwe MD, Francis Wellens MD. Pacing Clin Electrophysiol. 2005 Oct;28(10):1131-4.

Initial experience with an endoscopic radial artery harvesting technique. F. Casselman, M. La Meir, Cammu G, Wellens F, De Geest R, Degrieck I, Van Praet F, Vermeulen Y, Vanermen H. J Thorac Cardiovasc Surg. 2004 Sep;128(3):463-6.

Pneumoperitoneum in Repair of Giant Hernias and Eventrations. M. La Meir, T. Vierendeels, M. Poortmans. Acta chir belg, 2002, 102, 263-265.

Recurrence of Gallstone Ileus with Crohn's Disease. M. La Meir, Y. Van Molhem. Acta chir belg, 2001, 101,35-37.

\section{ABSTRACTS}

Low Complexity of the Atrial Fibrillation Substrate in Patients with Paroxysmal Atrial Fibrillation. B. Maesen, M. La Meir, S. Zeemering, J. Nijs, D.H. Lau, J. Eckstein, M. Granier, L. Pison, Harry Crijns, J. Maessen, S. Verheule, U. Schotten. Heart Rhythm, Vol 9, No. 5, May Supplement 2012, S32. 
First demonstration in humans that the integrity of the ganglionated plexi are necessary for the innervation of the AV node by the right vagus nerve. Xhaët $\mathrm{O}$, Blommaert $\mathrm{D}$, Deceuninck $\mathrm{O}$, Collet B, Dormal F , Ballant E, La Meir M, De Roy L. J Interv Card Electrophysiol 2009;24:235-38

Surgical treatment of stand-alone longlasting persistent AF using a monolateral thoracoscopic approach. M. La Meir, L. de Roy, D. Blommaert, M. Buche, J. Maessen.

Interact CardioVasc Thorac Surg 2008;7:S1-S138

Thoracoscopic epicardial pulmonary vein isolation is a realistic alternative for endocardial radiofrequency ablation: lower risk of arterial embolism. L. Sauren, M. La Meir, L. de Roy, L. Pison, E. van der Veen, W. Mess, H. Crijns, J. Maessen.

Interact CardioVasc Thorac Surg 2008;7:S1-S138

Evaluation of morphological and mechanical remodelling of the left atrium after posterior wall isolatioin by right thoracoscopic approach in refractory persistent atrial fibrillation. Xhaët O, Floria Mariana, La Meir M, Blommaert D, Deceuninck O, Collet B, Dormal F, Alsteen G, De Roy L. ECAS 13-15.04.2008. J Interv Card Electrophysiol 2008;21:75

Ablation Of The Pulmonary Veins Using An Irrigated Tip RF Ablation Catheter Reduces Cerebral Microemboli Versus A Non-irrigated-tip RF Ablation Catheter Sauren L., De Roy L., Pison L., La Meir M., Van Der Veen E., Mess W., Crijns H., Maessen J. American Heart Association Scientific Sessions 2007. Circulation 2007 ; 116 : II-725.

Epicardial Ablation And Isolation Of Ganglionated Plexi In Refractory Pesistent Atrial Fibrillation : Does It Really Matter? Mariana Floria, Luc De Roy, Dominique Blommaert, Olivier Deceuninck, Benoit Collet, Fabien Dormal, Danielle Freches, Mark La Meir. American Heart Association Scientific Sessions 2007. Circulation 2007 ; 116 : II-140.

Thoracoscopic Epicardial Pulmonary Vein Isolation Is A Realistic Alternative For Endocardial Radiofrequency Ablation : Lower Risk Of Arterial Embolism And Shorter Procedure Times. Sauren L., La Meir M., Pison L., De Roy L., Van Der Veen E., Mess W., Crijns H., Maessen J.American Heart Association Scientific Sessions 2007. Circulation 2007 ; $116:$ II-731.

Efficacy of posterior left atrium wall isolation and ganglionated plexi ablation by right thoracoscopic approach in refractory persistent atrial fibrillation patients.Floria M., De Roy L., Blommaert D., Collet B., Mélanie C., Dormal F., La Meir M. $3^{\text {rd }}$ Annual Congress of the ECAS 03-05.06.2007. J Interv Card Electrophysiol (2007) 18: 115.

Cerebral micro embolic signals burden during AF ablation; endocardial versus epicardial approach. Sauren L., La Meir M., De Roy L., van der Veen E., Mess W., De Roy L., Crijns H., Maessen J. $3^{\text {rd }}$ Annual Congress of the ECAS 03-05.06.2007. J Interv Card Electrophysiol (2007) 18: 49.

Endocardial atrial fibrillation ablation procedures are associated with profuse microembolic signals whereas epicardial ablation is not. Sauren L., La Meir M., Bodifee E., Van der Veen E., De Roy L., Mess W., Crijns H., Maessen J. XVI European Stroke Conference Glasgow 29.05-01.06.2007. Cerebrovasc Diseases 2007. 
Is there still a treatment option for symptomatic patients with refractory persistent atrial fibrillation? De Roy L., Sausiuc M., Blommaert D., Collet B., Alsteen G., Dormal F., La Meir M. BSC $26^{\text {th }}$ annual scientific meeting. 01-04.02.2007. Acta Cardiol. 2007; 62 (1): 65.

Thoracoscopic microwave left atrial exclusion : a new treatment for persistent atrial fibrillation (AF) ? De Roy L., Blommaert D., Deprez F., Collet B., Dormal F., Mancini I., La Meir M. BWGCPE $24^{\text {th }}$ annual meeting 7-8.10.2005. Acta Cardiol. June 2006; 61 (3): 369.

Pulsed pressure variation and stroke volume variation: predictive parameters of response to a fluid challenge in coronary artery surgery. R. Guijarro Ceballos, M. Gourdin, C. Dransart, M. La Meir et al. Revista Espanola de Anestesiología y Reanimación, June 2005

Pulsed pressure variation and stroke volume variation: predictive parameters of response to a fluid challenge in coronary artery surgery. M. Gourdin, C. Dransart, M. La Meir et al. European Journal of Anaesthesiology, Vol. 22, Supplement 34, 2005

Redo mitral/tricuspid valve surgery with port-access: Evolution to the standard approach : M. La Meir, E. Mazzaro, F. Wellens et al. Acta chir belg November 2003

\section{POSTERS}

Ablation Of The Pulmonary Veins Using An Irrigated Tip RF Ablation Catheter Reduces Cerebral Microemboli Versus A Non-irrigated-tip RF Ablation Catheter. Sauren L., De Roy L., Pison L., La Meir M., Van Der Veen E., Mess W., Crijns H., Maessen J. American Heart Association Scientific Sessions 2007, Orlando, Florida.

Thoracoscopic Epicardial Pulmonary Vein Isolation Is A Realistic Alternative For Endocardial Radiofrequency Ablation : Lower Risk Of Arterial Embolism And Shorter Procedure Times. Sauren L., La Meir M., Pison L., De Roy L., Van Der Veen E., Mess W., Crijns H., Maessen J.American Heart Association Scientific Sessions 2007, Orlando, Florida.

June 2006: Development of a true minimal invasive approach for treatment of stand-alone AF. La Meir M., De Roy L., Blommaert D., Buche M., Maessen J. ISMICS, San Francisco, California.

June 2006: A new technique of pulmonary vein isolation through a monolateral left thoracoscopic approach combined with left atrial appendage occlusion. La Meir M., De Roy L., Blommaert D., Buche M., Maessen J. ISMICS, San Francisco, California.

February 2006: Long-standing persistent atrial fibrillation : is this treatable with epicardial microwave pulmonary vein isolation? De Roy L., Blommaert D., Dumont F., Collet B., Dormal F., Alsteen G., Mancini I., La Meir M. SBC. Brussels, Belgium.

January 2006: Surgical Isolation of the Pulmonary Veins Through Right Thoracoscopic Approach: A One-Hour, Skin-to-Skin Procedure. La Meir M., De Roy L., Blommaert D., Buche M., Maessen J. NewEra Cardiac Care 9, Newport Beach, California. 
January 2006: Feasibility of Pulmonary Vein Isolation Through a Left Thoracoscopic Approach Combined with Left Atrial Appendage Occlusion. La Meir M., De Roy L., Blommaert D., Buche M., Maessen J. NewEra Cardiac Care 9, Newport Beach, California.

\section{PRESENTATIONS}

Minimally Invasive Surgical Techniques: For Which Patients? Cardiostim, $18^{\text {th }}$ World Congress, Nice, France, June 13-16, 2012.

What is the future of hybrid procedures in ablation of atrial fibrillation? 15th International Prague Workshop on Catheter Ablation, IKEM, Czech republic, March 18-21, 2012. Faculty.

Organizing committee Third edition of the Hybrid AF ablation Course, life surgery, Maastricht, The Netherlands, February 17, 2012.

AF Hybrid Therapies. Un update assessment. WSA ICPES, Athens, Greece, December 11-14, 2011. Faculty.

Co-Chair: Techniques and Technologies in the Advanced EP laboratory.

Atrial fibrillation ablation: what's left for the surgeon? EHRA Europace, Madrid, Spain, June 26-29, 2011

Unipolar RF. $11^{\text {th }}$ ISMICS Annual Meeting, Postgraduate Course, Washington DC, DC, June 8-11, 2011. Faculty.

Advances in Hybrid Surgical Catheter Ablation of Atrial Fibrillation. Stanford Biodesign New Arrhythmia Technologies Retreat, Stanford, California, May 3, 2011

Hybrid atrial fibrillation - current state. M. La Meir.Techno-College Cardiac Programme. $24^{\text {th }}$ Annual Meeting. Geneva, Switzerland. Faculty. 11-15.9.2010.

Back to the future. Chairman Post Graduate Course AF. $10^{\text {th }}$ ISMICS Annual Meeting. Berlin, Germany. 15-19.6.2010.

A Hybrid Thoracoscopic and Transvenous Approach for Treatment of Patients with Atrial Fibrillation. 10 $0^{\text {th }}$ ISMICS Annual Meeting. Berlin, Germany. 15-19.6.2010.

Minimally-Invasive Treatment of Atrial Fibrillation. $10^{\text {th }}$ ISMICS Annual Meeting. Berlin, Germany. 15-19.6.2010.

Rationale of hybrid DEEP AF procedure and initial results. M. La Meir. Boston AF symposium, satellite Atricure. Boston, Massechusettes. 14-16.1.2010.

AF a combined surgical and EP approach. M. La Meir. HRC. Birmingham, UK. Faculty. 1821.10.2009

Left-sided ablation for AF. M. La Meir. Post Graduate Course ISMICS. San Francisco, California. 3-6.6.2009. 
Hybrid approaches in AF. M. La Meir. ACTS. New York, NY. Faculty. 6-7.5.2009.

Minimal invasive treatment of AF. Presentation and life procedure. M. La Meir. ESTECH $5^{\text {th }}$ AF Seminar - Expert sessions. Massa, Italy. 22-23.5.2009.

Hybrid approaches in AF. M. La Meir. ESCVS. Warsaw Poland. Faculty. 30-2.5.2009.

First demonstration in humans that the integrity of the ganglionated plexi are necessary for the innervation of the AV node by the right vagus nerve. Xhaët $O$, Blommaert $D$, Deceuninck $O$, Collet B, Dormal F, Ballant E, La Meir M, De Roy L. ECAS. Paris, France. 13-15.04.2009.

Minimal invasive treatment of AF. EPGS. Amsterdam, The Netherlands. 2-3.4.2009.

Totally Thorascopic Maze. M. La Meir. State of the Art of Atrial Fibrillation Ablation: Dallas Symposium. Texas. 6-7.3.2009.

Left Mini Approach: Microwave. M. La Meir. Re-Evolution Summit: Minimal Access Cardiac Surgery. Houston, Texas. 5-7.3.2009.

Ablation for atrial fibrillation: monolateral approach. M. La Meir. 13th European Vascular Course, Hybrid cardiac Program. Maastricht, The Netherlands. Faculty. 26-28.2.2009.

Thoracoscopic ablation in persistent AF: an alternative to percutaneous catheter ablation? De Roy L, Blommaert D, Xhaët O, Deceuninck O, Collet B, Alsteen G, Dormal F, La Meir M, Jamart J. 13th European Vascular Course, Hybrid cardiac Program. Maastricht, The Netherlands. 26-28.2.2009.

Hybrid approaches to minimal invasive treatment of AF. M. La Meir. $4^{\text {th }}$ Integrated Cardiovascular Repair Workshop Innsbruck, Austria. Faculty. 4-6.12.2008.

Role of Ganglionated Plexi-Ablation - How Important is this Procedure in Surgery. M. La Meir. 1st Asia-Pacific Heart Rhythm Society Scientific Session. Singapore. Faculty. 2729.11.2008.

Novel Methods for Preventing and Treating Postoperative Atrial Fibrillation. M. La Meir. 1st Asia-Pacific Heart Rhythm Society Scientific Session. Singapore. Faculty. 2729.11.2008.

Minimal invasive combined endoand epicardial ablation: the best of two worlds. M. La Meir. Getrhythm, $3^{\text {rd }}$ Dutch Symposium on AF, Utrecht, The Netherlands. 20-21.12.2008.

AF surgery in Belgium and the Netherlands. M. La Meir. Heart Rhythm Congress. Birmingham, England. 19-22.10.2008.

Minimal invasive combined endoand epicardial ablation: the best of two worlds. M. La Meir. International Symposium of Hybrid Approach to Heart Disease (ISHAHD). Beijing, China. Faculty. 18-19.10.2008. 
Thoracoscopic Ablation during Lone AF procedures. Presentation and life procedure. M. La Meir. ESTECH $4^{\text {th }}$ AF Seminar - Expert sessions. Massa, Italy. 9-12.10.2008.

AV node innervation from the right vagal nerve requests integrity of the epicardial ganglionated plexi: first documentation in humans. Xhaët $\mathrm{O}$, Floria $\mathrm{M}$, Blommaert $\mathrm{D}$, Deceuninck O, Collet B, Dormal F, Alsteen G, La Meir M, De Roy L. The $2^{\text {nd }}$ Belgium Heart Rhythm Meeting. Brussels, Belgium. 2-4.10.2008.

State of the Art in Minimally Invasive Approaches for Surgical Ablation. Mark La Meir. 9th international Dead Sea Symposium (IDSS). Tel Aviv Convention Center, Israel. 2224.09.2008. Faculty.

Hybrid treatment of AF. J. Maessen - M. La Meir Techno-college $22^{\text {nd }}$ EACTS Annual Meeting. September 13-17.2008, Lisbon, Portugal.

Chirurgische Behandlung von Lone AF mit Cobra Adhere XL. M. La Meir. ESTECH / HSC AF Seminar. Frankfurt, Germany. 27.05.2008

Surgical treatment of stand-alone longlasting persistent AF using a monolateral thoracoscopic approach. M. La Meir, L. de Roy, D. Blommaert, M. Buche, J. Maessen.

$57^{\text {th }}$ ESCVS annual Congress.Barcelona, Spain. 24-27.04.2008.

Thoracoscopic epicardial pulmonary vein isolation is a realistic alternative for endocardial radiofrequency ablation: lower risk of arterial embolism. L. Sauren, M.L. Meir, L. de Roy, L. Pison, E. van der Veen, W. Mess, H. Crijns, J. Maessen.

$57^{\text {th }}$ ESCVS annual Congress.Barcelona, Spain. 24-27.04.2008.

Evaluation of morphological and mechanical remodelling of the left atrium after posterior wall isolatioin by right thoracoscopic approach in refractory persistent atrial fibrillation. Xhaët O, Floria Mariana, La Meir M, Blommaert D, Deceuninck O, Collet B, Dormal F, Alsteen G, De Roy L. ECAS. Marseille, France. 13-15.04.2008

The hybrid procedure for treatment of AF: the surgeon. M. La Meir. First crossing borders meeting. Maastricht, The Netherlands. 15-2-2008

Cerebral micro embolic burden during AF ablation. L. Sauren, M. La Meir, L. de Roy, L. Pison, E. van der Veen, H. Crijns, W. Mess, J. Maessen. First crossing borders meeting. Maastricht, The Netherlands. 15-2-2008

Epicardial ablation of persistent AF : who are the best candidates ? De Roy L., Floria Mariana, Blommaert D, Collet B, Dormal F, Alsteen G, Deceuninck O, Colard E, La Meir M Belgium Society of Cardiology 31-01-2008

Ablation Of The Pulmonary Veins Using An Irrigated Tip Rf Ablation Catheter Reduces Cerebral Microemboli Versus A Non-irrigated-tip Rf Ablation Catheter. Sauren L., De Roy L., Pison L., La Meir M., Van Der Veen E., Mess W., Crijns H., Maessen J. American Heart Association Scientific Sessions 2007. Circulation 2007 ; 116 : II-725. 
Thoracoscopic Epicardial Pulmonary Vein Isolation Is A Realistic Alternative For Endocardial Radiofrequency Ablation : Lower Risk Of Arterial Embolism And Shorter Procedure Times. Sauren L., La Meir M., Pison L., De Roy L., Van Der Veen E., Mess W., Crijns H., Maessen J. American Heart Association Scientific Sessions 2007. Circulation 2007 ; 116 : II-731.

Epicardial Ablation And Isolation Of Ganglionated Plexi In Refractory Pesistent Atrial Fibrillation : Does It Really Matter ? Floria M., De Roy L., Blommaert D., Deceuninck O., Collet B., Dormal F., Freches D., La Meir M. American Heart Association Scientific Sessions 2007. Circulation $2007 ; 116$ : II-140.

Transmurality is not always the issue in treatment of AF. M. La Meir. Second Get rhytm Symposium, The Hague, The Netherlands. 01.11.07

Surgical treatment of lone AF and management of the LAA using a monolateral thoracoscopic approach. M. La Meir. $3^{\text {rd }}$ APAFS meeting Taipei, Taiwan. 19.10.07

Thoracoscopic treatment of lone AF. M. La Meir. ISMICS Lunch Symposium, Rome. 07.06.2007

Thoracoscopic treatment of lone AF. M. La Meir. Second Estech AF seminar, Castelgondolfo, Italy. 05.06.2007

Efficacy of posterior left atrium wall isolation and ganglionated plexi ablation by right thoracoscopic approach in refractory persistent atrial fibrillation patients.Floria M., De Roy L., Blommaert D., Collet B., Mélanie C., Dormal F., La Meir M. $3^{\text {rd }}$ Annual Congress of the ECAS 03-05.06.2007.

Cerebral micro embolic signals burden during AF ablation; endocardial versus epicardial approach. Sauren L., La Meir M., De Roy L., van der Veen E., Mess W., De Roy L., Crijns H., Maessen J. $3^{\text {rd }}$ Annual Congress of the ECAS 03-05.06.2007.

Endocardial atrial fibrillation ablation procedures are associated with profuse microembolic signals whereas epicardial ablation is not. Sauren L., La Meir M., Bodifee E., Van der Veen E., De Roy L., Mess W., Crijns H., Maessen J. XVI European Stroke Conference Glasgow 29.05-01.06.2007.

Is there still a treatment option for symptomatic patients with refractory persistent atrial fibrillation? De Roy L., Sausiuc M., Blommaert D., Collet B., Alsteen G., Dormal F., La Meir M. BSC $26^{\text {th }}$ annual scientific meeting. 01-04.02.2007.

Advanced techniques in thoracoscopic ablation and mitral valve repair. Faculty. Dr Cherai Foundation, Chennai, India. 11.2006.

Advanced techniques in thoracoscopic ablation and mitral valve repair. Faculty. IJN National Heart Institute, Kuala Lumpur, Malaysia. 11.2006. 
The true minimal invasive approach for treatment of stand-alone AF. Guidant meeting, Leogang, Austria. 9.2006.

Is transmurality or conduction bloc necessary in the treatment of AF. First Dutch symposium on AF. Utrecht, The Netherlands. 9.2006.

Treatment of isolated atrial fibrillation with a right thoracoscopic approach. 10th World Congress of Endoscopic Surgery, Berlin, Germany. 9.2006.

New ultrasonic radiation technology reduces cerebral microemboli during extracorporeal circulation. A multi-center animal study. L Souren, M. La Meir, et al., EACTS, Stockholm, Sweden. 9.2006.

AF mechanisms and the success of treatment. Guidant, Brussels, Belgium. 6.2006.

Current treatment of atrial fibrillation. 72. Jahrestagung der DGK, Mannheim, Germany. 4.2006 .

Stand-alone treatment of isolated atrial fibrillation with a right thoracoscopic approach. Second international Chinese congress of cardiothoracic surgery. Chengdu, China. 3.2006.

Stand-alone treatment of isolated atrial fibrillation with a right thoracoscopic approach. Faculty. New horizons in endoscopic surgery, Kuala Lumpur, Malaysia. 3.2006.

Chairman Atrial Fibrillation. CSUP meeting, Lech, Austria. 2.2006.

Microwave Ablation for atrial fibrillation. La Meir M., De Roy L., Blommaert D., Buche M., Maessen J. CSUP meeting, Lech, Austria. 2.2006.

Long-standing persistent atrial fibrillation : is this treatable with epicardial microwave pulmonary vein isolation? De Roy L., Blommaert D., Dumont F., Collet B., Dormal F., Alsteen G., Mancini I., La Meir M. SBC. Brussels, Belgium. 2.2006.

Surgical Isolation of the Pulmonary Veins Through Right Thoracoscopic Approach: A OneHour, Skin-to-Skin Procedure. La Meir M., De Roy L., Blommaert D., Buche M., Maessen J. NewEra Cardiac Care 9, Newport Beach, California. 1.2006.

Interventional treatment of cardiac arrhythmias. Aspect of the thoracoscopic approach to pulmonary vein isolation. De Roy L., Blommaert D., Dumont F., Collet B., Dormal F., Alsteen G., Mancini I., La Meir M. RETAC meeting. Brescia, Italy. 12.2005.

Moderator BACTS $10^{\text {th }}$ Anniversary Congress, Brussels, Belgium. 11.2005.

Interventions en rythmologie : ablation dans les arythmies supraventriculaires. Congrès de l'association franco-libanaise de cardiologie. De Roy L., Blommaert D., Dumont F., Collet B., Dormal F., Alsteen G., Mancini I., La Meir M. Beyrouth, Lebanon. 11.2005. 
College on options and outcomes in the surgical treatment of atrial fibrillation. What can the cardiologist do in the cath-lab? De Roy L., Blommaert D., Dumont F., Collet B., Dormal F., Alsteen G., Mancini I., La Meir M. OLV. Aalst, Belgium. 10.2005.

Thoracoscopic microwave left atrial exclusion : a new treatment for persistent atrial fibrillation (AF) ? De Roy L., Blommaert D., Deprez F., Collet B., Dormal F., Mancini I., La Meir M. BWGCPE $24^{\text {th }}$ annual meeting 7-8.10.2005.

Linear ablation, focal PV ablation circumferential PV ablation, surgery for AF. De Roy L., Blommaert D., Deprez F., Collet B., Dormal F., Mancini I., La Meir M. Second middle east Cardiopace. Beyrouth, Lebanon. 9.2005.

Treatment of lone atrial fibrillation with a right thoracoscopic approach The $4^{\text {th }}$ EACTS/ESTS joint meeting. Barcelona, Spain. 9.2005.

Nonlaser and laser extraction of pacemaker and implantable cardioverter defibrillator leads. F. Wellens, M. La Meir, Y. Degrieck, et al. The $4^{\text {th }}$ EACTS/ESTS joint meeting. Barcelona, Spain. 9.2005.

Starting a minimal invasive program for stand-alone atrial fibrillation The $4^{\text {th }}$ EACTS/ESTS joint meeting, side symposium. Barcelona, Spain. 9.2005.

Treatment of lone atrial fibrillation with a right thoracoscopic approach.

The $24^{\text {th }}$ Meeting of the Society of Cardiac Surgeons. Faculty. La Coruna, Spain. 6.2005.

Pulsed pressure variation and stroke volume variation: predictive parameters of response to a fluid challenge in coronary artery surgery. R. Guijarro Ceballos, M. Gourdin, C. Dransart, M. La Meir et al. The $27^{\text {th }}$ Meeting of the Spanish Society of Anaesthesiology. Palma de Mallorca, Spain. 6.2005.

Pulsed pressure variation and stroke volume variation: predictive parameters of response to a fluid challenge in coronary artery surgery. M. Gourdin, C. Dransart, M. La Meir et al. Euroanaesthesia 2005. Vienna, Austria. 5.2005.

Minimally invasive atrial fibrillation surgery

Live Case and Lecture Symposium

F. Wellens - M. La Meir. Barcelona, Spain. 5.2005

Surgical treatment of concomitant atrial fibrillation

The $52^{\text {nd }}$ Annual Conference of the Israel Heart Society. Tel-Aviv, Israel. 4.2005.

Pre- and peroperative management of carotid artery stenosis

UCL Mont-Godinne, Belgium. 4.2005.

Redo mitral/tricuspid valve surgery with port-acces : evolution to the standard approach. The Belgian Association of Cardio-Thoracic Surgery. Brussels, Belgium. 11.2003.

Musclesparing anterolateral thoracotomy.

Dutch Association of Surgery. The Netherlands. 5.2001. 
Mitral valve repair.

Seminar AZM. Maastricht, The Netherlands. 7.2000.

Vascular surgery : classic or endovascular?

MCNOL Bree - Maaseik, Belgium. 3.1999.

Profundoplasty : technique and results.

Thesis V.U.B. Brussels, Belgium 6.1985.

Cleft lip and palate : classification and surgical techniques.

Trainee seminar Brugmann Hospital. Brussels, Belgium. 1. 1983.

\section{WORKSHOPS}

2005 - : Workshops on atrial fibrillation with visiting surgeons from Europe, United States, Africa and Asia. UCL mont-Godinne, Yvoir, Belgium. AZM Maastricht, The Netherlands.

\section{PROCTORING}

2005 - : Training and visiting surgeon for thoracoscopic and concomitant treatment of atrial fibrillation in Europe, United States and Asia.

\section{LIVE SURGERY}

Latest Techniquas in Cardiac Surgery. The Leipzig - Dallas Joint Symposium. Leipzig, Germany. 3-4.12.2009

Minimal invasive treatment of AF. M. La Meir. ESTECH $5^{\text {th }}$ AF Seminar - Expert sessions. Massa, Italy. 22-23.5.2009

Ablation for atrial fibrillation: monolateral approach. M. La Meir. 13th European Vascular Course, Hybrid cardiac Program. Maastricht, The Netherlands. 26-28.2.2009

Thoracoscopic Ablation during Lone AF procedures. Presentation and life procedure. M. La Meir. ESTECH $4^{\text {th }}$ AF Seminar - Expert sessions. Massa, Italy. 9-12.10.2008

Stand-alone treatment of isolated atrial fibrillation with a right thoracoscopic approach. Gleneagles, Bandar Seri Begawan, Brunei. 7.2007

Advanced techniques in thoracoscopic ablation and mitral valve repair, Dr Cherai Foundation, Chennai, India. 11.2007 
Advanced techniques in thoracoscopic ablation and mitral valve repair, IJN National Heart Institute, Kuala Lumpur, Malaysia. 11.2007

Stand-alone treatment of isolated atrial fibrillation with a right thoracoscopic approach.

Gleneagles, Bandar Seri Begawan, Brunei. 11.2006

Current treatment of atrial fibrillation. 72. Jahrestagung der DGK, Mannheim, Germany. 4.2006

Stand-alone treatment of isolated atrial fibrillation with a right thoracoscopic approach.

Faculty. New horizons in endoscopic surgery, Kuala Lumpur, Malaysia. 3.2006

OLV-College on Advanced Mitral Valve Surgery.

Responsible for the training sessions : minimally invasive video-assisted mitral valve repair in the wet-lab. 6.2003 





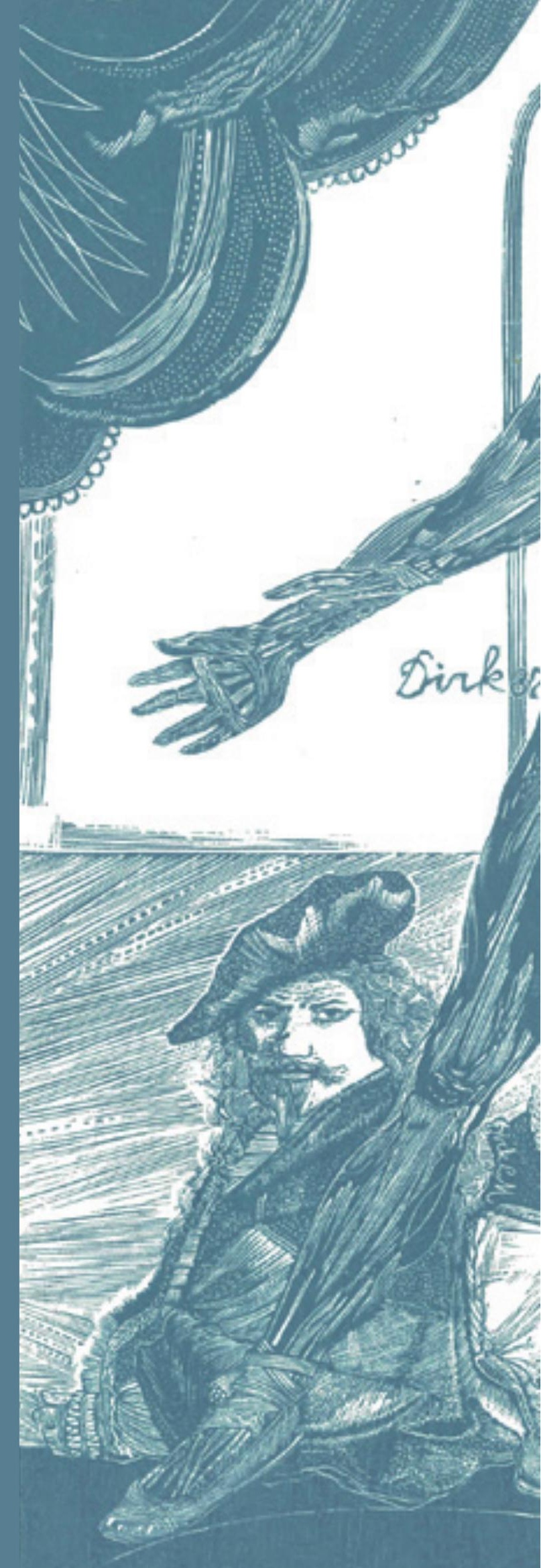

